\title{
Cellular mechanisms responsible for development of sensitivity of the bovine corpus luteum to prostaglandin F2 alpha
}

\author{
Madhusudan P. Goravanahally \\ West Virginia University
}

Follow this and additional works at: https://researchrepository.wvu.edu/etd

\section{Recommended Citation \\ Goravanahally, Madhusudan P., "Cellular mechanisms responsible for development of sensitivity of the bovine corpus luteum to prostaglandin F2 alpha" (2009). Graduate Theses, Dissertations, and Problem Reports. 4470.}

https://researchrepository.wvu.edu/etd/4470

This Dissertation is protected by copyright and/or related rights. It has been brought to you by the The Research Repository @ WVU with permission from the rights-holder(s). You are free to use this Dissertation in any way that is permitted by the copyright and related rights legislation that applies to your use. For other uses you must obtain permission from the rights-holder(s) directly, unless additional rights are indicated by a Creative Commons license in the record and/ or on the work itself. This Dissertation has been accepted for inclusion in WVU Graduate Theses, Dissertations, and Problem Reports collection by an authorized administrator of The Research Repository @ WVU. For more information, please contact researchrepository@mail.wvu.edu. 
Cellular Mechanisms Responsible for Development of Sensitivity of the Bovine Corpus Luteum to Prostaglandin F2 alpha

\author{
Madhusudan P. Goravanahally
}

\begin{abstract}
Dissertation submitted to the Eberly College of Arts and Sciences at West Virginia University in partial fulfillment of the requirements for the degree of
\end{abstract}

Doctor of Philosophy in Biology

Jorge A Flores, Ph.D., Chair

E Keith Inskeep, Ph.D.

Jianbo Yao, Ph.D.

Kevin Daly, Ph.D

Christy Foran, Ph.D.

Department of Biology

Morgantown, West Virginia, U.S.A.

2009

Keywords: corpus luteum, sensitivity, Luteolysis, $\mathbf{P G F}_{2 \alpha}, \mathbf{C A M K K 2}$ 


\title{
Abstract \\ Cellular Mechanisms Responsible for Development of Sensitivity of the \\ Bovine Corpus Luteum to Prostaglandin F2 alpha
}

\begin{abstract}
Madhusudan P. Goravanahally
Prostaglandin F2 alpha $\left(\mathrm{PGF}_{2 \alpha}\right)$ brings about regression of the bovine corpus luteum (CL). This luteolytic property of $\mathrm{PGF}_{2 \alpha}$ is used in beef and dairy cattle to synchronize estrus. A limitation of this protocol is an insensitivity of the early $\mathrm{CL}$ to luteolytic actions of $\mathrm{PGF}_{2 \alpha}$. The mechanisms underlying this differential luteal sensitivity are poorly understood. Therefore the main objective of the current study is to understand the cellular mechanism of luteal insensitivity. The developing $\mathrm{CL}$ has a maximum number of $\mathrm{PGF}_{2 \alpha}$ receptors; therefore differences in signaling events might be responsible for luteal insensitivity. Hence differential gene expression at two developmental stages of CL, days 4 (D-4) and 10 (D-10) post estrus, might account for differences in signal transduction pathways associated with luteal sensitivity. For example, differential expression of protein kinase $\mathrm{C}$ epsilon (PKCe /PRKCE) and its ability to regulate $\mathrm{PGF}_{2 \alpha}$-stimulated rise in intracellular calcium concentration have been proposed to be part of luteal resistance mechanism. Therefore the current study investigates the: 1) physiological role of PRKCE in regulating the ability of $\mathrm{PGF}_{2_{\alpha}}$ to inhibit progesterone synthesis, 2) role of $\mathrm{PGF}_{2_{\alpha}}$-stimulated rise in intracellular calcium in progesterone inhibitory actions of $\mathrm{PGF}_{2 \alpha}, 3$ ) differential expression of a large portion of the luteal transcriptome during its developmental transition from early to mature stage, and 4) role of differentially expressed CAMKK2 in acquisition of luteolytic sensitivity to $\mathrm{PGF}_{2 \alpha}$. Down-regulation of PRKCE significantly reduced the ability of $\mathrm{PGF}_{2_{\alpha}}$ to inhibit $\mathrm{LH}$-stimulated progesterone accumulation. A pharmacological increase in intracellular calcium concentration $\left[\mathrm{Ca}^{2+}\right] \mathrm{i}$ significantly inhibited LH-stimulated progesterone accumulation irrespective of luteal developmental stage. More importantly, buffering the rise in $\left[\mathrm{Ca}^{2+}\right] \mathrm{i}$ reduced the ability of $\mathrm{PGF}_{2 \alpha}$ to inhibit progesterone accumulation. Microarray analysis identified 167 genes that were expressed differentially $(\mathrm{p}<0.05)$. These were categorized into genes involved in cell signaling $(12 \%)$, steroidogenesis and metabolism (10.2\%), protein degradation (5.3\%), transcription regulation and DNA biosynthesis (18.5\%), protein biosynthesis and modification (18.5\%), extracellular matrix and cytoskeletal proteins (9.5\%), antioxidant property (3\%), miscellaneous (17\%), and unknown functions $(6 \%)$. In addition, the in vivo administration of $\mathrm{PGF}_{2 \alpha}$ increased the expression of a guanine nucleotide binding protein (G protein), beta polypeptide 1 (GNB1) in D-4 CL and calcium/calmodulin dependent kinase kinase 2, beta (CAMKK2) in D-10 CL. Furthermore, large and small luteal steroidogenic cells, known to be targets for actions of $\mathrm{PGF}_{2 \alpha}$ were demonstrated to be a cellular source for CAMKK2. More importantly, in vitro, a CAMKK2 inhibitor significantly reduced the ability of $\mathrm{PGF}_{2 \alpha}$ to inhibit progesterone accumulation. In summary, a developmental increase in PRKCE expression combined with its ability to regulate $\left[\mathrm{Ca}^{2+}\right]$ i and the availability of CAMKK2 to mediated the actions of rise in $\left[\mathrm{Ca}^{2+}\right]$ i might be important components of the mechanism rendering the bovine $\mathrm{CL}$ sensitive to $\mathrm{PGF}_{2 \alpha}$.
\end{abstract}




\section{Contents}

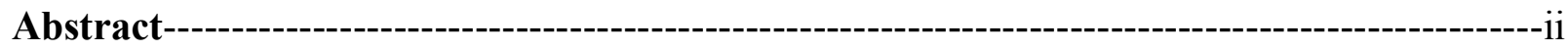

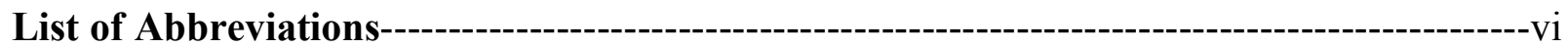

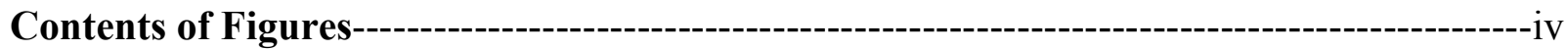

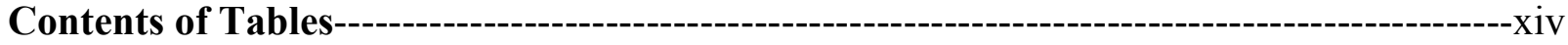

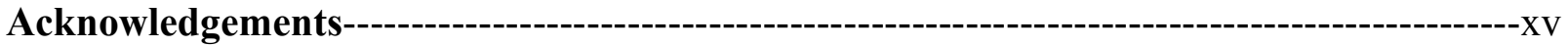

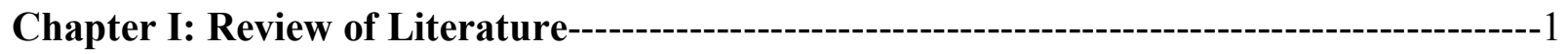

I. History----------------------------------------------------------------------------------------------------------1

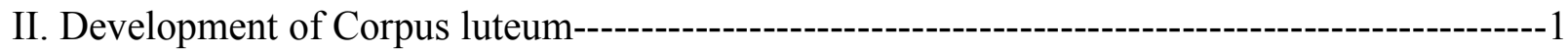

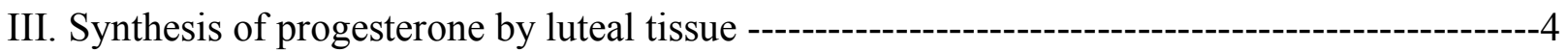

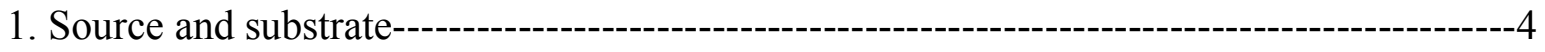

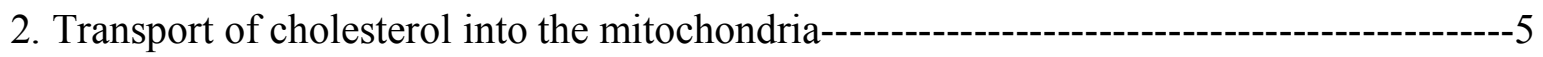

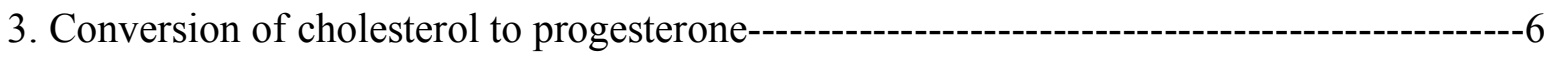

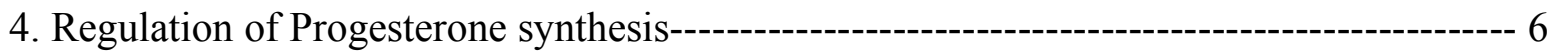

IV. Identification of $\mathrm{PGF}_{2 \alpha}$ as a luteolytic factor-----------------------------------------------------------8

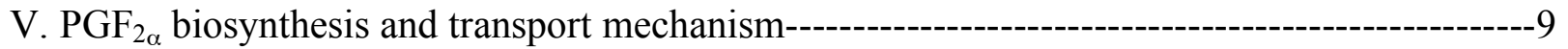

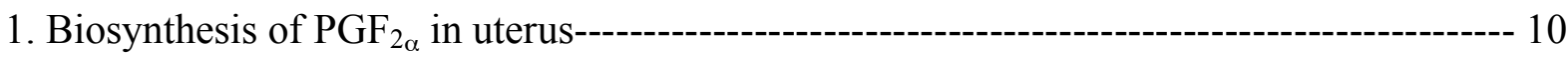

2. $\mathrm{CL}$ as an additional source of $\mathrm{PGF}_{2_{\alpha}}$---------------------------------------------------------------11

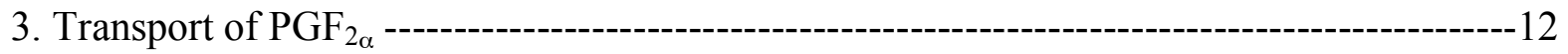

VI. Regulation of $\mathrm{PGF}_{2 \alpha}$ synthesis and initiation of luteolysis----------------------------------------13 
VII. PGF ${ }_{2 \alpha}$ signaling during luteolysis------------------------------------------------------------------15

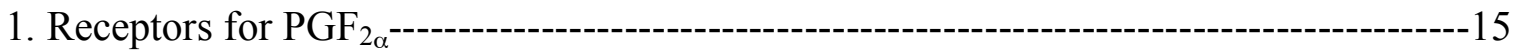

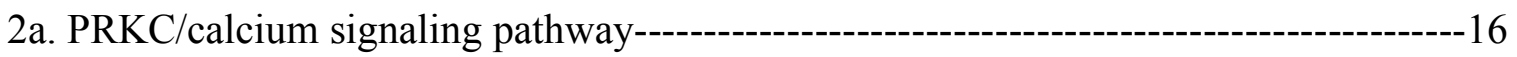

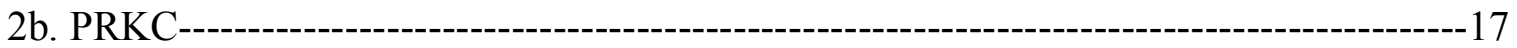

2c. $\mathrm{Ca}^{2+}$-calmodulin dependent kinase kinase 2, beta (official symbol, CAMKK2/

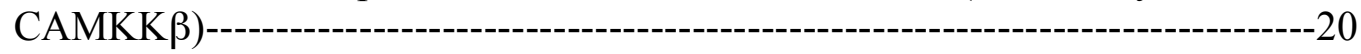

VIII. Functional luteolysis: inhibition of progesterone synthesis-------------------------------------21

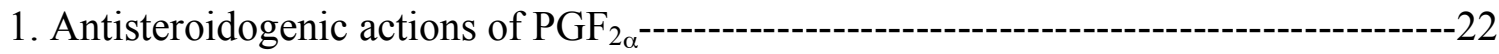

2. Mediators of antisteriodogenic actions of $\mathrm{PGF}_{2 \alpha^{-}}$

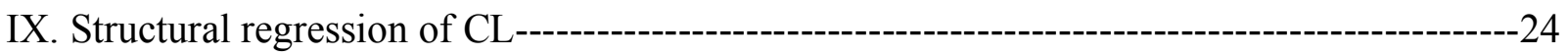

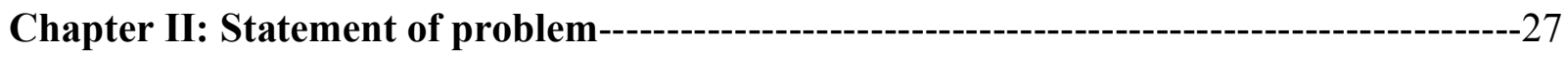

Chapter III: PKC epsilon and an increase in intracellular calcium concentration are necessary for PGF2alpha to inhibit LH-stimulated progesterone secretion in cultured

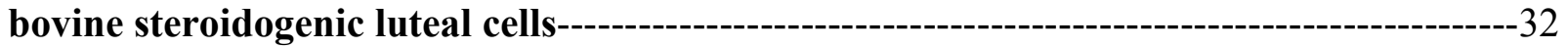

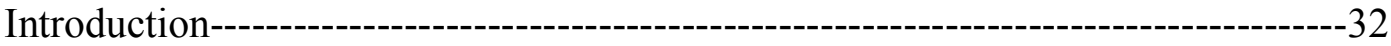

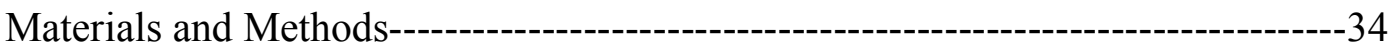

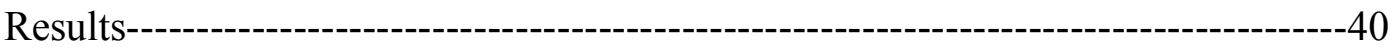

Discussion---------------------------------------------------------------------------------------43 
Chapter IV: Differential Gene Expression in the Bovine Corpus Luteum During Transition from Early to Mid-Phase and Its Potential Role in Acquisition of Luteolytic

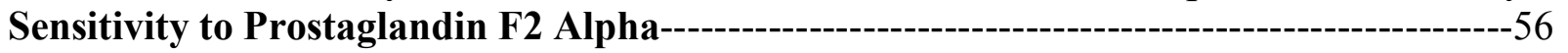

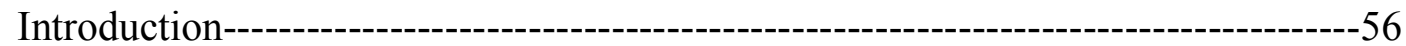

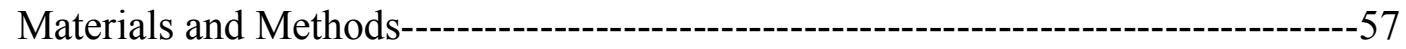

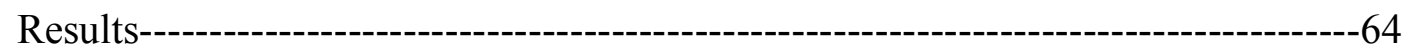

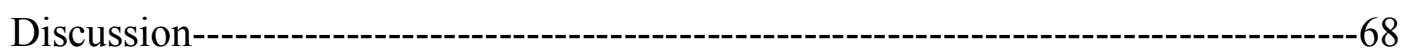

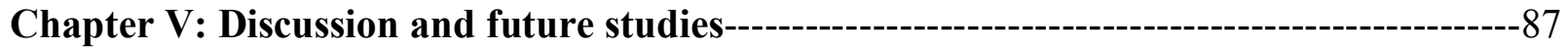

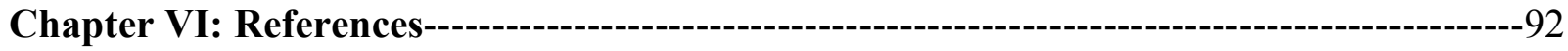

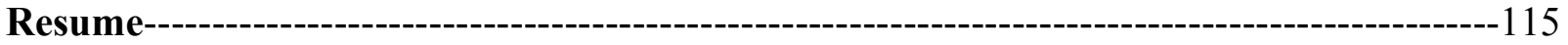




\section{List of Abbreviations}

$\alpha H S D$ - $\alpha$-Hydroxysteroid Dehydrogenase

$\beta$ HSD-beta -Hydroxysteroid Dehydrogenase/delta5, delta 4, isomerase

$\left[\mathrm{Ca}^{2+}\right] \mathrm{i}-$ Intracellular Calcium Concentration

9K-PGR - 9-Keto-Prostaglandin Reductase

AA - Arachidonic Acid

AKR - Aldo-Keto Reductase

AngII - Angiotensin II

AP-1 - Acitvator Protein -1

CaM - Calmodulin

CAMKK2/CAMKK $\beta-\mathrm{Ca}^{2+}$-Calmodulin Dependent Kinase Kinase 2, Beta

cAMP - Cyclic Adenosine Monophosphate

CL - Corpus Luteum

COX- Cyclooxygenase

cPLA2 - Cytosolic Phospholipase A2

CSF - Colony-Stimulating Factor

DAG - Diacylglycerol

DAX-1 - Dosage sensitive sex reversal; Adrenal hypoplasia congenital; X chromosome; gene 1

DDBX - Dihydrodiol Dehydrogenase 3

EDN1 - Endothelin-1

EDNR - Endothelin Receptor

eNOS - Endothelial Nitric Oxide Synthase

ER - Endoplasmic reticulum

Fas-L - Fas Ligand 
FCS - Fetal Calf Serum

FP - Prostanglandin F2 receptors

GC - Granulosal Cells

GH - Growth Hormone

GNB - Guanine Nucleotide-Binding Protein (G Protein), Beta Polypeptide

GPCR - G-Protein Coupled Receptor

HDL-High Density Lipoprotein

HMG-CoA -3-Hydroxy-3-Methlylgluaryl Coenzyme A

IF- Interferon

IGF-1 - Insulin-Like Growth Factor-1

IL - Interleukin

KCIP-1 - Kinase C Inhibitor Protein-1

$\mathrm{kDa}$ - Kilo Daltons

LDL - Low-Density Lipoprotein

LH- Luteinizing Hormone

LLCs - Large Luteal cells

MAPK - Mitogen-Activated Protein Kinase

MCP-1 - Monocyte Chemo-Attractant Protein-1

NAPDH - Nicotinamide Adenine Dinucleotide Phosphate

OATP- 12-Transmembrane Organic Anion Transporting Polypeptides

P4 - Progesterone

P-450scc - Cholesterol Side-Chain Cleavage Cytochrome P-450

PBR - Peripheral-Type Benzodiazepine Receptor

PGDH - Prostaglandin-15 Dehydrogenase

PGES - PGE Synthase

PGES - Prostaglandin E Synthase 
$\mathrm{PGF}_{2 \alpha^{-}}$Prostaglandin F2 alpha

PGFM - 13,14-Dihyro-15-Keto Prostaglandin F2 Alpha

PGHS - Prostaglandin G/H Synthase

PGT - Prostaglandin Transporter

PHFS - PGF Synthase

PKA - Protein Kinase A

PKA - Protein Kinase A

PKCI-1 - Protein Kinase C Inhibitor-1

PLC - Phospholipase C

PRKC/PKC - Protein Kinase C

$\mathrm{PRKCE} / \mathrm{PKC} \varepsilon$ - Protein Kinase C epsilon

PRL - Prolactin

PTGS2 - Prostaglandin-Endoperoxide Synthase 2

RACKs - Receptors For Activated Kinases

RIA - Radioimmunoassay

ROS - Reactive Oxygen species

S.C - Subcutaneous

SCP-1 - Sterol Carrier Protein

SiRNA - Small Interfering RNA

SLCs - Small Luteal Cells

StAR- Steroidogenic Acute Regulatory Protein

TNF - Tumor Necrosis Factor

UOP - Utero-Ovarian plexus

VEGF- Vascular Endothelial Growth Factor

YWHAZ - Tyrosine 3monooxygenase/Tryptophan 5-Monooxygense Activation Protein, zeta polypeptide 


\section{Content of Figures}

\section{Chapter I: Review of Literature}

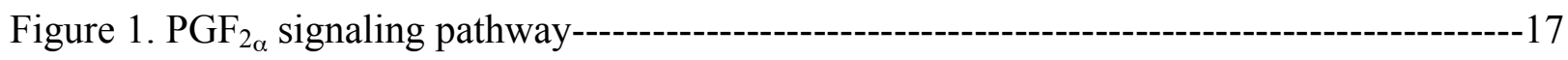

Figure 2. PRKC isozyme specific domains and co-factor requirement--------------------------------18

\section{Chapter III: PKC epsilon and an increase in intracellular calcium concentration are necessary for PGF2alpha to inhibit LH-stimulated progesterone secretion in cultured bovine steroidogenic luteal cells}

Figure 1. Time-course reduction in PKCE (PRKCE) mRNA expression after transfection of luteal steroidogenic cells with PRKCE specific siRNA. (A) Representative RT-PCR products obtained from total RNA using the PRKCE and GAPDH primers. The amount of total RNA was adjusted to $200 \mathrm{ng}$ per reaction and 40 cycles were used for PRKCE; while 28 cycles were used for GAPDH. The size of the amplified products for the GAPDH and PRKCE were 900 and 500 bp, respectively. PRKCE and GAPDH mRNA expression after 48, 72, and $96 \mathrm{~h}$ of transfection with PRKCE specific siRNA are shown. Lanes labeled media, non-specific (Non-sp) siRNA, and Transfection reagent represent respective treatments without PRKCE specific siRNA treatment. GAPDH was used as the control gene to normalize the PRKCE mRNA expression. (B) Quantitative analysis of the RT-PCR products obtained in four $(\mathrm{n}=4)$ replicates similar to those shown in panel A. Data are the mean \pm SEM of the densitometry measurements for PRKCE relative to GAPDH mRNA. Statistical comparisons were made between different treatments. Different letters above each SEM represent different values $(\mathrm{P}<0.05)$----------------47

Figure 2. Reduction in PRKCE protein. (A) Representative Western blot showing the amount of PRKCE and actin expressed in protein samples prepared from luteal steroidogenic cells after 48, 72, and $96 \mathrm{~h}$ of transfection with PRKCE specific siRNA (lanes 1-3). Lanes labeled $4-6$, contained protein samples from indicated control treatments (media, Non-sp siRNA, and transfection reagent, respectively). (B) Semi-quantitative analysis of the densitometry derived 
from four experiments similar to the one shown in panel A. the $y$-axis shows the ratio of the optical density ratio of PRKCE to that of its corresponding $\beta$-actin. The data are shown as mean \pm SEM, and comparisons were made between different treatments. Values with different letters denote differences by one-way ANOVA followed by Tukey-Kramer honestly significant difference $(\mathrm{P}<0.05)$ $-48$

Figure 3. PKC $\alpha$ and PKC $\beta I I$ protein after $96 \mathrm{~h}$ transfection of luteal steroidogenic cells with PRKCE specific siRNA. (A) Representative Western blot showing the amount of PKC $\alpha$, PKC $\beta I I$ KC $\varepsilon$ and actin detected in protein samples prepared from luteal steroidogenic cells after $96 \mathrm{~h}$ of transfection with PRKCE specific siRNA (lane 1). Lanes labeled 2 - 4, contained protein samples from indicated control treatments (media, Non-sp siRNA, and transfection reagent, respectively. B and C) Semi-quantitative analysis of the densitometry derived from four experiments similar to the one shown in panel A for PKC $\alpha$ (B) and PKC $\beta I I(C)$. The y-axis shows the ratio of the optical density ratio of PKC isozyme to that of its corresponding $\beta$-actin. The data are shown as mean $\pm \mathrm{SEM}$, and comparisons were made between different treatments by one-way ANOVA followed by Tukey-Kramer honestly significant difference-

Figure 4. Effects of PRKCE down-regulation on the ability of $\mathrm{PGF}_{2 \alpha}$ to inhibit the LH-stimulated progesterone synthesis/secretion in cultures of steroidogenic luteal cells transfected for $96 \mathrm{~h}$ with PRKCE specific siRNA (filled bars) or with transfection regents (control, open bars). Progesterone accumulation was determined in culture media after $4 \mathrm{~h}$ of incubation in the following treatments: $\mathrm{LH}(100 \mathrm{ng} / \mathrm{ml}), \mathrm{PGF}_{2 \alpha}(1 \mu \mathrm{g} / \mathrm{ml})$ and a combination of $\mathrm{PGF}_{2 \alpha}$ and $\mathrm{LH}$. Data are presented as mean \pm SEM of four individual replicates $(n=4$ cows). For each treatment group, statistical comparisons were made between PRKCE down-regulated (PRKCE siRNA) and control (not PRKCE down-regulated); different letters above each SEM denote different values, $\mathrm{P}<0.05$ $-50$

Figure 5. Effect of the $\mathrm{Ca}^{2+}$ ionophore, A23187, on basal and LH-stimulated progesterone synthesis/secretion $(\mathrm{ng} / \mathrm{ml})$ in cultured steroidogenic cells collected from Day 4 (panel A) and Day 10 (panel B) bovine CL. Progesterone accumulated in culture media was determined after $4 \mathrm{~h}$ of incubation in the following treatments: media alone (Media), LH (100 ng/ml), LH and 
$\mathrm{PGF}_{2 \alpha}(1000 \mathrm{ng} / \mathrm{ml})$, or LH and A23187 (0.1, 1, 10, and $\left.100 \mu \mathrm{mol}\right)$. As explained in Materials and Methods, these treatments also contained $0.1 \%$ of the solvent used for $\mathrm{PGF}_{2 \alpha}$ and $\mathrm{A} 23187$, DMSO. Data are presented as the mean \pm SEM of four Day 4 and 10 Day 10 individual replicates ( $\mathrm{n}=4$ and 10 cows respectively). Statistical comparisons were made across treatments, and means with different letters, differ within each panel $(\mathrm{P}<0.05)$ $-51$

Figure 6. Effect of the cell-permeable calcium chelator, Bapta-AM, on basal and LHstimulated progesterone synthesis/secretion $(\mathrm{ng} / \mathrm{ml})$ in cultured steroidogenic cells collected Day 10 bovine CL. Progesterone accumulated in culture media was determined after $4 \mathrm{~h}$ of incubation in the following treatments: media alone (Media), LH (100 ng/ml), LH and PGF $_{2 \alpha}$ $(1000 \mathrm{ng} / \mathrm{ml})$, or LH and Bapta-AM $(0.1,1,10$, and $100 \mu \mathrm{mol})$. As explained in Materials and Methods, these treatments also contained $0.1 \%$ of the solvent used for $\mathrm{PGF}_{2 \alpha}$ and Bapta-AM, DMSO. Data are presented as the mean \pm SEM of four Day 10 individual replicates $(n=4 \mathrm{CL}$ obtained from 4 cows). Statistical comparisons were made across treatments, and means with different letters denote different values, $\mathrm{P}<0.05$

Figure 7. Real-time PCR analysis of the effect of down-regulation of PRKCE mRNA on the expression of $\mathrm{PGF}_{2 \alpha}$ metabolic genes. Comparisons of mRNA expression data were made between the control (without PRKCE down-regulation) and PRKCE down-regulated steroidogenic cells treated either with $\mathrm{PGF}_{2 \alpha}(\mathbf{A}), \mathrm{LH}(\mathbf{B})$, and combination of $\mathrm{PGF}_{2 \alpha}$ and $\mathrm{LH}$ (C). The genes analyzed were as follows: aldoketoredutase 1B5 (AKR1B5), prostaglandin-15 dehydrogenase (PGDH), prostaglandinE synthase (PGES), 9-keto-prostagalndin reductase (9KPGR), and cyclooxygenase-2 (COX-2). The expression data were presented as mean $\pm \mathrm{SE}$. The comparison of means between treatments by t-test did not show significant differences with any

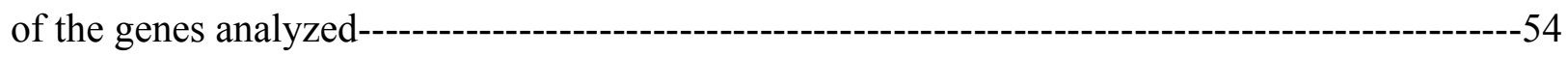

\section{Chapter IV: Differential Gene Expression in the Bovine Corpus Luteum During Transition from Early to Mid-Phase and Its Potential Role in Acquisition of Luteolytic Sensitivity to Prostaglandin F2 Alpha}

Figure 1. Real-time RT-PCR confirmation of 9 differentially expressed genes in Day-10 CL 
compared to Day-4 CL that were identified by microarray analysis, $\mathrm{P}<0.05$. CAMKK2: calcium/calmodulin dependent kinase kinase 2, beta; YWHA: tyrosine 3monooxygenase/tryptophan 5-monooxygenase activation protein, zeta polypeptide; PGAM5: phosphoglycerate mutase family member 5; PTPRR: protein tyrosine phosphatase, receptor type, R; AURKB: aurora kinase B; GNB1: guanine nucleotide binding protein (G protein), beta polypeptide 1; TMEM176A: transmembrane protein 176A; RGS2: regulator of G protein signaling 2, 24kDa; INPP1: inositol polyphosphate-1 phosphatase. The data is shown as mean \pm SEM, values with differing letters denoting statistically significant differences $(\mathrm{P}<0.05)------81$

Figure 2. Real-time RT-PCR analysis of the effect of exogenous PGF2 $\alpha$ on expression of selected genes that are identified by microarray to be differentially expressed in Day-10 CL compared to Day-CL, $\mathrm{P}<0.05$. NS represents normal saline. CAMKK2: calcium/calmodulin dependent kinase kinase 2, beta; YWHAZ: tyrosine 3-monooxygenase/tryptophan 5monooxygenase activation protein, zeta polypeptide; RGS2: regulator of G protein signaling 2, 24kDa; GNB1: guanine nucleotide binding protein (G protein), beta polypeptide 1; SPARCL1: SPARC-like 1; PKN1: protein kinase N1. The data is shown as mean \pm SEM, values with differing letters denoting statistically significant differences $(\mathrm{P}<0.05)$

Figure 3. Specificity of the $66 \mathrm{kDa}$ protein band detected by the SC 9629 antibody. In this representative Western blot, $30 \mu \mathrm{g}$ sample proteins isolated from a day 10 corpus luteum was run in each lane. The right lane is a representative Western blot demonstrating that the CaMKK2 antibody detected a protein band of approximately $66 \mathrm{kDa}$ (right panel). The left lane correspond with the experimental conditions where the primary antibody was preincubated with an excess amount of antigenic peptide prior to its use in the Western blot $-83$

Figure 4. Representative Western blot analysis of the calcium/calmodulin dependent kinase kinase 2, beta (CAMKK2) expressed in the bovine CL and semi-quantitative analysis of the densitometry derived from Western blots using protein samples isolated from d-4 and d-10 bovine corpora lutea. Panel A compares the total sample protein needed to detect CaMKK2 in protein samples isolated from day 4 and 10 corpora lutea. For each developmental stage, 5, 10, 
20, and $40 \mu \mathrm{g}$ / lane sample protein were used. This representative Western blot demonstrates the amount of CaMKK2 and actin expressed in each protein samples collected at d-4 (lanes 14) and d-10 (lanes 5-8) of the estrous cycle. The CaMKK2 antibody detected a protein band of approximately $66 \mathrm{kDa}$, whereas the actin antibody detected a protein band of about $43 \mathrm{kDa}$. In panel B, the y-axis shows the ratio of the optical density (o.d) for CaMKK2 corrected by the detected o. d. for its corresponding actin. The data is shown as mean \pm SEM, values with differing letters denoting statistically significant differences $(\mathrm{P}<0.001)-------------------------84$

Figure 5. Specific detection of calcium/calmodulin dependent kinase kinase 2, beta (CAMKK2) in day 10 bovine CL (panels A and B) by immunohistochemistry. Panel A demonstrates the specificity of the assay by a dramatic reduction of immunoreactivity when the primary antibody was pre-incubated with the antigenic peptide. Panel $\mathrm{C}$ shows immunoreactivity in small (S) and large luteal cells (L). Panel D illustrate lack of immunoreactivity in endothelial cells (arrow labeled E) and immunoreactivity in the cytoplasm of a large (arrow labeled L) and small (arrow labeled (S) luteal cells. Some unidentified cells are observed in the lumen of the blood vessel. Images in panels $\mathrm{A}$ and $\mathrm{B}$ are shown at the same magnification and the bar on the lower right corner of panel $\mathrm{A}$ indicates $100 \mu \mathrm{m}$. In panels $\mathrm{C}$ and $\mathrm{D}$, the bars in the lower right corners indicate 100 and $50 \mu \mathrm{m}$ respectively. The nuclei were counterstained by brief exposure to Harris's Hematoxylin solution $-85$

Figure 6. Role of CAMKK2 in mediating the antisteroidogenic actions of $\mathrm{PGF}_{2 \alpha}$. This figure represents the accumulation of progesterone in media secreted by steroidogenic cells derived from D-10 CL $(\mathrm{n}=4)$ over a period of $12 \mathrm{~h}$. The treatments include media (control), CAMKK2 inhibitor, STO-609 in presence or absence of $\mathrm{PGF}_{2 \alpha}$. The progesterone values are expressed as percentage of control (mean $\pm \mathrm{SE}$ ), and the bars with symbol * and ** indicate significant differences $(\mathrm{P}<0.05)$ between treatment groups----

\section{Chapter V: Discussion and future studies}

Figure 1. Proposed model for $\mathrm{PGF}_{2 \alpha}$-induced luteolytic signaling pathway------------------------91 


\section{Content of Table}

1. Chapter III: PKC epsilon and an increase in intracellular calcium concentration are necessary for PGF2alpha to inhibit LH-stimulated progesterone secretion in cultured bovine steroidogenic luteal cells

Table 1. Primer sequence, accession number, of investigated genes--------------------------------46

2. Chapter IV: Differential Gene Expression in the Bovine Corpus Luteum During Transition from Early to Mid-Phase and Its Potential Role in Acquisition of Luteolytic Sensitivity to Prostaglandin F2 Alpha

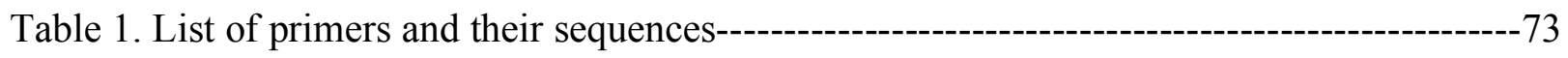

Table 2. Classification of differentially expressed genes according to their functions-------------73

Table 3. Genes classified under hormonal cell signaling--------------------------------------74

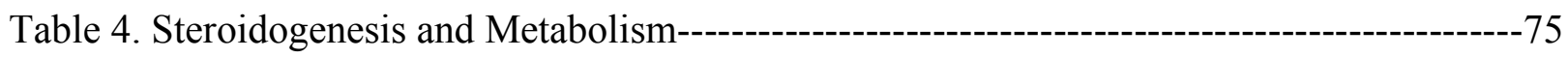

Table 5. RNA processing, transcription regulation and DNA synthesis----------------------------76

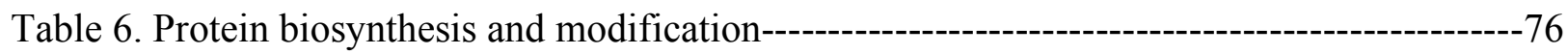

Table 7. Antioxidant property-------

Table 8. Extracellular matrix and cytoskeletal proteins-----------------------------------------------78

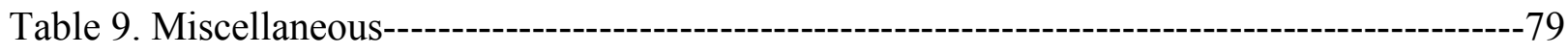

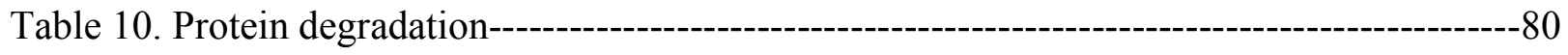

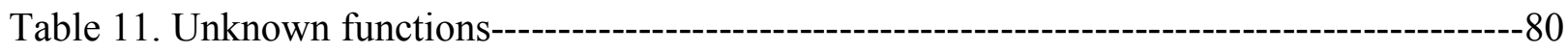




\section{Acknowledgement}

Dr Flores, my beloved advisor is a great mentor, teacher without whom I would not have completed $\mathrm{PhD}$. I am very thankful to him for giving me an opportunity to work in his laboratory. He is a very caring advisor and always welcomed and incited new scientific ideas from me. I am greatly touched by his sensitivity and understandability of my emotions and respect towards to my cultural background. He is the person who taught me how to communicate complex scientific ideas in a simple understandable manner. His encouraging and moral lessons are always great source of inspiration to me. He always looked after me like one of his family member. I greatly thank him for his long lasting patience, help and support during my tenure of PhD. Apart from scientific learning, he has taught me how to be a good human being and survive in this competitive society.

Dr Keith Inskeep is a great source of inspiration to my work. His constant dedication towards reproductive physiology is amazing and encouraging. I am very thankful for his help in teaching me effective writing skills and providing an opportunity to work in his laboratory. His intelligence, simplicity and down to earth human nature always inspire and wonder me. I feel very fortunate to work with such a legend in reproductive physiology.

I would like to thank Dr Jianbo Yao for giving me an opportunity to work in his laboratory and supporting me economically at the time of financial difficulties. He always treated me like his friend and thanks for several refreshing long exciting conversations at his office. I am very grateful for Dr Christy Foran and Kevin Daly for their constant support and intellectual guidance throughout my tenure of PhD. I express my gratitude to all my colleagues Fernando, Matt Doer, Justin, Aritro Sen, Mohamed, Julie, Marietta, and Matt Dean for their help at various stages of my PhD. I am very thankful for my friends Baneshwar, Vijay, Satpal, Ragu, Jyothsna and fellow graduate students who made my stay wonderful at Morgantown. Finally I would to 
like to thank my wonderful wife Sneha and family for all their blessings, support and inspiration. 


\section{Chapter I: Review of literature}

\section{History}

It was Regnier de Graaf who first described that "globular bodies" appeared on rabbit ovary after coitus and remained there until after parturition [De Graaf R, 1643]. The term corpora lutea, meaning "yellow bodies" was first given by Marcello Malpighi [Malpighi M, 1689]. Prenant [Prenant LA, 1898] suggested that corpus luteum might produce substances that regulate pregnancy and act as a gland of internal secretion. Beard [Beard J, 1897] proposed that corpora lutea were responsible for inhibition of estrus and ovulation during pregnancy. In rabbit that the corpora lutea were required for implantation and maintenance of pregnancy was first demonstrated by Fraenkel [Fraenkel L, 1903]. Later, Corner and Allen [Corner GW and Allen WM, 1929] demonstrated that the alcoholic extract of corpora lutea from sows was capable of maintaining pregnancy in ovariectomized rabbits. Subsequently in 1934, four different groups of scientists isolated and purified a crystalline form of luteal factor [Allen WM and Wintersteiner O, 1934; Butenandt A et al, 1934; Hartmann H and Wettstein A, 1934; Slotta KH et al, 1934]. In the same year, Slotta et al. described the structural formula of luteal factor and named it as progesterone [Slotta KH et al, 1934].

\section{Development of Corpus luteum}

The corpus luteum (CL) is a transient endocrine gland formed from the ovulated follicle, and it secretes the primary steroid hormone progesterone. The development of CL is a complex process. The rate of growth of CL is very rapid and can be compared to the process of wound healing and tumor formation [Smith MF et al, 1994]. For example, the CL of cattle weighs an average of $3 \mathrm{~g}$ during Day 3 after ovulation, whereas it weighs on average of $5.1 \mathrm{~g}$ on Days 14 post-estrus [Fields MJ and Fields PA, 1996]. The pre-ovulatory surge of luteinizing hormone (LH) induces ovulation of a follicle followed by luteinization and differentiation of residual follicular cells [Lipner H, 1988; McClellan MC et al, 1975; Niswender GD and Nett TM, 1988]. The luteinization process is a transition of pre-ovulatory follicle into a highly vascular tissue capable of secreting large quantities of progesterone. The capacity to secrete high rates of progesterone is accomplished by increased expression of progesterone producing enzymes such as cholesterol side-chain cleavage cytochrome P-450 complex (P-450scc) and 3beta - 
hydroxysteroid dehydrogenase/delta5, delta 4, isomerase (3beta -HSD), steroid acute regulatory protein (StAR), 3-hydroxy-3-methlylgluaryl coenzyme A (HMG-CoA) and decreased expression of the enzymes that convert progesterone to estrogens such as 17 -hydroxylase cytochrome P450 and aromatase cytochrome P-450 [Bao B and Garverick HA, 1998]. Granulosal cells express low amounts of HDL prior to luteinization [O'Shaughnessy PJ et al, 1990]. However, there is an increased expression of mRNA for HDL-receptor after luteinization [Landschulz KT et al, 1996]. During differentiation and growth of CL, there is an extensive tissue remodeling including, intermixing and migration of endothelial cells, thecal cells and fibroblasts in such a way that they are in close proximity to one another. During initial development, the wall of the follicle collapses into folds [Pederson ES, 1951; Priedkalns J and Weber AF, 1968] and capillaries invade the developing CL which appears to be under the influence of angiogenic and mitogenic factors such as fibroblast growth factor [Gospodarowicz D et al, 1985], platelet-derived growth factor [Khachigian LM et al, 1996], insulin-like factor-1 [Suh DY et al, 1992], heparin binding growth factor [Grazul-Bilska AT et al, 1992], and vascular endothelial growth factor (VEGF) [Redmer DA and Reynolds LP, 1996]. Neovascularization is an important process that occurs during the CL development. It consists of breakdown of the basement membrane, migration and proliferation of pericytes and endothelial cells followed by the development of capillaries. Capillary lumina constitute about $22 \%$ of total CL weight and endothelial cells constitute approximately $50 \%$ of the total luteal cell population. Consequently, the rate of blood flow to the $\mathrm{CL}$ is approximately $6-10 \mathrm{ml} / \mathrm{gm} / \mathrm{min}$ and rate of oxygen consumption per unit weight is six times greater than liver, kidney, or heart. Granulosal cells undergo hypertrophy without proliferation whereas the thecal and endothelial cells, and fibroblasts undergo mitosis and migration during the development of CL. For example, in sheep, from days 4 to 16 of estrous cycle fibroblasts approximately get double in number (from 21 to $50 \times 10^{6}$ ), whereas the number of endothelial cells increased by six-fold (18 to $\left.120 \times 10^{6}\right)$ [Farin CE et al, 1986].

The cells secreting progesterone are derived from differentiation of resident granulosal and thecal cells. The large luteal cells $(20-30 \mu \mathrm{m})$ designated as LLCs are derived from granulosal cells and small luteal cells $(<20 \mu \mathrm{m})$ designated as SLCs are derived from thecal cells [Alila HW and Hansel W, 1984]. During the development, the number of SLCs increases 5-fold (10 to $50 \times$ $10^{6}$ ), however size remains constant, whereas the size of LLCs increase approximately to twofold while their number remains constant $\left(15 \times 10^{6} / \mathrm{CL}\right.$ in sheep). Cellular hypertropy during the 
development is associated with an increase in cytoplasmic:nuclear ratio, increased number of smooth endoplasmic reticulum, increase in size of golgi apparatus, and increased number and complexity of mitochondria [Cavazos LF et al, 1969; Priedkalns J et al, 1968]. In terms of total cellular percentage of luteal tissue, LLCs constitute 4\% and SLCs comprise 19\% [Rodgers RJ et al, 1984]. It is important to note that LLCs make up $25 \%$ of the volume of the CL even though they add up to only $4 \%$ of luteal cell population. In addition to their morphological differences, they exhibit distinct biochemical differences and similarities. The basal amount of progesterone produced by LLCs is more than that produced by SLCs. For example, in monkey and sheep, large cells produce more than 10 times as much progesterone as produced by small cells, whereas human large cells produce twice as much as small cells [Ohara A et al, 1987]. In addition, LLCs do not respond to progesterone stimulatory action of LH, whereas SLCs respond to LH by increased production of progesterone [Fitz TA et al, 1982]. Immune cells such as plasma cells, lymphocytes and granular leukocytes form the important cellular components (7\%) of CL in addition to steroidogenic luteal cells.

In ruminants, development and maturation of CL is under the influence of several hormones. For example in ruminants and primates, LH is the primary luteotropic hormone that supports the growth of CL. In primates [Fraser HM et al, 1986] and sheep [Kaltenbach CC et al, 1968] hypophysectomy caused regression of CL and this effect can be reversed by exogenous LH. In addition, pulses of LH are required for growth and development of fully functional CL in cattle, and to maintain secretion of progesterone during late luteal phase in sheep [Peters KE et al, 1994]. In dogs and cats, both LH and prolactin appear to be important for normal development of CL, however their specific requirements appear to differs with different stages of luteal development and pregnancy [Concannon PW et al, 2009].

In rodents, prolactin plays an important role in maintaining the function of the CL throughout the pregnancy. The important function of prolactin is to prevent premature expression of progesterone catabolizing enzyme, $20 \alpha$-hydroxysteroid dehydrogenase (20 $\alpha$ HSD). In addition, estradiol secreted by luteal cells has been shown to support the development of the CL by stimulating the synthesis of progesterone, vascularization and growth of CL [Stocco C et al, 2007]. In 1981, Rothchild [Rothchild I, 1981] proposed that progesterone secreted from CL might play an important protective role against regression. Accordingly, several investigators provided evidences to support this hypothesis. For example, in rats, administration of 
progesterone antibody or progesterone receptor antagonist directly into the ovary inhibited the production of progesterone and administration of synthetic progesterone enhanced the synthesis of progesterone [Telleria CM and Deis RP, 1994; Telleria CM et al, 1999]. The ability of progesterone to auto-stimulate its own synthesis might be due to its ability to down-regulate the

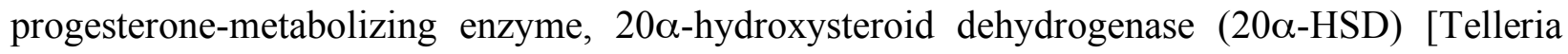
CM et al, 1999]. In addition, progesterone inhibited luteal cell death by decreasing the expression of Fas [Kuranaga $\mathrm{E}$ et al, 2000]. In rodents, prolactin (PRL) has been shown to sustain the function of the CL by preventing the premature expression of 20 $\alpha$-HSD [Grosdemouge I et al, 2003]. In agreement to Rothchild's hypothesis, in sheep progesterone might prevent the apoptosis of small luteal cells by preventing the ability of oxytocin to stimulate an increase in intracellular calcium [Niswender GD et al, 2007].

\section{Synthesis of progesterone by luteal tissue}

\section{Source and substrate}

Progesterone is the primary steroid hormone secreted by the bovine CL. However, pigs, rats, humans, cattle, and other species retain their ability to produce estradiol. The synthesis of progesterone is the least complex steroidogenic pathway in the ovary. Cholesterol is the starting substrate for the synthesis of P4. It has been shown that ovarian tissue preferentially utilizes lipoprotein-derived cholesterol rather than de novo synthesized cholesterol [Andersen JM and Dietschy JM, 1978]. However, luteal cells are capable of utilizing acetate as a source of cholesterol under the conditions of lipid deprivation [Cook B et al, 1967]. Most of the cholesterol for steroidogenesis in the CL is derived from low-density lipoprotein (LDL) and high-density lipoprotein (HDL) [Hwang J and Menon KM, 1983; Ohashi M et al, 1982]. LDL is transported into the luteal cell via receptor-mediated endocytosis [Brown MS and Goldstein JL, 1986], where in the cell the endosome combines with lysosome to release free cholesterol and LDL receptor is recycled [Grummer RR and Carroll DJ, 1988]. HDL uptake into the cell occurs after binding to a plasma membrane-bound HDL binding protein; however, the exact mechanism of release and transport of cholesterol inside the cell is not clear [Lestavel S and Fruchart JC, 1994]. Once the free cholesterol is released inside the cell, it can be utilized in steroidogenesis or reesterified with fatty acids by cholesterol ester synthetase and stored in the form of lipid droplets. Stored cellular cholesterol ester can be utilized as free cholesterol after being hydrolyzed by a 
cholesterol esterase [Johnson WJ et al, 1997]. This step is hormonally controlled as cholesterol esterase is activated by protein kinase A (PKA)-dependent phosphorylation [Caffrey JL et al, 1979; Pittman RC et al, 1975].

\section{Transport of cholesterol into the mitochondria}

Cholesterol is transported to the inner mitochondrial membrane by a complex process. The transport of cholesterol from outer to inner mitochondrial membrane is the rate-limiting step during steroidogenic pathway. During this transport mechanism that peptide hormones and the secondary messenger cAMP accelerate the transport of cholesterol and enhance steroidogenesis [Miller WL, 1988; Simpson ER and Waterman MR, 1983]. The transport of cholesterol to outer mitochondrial membrane appears to be mediated by cytoskeleton [Crivello JF and Jefcoate CR, 1978] and sterol binding proteins [Scallen TJ et al, 1985]. Steroidogenic acute regulatory protein (StAR) [Stocco DM and Clark BJ, 1996] and peripheral-type benzodiazepine receptor (PBR) [Papadopoulos V, 1993] are involved in the transport of cholesterol from outer to inner mitochondrial membrane. StAR is initially formed as a $37 \mathrm{kDa}$ and subsequently cleaved to inactive 30- and 32-kDa proteins upon transport to mitochondria. The X-ray crystal structure of StAR has homology to MLN64, a domain found in other lipid-transfer molecules, and can bind to sterol and facilitate the transfer of cholesterol from sterol rich unilammelar vesicles to acceptor membranes [Tsujishita Y and Hurley JH, 2000] [Kallen CB et al, 1998; Tuckey RC et al, 2002]. Supporting its role, addition of StAR to isolated mitochondria stimulated steroidogenesis [Bose $\mathrm{H}$ et al, 2002]. It has been proposed that cholesterol is being transported into the inner mitochondrial membrane during the insertion of StAR protein. Mutations in the StAR gene significantly reduced adrenal and gonadal steroid synthesis in patients affected with congenital lipoid adrenal hyperplasia, clearly suggesting the critical role of StAR in mitochondrial cholesterol transport. PBR is an $18 \mathrm{kDa}$ protein and has high affinity for benzodiazipine diazepam [Gavish M et al, 1999; Papadopoulos V, 1993]. The ligands for PBR stimulated steroid synthesis in various cell types, and in isolated mitochondria [Lacapere JJ and Papadopoulos V, 2003; Papadopoulos V, 1993]. Greater concentrations of PBR have been reported to be located at outer/inner mitochondrial membrane sites [Culty ML et al, 1999] and it has high affinity to bind the cytosolic carboxy-terminal domain of the cholesterol [Lacapere JJ et al, 2001; Li H and Papadopoulos V, 1998]. Further, fluorescent resonance energy transfer 
between StAR and PBR has indicated that these two molecules might interact such that StAR might transport the cholesterol to PBR in outer mitochondrial membrane [West LA et al, 2001].

\section{Conversion of cholesterol to progesterone}

The enzymes present in contact with the inner mitochondrial hydrophobic membrane, cytochrome P450 side-chain cleavage (P450scc), and matrix enzymes such as adrenodixin and adrenodoxin reductases catalyze the conversion of cholesterol to pregnenolone [Stone D and Hechter O, 1954]. This reaction consists of three steps, 20a-hydroxylation, 22-hydroxylation, and cleavage of cholesterol side chain to yield pregnenolone and isocaproic acid. Each step of catalysis requires 3 molecules of nicotinamide adenine dinucleotide phosphate (NAPDH). Adrenodixin and adrenodoxin reductase enzyme help in transport of electron from NADPH to P450scc.

Pregnenolone is then transported into smooth endoplasmic reticulum and converted into progesterone by an enzyme, 3-beta-hydroxysteroid dehydrogenase (3- $\beta$ HSD) [Hanukoglu I, 1992; Stocco C et al, 2007]. This enzyme is a $42 \mathrm{kDa}$ protein that has both dehydrogenase and isomerase activity in a single protein. Progesterone then appears to diffuse out of the cells as there is no evidence for its cellular storage. Corpora lutea of cattle secrete additional steroids such as 20beta-hydroxy-preg-4-en-3-one, and 20alpha-hydroxyl steroids.

\section{Regulation of Progesterone synthesis}

In most species, LH is the primary hormone involved in the regulation of progesterone synthesis and secretion from a CL. LH stimulated the synthesis of progesterone in sheep [Hoyer PB et al, 1984], cattle [Alila HW et al, 1988b], human [Ohara A et al, 1987], and pig [Tekpetey FR and Armstrong DT, 1991]. In primates, secretion of progesterone is dependent on the pulsatile secretion of LH throughout the luteal phase [Fraser HM et al, 1986], whereas in sheep, only basal amounts of LH secretion are sufficient to maintain the secretion of progesterone [McNeilly AS et al, 1992]. In cattle, it appears that only basal amounts of LH are required to maintain the secretion of progesterone during the later luteal phase, however the pulsatile secretion of LH is necessary for the development of CL [Peters KE et al, 1994]. In rodents, prolactin (PRL) produced from the pituitary gland in response to mating reflex has role in maintaining the secretion of progesterone from CL [Richards JS and Williams JJ, 1976]. However, the role of 
prolactin in regulation of luteal function is not clear in cattle [Hansel W et al, 1973] and sheep [Niswender GD, 1974].

The action of LH on steroidogenic cells is mediated via cell membrane receptors. In cattle [Chegini $\mathrm{N}$ et al, 1991] and sheep [Harrison LM et al, 1987], the receptors for LH are present on both LLC and SLC, however only SLCs are responsive to progesterone stimulatory actions of LH. Upon binding to its receptors, $\mathrm{LH}$ activates adenylate cyclase to release the secondary messenger, cAMP. An enzyme, protein kinase A (PKA) is then activated by cAMP to mediate the actions of LH [Davis JS et al, 1996; Hoyer PB et al, 1984; Marsh JM, 1976]. It has been shown that LH does not affect the transcription or the activity of P-450scc or 3beta -HSD [Marsh JM, 1976; Wiltbank MC et al, 1993]. However, it seems that LH is required for the normal expression of StAR, P-450sce and 3beta -HSD during development of CL [Niswender GD et al, 2000]. The evidence has indicated that the acute stimulatory action of LH on progesterone secretion is independent of transcription mechanisms [Marsh JM, 1970]. It is now clear that PKA enhances progesterone synthesis by phosphorylation of StAR, thereby enhancing the rate of transport of cholesterol into the mitochondrial membrane [Arakane $\mathrm{F}$ et al, 1997; Epstein LF and Orme-Johnson NR, 1991]. In addition, LH has been shown to activate cholesterol esterase, however the amount of progesterone stimulation with this mechanism appears to be minimal [Wiltbank MC et al, 1993]. LH has been shown to activate phospholipase $\mathrm{C} /$ protein kinase C (PLC/PRKC) system in SLCs. However, the role this system in activation of progesterone is not clear [Davis JS et al, 1996]. Binding of LH to its receptors on LLC does not affect the intracellular concentrations of cAMP or increase the progesterone. However, LLC secrete large quantities of progesterone $(>80 \%)$ independent of LH stimulation and it appears that PKA is constitutively active in these cells [Hoyer PB et al, 1984]. In addition to LH, various other hormones influence the synthesis and secretion of progesterone from the luteal tissue. For example, growth hormone (GH) [Liebermann J and Schams D, 1994] and Insulin-like growth factor-1 (IGF-1) [Constantino CX et al, 1991; Devoto L et al, 1995] have been shown to increase the secretion of P4. Supporting their action, receptors for GH have been characterized in bovine, ovine, and rat luteal tissue [Carlsson B et al, 1993; Juengel JL et al, 1997; Lucy MC et al, 1993]. It has been shown that early CL produce greater amounts of prostaglandin E and I series, so authors suggested they have role in the development of CL. Accordingly, prostacyclin (PGI2) 
and PGE2 stimulated progesterone synthesis from luteal tissues of cattle, sheep and humans [Alila HW et al, 1988a; Bennegard B et al, 1990; Fitz TA et al, 1984]. In addition, $\mathrm{PGF}_{2_{\alpha}}$ stimulated luteal progesterone synthesis during early luteal phase [Choudhary E et al, 2005]. Ability of PGE2 and $\mathrm{PGF}_{2 \alpha}$ to stimulate progesterone synthesis has been shown to be important in preventing the apoptosis of steroidogenic cells [Bowolaksono A et al, 2008].

\section{Identification of $\mathrm{PGF}_{2_{\alpha}}$ as a luteolytic factor}

In general the estrous cycle consists of short follicular phase followed by long luteal phase. During the follicular phase, increasing concentration of estrogen secreted from growing follicles stimulates LH surge. This is followed by ovulation of the dominant follicle and formation of CL. If animal become pregnant, luteal function must be maintained throughout gestation, but if fertilization does not occur, luteal regression (luteolysis) has to occur for initiation of new ovarian cycle with another chance for pregnancy [McCracken JA et al, 1999]. The factors involved in regression of CL and their detailed cellular mechanism of action has been an area of intense investigation. During luteolysis two related events occur; first there is a loss or reduction in the capacity to synthesize and secrete progesterone. Subsequently, decline in progesterone is followed by the loss of luteal cellular components [Knickerbocker JJ et al, 1988; McGuire WJ et al, 1994]. Several observations have indicated that uterus is involved in the process of luteolysis. In 1923, Loeb was the first investigator to demonstrate that uterus might be involved in controlling the life span of CL by providing evidence that hysterectomy in guinea pigs extended life of the CL [Loeb L, 1923]. Subsequently, similar results were reported in other species such as pseudopregnant rats [Bradbury J, Brown WE, Gray LA, 1950], mice [Bartke A, 1970], hamsters [Caldwell BV et al, 1967], cattle, sheep [Wiltbank J, Casida, LE., 1956], and horses [Stabenfeldt GH et al, 1974]. In these animals, unilateral hysterectomy prolonged the life of the ipsilateral CL only if the vascular connection from the intact uterine horned is blocked [O'Shea JD et al, 1974]. However, hysterectomy did not prolong the length of the cycle or life of the CL in primates or humans, mouse, squirrel, opossum, and dogs [Niswender GD and Nett TM, 1994].

In 1969, Pharriss and Wyngarden [Pharriss BB and Wyngarden LJ, 1969] demonstrated that $\mathrm{PGF}_{2_{\alpha}}$ brings about luteolysis in pseudopregnant rats. They reported that injections of large 
amounts of $\mathrm{PGF}_{2 \alpha}(1 \mathrm{mg} / \mathrm{kg} /$ day S.C) into rats shortened the length of pseudopregnancy and decreased the progesterone content of the CL. In sheep, intra-arterial infusion (carotid artery) of $\mathrm{PGF}_{2 \alpha}$ into the auto-transplanted ovary with vascular anastomoses to the vessels of the neck decreased the concentrations of progesterone in ovarian venous blood [McCracken J, 1971], which has been further elucidated [Bonnin P et al, 1999]. In sheep, it was demonstrated that $\left[\mathrm{H}^{3}\right] \mathrm{PGF}_{2 \alpha}$ was transferred from uterine vein to ovarian artery by a countercurrent transfer mechanism [McCracken JA et al, 1971]. In addition, infusion of $\left[\mathrm{H}^{3}\right] \mathrm{PGF}_{2_{\alpha}}$ into uterine vein appeared in adjacent ovary after a time period of 20-30 min[McCracken JA et al, 1972]. Similar experiments have demonstrated that $\mathrm{PGF}_{2 \alpha}$ is a luteolytic factor that is released from the uterus and delivered back to the corpus luteum, where it initiates the process of luteolysis. In cow, arachidonic acid released from endometrium was initially proposed to be a luteolytic substance [Hansel $\mathrm{W}$ et al, 1975]. Subsequently, $\mathrm{PGF}_{2_{\alpha}}$ has been shown to increased in an episodic manner in ovarian venous blood around the time of luteolysis [Nancarrow CD et al, 1973]. In agreement with this finding, PGFM, a metabolite of $\mathrm{PGF}_{2 \alpha}$ increased in peripheral blood of cattle during luteolysis [Kindahl $\mathrm{H}$ et al, 1980]. It is clear that $\mathrm{PGF}_{2_{\alpha}}$ is the primary luteolytic factor that initiates the process of luteolysis in most of the animal species studied for example pig [Bazer FW and Thatcher WW, 1977], mares [Douglas RH and Ginther OJ, 1976], goats [Homeida AM and Cooke RG, 1982], guinea pigs [Horton EW and Poyser NL, 1976], and rat [Pharriss BB and Wyngarden LJ, 1969].

\section{PGF $_{2_{\alpha}}$ biosynthesis and transport mechanism}

Prostaglandins (PGs) belong to family of eicosanoids, which are unsaturated lipids derived from arachidonic acid $\left(\mathrm{C}_{20: 4, \mathrm{n}-6}\right)$ or similar polyunsaturated fatty acid precursors. Chemically, PGs are polyunsaturated 20 -carbon fatty acids having a cyclopentane ring. PGs are designated by letters from A-J, indicating the nature and location of substitutes on the cyclopentane ring, and the position of double bonds within the ring. The numerical subscript (1,2 or 3$)$ has been attached based on the number of double bonds in the alkyl side chains. $\mathrm{PGF}_{2 \alpha}$ belongs to 2-series which are derived from eicosatetraenoic acid (arachidonic acid). The subscript alpha $(\alpha)$ indicates the spatial position of the hydroxyl group at C-9 in the cylcopentane ring and the molecule has additional double bonds at position 5 and 6 [Moore PK, 1985]. 


\section{Biosynthesis of $\mathrm{PGF}_{2 \alpha}$ in Uterus}

In uterus, $\mathrm{PGF}_{2 \alpha}$ is synthesized in endometrium and epithelial cells of endometrium synthesize large quantities of $\mathrm{PGF}_{2 \alpha}$, whereas, stromal cells preferentially synthesize PGE2 [Fortier MA et al, 1988]. The release of arachidonic acid from membrane lipids is the first step in a series of enzymatic reactions leading to formation of $\mathrm{PGF}_{2 \alpha}$. These actions are mediated by a group of enzymes of the phospholipase A2 family [Clark JD et al, 1995]. These enzymes catalyze the release of fatty acids from sn-2 position of phospholipids. Two formas of PLA2 in mammalian cells are secretory PLA2 (sPLA2) and cytosolic PLA2 (cPLA2) [Ackermann EJ and Dennis EA, 1995; Clark JD et al, 1995; Dennis EA, 1994; Kudo I et al, 1993]. These enzymes are calcium $\left(\mathrm{Ca}^{2+}\right)$-independent and mediate the release of arachidonic acid in several cell types. cPLA2 preferentially catalyzes the release of arachidonic acid from sn-2 position of lipids [Clark JD et al, 1991; Sharp JD et al, 1991]. Intracellular $\mathrm{Ca}^{2+}$ is required for translocation and binding of cPLA2 to the membrane [Channon JY and Leslie CC, 1990]. cPLA2 can be activated by various cytokines and growth factors such as interleukin-1, tumor necrosis factor (TNF), colony-stimulating factor (CSF), epidermal growth factor, c-Kit ligand, and interferon$\gamma$ (IFN $\gamma)$ [Clark JD et al, 1995]. The activity of cPLA2 has been localized primarily to nuclear membrane and endoplasmic reticulum (ER). Interestingly, these sites are shared by cyclooxygenase-2 (COX-2), an important enzymes involved in PG synthesis.

Next step during the synthesis of PG is conversion of arachidonic acid to an endoperoxide, PGH2, by prostaglandin $\mathrm{G} / \mathrm{H}$ synthase (PGHS) (also called cyclooxygenase, COX). These enzymes are present on the luminal surface of ER and capable of moving between ER and nuclear membrane [Spencer AG et al, 1998]. Two biochemically identical forms of PGHS are PGHS-1 (COX-1) and PGHS-2 (COX-2), and share $60 \%$ of the sequence similarity [Smith WL et al, 1996]. Despite their similarities in the reaction catalyzed, they are subjected to different regulatory mechanism and have different mRNA stability [Dubois RN et al, 1998; Smith WL et al, 2000]. PGHS-1 is expressed constitutively in most of the mammalian tissues, whereas PGHS-2 is an inducible enzyme that can be induced rapidly by cytokines, growth factors and tumor inducers [Herschman HR, 1996]. PGH2 can be utilized to make other types of

prostanoids such as PGD2, PGE2, or $\mathrm{PGF}_{2 \alpha}$ by isomerase/reductases. PGH2 can be directly converted into $\mathrm{PGF}_{2 \alpha}$ by 9,11-endoperoxide reductase commonly called as PGF synthase 
(PGFS). It reduces the 9-, 11-endoperoxide group of PGH2 to two -hydroxyl groups of $\mathrm{PGF}_{2 \alpha}$. Alternatively, PGD2 can be converted into $\mathrm{PGF}_{2 \alpha}$ by 11-ketoreductase or PGE2 can be converted into $\mathrm{PGF}_{2 \alpha}$ by 9-keto-prostaglandin reductase (9K-PGR). In bovine endometrium, 9K-PGR has been shown to produce $\mathrm{PGF}_{2_{\alpha}}$ and it has an additional capacity to metabolize progesterone by its $20 \alpha$-hydroxysteroid (20 $\alpha$-HSD) activity [Asselin E and Fortier MA, 2000]. In presence of NADPH, PGFS can convert PGD2 to $9 \alpha, 11 \alpha-P G F 2$, and these are involved in the contractibility of vascular smooth muscle and airway tract [Watanabe K, 2002].

In cow, three different types of PGFS have been isolated, the lung types PGFS1 [Watanabe K et al, 1985] and PGFS2 [Watanabe $\mathrm{K}$ et al, 1985], and the liver type dihydrodiol dehydrogenase 3 (DDBX) [Suzuki $T$ et al, 1999]. PGFS purified from bovine lung is a 36.6 $\mathrm{kDa}$ monomeric protein and consists of 323 amino acids and it has high sequence similarity to family members of aldo-keto reductase (AKR). A recently identified AKR1B5 has been shown to be primarily responsible for the production of $\mathrm{PGF}_{2_{\alpha}}$ in bovine endometrium and it has capacity to metabolize progesterone due to its $20 \alpha-\mathrm{HSD}$ activity [Madore E et al, 2003].

\section{2. $\mathrm{CL}$ as an additional source of $\mathrm{PGF}_{2_{\alpha}}$}

In addition to uterus, corpora lutea of most mammalian species produce prostaglandins [Olofsson J and Leung PC, 1994] and CL is a rich source of arachidonic acid. Luteal cells from cattle [Milvae RA et al, 1983; Pate JL, 1988], sheep [Rexroad CE, Jr. and Guthrie HD, 1979], pseudopregnant rats [Olofsson J et al, 1992], pigs [Guthrie HD et al, 1978], and rhesus monkeys [Johnson MS et al, 1988] produce prostaglandins. Sheep CL express mRNAs for COX-1, COX-2, and prostaglandin metabolizing enzyme prostaglandin-15 dehydrogenase (PGDH) [Tsai SJ and Wiltbank MC, 1997]. Recently, CL of cattle have been shown to have machinery for biosynthesis and transport of PGs [Arosh JA et al, 2004]. These studies have indicated that bovine CL express constant amounts of COX-1, PGDH and PGFS (AKR1B5) throughout the lifespan of CL, whereas expression of PGES, PG transporter, receptor for PGE and $\mathrm{PGF}_{2 \alpha}$ vary with the stages of estrous cycle. Authors have suggested that CL preferentially produces $\mathrm{PGF}_{2 \alpha}$ during luteolysis, whereas greater amount of PGE2 production occurs during the luteal maintenance. 


\section{Transport of $\mathrm{PGF}_{2 \alpha}$}

$\mathrm{PGF}_{2 \alpha}$ synthesized in endometrium is transported to ovary by a utero-ovarian vascular pathway to initiate the process of luteolysis [McCracken JA et al, 1972]. The transfer of PGs from uterine venous vessels to ovarian artery primarily occurs at a specialized vascular network called utero-ovarian plexus (UOP) [Ginther OJ, 1981]. In pigs, the direction of release of endometrial $\mathrm{PGF}_{2_{\alpha}}$ differ depending on the need and function, for example it is preferentially released into circulation during luteolysis, whereas it is secreted directly into the lumen of uterus during maternal recognition of pregnancy [Bazer FW and Thatcher WW, 1977]. This directional transport of PGs cannot be explained by simple diffusion. PGs are charged anions and therefore have poor capacity to pass through biological membranes by simple diffusion and moreover the rate of transport of PGs by this mechanism is too slow to bring about their biological effects [Nelson DL and COX MM, 2000]. Therefore, it was proposed that the carrier-mediated proteins are required to selectively transport PGs. Prostaglandin transporter (PGT) has been identified in human liver [Lu R et al, 1996], rat kidney [Kanai $\mathrm{N}$ et al, 1995], and mouse lung [Pucci ML et al, 1999].

PGT is a polypeptide belonging to super family of 12-transmembrane organic anion transporting polypeptides (OATPs) [Schuster VL, 1998; Schuster VL, 2002]. It mediates efflux and influx of newly synthesized PGs and it is highly expressed in tissues producing large quantities of PGs [Bao Y et al, 2002]. In cattle, both mRNA and protein of PGT are expressed in endometrium, myometrium, and smooth muscle cells of UOP. Its expression pattern is consistent with its role in the compartmental transport of $\mathrm{PGF}_{2 \alpha}$ from uterus to ovary during luteolysis [Banu SK et al, 2003]. The compartmental transport of $\mathrm{PGF}_{2 \alpha}$ is important because of its high rate of clearance via lung, for example, $65 \%$ and $99 \%$ of PG is metabolized by single pass through the lung in cattle and sheep, respectively [McCracken JA et al, 1999]. Bovine CL expresses PGT, specifically on LLC and its mRNA expression is greatest during late luteal phase of the estrous cycle (Days 13-15). However the amount of protein remains constant throughout the estrous cycle. Therefore, authors suggested that PGT might play an important role in influx and efflux of available luteal PGE2 or $\mathrm{PGF}_{2 \alpha}$ in a competitive manner for their autocrine or paracrine effects [Arosh JA et al, 2004]. 


\section{Regulation of $\mathrm{PGF}_{2 \alpha}$ synthesis and initiation of luteolysis;}

The release of free AA from phospholipids is a rate-limiting step during PG synthesis [Kunze H and Vogt W, 1971; Lands WE and Samuelsson B, 1968]. Released AA is quickly converted to $\mathrm{PGF}_{2 \alpha}$ by cyclooxygenases [Vane JR and Botting RM, 1995]. However, during luteolysis, $\mathrm{PGF}_{2 \alpha}$ is secreted from uterus in the form of 4 to 8 discrete pulses at intervals of 6 to $8 \mathrm{~h}$ [Nancarrow CD et al, 1973; Thorburn GD et al, 1973]. The exact mechanism of the initiation of $\mathrm{PGF}_{2 \alpha}$ synthesis from uterus is not clearly understood. In sheep, pulses of oxytocin or neurophysin occured concurrently with the PGFM pulses during luteolysis [Hooper SB et al, 1986]. In agreement, large pulses of oxytocin/neurophysin have been reported to occur in cattle [Walters DL and Schallenberger E, 1984] and goats [Cooke RG and Homeida AM, 1984] during luteolysis. In addition, oxytocin stimulated the synthesis of $\mathrm{PGF}_{2_{\alpha}}$ in the uterus [Roberts JS and McCracken JA, 1976; Sharma SC and Fitzpatrick RJ, 1974][Schams D, 1989]. Neurophysin is released in an episodic manner lasting for few minutes at a frequency of 3 pulses per hour in sheep during follicular phase and in ovariectomized ewes during estradiol replacement [McCracken JA et al, 1991]. Authors of this study indicated that an episodic pattern of release of oxytocin might cause large pulsatile episodes of uterine $\mathrm{PGF}_{2_{\alpha}}$, proposing that neurohypophyseal oxytocin might act as a central pulse generator signal.

In cattle and sheep, corpora lutea secrete large quantities of oxytocin [Fields PA et al, 1983][Wathes DC and Swann RW, 1982]. In cattle and sheep, LLC appear to be the cellular source of oxytocin [Fields MJ and Fields PA, 1986; Fields PA et al, 1983][Rodgers RJ et al, 1983]. Moreover, in cattle exogenous $\mathrm{PGF}_{2_{\alpha}}$ increased oxytocin in jugular venous blood that

peaked within 15-20 min [Schams D and Karg H, 1982]. In sheep, treatment with cloprostenol, an analog of $\mathrm{PGF}_{2_{\alpha}}$, increased the secretion of oxytocin from the ovary with the $\mathrm{CL}$ and not from the opposite ovary or the brain [Flint AP and Sheldrick EL, 1982]. This study clearly indicated that the oxytocin came from the CL and not from neurohypophysis following $\mathrm{PGF}_{2}$, injection. It was proposed that oxytocin synthesized in CL is totally discharged with each pulse of $\mathrm{PGF}_{2 \alpha}$, and an interval between pulses of $\mathrm{PGF}_{2 \alpha}$ might be required to re-synthesize luteal oxytocin for subsequent secretion [Flint AP et al, 1990]. However, this was shown to be unlikely because of the low mRNA for oxytocin during luteolysis in sheep [Ivell R et al, 1990]. The contribution of neurohypophysis to circulating oxytocin during luteolysis is $\sim 10 \%$, whereas 
$\sim 50 \%$ from CL. However, as luteolysis progresses, the relative contribution of oxytocin from the neurophysis is proportionately greater [McCracken JA et al, 1996]. Regardless of the magnitudes of contributions of oxytocin from CL or neurohypophysis, it has been proposed that small increases in circulating concentrations of oxytocin, due to central oxytocin pulse generator, stimulate the subluteolytic amounts of $\mathrm{PGF}_{2_{\alpha}}$, from uterus, which in turn stimulate large supplemental release of luteal oxytocin [McCracken JA et al, 1999]. Subsequently, stimulating large quantities of uterine $\mathrm{PGF}_{2_{\alpha}}$, to initiate the process of luteolysis. Importantly, in sheep both in vivo and in vitro treatment with $\mathrm{PGF}_{2 \alpha}$, stimulated the luteal production of $\mathrm{PGF}_{2 \alpha}$ [Tsai SJ and Wiltbank MC, 1997]. The authors of these studies have proposed that local production of luteal $\mathrm{PGF}_{2 \alpha}$ can act in an autocrine or paracrine manner to increase the luteolytic effect of uterine $\mathrm{PGF}_{2}$, by forming positive feedback loop during luteolysis.

It has been shown that the ability of oxytocin to stimulate uterine $\mathrm{PGF}_{2_{\alpha}}$, synthesis in ovariectomized animals depends on the pre-exposure to progesterone and can be enhanced by acute or chronic treatment with estrogen. In ovariectomized cows and ewes, oxytocin stimulated the secretion of uterine $\mathrm{PGF}_{2 \alpha}$, only after animals had been exposed to progesterone for 7-10 days [Homanics GE and Silvia WJ, 1988; Lafrance M and Goff AK, 1988]. The pre-exposure of uterus to progesterone has been proposed to prime the uterus for the release of $\mathrm{PGF}_{2 \alpha}$ by increasing the accumulation of lipid precursors [Nissenson R et al, 1978; Soloff MS et al, 1983] [Boshier DP and Holloway H, 1973; McCracken JA, 1980]. It has been shown that progesterone prevented the ability of estrogen to up-regulate oxytocin receptors [Leavitt WW et al, 1985]. In addition, progesterone inhibited the action of oxytocin in uterus by non-genomic action by changing the conformation of oxytocin receptors [Grazzini E et al, 1998]. In sheep, withdrawal of progesterone increased the receptors for oxytocin in endometrium within $6 \mathrm{~h}$. Importantly, exposure to progesterone for 7-14 days down-regulated its own receptor in endometrium [Clarke CL, 1990; Milgrom E et al, 1973] and hypothalamus [Blaustein JD and Feder HH, 1979; Moguilewsky M and Raynaud JP, 1979]. Therefore, a model has been proposed for hormonal regulation of $\mathrm{PGF}_{2 \alpha}$ and initiation of luteolysis as follows (reviewed by [McCracken JA et al, 1999]). 1) The loss of progesterone receptors during the late luteal phase prevents the suppressing effect of progesterone on oxytocin receptors and allows estrogen to upregulate estrogen receptors in uterus, 2) Returning action of estrogen will stimulate the release of hypothalamic oxytocin pulse generator to stimulate low episodic levels of oxytocin, 3) Oxytocin 
will then stimulate the subluteolytic release of $\mathrm{PGF}_{2 \alpha}$ from uterus, which in turn stimulates the additional release of oxytocin from CL, 4) Increased oxytocin will further stimulate the secretion of $\mathrm{PGF}_{2_{\alpha}}$ from uterus and $\mathrm{CL}$ in positive feedback manner, 5) Additionally, $\mathrm{PGF}_{2_{\alpha}}$ released from CL stimulate its own synthesis of $\mathrm{PGF}_{2_{\alpha}}$ in a autocrine manner to complete the process of luteolysis.

\section{PGF $2_{\alpha}$ signaling during luteolysis:}

\section{Receptors for $\mathbf{P G F}_{\mathbf{2}_{\alpha}}$}

Fried et al. [Fried $\mathrm{J}$ et al, 1969] were the first to provide evidence for presence of $\mathrm{PGF}_{2_{\alpha}}$ receptors in endometrium by showing that 7-oxa-acetylenic analogs of $\mathrm{PGF}_{1_{\alpha}}$ prevented the contractibility of uterus. Later, binding sites for $\mathrm{PGF}_{2_{\alpha}}$ in CL have been identified in sheep [Balapure AK et al, 1989; Powell WS et al, 1974], rat [Bussmann LE, 1989], pig [Gadsby JE et al, 1990], and humans [Rao CV et al, 1977]. Subsequently, receptors for $\mathrm{PGF}_{2 \alpha}$ (FP) have been cloned and characterized in various tissues including CL in cattle [Sakamoto K et al, 1994], human [Lake S et al, 1994], rat [Kitanaka J et al, 1994], mouse [Sugimoto Y et al, 1994], and sheep [Graves PE et al, 1995]. FP receptors are members of seven-transmembrane domain receptor family and coupled to G-protein. It appears that in cattle there is single gene for FP consisting of 40 kilobases (kb)[Ezashi $\mathrm{T}$ et al, 1997] and organized with three exons and two introns, which is conserved across human, mouse, and cattle [Betz R et al, 1999; Hasumoto K et al, 1997]. The molecular weight of FP is $40 \mathrm{kDa}$ and it appears to be similar among species. The open reading frame of FP consists of 362 amino acid residues in cattle and sheep, 366 in mouse and rat, and 359 amino acids in human beings. The homology of bovine FP amino acid sequence is $98 \%$ with ovine, $86 \%$ with human beings, $80 \%$ with murine and $78 \%$ with rat [Anderson LE et al, 2001]. There are two isoforms of FP, $\mathrm{FP}_{\mathrm{A}}$ and $\mathrm{FP}_{\mathrm{B}}$ [Pierce KL et al, 1997]. These isoforms have been suggested to arise from alternative mRNA splicing mechanism. $\mathrm{FP}_{\mathrm{B}}$ is a truncated form of $\mathrm{FP}_{\mathrm{A}}$, lacking 46 amino acids at the carboxy-terminal end and four putative protein kinase $\mathrm{C}(\mathrm{PKC})$ phosphorylation sites. $\mathrm{FP}_{\mathrm{A}}$ isoform is phosphorylated by $\mathrm{PGF}_{2_{\alpha}}$ via PKC dependent pathway, whereas $\mathrm{FP}_{\mathrm{B}}$ is not phosphorylated, so it was suggested that FP isoforms are regulated differentially by $\mathrm{PGF}_{2_{\alpha}}$ [Fujino $\mathrm{H}$ et al, 2000]. In cattle, mRNAs for FP receptor are expressed on LLC, SLC, and endothelial cells [Mamluk R et al, 1998], whereas in 
sheep, they are present on only LLC [Juengel JL et al, 1996] and expression of FP on luteal endothelial cells has not been confirmed. In cattle, FP mRNAs increased from early to late phase of estrous cycle, and decreased markedly in regressing CL [Sakamoto K et al, 1995]. Similar pattern of expression was reported in sheep [Graves PE et al, 1995] and pig [Gadsby JE et al, 1990] CL. Importantly, in cattle and sheep, in vivo and in vitro treatments with $\mathrm{PGF}_{2_{\alpha}}$ decreased the FP receptors similar to that observed during natural luteolysis [Juengel JL et al, 2000; Mamluk R et al, 1998]. The physiological significance of down-regulation of FP receptors during luteolysis is not clear,

\section{2a. PRKC/calcium signaling pathway}

$\mathrm{PGF}_{2 \alpha}$ has been shown to affect composition and fluidity of the luteal lipid membrane [Carlson JC et al, 1984; Leung PC et al, 1986; Raymond V et al, 1983]. Later it was shown that the action of $\mathrm{PGF}_{2_{\alpha}}$ might be mediated through an increase in intracellular $\mathrm{Ca}^{2+}$ derived from internal sources in rat luteal cells [Dorflinger LJ et al, 1984]. Around the same time, it was reported that hydrolysis of phoshatidylinositol 4, 5-biphosphate by phospholipase C (PLC) leads to the generation of secondary messenger inositol 1-4-5-trisphosphate $\left(\mathrm{IP}_{3}\right)$, which in turn stimulated the release of $\mathrm{Ca}^{2+}$ from ER [Berridge MJ and Irvine RF, 1984; Spat A et al, 1986]. Similarly, in steroidogenic cells of the ruminant CL, PGF $2_{\alpha}$ activated G-protein coupled FP receptors leading to activation of PLC. Once active, PLC acts on membrane lipids to produce intracellular secondary messengers such as $\mathrm{IP}_{3}$ and diacylglycerol (DAG) [Davis JS et al, 1988]. Acordingly, in bovine luteal cells, hydrolysis of phoshatidylinositol 4, 5 -biphosphate and mobilization of intracellular $\mathrm{Ca}^{2+}$ were stimulated by $\mathrm{PGF}_{2_{\alpha}}$ [Davis JS et al, 1987b]. Furthermore, $\mathrm{Ca}^{2+}$ and PRKC mediated the intracellular actions of $\mathrm{PGF}_{2 \alpha}$ in luteal cells [Wiltbank MC et al, 1991]. In bovine luteal cells, $\mathrm{PGF}_{2_{\alpha}}$ activated the Raf/MEK1/mitogenactivated protein kinase (MAPK) signaling pathway [Chen DB et al, 1998]. Activation of this pathway by $\mathrm{PGF}_{2 \alpha}$ increased the expression of c-fos and c-jun and activated transcription factors called activator protein-1 (AP-1). More recently, it has been shown that activation of Raf/MEK1/MAPK pathway by $\mathrm{PGF}_{2 \alpha}$ is mediated by PRKC in bovine luteal cells [Chen D et al, 2001] [Stocco $\mathrm{C}$ et al, 2007]. The constituents of AP-1 transcription factors, $c$-fos and $c-j u n$, regulated the expression of genes having AP-1 binding site on their promotor. Therefore, it was proposed that activation of $\mathrm{AP}-1$ by $\mathrm{PGF}_{2 \alpha}$ in bovine luteal cells might modulate the expression 
of genes during luteolysis. However, the detailed cellular and molecular mechanisms of luteolysis initiated by $\mathrm{PGF}_{2 \alpha}$ are not understood. The schematic representation of $\mathrm{PGF}_{2 \alpha}$ signaling pathway in bovine CL is indicated in figure 1.

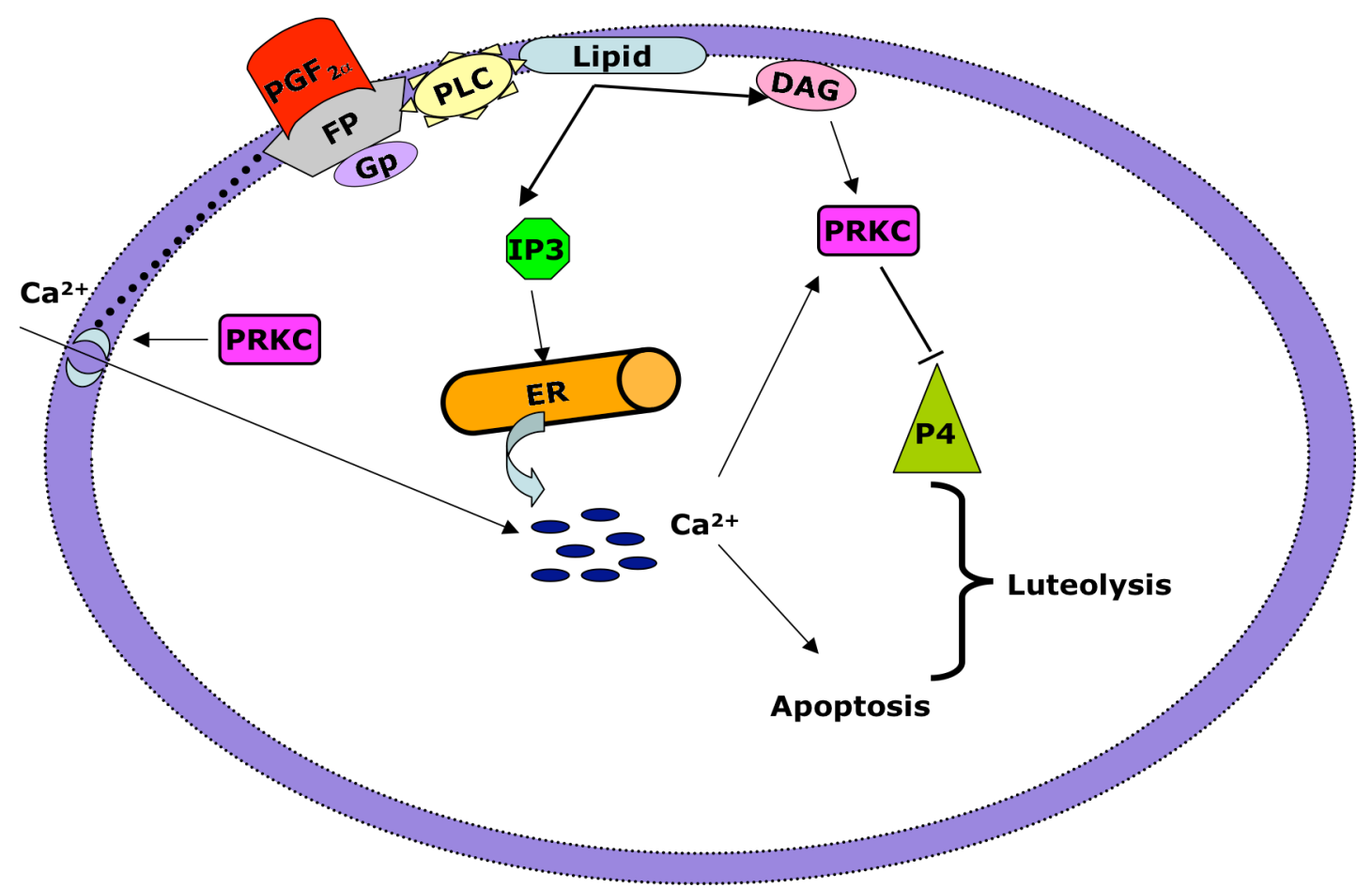

Figure 1. $\mathrm{PGF}_{2_{\alpha}}$ signaling pathway: PLC: phospholipase C; $\mathrm{PGF}_{2_{\alpha}}: \mathrm{PGF}_{2_{\alpha}}$ receptor; ER: endoplasmic reticulum; PRKC: protein kinase C; P4: progesterone; Gp: G-protein; DAG: diacylglycerol; IP3: inositoltriphosphate

\section{2b. PRKC}

Protein kinase $\mathrm{C}$ (PRKC) is a family of serine/threonine kinases with 11 isozymes. These enzymes are single polypeptide chain with regulatory region located at amino-terminal region having molecular weight of $20-70 \mathrm{kDa}$, whereas the catalytic unit is located at the carboxyterminal end with molecular weight of $45 \mathrm{kDa}$. Different isozymes have different subcellular localization and co-factor requirements [Nishizuka Y, 1988; Quest AF, 1996]. The conventional PRKC category includes four isozymes, alpha $(\alpha)$, beta I ( $(\Omega I)$, beta II (BII), and gamma $(\gamma)$. The 
novel PRKC category includes four additional isozymes, delta $(\delta)$, epsilon $(\varepsilon)$, theta $(\theta)$, and eta $(\eta)$. Finally, three more isozymes make up the atypical PRKC group, lambda $(\lambda)$, zeta $(\varsigma)$, and $\mathrm{mu}(\mu)$. The conventional isozymes are activated by diacylgycerol (DAG), $\mathrm{Ca}^{2+}$, and

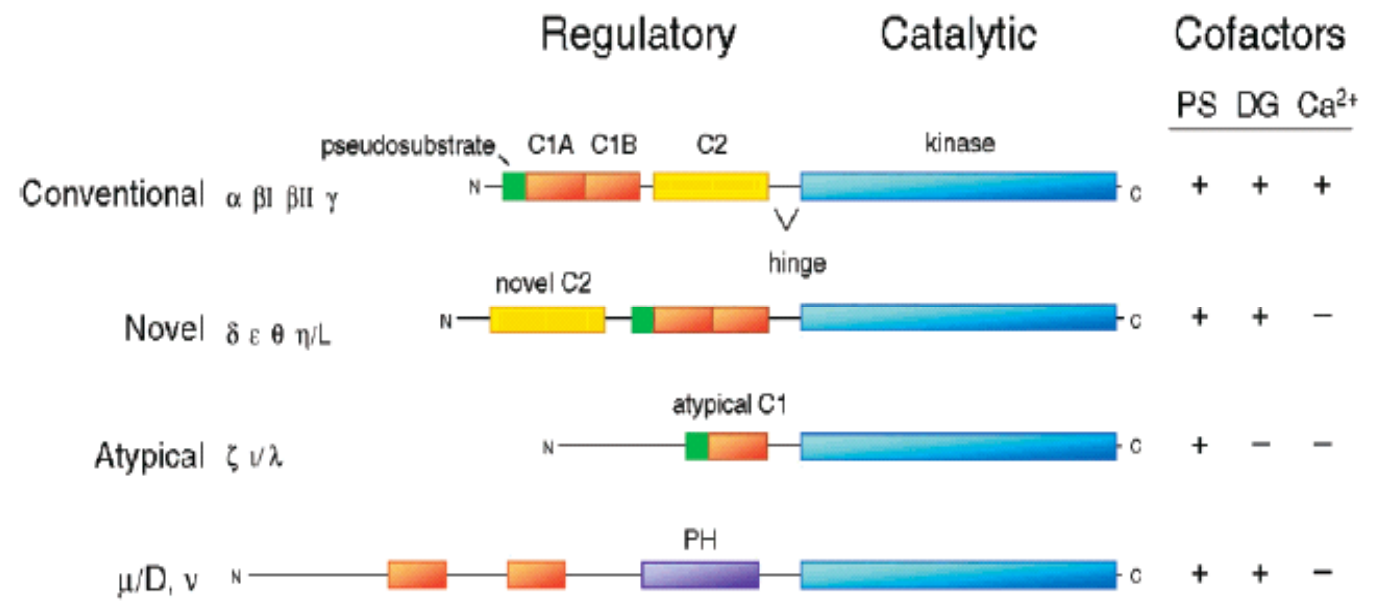

Figure 2. PRKC isozyme specific domains and co-factor requirement (adapted from [Newton $\mathrm{AC}, 2001])$.

phosphatidylserine, whereas, the novel isozymes depend on DAG and phosphotidylserine for their activation and atypical isozymes are activated by phosphotidylserine. The regulatory unit consists of two important domains, one is an autoinhibitory sequence (pseudosubstrate) and the other includes one or two membrane targeting modules (C1 and C2). Pseudosubstrate allosterically regulates the enzyme activity. During the inactive state of an enzyme, pseudosubstrate covers the substrate-binding site. Whenever the enzyme is activated by cofactor or co-factor- independent mechanisms, there will be a release of pseudosubstrate from the kinase core [Orr JW and Newton AC, 1994b; Orr JW and Newton AC, 1994a]. It has been shown that increased intracellular $\mathrm{Ca}^{2+}$ is essential for translocation of PRKC to membrane by increasing its affinity towards anionic lipids. $\mathrm{Ca}^{2+}$ binding with the enzyme engages $\mathrm{C} 2$ domain with the lipid membrane, thereby decreasing the dimensionality and increasing the probability of engaging $\mathrm{C} 1$ domain with DAG. Binding of PRKC domains to membrane releases the energy required to release pseudosubstrate from an active catalytic site, thereby activating the enzyme [Johnson JE et al, 2000]. In addition DAG, and phorbol esters act by increasing the affinity of PRKC to membranes by acting as molecular glue. It has been shown that the DAG binding to $\mathrm{C} 1$ domain results in presentation of contiguous hydrophobic surface, allowing increased 
affinity towards lipid membrane [Zhang $\mathrm{G}$ et al, 1995]. However, the action of DAG does not last long because of its rapid metabolism and therefore phorbol esters are 2 times more potent than DAG. In addition to these regulatory molecules, the anchoring proteins of PRKC are very important for translocation to its substrate, or regulators such as phosphatases and kinases, or to specific intracellular compartments [Mochly-Rosen D, 1995]. Accordingly, peptide agonists can be used to activate PRKC enzymes that are regulated by the anchoring proteins such as receptors for activated kinases (RACKs) [Csukai M and Mochly-Rosen D, 1999]. It has been proposed that the site on the enzymes that binds to anchoring proteins are masked by masking domain called pseudo-RACK sequence. This sequence is similar to the sequence of binding site on the anchoring protein. Therefore, peptide agonists similar to this sequence can disrupt intramolecular interaction by disengaging the pseudosubstrate RACK sequence from anchoring to the protein-binding site, thereby activating the enzyme. Accordingly, it has been show that $\mathrm{C} 2$ domain of PKCE (official symbol, PRKCE) has a pseudo-RACK sequence NDAPIGYD (V1 region) [Csukai M et al, 1997; Dorn GW, 2nd et al, 1999]. Agonists or antagonist with sequences similar to pseudo-RACK has been extensively utilized to activate or inactivate PRKCE in several cell systems.

Pharmacological activation of PKC with the phorbol esters inhibited steroidogenesis in luteal cells from human [Abayasekara DR et al, 1993] and sheep [Wiltbank MC et al, 1991]. In sheep luteal cells, $\mathrm{PGF}_{2 \alpha}$ prevented the lipoprotein-stimulated progesterone synthesis and had no effect in PRKC-deficient cells [Wiltbank MC et al, 1990]. It has been shown that anti-steroidogenic actions of PRKC might be due its ability to inhibit the expression of mRNAs encoding P-450scc and 3 $\beta$-HSD [McGuire WJ et al, 1994]. Moreover, in rat testicular microsomes, the activation of PLC activated PRKC resulting in decreased activity of 3 $\beta$-HSD, which suggested that PRKC might modulate the activity of $3 \beta$-HSD [Cooke GM and Robaire B, 1988]. In addition, activation of PRKC inhibited the transport of cholesterol across mitochondrial membrane [Wiltbank MC et al, 1993]. However, the detailed cellular mechanism by which PRKCs mediate the anti-steroidogenic actions of $\mathrm{PGF}_{2 \alpha}$ needs further investigation. 


\section{2c. $\mathrm{Ca}^{2+}$-calmodulin dependent kinase kinase 2, beta (official symbol, CAMKK2/ САМКK $\beta$ )}

CAMKK is a recently discovered enzyme and first discovered in rat brain, where it activated an inactive recombinant CaMK1V [Okuno S and Fujisawa H, 1993]. CAMKKs belong to protein kinase superfamily and perform the function of serine/threonine phosphorylation. Two types of CAMKK have been characterized in rat brain, CAMKK alpha and CAMKK beta [Edelman AM et al, 1996]. Bovine CAMKK2 is a $63 \mathrm{kDa}$ protein and consists of 579 amino acids. Both forms are expressed from distinct genes and both appear to be activated by $\mathrm{Ca} 2+-\mathrm{CaM}$ and capable of $\mathrm{Ca}^{2+}$-CaM-dependent autophosphorylation. Both forms activated downstream enzymes, CaMK1 and CaMK1V by phosphorylation-dependent mechanism. Accordingly, CAMMK2 stimulated CaMK1 by 25 -fold and CaMKIV by 12 -fold by phosphorylating amino acid residues at $\mathrm{Thr}^{177}$ and $\mathrm{Thr}^{200}$, respectively. However, in brain CAMKK2 and CaMK1V were co-localized in cerebellar region suggesting that CaMK1V might be acutely regulated by CAMKK2 [Anderson KA et al, 1998]. It has been suggested that CAMKK alpha might specifically regulate CaMK1. However, because of its ubiquitous distribution, it is unclear which of the isoforms regulate the activity of CaMK1 [Haribabu B et al, 1995; Picciotto MR et al, 1993]. Similar to other CaM kinase family, CAMKK2 has capacity to undergo an autophosphorylation upon binding with $\mathrm{Ca}^{2+}$-CaM. Phosphorylation will prevent the reformation of autoinhibitory conformation, thereby keeping the enzyme in an autonomously active state [Braun AP and Schulman H, 1995]. This property of autophosphorylation is observed with CaMK1 and CaMK1V. The activity of CAMKK2 is independent of $\mathrm{Ca}^{2+}-\mathrm{CaM}$ binding and subsequent autophosphorylation, however, these mechanisms can enhance its activity [Edelman AM et al, 1996]. Neverthless, it has been proposed that these mechanisms in vivo might have physiological consequences such as cellular distribution and protein-protein interaction with downstream signaling molecules. Neuronal tissue has been shown to be primary site of expression and expressed at lower amounts in testis, thymus, and spleen [Anderson KA et al, 1998; Tokumitsu H et al, 1995]. CaMK IV is expressed in steroidogenic tissues such as ovary, testis, and adrenal gland in addition to brain, thymus, and bone marrow, whereas, CaMKI is ubiquitously expressed [Haribabu B et al, 1995; Means AR et al, 1997]. However, there is no evidence on the expression and role of CAMKK2 in ovarian tissue to date. In rabbit aortic smooth muscle cells, epinephrine stimulated the activity of CaMKII followed by increase in mobilization of 
arachidonic acid [Muthalif $\mathrm{MM}$ et al, 1996]. In addition, $\mathrm{Ca}^{2+}$ play a very important role in oxytocin-induced $\mathrm{PGF}_{2 \alpha}$ release in bovine endometrium [Burns PD et al, 1998]. In agreement, oxytocin stimulated $\mathrm{PGF}_{2_{\alpha}}$ synthesis in ovine endometrium by activating ERK1/2. The activation of ERK1/2 depends on Ca2+-CaM in luteinized granulosal cells [Stocco CO et al, 2002]. Therefore, CAMKK2 might play a very important role in stimulation of $\mathrm{PGF}_{2 \alpha}$ synthesis from uterus and CL. In addition, the possibility of direct participation of CAMKK2 in mediating the antisteroidogenic actions of the rise in intracellular $\mathrm{Ca}^{2+}$ stimulated by $\mathrm{PGF}_{2 \alpha}$ needs further investigation.

\section{Functional luteolysis: inhibition of progesterone synthesis}

The pulsatile release of $\mathrm{PGF}_{2 \alpha}$ from the uterus around 17-18 days of estrous cycle initiates the process of luteolysis in the ruminant CL [Kindahl H et al, 1976; Wolfenson D et al, 1985] [Shirasuna $\mathrm{K}$ et al, 2004]. In cattle, direct measurement of $\mathrm{PGF}_{2_{\alpha}}$ in uterine-venous blood indicated that concentrations of $\mathrm{PGF}_{2_{\alpha}}$ increase on Day 14 and remain elevated on Days 15-20 [Shemesh M and Hansel W, 1975b]. It has been suggested that finite number of frequent $\mathrm{PGF}_{2_{\alpha}}$ pulses occurring over a period of $\sim 24 \mathrm{~h}$ was necessary for the initiation of functional luteolysis. Accordingly, $\mathrm{PGF}_{2 \alpha}$ inhibited the synthesis of progesterone in vivo in cattle, sheep, pigs, monkeys, human beings, pseudopregnant rats and rabbits [Niswender GD and Nett TM, 1994]. Similarly, in vitro $\mathrm{PGF}_{2_{\alpha}}$ treatment inhibited the synthesis and secretion of progesterone in luteal cells of mid to late CL [Niswender GD et al, 2000]. The decline in progesterone occurs over a period of $\sim 24-36 \mathrm{~h}$ and reduction in progesterone starts after the first pulse of $\mathrm{PGF}_{2 \alpha}$ in sheep, whereas in monkeys, the decline in progesterone occur over a period of $\sim 48 \mathrm{~h}$.

\section{Antisteroidogenic actions of $\mathrm{PGF}_{2_{\alpha}}$}

Juengel et al [Juengel JL et al, 1994] suggested that the down-regulation of receptors for LH by $\mathrm{PGF}_{2 \alpha}$ might be one of the mechanisms for antisteroidogenic actions of $\mathrm{PGF}_{2 \alpha}$. However, in cows [Spicer LJ et al, 1981] and ewes [Diekman MA et al, 1978], the decline in progesterone preceded the decrease in mRNA for $\mathrm{LH}$ receptor. It had been shown that $\mathrm{PGF}_{2_{\alpha}}$ might interfere with progesterone stimulatory actions of LH by affecting PKA. Accordingly, it was reported that the activity of PKA might be reduced by an increased degradation of cAMP due to the 
activition of phosphodiesterase enzyme [Agudo LS et al, 1984; Garverick HA et al, 1985]. This mechanism might be important in inhibiting the expression of StAR, because cAMP activated the promoter for StAR in MA-10 cells. LLC account for the most of the basal progesterone due to constitutively high activity of PKA [Diaz FJ et al, 2002]. Therefore, decrease in the activity of PKA by $\mathrm{PGF}_{2_{\alpha}}$ might be responsible for the inhibition of progesterone synthesis in LLC. $\mathrm{PGF}_{2 \alpha}$ decreased sterol carrier protein (SCP-2) [McLean MP et al, 1995] and cytoskeleton [Murdoch WJ, 1996] that are involved in cholesterol transport. Negative regulation of progesterone synthesis by affecting the activity of StAR has been suggested to be the major point of regulation by $\mathrm{PGF}_{2_{\alpha}}$. Both, in vivo and in vitro treatment of luteal tissues with $\mathrm{PGF}_{2_{\alpha}}$ decreased the expression of StAR mRNA in sheep and cattle. In addition, it was proposed that that $\mathrm{PGF}_{2 \alpha}$ might inhibit the translation of StAR mRNA. The orphan nuclear receptor, DAX-1 was proposed to mediate the inhibitory action of $\mathrm{PGF}_{2_{\alpha}}$ on StAR mRNA expression, because DAX-1 bound to a DNA hairpin structure on the StAR promoter. Accordingly. FGF $_{2_{\alpha}}$ induced DAX-1 RNA and inhibited progesterone synthesis in rat CL [Sandhoff TW and McLean MP, 1999; Zazopoulos E et al, 1997]. Activation of the proteosome system by $\mathrm{PGF}_{2_{\alpha}}$ might be another mechanism of regulation of StAR, because the inhibitors of proteosome system increased StAR protein and stimulated progesterone synthesis in rat and human granulosa-luteal cells [Tajima K et al, 2001]. Phosphorylation of StAR at positions Ser194/195 by PKA increased the steroidogenic activity [Arakane F et al, 1997]. Therefore, inhibitory actions of $\mathrm{PGF}_{2_{\alpha}}$ on PKA activity might reduce the ability of StAR to transport cholesterol into mitochondria. Activation of PKC partially inhibited progesterone in luteal cells supplied with 25-hydroxycholesterol and this effect was abolished in PKC deficient cells, which suggested that PKC inhibited cholesterol side chain cleavage enzyme [Wiltbank MC et al, 1990]. However, inhibition of progesterone by $\mathrm{PGF}_{2_{\alpha}}$ was not associated with decrease in mRNA or protein of P450Scc enzyme complex [Belfiore CJ et al, 1994; Rodgers RJ et al, 1995]. In addition, $\mathrm{PGF}_{2_{\alpha}}$ did not reduced $3 \beta-\mathrm{HSD}$ during its initial $24 \mathrm{~h}$ of treatment. Therefore, it was proposed that progesterone inhibitory actions of $\mathrm{PGF}_{2_{\alpha}}$ might not be mediated by inhibition of P450Scc or $3 \beta$-HSD.

In cattle, FP receptors are present on both LLC and SLC, however in sheep high affinity FP receptors are absent on SLC [Fitz TA et al, 1982] [Wiltbank MC et al, 1993]. However, 
activation of PRKC inhibited PKA-stimulated progesterone synthesis in SLC suggesting that antisteroidogenic actions of $\mathrm{PGF}_{2_{\alpha}}$ in ovine SLC might be indirect. Therefore, the identity of the factor that activate PKC in ovine CL was not known until recent. The receptors for oxytocin are present on SLC and treatment of luteal tissues with oxytocin decreased the secretion of progesterone [Bennegard-Eden B et al, 1995; Pitzel L et al, 1993]. In addition, PGF $_{2 \alpha}$ stimulated the secretion of oxytocin from luteal tissue [Flint AP and Sheldrick EL, 1982]. Therefore, it is tempting to speculate that oxytocin might be the ideal candidate to mediate antisteroidogenic actions of $\mathrm{PGF}_{2 \alpha}$ in SLC. More recently, it was shown that oxytocin stimulated increase in intracellular $\mathrm{Ca}^{2+}$ in SLC, and this action was abolished by progesterone [Niswender GD et al, 2007]. These authors have proposed that $\mathrm{PGF}_{2_{\alpha}}$ stimulate LLC to secrete oxytocin, which then bind to its receptors on SLC and inhibit synthesis of progesterone. Once the intraluteal concentrations of progesterone declines, then oxytocin might induce the apoptosis of SLC by raising $\left[\mathrm{Ca}^{2+}\right] \mathrm{i}$.

\section{Mediators of antisteroidogenic actions of $\mathrm{PGF}_{\mathbf{2}_{\alpha}}$}

In cattle, $\mathrm{PGF}_{2 \alpha}$ increased endothelin-1 (EDN1) in regressing CL and ovarian venous blood, which suggested that EDN1 might be a mediator of luteolysis [Ohtani M et al, 1998]. In addition, EDN1 and angiotensin II (AngII) inhibited progesterone synthesis in bovine luteal cells [Girsh E et al, 1996; Miyamoto A et al, 1997]. Both LLC and SLC express mRNA for ET type A receptor (ETA) [Meidan R et al, 1999] and action of EDN1 is mediated through selective ETA type receptor [Girsh E et al, 1996]. Therefore, it is clear that in cattle, EDN1 mediate the antisteroidogenic actions of $\mathrm{PGF}_{2 \alpha}$. Delivery of EDNRA and EDNRB receptor antagonists into the ovine $\mathrm{CL}$ inhibited progesterone inhibitory actions of $\mathrm{PGF}_{2_{\alpha}}$ during first $12 \mathrm{~h}$, which indicated the role of EDN1 in mediating the antisteroidogenic actions of $\mathrm{PGF}_{2 \alpha}$ [Doerr MD et al, 2008]. In cattle, a donor of nitric oxide (NO) inhibited the synthesis of progesterone in luteal cells [Skarzynski DJ and Okuda K, 2000]. In addition, administration of NO synthase (NOS) inhibitor to cow inhibited luteolytic actions of $\mathrm{PGF}_{2 \alpha}$, which was indicated by prolonged length of estrous cycle [Skarzynski DJ et al, 2003]. NO mediated the acute increase in luteal blood flow during first $30 \mathrm{~min}$ to $2 \mathrm{~h}$ after $\mathrm{PGF}_{2_{\alpha}}$ administration. Accordingly, in cattle, $\mathrm{PGF}_{2_{\alpha}}$ induced expression of endothelial nitric oxide synthase (eNOS) in the periphery of CL and NO 
donor induced acute increase in the luteal blood flow and decreased the length of estrous cycle [Acosta TJ et al, 2002; Shirasuna K et al, 2008]. This acute increase in blood flow has been proposed to be important in stimulating capillary endothelial cells to secrete vasoactive amines such as EDN1 and Ang II. These vasoactive amines facilitate a decrease in the luteal blood flow by vasoconstriction and inhibition of progesterone synthesis [Acosta TJ et al, 2002; Ohtani M et al, 1998]. In addition, early luteal resistance to $\mathrm{PGF}_{2_{\alpha}}$ was suggested to be due to the lack of ability of $\mathrm{PGF}_{2_{\alpha}}$ to induce eNOS in the periphery of CL and subsequent absence of acute increase in luteal blood flow [Shirasuna K et al, 2008].

However, it has been shown that there is an inverse relationship between the expression of EDN1 and NOS throughout the estrous cycle. The expression of NOS (both eNOS and iNOS) was elevated in the early CL and declined towards the end of cycle, whereas the expression of EDN1 increased during luteolysis. In addition, NO inhibited the expression of EDN1 in luteal endothelial cells. Therefore, it was proposed that low amounts of NO during luteolysis might facilitate an increased expression of EDN1 and greater amounts of NO during the early luteal stages might be responsible for low EDN1 expression [Rosiansky-Sultan M et al, 2006]. In addition, lower expression of EDN1 during early $\mathrm{CL}$ and inability of $\mathrm{PGF}_{2_{\alpha}}$ to induce its expression has been suggested to be part of mechanism responsible for early luteal resistance to $\mathrm{PGF}_{2 \alpha}$. However, the expression pattern of NOS and its role throughout the estrous cycle remains controversial.

In cattle, tumor necrosis factor alpha $(\mathrm{TNF} \alpha)$ and its receptors are expressed in CL [Sakumoto $\mathrm{R}$ et al, 2000]. In cattle and sheep, TNF $\alpha$ secretion was increased in regressing CL suggesting its role during luteolysis [Ji I et al, 1991; Shaw DW and Britt JH, 1995]. In cattle, TNF $\alpha$ inhibited in vivo progesterone synthesis in CL only after pre-exposure to $\mathrm{PGF}_{2_{\alpha}}$ and EDN1 [Ohtani $\mathrm{M}$ et al, 2004]. Supporting this observation, $\mathrm{TNF} \alpha$ and $\mathrm{PGF}_{2_{\alpha}}$ were synergistically inhibited progesterone synthesis in porcine CL [Wuttke W et al, 1998]. Therefore, it was proposed that TNF $\alpha$ facilitates a rapid decline in progesterone synthesis after initial decline by $\mathrm{PGF}_{2 \alpha}$ and EDN1.

\section{Structural regression of CL}

Structural regression is characterized by decrease in the weight and size of CL. In cattle, structural luteolysis started $12 \mathrm{~h}$ after an initial functional luteolysis following the administration 
of $\mathrm{PGF}_{2_{\alpha}}$ [Neuvians TP et al, 2004]. As a consequence, the size of the regressed CL is greatly reduced to a tiny white scary structure called corpus albicans, which is eventually reabsorbed and replaced with ovarian stroma. It is well established that the structural regression of CL occurs by the process of apoptosis of luteal and endothelial cells. Morphological changes were not evident until 24-36 h after $\mathrm{PGF}_{2 \alpha}$ injection and interestingly endothelial cells were first to undergo apoptosis [Sawyer HR et al, 1990]. There is a substantial amount of evidence supporting the participation of immune cells in structural luteolysis [Murdoch WJ et al, 1988]. Injection of $\mathrm{PGF}_{2 \alpha}$ into mid cycle cows and ewes resulted in an increased expression of monocyte chemo-attractant protein-1 (MCP-1), which is a potent chemo-attractant to immune cells [Tsai SJ et al, 1997]. In addition, MCP-1 was highly expressed in regressing rat CL [Townson DH et al, 1996]. Therefore, MCP-1 appears to be initial trigger for the infiltration of immune cells during luteolysis. The primary role of macrophages during luteolysis appears to be phagocytosis of apoptotic luteal cells and degradation of the extracellular matrix [Paavola LG, 1979; Pepperell JR et al, 1992]. In addition, T-lymphocytes secrete interferon- $\gamma$ (IFN- $\gamma$ ) that induces the expression of major histocompatibility complex antigens on cultured bovine luteal cells [Fairchild DL and Pate JL, 1989]. The cytokines, TNF $\alpha$, IL-1, and IFN- $\gamma$ were synergistically stimulated the synthesis of $\mathrm{PGF}_{2}$ from bovine luteal cells [Benyo DF and Pate JL, 1992; Nothnick WB and Pate JL, 1990]. These cytokines induced apoptosis in various cell types [Gupta S, 2003]. In cattle, Fas and Fas-ligand system appear to play an important role in the regulation of luteal cell- apoptosis. For example, expression of Fas is greater during structural regression of CL (Days 19-21). Futhermore, IFN- $\gamma$ increased the expression of Fas mRNA in luteal cells. Importantly, Fas-ligand induced apoptosis in luteal cells that were preexposed to IFN- $\gamma$ alone or with TNF $\alpha$ [Taniguchi $\mathrm{H}$ et al, 2002]. In addition, progesterone antagonist increased the expression of Fas mRNA and subsequent treatment with Fas ligand induced an apoptosis in bovine luteal cells [Okuda K et al, 2004]. This observation strongly supports the luteo-protective role of progesterone and it could be the reason for initiation of structural luteolysis after decline in progesterone.

$\mathrm{PGF}_{2_{\alpha}}$ induced apoptosis in luteal cells of several species [Niswender GD et al, 2000]. Formation of DNA ladder is an indication of cells undergoing apoptosis. In cattle, administration of $\mathrm{PGF}_{2 \alpha}$ induced DNA ladder formation in CL after 24-48 h [Juengel JL et al, 
1993]. The pro-apoptotic protein mRNAs of bax and caspase-3 were increased in regressing CL on Days 21 of cycle, whereas low amounts of these mRNAs were observed in pregnant CL [Rueda BR et al, 1997]. In addition, the reactive oxygen species (ROS) have been shown to be involved in apoptosis of luteal cells and addition of $\mathrm{PGF}_{2_{\alpha}}$ induced apoptosis by increasing the production of ROS [Sakka E et al, 1997]. In luteal cells, NO mediated $\mathrm{PGF}_{2_{\alpha}}$-induced apoptosis by inducing the expression of Fas, caspase-3, and DNA ladder formation, which suggested that NO might play role in structural luteolysis [Korzekwa AJ et al, 2006]. 


\section{Chapter II: Statement of problem}

The regression of $\mathrm{CL}$ is initiated by $\mathrm{PGF}_{2 \alpha}$ in most species studied, including cattle [McCracken JA et al, 1970; Niswender GD et al, 2000]. Because of this property, $\mathrm{PGF}_{2 \alpha}$ has been routinely used for synchronization of estrous. However, the limitation of this approach is that the sensitivity of CL to $\mathrm{PGF}_{2_{\alpha}}$ - induced luteolysis varies depending on the developmental stage of CL. Specifically in cattle, the early developmental stages (on or before day-5) of CL is insensitive to the luteolytic actions of $\mathrm{PGF}_{2 \alpha}$ and the aging $\mathrm{CL}$ has increased sensitivity to $\mathrm{PGF}_{2 \alpha}$ compared to the early CL [Choudhary E et al, 2005; Copelin JP et al, 1988; Inskeep EK, 1973; Sayre BL et al, 2000; Watts TL and Fuquay JW, 1985]. Therefore it is clear that: 1) $\mathrm{PGF}_{2 \alpha}$ is the initiator of luteolysis in the cattle, and 2) the sensitivity of CL is increased with developmental aging. However, the cellular mechanisms responsible for this developmental differences to $\mathrm{PGF}_{2 \alpha}$ is not clearly understood.

Several ideas have been proposed to be part of mechanisms responsible for developmental sensitiveness of CL as follows. 1) Alterations in the luteal expression of components associated with $\mathrm{PGF}_{2 \alpha}$ metabolism. For instance, resistance of early ovine $\mathrm{CL}$ has been attributed to increased expression of the $\mathrm{PGF}_{2 \alpha}$ catabolizing enzyme, hydroxyprostaglandin dehydrogenase 15-(NAD) (HPGD) [Silva PJ et al, 2000]. The inability of $\mathrm{PGF}_{2 \alpha}$ to induce the expression of prostaglandin-endoperoxide synthase $2(P T G S 2)$ and subsequent intraluteal $\mathrm{PGF}_{2 \alpha}$ synthesis in the early bovine $\mathrm{CL}$ was implicated in luteolytic insensitivity to $\mathrm{PGF}_{2 \alpha}$ [Tsai SJ and Wiltbank MC, 1998]. 2) Differences in signal transduction due to differential expression of genes associated with $\mathrm{PGF}_{2_{\alpha}}$ receptor. For example, increased expression of protein kinase $\mathrm{C}$ inhibitor-1 (PKCI-1) [now known as histidine triad nucleotide binding protein, (HINT1)] and kinase $\mathrm{C}$ inhibitor protein-1 (KCIP-1) [now known as tyrosine 3monooxygenase/tryptophan 5monooxygense activation protein, zeta polypeptide (YWHAZ)] were reported to be involved in insensitivity of the early ovine CL [Juengel JL et al, 1998]. Greater expression of PRKCE in D10 bovine $\mathrm{CL}$ has been proposed to participate in acquisition of luteolytic sensitivity to $\mathrm{PGF}_{2 \alpha}$ [Sen A et al, 2005]. 3) Alterations in the expression of locally produced hormones/factors that mediate the anitsteroidogenic actions of $\mathrm{PGF}_{2_{\alpha}}$. Inability of $\mathrm{PGF}_{2_{\alpha}}$ to induce eNOS in the early 
bovine CL and subsequent absence of acute increase in luteal blood flow has been proposed be mechanism of early luteal resistance [Shirasuna $\mathrm{K}$ et al, 2008]. $\mathrm{PGF}_{2_{\alpha}}$ caused an acute increase in luteal blood flow during the initial stages of luteolysis and this event has been proposed to be due to ability of $\mathrm{PGF}_{2 \alpha}$ to induce vasodilator eNOS. In addition, low expression of endothelin converting enzyme-1 (ECE-1) and EDN1 peptide in early CL and inability of $\mathrm{PGF}_{2 \alpha}$ to induce EDN1 in early CL has been proposed to be one of the mechanisms responsible for refractoriness of early CL [Levy $\mathrm{N}$ et al, 2001; Levy $\mathrm{N}$ et al, 2000]. 4) The ability of the early CL to preferentially produce greater amount luteo-protective PGE2. The expression of PGES was greater in the early CL and decreased in regressing CL [Arosh JA et al, 2004]. In addition, the ability of PGES to convert PGH2 to PGE2 was 150 -fold greater than conversion of PGH2 to $\mathrm{PGF}_{2 \alpha}$ by PGFS, there by producing greater amounts of PGE2 [Madore E et al, 2003]. PGE2 has been shown to be luteo-protective by promoting progesterone synthesis. In addition, $\mathrm{PGF}_{2 \alpha}$ has stimulated its own synthesis in $\mathrm{CL}$ via $\mathrm{PRKC} / \mathrm{Ca}^{2+}$ pathways by inducing the expression of COX-2 [Tsai SJ and Wiltbank MC, 1997]. Accordingly, the inability of $\mathrm{PGF}_{2_{\alpha}}$ to induce COX-2 in th early CL had been implicated in the mechanism of luteolytic sensitivity [Tsai SJ and Wiltbank MC, 1998].

Sen et al [Sen A et al, 2004] analyzed the expression pattern of array of PKC specific isozymes at two developmental (D-4 and -10) stages of bovine CL. The expression of PRKCE was greater in D-10 CL compared to D-4 CL. This observation led these authors to propose that the differential expression of PRKCE as a function of development could play a role in the observed transitional resistance/susceptibility to $\mathrm{PGF}_{2 \alpha}$-induced luteal regression. In addition, specific PRKCE inhibitors abrogated the increase in $\left[\mathrm{Ca}^{2+}\right]$ i stimulated by $\mathrm{PGF}_{2 \alpha}$, [Sen A et al, 2005]. Moreover, the magnitude of intracellular $\mathrm{Ca}^{2+}$ signal stimulated by $\mathrm{PGF}_{2 \alpha}$ is greater in $\mathrm{D}-$ 10 CL compared to early CL [Choudhary E et al, 2005; Sen A et al, 2005]. Therefore the ability of $\mathrm{PGF}_{2 \alpha}$ to stimulate greater magnitudes of $\left[\mathrm{Ca}^{2+}\right] \mathrm{i}$ coincides with an increased expression of PRKCE. Therefore it was proposed that regulation of $\left[\mathrm{Ca}^{2+}\right]$ i might be a cellular mechanism through which PRKCE could mediate the inhibitory actions of $\mathrm{PGF}_{2_{\alpha}}$ on progesterone synthesis.

Further, effect of intracellular $\mathrm{Ca}^{2+}$ on steroidogenesis appears to be biphasic. In addition to inhibitory actions of high cytoplasmic $\mathrm{Ca}^{2+}$ on progesterone synthesis, the stimulatory effect of 
$\mathrm{Ca}^{2+}$ on LH-stimulated progesterone has been reported. For example, absence of $\mathrm{Ca}^{2+}$ in culture media reduced the ability of $\mathrm{LH} / \mathrm{hCG}$ to stimulate progesterone synthesis by $50 \%$ [Manna PR et al, 1999; Sullivan $\mathrm{MH}$ and Cooke BA, 1986]. In addition, $\mathrm{Ca}^{2+}$ ionophore A23187 stimulated hCG-stimulated progesterone synthesis and STAR expression in an additive manner [Manna PR et al, 1999], which inidcated that effect of $\mathrm{Ca}^{2+}$ is not related to $\mathrm{LH}$ binding, but rather to cytoplasmic events. The stimulatory effect of Angiotensin II (Ang II) on adrenal steroidogenesis was associated with PLC activity and subsequent generation of $\mathrm{IP}_{3}$ and mobilization of intracellular $\mathrm{Ca}^{2+}$ [Barrett PQ et al, 1989]. The stimulatory effect of $\mathrm{Ca}^{2+}$ on $\mathrm{LH}$-stimlated progesterone is implied in the observations that a luteotrophic hormone increased $\mathrm{IP}_{3}$, and $\left[\mathrm{Ca}^{2+}\right] \mathrm{i}$ in bovine luteal cells and porcine granulosa cells [Alila HW et al, 1990; Davis JS et al, 1987a; Flores JA et al, 1998]. Furthermore, $\mathrm{PGF}_{2_{\alpha}}$ stimulated LH-stimulated progesterone synthesis in the early bovine CL [Choudhary E et al, 2005; Levy $\mathrm{N}$ et al, 2001]. Therefore, the magnitude of $\mathrm{Ca}^{2+}$ signal stimulated by an agonist through its receptor might determine if the cellular response is luteolytic or luteotrophic at given developmental stage. The important implications of this interpretation is that by simply raising $\left[\mathrm{Ca}^{2+}\right] \mathrm{i}$ to the appropriate threshold, one might be able to reduce progesterone regardless of the luteal developmental stage.

More importantly, lack of functional $\mathrm{PGF}_{2 \alpha}$ receptors does not seem to explain the mechanism of luteal insensitivity, because early CL (by Day-2) already express $\mathrm{PGF}_{2_{\alpha}}$ receptors with equal affinity and concentrations as observed in mature CL [Wiltbank MC et al, 1995]. Supporting this observation, $\mathrm{PGF}_{2 \alpha}$ can elicit distinct physiological responses in the early corpora lutea [Choudhary E et al, 2005; Levy $\mathrm{N}$ et al, 2000]. Therefore, the general idea upon which our current hypotheses were formulated was that the differences in components of signal transduction associated with luteal FP receptors at different developmental stages might be, at least in part, responsible for observed differences elicited by $\mathrm{PGF}_{2 \alpha}$. Furthermore, looking at the differential expression of single gene at a time might not be effective in unraveling the differences in complex signal transduction pathway associated with $\mathrm{PGF}_{2_{\alpha}}$ receptor. Therefore, studying global changes in the luteal transcriptome during its transition from early to mature stage might identify several genes that might play a role in developmental sensitiveness.

The hypotheses have been formulated based on the above discussed observations as follows: 
Hypothesis 1a: PRKCE-mediates the anti-steroidogenic actions of $\mathrm{PGF}_{2 \alpha}$.

This hypothesis was tested using siRNA strategy to down- regulate the expression of PRKCE in steroidogenic cells. The expectancy was that PRKCE-specific siRNA should downregulate significant amount of mRNA and protein of PRKCE. This should allow us to test the role of PRKCE in mediating the antisteroidogenic actions of $\mathrm{PGF}_{2 \alpha}$ on LH-stimulated progesterone synthesis. Under low cellular concentrations of PRKCE, we predicted that the ability of $\mathrm{PGF}_{2_{\alpha}}$ to inhibit LH-stimulated progesterone synthesis might be compromised.

Hypothesis1b: PRKCE was necessary for the expression of key genes of prostaglandin synthesis/metabolism that would favor $\mathrm{PGF}_{2 \alpha}$ synthesis; whereas in PRKCE down-regulated cells, the expression of key genes of prostaglandin synthesis/metabolism would be such that synthesis of PGE2 would be favored. This hypothesis was tested by determining changes in the expressions of key prostaglandin metabolic genes in PRKCE-down-regulated cells by real-time PCR.

Hypothesis 2: The rise in $\left[\mathrm{Ca}^{2+}\right] \mathrm{i}$ is the cellular mechanism through which $\mathrm{PGF}_{2 \alpha}$ inhibits luteal progesterone. We reason that if a pharmacological treatment (calcium ionophore, A23187) is used to increase $\left[\mathrm{Ca}^{2+}\right] \mathrm{i}$, this should inhibit LH-stimulated progesterone syntheis with equal effectiveness, regardless of the developmental stage (D-4 or -10) of CL. In addition, if the $\mathrm{PGF}_{2 \alpha}$-stimulated increase in $\left[\mathrm{Ca}^{2+}\right] \mathrm{i}$ is prevented with a intracellular $\mathrm{Ca}^{2+}$ chelator (BAPTA$\mathrm{AM})$, then $\mathrm{PGF}_{2 \alpha}$ will not be able to inhibit progesterone secretion

Hypothesis 3a: The differential gene expression during the developmental transition of corpora lutea from D-4 to D-10 might include genes encoding components of signal transduction pathways that might change the nature of the elicited response, or the luteal sensitivity to luteolytic actions of $\mathrm{PGF}_{2 \alpha}$. This hypothesis was tested by utilizing array that contained 8,329 unique bovine genes that was developed by Center for Animal Functional Genomics (CAFG) at Michigan State University. The expected result was that at least a portion of genes on the array might be differentially expressed in D-10 CL that could potentially explain the differential sensitivity of the bovine CL to $\mathrm{PGF}_{2_{\alpha}}$ 
Hypothesis 3b: Some of the selected genes that are differentially expressed during transition from D-4 to D-10 developmental stage might be responsive to in vivo $\mathrm{PGF}_{2 \alpha}$ treatment on the D4 or -10 of the estrous cycle. We selected some differentially expressed genes based on the literature that indicated these genes might participate in $\mathrm{PGF}_{2 \alpha}$ signaling. This hypothesis was tested utilizing real-time PCR using gene specific primers. The expected result was that the expression of some of the selected genes might be altered (increased/decreased) by exogenous $\mathrm{PGF}_{2 \alpha}$ that might potentially explain their role in acquisition of luteolytic sensitivity to $\mathrm{PGF}_{2 \alpha}$.

Hypothesis 3c: CAMKK2 mediates the actions of increasing $\left[\mathrm{Ca}^{2+}\right] \mathrm{i}$ stimulated by $\mathrm{PGF}_{2_{\alpha}}$ on inhibiting progesterone. Observations from our microarray results have indicated that the expression of CAMMK2 was more than two fold greater in D-10 CL compared to D-4 CL. Furthermore, our preliminary studies have indicated that exogenous $\mathrm{PGF}_{2_{\alpha}}$ increased the expression of CAMKK2. This increase in CAMKK2 occurred at a luteal developmental stage that is sensitive to $\mathrm{PGF}_{2_{\alpha}}$. More importantly, its increased expression coincides with the luteal developmental stage at which $\mathrm{PGF}_{2 \alpha}$ has ability to elicit a greater rise in $\left[\mathrm{Ca}^{2+}\right] \mathrm{i}$ [Choudhary E et al, 2005]. In many biological system, the actions of raising $\left[\mathrm{Ca}^{2+}\right] \mathrm{i}$ are mediated via calmodulin-dependent protein kinases. Therefore we chose to study the role of CAMKK2 during the antisteroidogenic actions of $\mathrm{PGF}_{2 \alpha}$. Our prediction was that if the activity of CAMMK2 is inhibited, then the ability of $\mathrm{PGF}_{2 \alpha}$ to inhibit the progesterone synthesis is compromised under in vitro conditions. This hypothesis was tested using commercially available STO-609, which has been shown to be CAMMK2 specific inhibitor [Tokumitsu $\mathrm{H}$ et al, 2002]. 


\section{Chapter III: PKC epsilon and an increase in intracellular calcium concentration are necessary for PGF2alpha to inhibit LH-stimulated progesterone secretion in cultured bovine steroidogenic luteal cells}

\section{Introduction}

The corpus luteum (CL) is a transient endocrine gland whose primary secretory product is progesterone (P4). The life span of the CL and consequently the amount of P4 it secretes is regulated according to reproductive physiological status. Substances reducing P4 secretion and shortening the luteal life span are said to be luteolytic [McCracken JA et al, 1999; Niswender GD and Nett TM, 1994].

In most species, including human beings, $\mathrm{PGF}_{2 \alpha}$ is recognized as an important if not the main luteolytic factor [Arosh JA et al, 2004; Auletta FJ and Flint AP, 1988; Guthrie HD et al, 1978; Olofsson J et al, 1992; Pate JL, 1988; Patwardhan VV and Lanthier A, 1980; Rexroad CE, Jr. and Guthrie HD, 1979]. During the ovarian cycle, the transition from early to mid-luteal phase is associated with changes in resistance/ susceptibility to the luteolysin $\mathrm{PGF}_{2 \alpha}$; in cows, the $\mathrm{CL}$ is resistant to exogenous $\mathrm{PGF}_{2 \alpha}$ prior to day 5 of the estrous cycle [Choudhary E et al, 2005; Copelin JP et al, 1988; Inskeep EK, 1973; Sayre BL et al, 2000; Silva PJ et al, 2000; Silvia WJ and Niswender GD, 1984; Tsai SJ and Wiltbank MC, 1997; Wiltbank MC et al, 1995]. The cellular basis controlling luteal function during these physiological transitions, although studied intensely, is incompletely understood.

In steroidogenic cells of the ruminant $\mathrm{CL}, \mathrm{PGF}_{2 \alpha}$ activates its plasma membrane Gprotein-coupled receptor, which in turn activates the membrane-bound phosphoinositide specific phospholipase C (PLC), yielding inositol 1,4,5 trisphosphate (IP3) and diacylglycerol [Davis JS et al, 1988]. Indeed, in bovine luteal cells, $\mathrm{PGF}_{2 \alpha}$ stimulated phosphatidylinositol 4,5-biphosphate hydrolysis and mobilized intracellular $\mathrm{Ca}^{2+}$ [Davis JS et al, 1987b]. Accordingly, calcium and PRKC have been shown to be the intracellular mediators of PGF $2 \alpha$ actions in luteal cells [Wiltbank MC et al, 1991]. The regulatory effects of intracellular calcium concentration $\left(\left[\mathrm{Ca}^{2+}\right] \mathrm{i}\right)$ on progesterone might be biphasic as there is also evidence for a 
calcium requirement to support P4 synthesis by bovine luteal cells and LH, a luteotrophic hormone, increases IP3, and $\left[\mathrm{Ca}^{2+}\right] \mathrm{i}$ in bovine luteal cells and in porcine granulosa cells [Alila HW et al, 1990; Davis JS et al, 1987a; Flores JA et al, 1998]. Therefore, there might exist thresholds of $\left[\mathrm{Ca}^{2+}\right] \mathrm{i}$ that support or inhibit $\mathrm{P} 4$ synthesis.

Choudhary et al, [Choudhary E et al, 2005] tested the ability of increasing concentrations of $\mathrm{PGF}_{2 \alpha}$ to increase the $\left[\mathrm{Ca}^{2+}\right] \mathrm{i}$ in large (LLC) and small (SLC) bovine luteal cells as function of development. Day-10 steroidogenic cells were more responsive to $\mathrm{PGF}_{2 \alpha}$ than Day-4 cell. Response amplitudes and number of responding cells were significantly affected by agonist concentration, luteal development and cell type. Response amplitudes were greater in LLC than in SLC; responses of maximal amplitude were elicited with lower agonist concentrations from Day-10 than from Day -4 cells. Furthermore, on Day-10, as concentrations of $\mathrm{PGF}_{2 \alpha}$ increased, larger percentages of SLC responded. Based on those results Choudhary et al proposed that the lower efficacy of $\mathrm{PGF}_{2 \alpha}$ in the early CL was likely related to signal transduction differences associated with the $\mathrm{PGF}_{2 \alpha}$ receptor at those two developmental stages [Choudhary E et al, 2005].

The array of PKC isozymes expressed in whole bovine CL includes $\alpha, \beta \mathrm{I}, \beta \mathrm{II}, \varepsilon$ and $\mu$ [Davis JS et al, 1996; Orwig KE et al, 1994; Sen A et al, 2004; Sen A et al, 2005]; and it has been demonstrated that the amount of PKCE (PRKCE) expressed in the Day10 CL is greater than in the Day-4 CL [Sen A et al, 2004]. The latter observation led Sen et al, to propose that differential expression of PRKCE as a function of development could play a role in the observed transitional resistance/susceptibility to $\mathrm{PGF}_{2 \alpha}$-induced luteal regression [Sen A et al, 2004; Sen A et al, 2005]. Sen et al, had further hypothesized that regulation of $\left[\mathrm{Ca}^{2+}\right] \mathrm{i}$ was a cellular mechanism through which PRKCE could mediate actions of $\mathrm{PGF}_{2 \alpha}$ on P4 secretion [Sen A et al, 2005]. Additionally, there is evidence indicating that when bovine follicular theca cells are isolated and their luteinization is induced under in vitro tissue culture conditions, they express PKC $\delta$ [Budnik LT and Mukhopadhyay AK, 2002]. As PKC $\delta$ has been reported to play an important role in other species such as in rabbits and rodents [Maizels ET et al, 1996; Peters CA et al, 2000], this PKC isozyme might also be important for the physiology of the bovine ovary. 
Endothelial cells of the bovine CL do not express PRKCE, although they do express the other PRKC isozymes described in the bovine CL [Sen A et al, 2006]. Data obtained with Western blot and immunohistological assays indicated that steroidogenic cells are the main source of PRKCE in the bovine CL [Sen A et al, 2006]. Therefore, in experiment 1, in order to assess the potential physiological role of PRKCE, we have used a siRNA strategy to downregulate the expression of this PKC isozyme in luteal steroidogenic cells. In experiment 2, we used the PRKCE down-regulated cells to test two hypotheses. Our first working hypothesis was that PRKCE expression was necessary for $\mathrm{PGF}_{2 \alpha}$ to inhibit LH-stimulated $\mathrm{P} 4$ secretion in vitro. The second working hypothesis was that PRKCE was necessary for the expression of key genes of prostaglandin synthesis/metabolism that would favor PGF $_{2 \alpha}$ synthesis; whereas in PRKCE down regulated cells, the expression of key genes of prostaglandin synthesis/metabolism would be such that synthesis of PGE2 would be favored. Finally, in experiment 3 , we tested the hypothesis that $\left[\mathrm{Ca}^{2+}\right] \mathrm{i}$ is the cellular mechanism through which $\mathrm{PGF}_{2 \alpha}$ inhibits luteal progesterone. We reasoned that if a pharmacological treatment is used to increase $\left[\mathrm{Ca}^{2+}\right] \mathrm{i}$, this should inhibit luteal progesterone secretion with equally effectiveness, regardless of the developmental stage of the CL. Therefore, we used a pharmacological agent to increase $\left[\mathrm{Ca}^{2+}\right] \mathrm{i}$ and examine its effects on LH-induced $\mathrm{P} 4$ secretion in luteal cells collected from early (Day-4) and mid-cycle (Day-10) bovine CL. Furthermore, this hypothesis was also tested by using a pharmacological agent to buffer any increase in $\left[\mathrm{Ca}^{2+}\right] \mathrm{i}$ and examine, under conditions of low $\left[\mathrm{Ca}^{2+}\right]$ i, the anti-steroidogenic effect of $\mathrm{PGF}_{2 \alpha}$ on $\mathrm{LH}$-induced $\mathrm{P} 4$ secretion in cultures of luteal cells collected from mid-cycle (Day-10) CL.

\section{Methods}

Tissue collection

Non-lactating beef (experiments 1 and 2) or dairy (experiment 3) cows were observed visually for estrus twice daily at approximately 12-h intervals for a minimum of 30 min per observation. The day when standing estrus was observed was designated as Day 0 [Casida LE, 1959]. For experiments 1 and 2, the CL from four beef cows on Day-6 of the estrous cycle were collected in ice-cold saline and transported to the laboratory for luteal cell dispersion as 
described below. For experiment 3, 14 non-lactating dairy cows were synchronized with $25 \mathrm{mg}$ PGF $_{2 \alpha}$ analog (Lutalyse ${ }^{\circledR}$; Pfizer Animal Health., New York, NY) and ovaries on Day-4 ( $\mathrm{n}=$ 4) or CL on Day-10 $(n=10)$ were collected surgically as described below and transported to the laboratory in ice-cold saline for dissociation and luteal cell enrichment as described below. The surgical procedure was performed via supravaginal incision under epidural anesthesia. For the epidural anesthesia, 6-9 $\mathrm{ml}$ 2\% lidocaine was administered for cows weighing 450-700 kg (Butler Company, Columbus, OH). After surgery, penicillin (300,000 units) was administered intramuscularly to protect against post-surgical infection. The CL or ovary was collected into ice-cold saline at $\mathrm{pH} 7.4$ and transported to the laboratory within 15 to 30 min after collection. The Animal Care and Use Committee of West Virginia University approved all procedures for these experiments (ACUC protocol \# 060401).

\section{Luteal cell dispersion and purification}

In the laboratory, the $\mathrm{CL}$ was dissected free of connective tissue, weighed, placed into cell dispersion medium (CDM, M-199 containing 0.1\% BSA, 25 mM Hepes, $100 \mathrm{U} / \mathrm{ml}$ fungicide), and cut into small (about $1 \mathrm{~mm}^{3}$ ) fragments. The tissue fragments were processed for tissue dissociation as previously described [Choudhary E et al, 2005]. Luteal endothelial cells were separated by a procedure previously described [Choudhary E et al, 2005; Levy N et al, 2001; Mamluk R et al, 1998; Webb BL et al, 1997]. Briefly, magnetic tosylactivated beads (Dynal Biotech, Lake Success, NY) were used to separate endothelial cells and the nonadherent cells, steroidogenic enriched luteal cells) were collected. The cell population designated as steroidogenic cells represented a heterogeneous population of cells including fibroblasts, pericytes, lymphoid and possibly few endothelial cells not removed by the separation procedure. Cell viability and density were determined using Trypan Blue exclusion and a hemocytometer; luteal cell viability was usually greater than $96 \%$.

Experiment 1. Validation of siRNA methodology for specifically downregulating PRKCE expression in enriched steroidogenic luteal cells.

Day-6 dissociated luteal steroidogenic cells were cultured overnight at a cell density of

$1 \times 10^{6}$ cells/well in $35 \mathrm{~mm} 24$ - well culture dishes (Corning Inc, Corning NY) containing 1 $\mathrm{ml}$ Medium 199 supplemented with 5\% fetal calf serum (FCS, GIBCO) at $37^{\circ} \mathrm{C}(95 \%$ air, $5 \%$ 
CO2). The next day cells were transiently transfected with PRKCE-specific siRNA kit (Upstate Cell Signaling solutions, Lake Placid NY) using lipofectin 2000 kit (Invitrogen Life Technologies) following the procedure recommended by the manufacturer. After transfection for $4 \mathrm{hr}$, the cultures were provided with M199 supplemented with 10\% FCS, and incubated for a total of 48, 72 or 96 hours. After each of these time points, the cells were collected by adding $2 \mathrm{ml} \mathrm{M} 199$ containing $0.25 \%$ trypsin (GIBCO) to cover the monolayer and leaving the culture dish for about $1 \mathrm{~min}$ at room temperature. The cells were aspirated and washed one time with M199 containing 5\% FCS and once with M199 without FCS. Cells collected from duplicate wells were pooled and the efficiency of transfection at 48, 72 and $96 \mathrm{~h}$ was analyzed by RTPCR and Western blot analysis. Control groups included cells cultured in presence of M199 alone, M199 and transfecting reagent, and cells treated with non-specific siRNA duplex (nonspecific siRNA).

Experiment 2. Effects of down-regulating PRKCE expression by the siRNA protocol on: A) the ability of $\mathrm{PGF}_{2 \alpha}$ to inhibit the LH-stimulated $\mathrm{P} 4$ accumulation, and $\mathrm{B}$ ) on the expression of key genes involved in prostaglandin synthesis and metabolism.

Hypothesis 1: PRKCE is necessary for $\mathrm{PGF}_{2 \alpha}$ to be able to inhibit $\mathrm{P} 4$ secretion. To examine the ability of $\mathrm{PGF}_{2 \alpha}$ (Cayman Chemical, Ann Arbor, MI) to inhibit LH-induced progesterone accumulation, the siRNA transfected and control cells (not treated with PRKCE siRNA) were treated, after $96 \mathrm{~h}$, with100 ng/ml of $\mathrm{LH}, 1000 \mathrm{ng} / \mathrm{ml}$ of $\mathrm{PGF}_{2 \alpha}$, or a combination of $\mathrm{LH}$ and $\mathrm{PGF}_{2 \alpha}$ for $4 \mathrm{hrs}$. After this time, the cell free medium was collected from each treatment and frozen until determination of $\mathrm{P} 4$ by radioimmunoassay (RIA). The RIA used for measurements of P4 in the culture media has been described previously [Sheffel CE et al, 1982]. The standard curve for this RIA ranged from $10 \mathrm{pg} / \mathrm{ml}$ to $800 \mathrm{pg} / \mathrm{ml}$, and the intra- and interassay coefficients of variation were $9.2 \%$ and $12.8 \%$, respectively.

Hypothesis 2: PRKCE is necessary for the expression of key prostaglandin biosynthetic/metabolizing enzymes. For the real time quantitative determination of gene expression of key prostaglandin biosynthetic/metabolizing enzymes in PRKCE down-regulated and control (not downregulated) cells, RNA samples were obtained from the cells collected in the experiment described under Hypothesis 1. The genes examined were: aldoketoredutase 1B5 
(AKR1B5), prostaglandin-15 dehydrogenase (PGDH), prostaglandin E synthase (PGES), 9keto-prostagalndin reductase (9K-PGR), and cyclooxygenase-2 (COX-2). Enriched steroidogenic cells were treated with the PRKCE siRNA protocol and after $96 \mathrm{~h}$ of culture the cells were treated with $\mathrm{LH}(100 \mathrm{ng} / \mathrm{ml}), \mathrm{PGF}_{2 \alpha}(1000 \mathrm{ng} / \mathrm{ml})$, or a combination of $\mathrm{LH}$ and $\mathrm{PGF}_{2 \alpha}$ for $4 \mathrm{~h}$. The cells were collected by a brief trypsin treatment and total RNA was isolated with Trizol reagent according to the manufacturer's instructions (GIBCO). Total RNA was quantified spectroscopically at $260 \mathrm{~nm}$ and integrity of the RNA was determined by $2 \%$ agarose gel electrophoresis. Specific primers were designed by using primer3 software. The primer sequences and their accession numbers are shown in table 1. The single-step RT-PCR was carried out and cDNA product for each gene was column purified. Ten-fold serial dilutions of cDNA for each of the genes were used as templates to generate standard curves. Total RNA samples were reverse transcribed and used as templates in an iQ5 cycler (Bio-Rad Laboratories, Hercules, CA). The $25 \mu$ reaction mixture contained $12.5 \mu$ SYBER green mix (BioRad Laboratories), $2 \mu \mathrm{l}$ cDNA sample, $2.5 \mu \mathrm{l}$ each sense and antisense primers $(0.5 \mu \mathrm{mol})$ and $5.5 \mu \mathrm{l}$ of RNAse free $\mathrm{H} 2 \mathrm{O}$. The standard curves of threshold cycle (ct value) versus log starting quantity for the genes of interest were obtained. The conditions used were as follows: inactivation of RT enzyme, $95^{\circ} \mathrm{C} / 3 \mathrm{~min}$; denaturation, $95^{\circ} \mathrm{C} / 30 \mathrm{sec}$; annealing, $55^{\circ} \mathrm{C} / 30 \mathrm{sec}$; and extension, $72^{\circ} \mathrm{C} / 1 \mathrm{~min}$ with fluorescence acquisition. The melt-curves were generated from $55^{\circ} \mathrm{C}$ to $95^{\circ} \mathrm{C}$ with $0.5^{\circ} \mathrm{C}$ increments in temperature. The melt-curves were observed for presence of single amplification product. The slope and intercept values obtained from the standard curve were used to determine the starting quantity for each gene using linear regression equation and gene expression for the desired gene was normalized using $\beta$-actin as the reference gene.

Experiment 3. The working hypothesis was that a rise in $\left[\mathrm{Ca}^{2+}\right] i$ is the cellular mechanism through which $P G F_{2 \alpha}$ inhibits luteal P4.

Effect of a pharmacological increase in $\left[\mathrm{Ca}^{2+}\right]$ i on the LH-stimulated P4 secretion in Day-4 and -10 luteal steroidogenic cells. We predicted that if $\left[\mathrm{Ca}^{2+}\right] \mathrm{i}$ is increased by a pharmacological treatment, this increase in $\left[\mathrm{Ca}^{2+}\right]$ i should be equally effective in reducing the LH-stimulated P4 secretion regardless of the developmental stage of the CL. The enriched steroidogenic cells $\left(1 \times 10^{5}\right.$ cells/well $)$ isolated from Day-10 and Day-4 CL of PGF $2 \alpha^{-}$ 
synchronized non-lactating dairy cows were cultured overnight in $15 \mathrm{~mm} 24$-well culture plates in medium M199 supplemented with 0.1\% BSA and 0.5\% FCS. The next morning, the cells were treated in duplicate wells for $24 \mathrm{hr}$ with M199 (control), LH (100 ng/ml), PGF $2 \alpha$, $(1.0 \mu \mathrm{g} / \mathrm{ml})$, and a combination of $\mathrm{LH}$ and $\mathrm{PGF}_{2 \alpha}$. The ability of increasing concentrations of the calcium ionophore, A23187 (0.1, 1, 10, or $100 \mu \mathrm{mol}$, (Invitrogen Detection Technologies), to inhibit basal and LH -stimulated P4 synthesis/secretion was tested in duplicate wells. The medium for the control group contained $0.1 \%$ dimethylsufoxide (DMSO, Pierce Rockport, IL), the solvent used for $\mathrm{PGF}_{2 \alpha}$ and $\mathrm{A} 23187$. The cell-free media were collected and frozen until later measurements of P4 by RIA. The concentrations of A23187 used were based on singlecell studies, in which a concentration of $1 \mu \mathrm{mol}$ A23187 was usually effective in increasing $\left[\mathrm{Ca}^{2+}\right] \mathrm{i}$ to values comparable to those seen when cells were stimulated with $\mathrm{PGF}_{2 \alpha}$ at a concentration of $1000 \mathrm{ng} / \mathrm{ml}$. The concentration range used of the $\mathrm{Ca}^{2+}$ ionophore should assure a very good probability of eliciting a wide range in increases in $\left[\mathrm{Ca}^{2+}\right] \mathrm{i}$ that would allow testing its effect on the LH-stimulated P4 synthesis/secretion in Day-4 and -10 steroidogenic cells.

If the $P G F_{2 \alpha}$-stimulated increase in $\left[\mathrm{Ca}^{2+}\right] i$ is prevented, $P G F_{2 \alpha}$ will not be able to inhibit P4 secretion. This experiment examined the ability of $\mathrm{PGF}_{2 \alpha}$ to inhibit LH-stimulated $\mathrm{P} 4$ secretion in Day-10 luteal cells under conditions in which elevations in $\left[\mathrm{Ca}^{2+}\right]$ i were buffered. This was accomplished by testing the effect of 1,2-bis (2-aminophenoxy) ethane-N, N, N', N'-teyracetic acid tetrakis acetomethyl ester, Bapta-AM (Invitrogen Detection Technologies, Carlsbad, CA), an effective pharmacological agent known to buffer changes in $\left[\mathrm{Ca}^{2+}\right] \mathrm{i}$ [Midzak AS et al, 2007; Nikonenko I et al, 2005]. The concentration range chosen, 0.1 to $1000 \mu \mathrm{mol}$, was based on preliminary single-cell studies indicating that at the concentration of $10 \mu \mathrm{mol}$, Bapta-AM effectively prevented the typical increase in $\left[\mathrm{Ca}^{2+}\right] \mathrm{i}$ induced by PGF2 in luteal steroidogenic cells. The enriched Day-10 steroidogenic cells $\left(1 \times 10^{5}\right.$ cells/well $)$ isolated as described above were cultured overnight in $15 \mathrm{~mm} 24$-well culture plates in medium M199 supplemented with $0.1 \%$ BSA and $0.5 \%$ FCS. The next morning, the cells were treated in duplicate wells for $24 \mathrm{hr}$ with M199 (control), LH (100 ng/ml), PGF $_{2 \alpha},(1.0 \mu \mathrm{g} / \mathrm{ml})$, and a combination of LH and PGF $2 \alpha$ with increasing concentration of Bapta-AM $(0.1,1,10,100$ or $1000 \mu \mathrm{mol})$. The effect of each treatment on basal and LH -stimulated P4 synthesis/secretion was tested in duplicate wells. The medium for the control group contained $0.1 \%$ dimethylsufoxide (DMSO, Pierce Rockport, IL), the solvent used for $\mathrm{PGF}_{2 \alpha}$ and Bapta. The cell-free media were collected and frozen until later 
measurements of P4 by RIA.

Semi-quantitative RT-PCR

The time-course effectiveness of the siRNA treatment in down-regulating PRKCE mRNA expression was determined by a semi-quantitative RT-PCR procedure (RT-PCR, Qiagen, Valencia, CA) previously validated and described [Orwig KE et al, 1994]. In this RT-PCR assay, PRKCE expression was normalized to the expression of GAPDH as the reference gene. The sequence of the PRKCE and GAPDH primers were those previously published: [Choudhary E et al, 2005], sense 5'-AGCTTGAAGCCCACAGCCTG-3'; antisense 5'CTTGTGGCCGTTGACCTGATG-3'; and (34), sense 5'TGTTCCAGTATGATTCCACCC-3'; antisense 5'- TGTTCCAGTATGATTCCACCC-3' respectively. The specificity for these primer sets have been documented [Choudhary E et al, 2005; Orwig KE et al, 1994][Choudhary E et al, 2005; Orwig KE et al, 1994], and confirmed here by using the nucleotide database of National Center for Biotechnology Information with BLAST. The RTPCR assay conditions were as follows: $50^{\circ} \mathrm{C}$ for $30 \mathrm{~min}$ for reverse transcription reaction, $95^{\circ} \mathrm{C}$ for $15 \mathrm{~min}$ for inactivation of RT enzyme, and then for PCR cycles consisted of $95^{\circ} \mathrm{C}$ for 50seconds for denaturing, $58^{\circ} \mathrm{C}$ for 30 seconds for annealing, $72^{\circ} \mathrm{C}$ for $1 \mathrm{~min}$ for extension and a final extension of $5 \mathrm{~min}$ at $72^{\circ} \mathrm{C}$. The RT-PCR products were electrophoresed on $2 \%$ agarose gel stained with ethidium bromide and viewed using the Fluro-S MultiImager (Bio-Rad Laboratories). Data were collected using densitometric analysis of Quantity One quantification software package (Version 4, Bio-Rad Laboratories). The intensity of the signal corresponding to PKC isozyme was standardized by the corresponding intensity of GAPDH control in that sample.

\section{Semi-quantitative Western blots}

Proteins were isolated from cells of siRNA treated and control groups using previously described methodology [Orwig KE et al, 1994]. Details for the semi-quantitative Western blot protocol used here have been described elsewhere [Sen A et al, 2004]. Briefly, protein samples (10 $\mu \mathrm{g} / \mathrm{lane})$ were resolved on an $8 \%$ polyacrylamide gel. The resolved proteins were transferred to polyvinylidene fluoride membrane (Biotechnology Systems, Boston, MA). The membranes were treated for immunodetection of the proteins of interest. The following 
primary antibodies were used: a mouse anti-actin monoclonal antibody ([used at a dilution of 1:3000 (v/v] Chemichon International, Inc., Temecula, CA); PKC isozyme specific ( $\alpha, \beta I, \beta I I$, $\varepsilon$,) polyclonal antibodies and their antigenic peptides ([antibodies used at dilution 1:1000] Gibco, Grand Island, NY). The following horseradish peroxidase-conjugated secondary antibodies were used here: anti-rabbit (1:5000, v/v; Amersham Pharmacia Biotech, and antimouse $(1: 30,000 \mathrm{v} / \mathrm{v}$; GIBCO). Densitometry of the bands of interest were performed using Quantity One quantitation software. The intensity of the signal corresponding to the protein of interest was standardized by the corresponding intensity of the actin control in that sample. This normalization of data allows an estimate, in a semi quantitative manner, the amount of protein in the samples of interest, as described earlier [Sen A et al, 2004].

\section{Statistics}

The statistical software program from Statistical Analysis System, JMP 3.0 was used for data analyses [Cary NC]. Data were expressed as means \pm SEM for all the experiments. One-way ANOVA was used to determine effects of different treatments. Tukey - Kramer HSD was used to compare the different treatments subgroups. A value of $\mathrm{P}<0.05$ was considered statistically significant.

\section{Results}

\section{Experiment 1}

Culturing steroidogenic cells collected from the Day-6 CL spontaneously induced the expression of PRKCE (data not shown). Expression of PRKCE was induced gradually by the tissue culture conditions, and as Day-6 luteal cells were cultured up to 6 days, PRKCE expression had been spontaneously increased to values comparable to those seen in Day-10 CL (data not shown). Fig. 1A shows a typical result of the time-course siRNA experiments performed. The summarized data shown in Fig. 1B indicate that there was a significant $(\mathrm{P}<$ 0.05) decrease in the amounts of mRNA encoding PRKCE after $72 \mathrm{~h}$ of transfection $(0.36 \pm$ 0.07) compared to the media treated control group $(1.03 \pm 0.05)$. Panels A and B in Fig. 1 show that this approach reduced PRKCE expression 65 and 75\% $(0.23 \pm 0.04)$ by 72 and 96 hrs of treatment respectively. This reduction was specific because no similar changes were observed 
in treatments receiving only experimental media (Media), receiving non-specific siRNA duplexes (Non-Sp siRNA), or receiving only transfection reagents (Transfection reagent, Fig. 1B).

The effectiveness of the siRNA transfection in reducing protein corresponding to PRKCE can be seen in the semiquantitative western blotting (Fig 2A). A visual reduction in protein was detected $72 \mathrm{~h}$ after transfection (Fig. 2A). However, the semi-quantitative analysis of the data indicated that a significant reduction $(\mathrm{P}<0.05)$ in the amount of PRKCE protein had not occurred until $96 \mathrm{~h}$ after transfection. At this time, there was a $50 \%$ reduction in the siRNA -treated group $(0.39 \pm 0.02)$ compared to control group $(0.82 \pm 0.07$, Media, Fig. $2 B)$. Figure 3 demonstrates the specificity of the siRNA transfection in down-regulating the PRKCE isozyme. This Western blot was carried out for other PKC isozymes, PKC $\alpha$ and PKC $\beta$ II, and there was no reduction in the amounts of these isozyme proteins even at $96 \mathrm{~h}$ after transfection with PRKCE-specific siRNA; a time by which there was significant reduction in PRKCE (Fig. 2B).

\section{Experiment 2}

Hypothesis 1: Effect of PRKCE down-regulation on the ability of $\mathrm{PGF}_{2 \alpha}$ to decrease the LHinduced P4 accumulation. Enriched steroidogenic cells $(n=4)$ transfected with PRKCE siRNA were cultured for $96 \mathrm{~h}$ and treated with $\mathrm{LH}, \mathrm{PGF}_{2 \alpha}$, and combination of $\mathrm{LH}$ and $\mathrm{PGF}_{2 \alpha}$ for $4 \mathrm{~h}$. The control group included cells treated with the hormones described above, but expressing normal amount of PRKCE. PRKCE down-regulation did not induce a decrease in the amount of P4 accumulation in the LH-stimulated cells (158.4 \pm 18.1$)$ compared to the control (202.4 \pm 11.4). As in previous experiments, the accumulation of $\mathrm{P} 4$ was significantly reduced $(\mathrm{P}<0.05)$ by $\mathrm{PGF}_{2 \alpha}(42.9 \pm 2.6)$ compared to LH -treated control group $(202.4 \pm 11.4)$. There was no difference in the amounts of accumulated $\mathrm{P} 4$ between $\mathrm{PGF}_{2 \alpha}$ treated PRKCE down-regulated cells $(34.9 \pm 8.1)$ and control group $(42.9 \pm 2.6)$. However, the ability of $\mathrm{PGF}_{2 \alpha}$ to decrease LH-stimulated P4 accumulation was significantly $(\mathrm{P}<0.05)$ inhibited in the $\mathrm{PKC} \varepsilon$ downregulated group, $124.4 \pm 7.4$ compared to control, $51.4 \pm 4.1$ (Fig. 4).

Hypothesis 2: Gene expression of key prostaglandin biosynthetic/metabolizing enzymes in PRKCE down-regulated cells. Real-time PCR analysis of total RNA for mRNA encoding Cox- 
2, AKR1B5, PGES, PGDH and PGE (2) -9-ketoreductase indicated that there were no significant differences in the expression of any of these genes as a functions of PRKCE downregulation, $\mathrm{LH}$ or $\mathrm{PGF}_{2 \alpha}$ treatment (Fig. 7).

\section{Experiment 3}

A rise in $\left[\mathrm{Ca}^{2+}\right]$ i is the cellular mechanism through which $P G F_{2 \alpha}$ inhibits luteal P4. Effect of a pharmacological increase in $\left[\mathrm{Ca}^{2+}\right]$ i on the LH-stimulated P4 synthesis/secretion in Day-4 and -10 luteal steroidogenic cells. As reported in previous studies [Choudhary E et al, 2005], basal P4 accumulation in cells collected form Day -4 CL was significantly lower than in those collected from Day $-10(7.6 \pm 2.2$ and $29.2 \pm 1.8$ respectively, Fig. 5A and 5B). LH significantly increased $(\mathrm{P}<0.05)$ the luteal progesterone accumulation in both Day- $4(49.5 \pm$ 16.3) and -10 cells $(65.7 \pm 3.7)$. This effect of LH was not inhibited by $\mathrm{PGF}_{2 \alpha}$ in Day- 4 cells (44.6 \pm 17.5$)$, whereas it was significantly inhibited in Day-10 cells ( $31 \pm 1.9$, Fig. 5A and 5B). When used at $0.1 \mu \mathrm{mol}, \mathrm{A} 23187$ did not reduce LH-stimulated P4 accumulation in Day -4 or 10 cells; but at higher concentration $(1.0-100 \mu \mathrm{mol})$, it negated the stimulatory effect of LH on $\mathrm{P} 4$ ( $\mathrm{P}<0.05$, Fig. $5 \mathrm{~A}-\mathrm{B}$ ). Basal $\mathrm{P} 4$ accumulation in Day -4 and -10 cells was not affected by any concentrations of A23187 tested (Fig. 5A and 5B, only $100 \mu$ mol A23187 shown).

If the PGF2 -stimulated increase in [Ca]i is prevented, $P G F_{2 \alpha}$ will not be able to inhibit P4 secretion. LH significantly increased $(\mathrm{P}<0.05)$ the luteal progesterone accumulation in Day10 cells (64.6 \pm 3 , Fig. 6). This effect of $\mathrm{LH}$ was completely inhibited by $\mathrm{PGF}_{2 \alpha}(21.1 \pm 2.1$, Fig. 6). Importantly, basal P4 accumulation (Fig. 6) was not affected by the Bapta-AM treatment, not even the highest concentration used $(20.9 \pm 4.1)$. When Bapta-AM was used at $0.1,1,10$ and $100 \mu \mathrm{mol}$ in combination with $\mathrm{LH}$, the values on $\mathrm{P} 4$ accumulation became intermediate between those observe for basal and LH alone (Fig. 6); and the stimulatory effect of LH was completely eliminated by $1000 \mu \mathrm{mol}$ Bapta (data not shown). Consequently, the effect of Bapta-AM on the anti-steroidogenic action of $\mathrm{PGF}_{2 \alpha}$ could only be tested up to 100 $\mu$ mol. The inhibitory effect of $\mathrm{PGF}_{2 \alpha}$ on LH-stimulated luteal $\mathrm{P} 4$ accumulation was not affected by Bapta when used at concentrations not exceeding $1 \mu \mathrm{mol}$, as the values for P4 accumulation clearly were not different from those observed for basal values $(\mathrm{P}<0.05$, Fig. 6). However, at 
10 and $100 \mu \mathrm{mol}$, Bapta-AM effectively reduced the ability of $\mathrm{PGF}_{2 \alpha}$ to inhibit the stimulatory effect of LH on P4 accumulation (Fig. 6).

\section{Discussion}

The roles of specific PKC isozymes in luteal physiology have received little attention to date. As discussed below, these studies were designed to test the effects of ablating PRKCE expression in order to examine its hypothesized function. Previous studies had indicated that a potential function for PRKCE might be to regulate quantitatively the intracellular calcium signal initiated by $\mathrm{PGF}_{2 \alpha}$ on one of its luteal targets, the steroidogenic cells. The present studies validate the effective and specific down-regulation of PRKCE by siRNA technology and provide strong evidence about the function of this $\mathrm{PKC}$ isozyme in luteal physiology. The data support the overall hypothesis that downregulating expression of PRKCE reduces the effectiveness of $\mathrm{PGF}_{2 \alpha}$ in reducing progesterone secretion. This observation extends the report that when PRKCE was inhibited with PRKCE-specific inhibitors, the $\mathrm{PGF}_{2 \alpha}-$ induced rise in $\left[\mathrm{Ca}^{2+}\right] \mathrm{i}$ was decreased in LLC and SLC and that this in turn had consequences (at least in part) in the ability of $\mathrm{PGF}_{2 \alpha}$ to inhibit LH-stimulated $\mathrm{P} 4$ secretion at this developmental stage [Sen A et al, 2005]. As previously reported [Choudhary E et al, 2005], LH induced an increase in the amount of P4 secretion. Interestingly, in the group where PRKCE expression was down regulated, the inhibitory effect of $\mathrm{PGF}_{2 \alpha}$ on LH-stimulated $\mathrm{P} 4$ secretion was significantly mitigated (Fig. 3). This observation has an important physiological corollary: both $\mathrm{PGF}_{2 \alpha^{-}}$ receptors and PRKCE are expressed in the same luteal cell type. Therefore, the isozyme PRKCE has an important compatible time (mid-luteal phase) and place (small and large luteal steroidogenic cells) of expression, for it to have a role in the luteal transition from resistance to sensitivity to luteolytic actions of $\mathrm{PGF}_{2 \alpha}$. Furthermore, if PRKCE expression is down regulated (this study) or if its activation is inhibited [Sen A et al, 2005], the anti-steroidogenic effect of $\mathrm{PGF}_{2 \alpha}$ on LH-stimulated $\mathrm{P} 4$ secretion is impaired.

Experiment 2 also tested the hypothesis that down-regulating PRKCE could influence the expression of key PG metabolizing enzymes that, in turn, could influence the balance of PG production from luteo-protective or luteotrophic to luteolytic. The mechanism for luteal 
resistance is not exactly known. However there is now evidence that regulation of key PG metabolizing enzymes observed during physiological states in which the life span of the CL is modified is likely to play an important role in this complex process [Asselin E and Fortier MA, 2000; Asselin E et al, 1997; Griffeth RJ et al, 2002; Hu YF et al, 1990; Patek CE and Watson J, 1976; Rexroad CE, Jr. and Guthrie HD, 1979; Shemesh M and Hansel W, 1975a; Silva PJ et al, 2000; Xiao CW et al, 1998]. The selection of the examined genes was based on the available evidence that, because of their key positions in the PG biosynthetic pathway, these genes have been shown to determine the accumulation of luteolytic or luteotrophic classes of PG [Asselin E and Fortier MA, 2000; Asselin E et al, 1997; Patek CE and Watson J, 1976; Shemesh M and Hansel W, 1975a; Xiao CW et al, 1998]. For example, we examined the effects of downregulating PRKCE on the expression of PGE2 and F synthases because of their more direct effect on determining whether PGH2 is metabolized to PGE2 or $\mathrm{PGF}_{2 \alpha}$. The results obtained were unexpected; the prediction was that because of low expression of PRKCE, exogenous $\mathrm{PGF}_{2 \alpha}$ would not be able to induce high increases in the cytosolic concentration of calcium, and consequently, the expression of PGE2 synthase/PGF $2 \alpha$ synthase ratio would favor PGE2 synthesis. The above conditions would favor luteal function. However, it is worth pointing out the importance of looking beyond steady states of mRNA encoding these enzymes; sometimes regulation may be at the level of protein or even enzyme activity and additional work is necessary before rejecting the tested hypothesis.

The developmental significance of a regulatory role played by cytosolic calcium concentrations in mediating the inhibitory actions of $\mathrm{PGF}_{2 \alpha}$ is documented by results obtained in experiment 3. As reported in previous studies [Choudhary E et al, 2005], $\mathrm{PGF}_{2 \alpha}$ reduced LHstimulated P4 secretion in Day10 cells only. Basal P4 secretion was not affected by the PGF $2 \alpha^{-}$ treatment at any of the two developmental stages tested. As the working hypothesis predicted, the pharmacological increase in $\left[\mathrm{Ca}^{2+}\right] \mathrm{i}$ induced by A23187 effectively mimicked the inhibitory effect of $\mathrm{PGF}_{2 \alpha}$ in Day -10 steroidogenic cells. Furthermore, as predicted by the working hypothesis, the A23187 treatment also inhibited LH-stimulated P4 secretion in Day -4 steroidogenic cells. This inhibitory effect of A23187 is most likely due to its demonstrated effect in increasing the intracellular concentration of calcium ions [Sen A et al, 2005] in these cells and not due to other non-specific effects. This interpretation is also supported by the observation that treatment with A23187 had no negative effect on basal P4 secretion at any of 
the two developmental stages tested.

Further support for the significance of a regulatory role played by the increase in $\left[\mathrm{Ca}^{2+}\right] \mathrm{i}$ in mediating the inhibitory actions of $\mathrm{PGF}_{2 \alpha}$ is documented by results obtained in experiment 3 where the cytoplasmic calcium buffering capacity of the cells was increased by Bapta-AM. At lower concentrations $(0.1$ and $1.0 \mu \mathrm{mol})$, the calcium buffering capacity of Bapta-AM was, most likely, at values that still allowed a $\mathrm{PGF}_{2 \alpha}$-stimulated increase in $\left[\mathrm{Ca}^{2+}\right] \mathrm{i}$; which in turn, preserved the ability of $\mathrm{PGF}_{2 \alpha}$ to inhibit LH-stimulated P4 secretion (Fig. 6). However, as the calcium buffering capacity in the cytoplasm of the steroidogenic cells was increased by increasing the concentration of Bapta AM (10 and $100 \mu \mathrm{mol})$, the calcium signaling feature of activating the $\mathrm{PGF}_{2 \alpha}$ receptors was most likely eliminated or at least reduced, and consequently, the ability of $\mathrm{PGF}_{2 \alpha}$ to inhibit LH-stimulated P4 secretion was also significantly reduced (Fig. 6). Similar effects of Bapta-AM on basal and hormonal-stimulated steroidogenesis have been reported in MA-10 Leydig cells (34). Therefore, the results of experiment 3 stress the calcium requirement for $\mathrm{PGF}_{2 \alpha}$ to inhibit LH-stimulated $\mathrm{P} 4$ secretion in the midphase $\mathrm{CL}$ and support the reported observation that the lower efficacy of $\mathrm{PGF}_{2 \alpha}$ to inhibit P4 secretion in the early $\mathrm{CL}$ is related to the reduced ability of $\mathrm{PGF}_{2 \alpha}$ to increase the cytoplasmic concentration of calcium at this developmental stage [Choudhary E et al, 2005]. Taken together, the results obtained in the A23187 and Bapta-AM experiments, strongly support the proposed hypothesis that an attenuation of the luteolytic actions of $\mathrm{PGF}_{2 \alpha}$ is associated with a compromise in the ability of $\mathrm{PGF}_{2 \alpha}$ to induce a rise in $\left[\mathrm{Ca}^{2+}\right] \mathrm{i}$ [Sen $\mathrm{A}$ et al, 2005]. Therefore these studies provide a strong linkage between the signal transduction utilized by the $\mathrm{PGF}_{2 \alpha}$ receptor at different developmental stages and quantitative aspects of the known intracellular mediator of $\mathrm{PGF}_{2 \alpha}$ actions in the $\mathrm{CL},\left[\mathrm{Ca}^{2+}\right]$ i. In this regard, species differences do exist, as in rat luteal cells the antigonadotropic action of $\mathrm{PGF}_{2 \alpha}$ is not mediated by elevated cytosolic calcium levels [Pepperell JR et al, 1989]. It appears that the bovine CL therefore, has the following commonalities with human $\mathrm{CL}: 1$ ) in both species, $\mathrm{PGF}_{2 \alpha}$ is luteolysin, 2) the luteolytic effect of $\mathrm{PGF}_{2 \alpha}$ appears only during mid- and late-luteal phase, and 3) in both, the humans and cows, changes in intracellular calcium appear to regulate luteal function ([Ottander U et al, 1999] and this study).

In summary, the evidence presented here strongly supports the idea that PRKCE, an isozyme highly expressed in steroidogenic luteal cells with acquired luteolytic response to 
$\mathrm{PGF}_{2 \alpha}$, has an important regulatory role in the ability of $\mathrm{PGF}_{2 \alpha}$ to inhibit LH-stimulated P4 secretion in vitro at this developmental stage. The data presented strongly support the hypothesis that luteal resistance to the luteolytic actions of $\mathrm{PGF}_{2 \alpha}$ is associated with a compromised ability of $\mathrm{PGF}_{2 \alpha}$ to induce a rise in $\left[\mathrm{Ca}^{2+}\right]$ i. If the $\mathrm{PGF}_{2 \alpha}$ receptor and its associated signal transduction is bypassed with a pharmacological agent to increase the $\left[\mathrm{Ca}^{2+}\right] \mathrm{i}$, the LH-stimulated P4 secretion in Day-4 steroidogenic cells is eliminated, an action that cannot be induced by $\mathrm{PGF}_{2 \alpha}$ at this developmental stage. Conversely, if the increase in $\left[\mathrm{Ca}^{2+}\right] \mathrm{i}$ typically induced by $\mathrm{PGF}_{2 \alpha}$ on Day-10 steroidogenic luteal cells is buffered by a pharmacological agent, then the ability of $\mathrm{PGF}_{2 \alpha}$ to inhibit the LH-stimulated P4 secretion is abrogated.

Table 1. Primer sequence, accession number, of investigated genes

\begin{tabular}{cccc}
\hline \multicolumn{1}{c}{ Gene } & Forward primer & Reverse primer & Acc\# \\
\hline \hline$\beta$ - Actin & GACATCCGCAAGGACCTCTA & ACGGAGTACTTGCGCTCAG & BC102948 \\
$P G D H$ & GGAAAGCTGGACATCTTGGT & GCAAATTGCGTTCAGTCTCA & BC102458 \\
$P G E S$ & GAACGACCCAGATGTGGAA & ATACGGCCCAGGAAGAAGAC & NM174443 \\
AKRIB5 & GACCTTGGGTACCGTCACAT & TCTTTCTCACTGGGAATCACG & S54973 \\
9 S-PGR & AAGAAATGCAGCCGTGAACT & GCTCCTTCTTCTGGGCTTTT & BC102943 \\
COX-2 & CATGATGTTCTTTGTTGGCATT & GCGAATTCCAACTTTCCATC & AF031698 \\
\hline
\end{tabular}


A
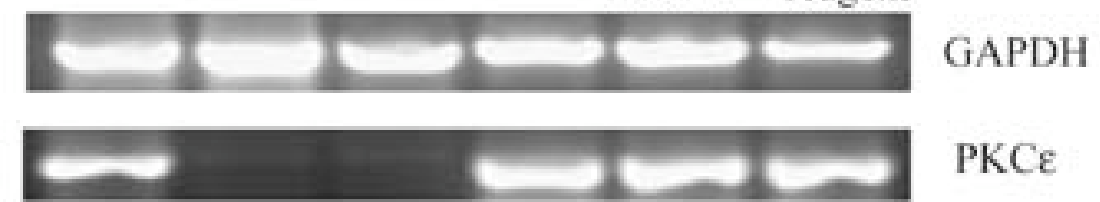

\section{B}

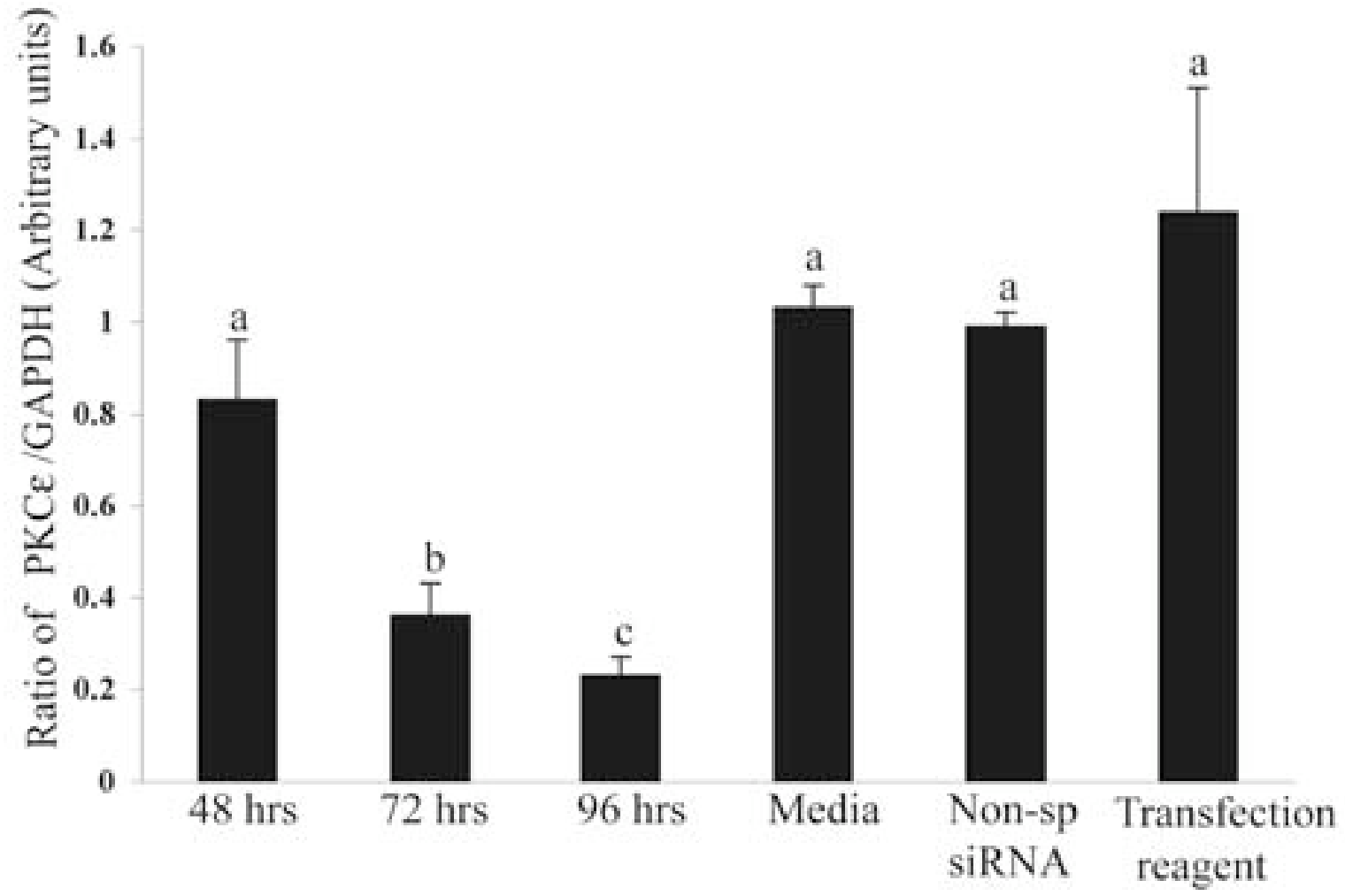

Figure 1. Time-course reduction in $\mathrm{PKC} \varepsilon$ (PRKCE) mRNA expression after transfection of luteal steroidogenic cells with PRKCE specific siRNA. (A) Representative RT-PCR products obtained from total RNA using the PRKCE and GAPDH primers. The amount of total RNA was adjusted to $200 \mathrm{ng}$ per reaction and 40 cycles were used for PRKCE; while 28 cycles were used for GAPDH. The size of the amplified products for the GAPDH and PRKCE were 900 and $500 \mathrm{bp}$, respectively. PRKCE and GAPDH mRNA expression after 48, 72, and $96 \mathrm{~h}$ of transfection with PRKCE specific siRNA are shown. Lanes labeled media, non-specific (Nonsp) siRNA, and Transfection reagent represent respective treatments without PRKCE specific 
siRNA treatment. GAPDH was used as the control gene to normalize the PRKCE mRNA expression. (B) Quantitative analysis of the RT-PCR products obtained in four $(n=4)$ replicates similar to those shown in panel A. Data are the mean \pm SEM of the densitometry measurements for PRKCE relative to GAPDH mRNA. Statistical comparisons were made between different treatments. Different letters above each SEM represent different values $(\mathrm{P}<$ $0.05)$.
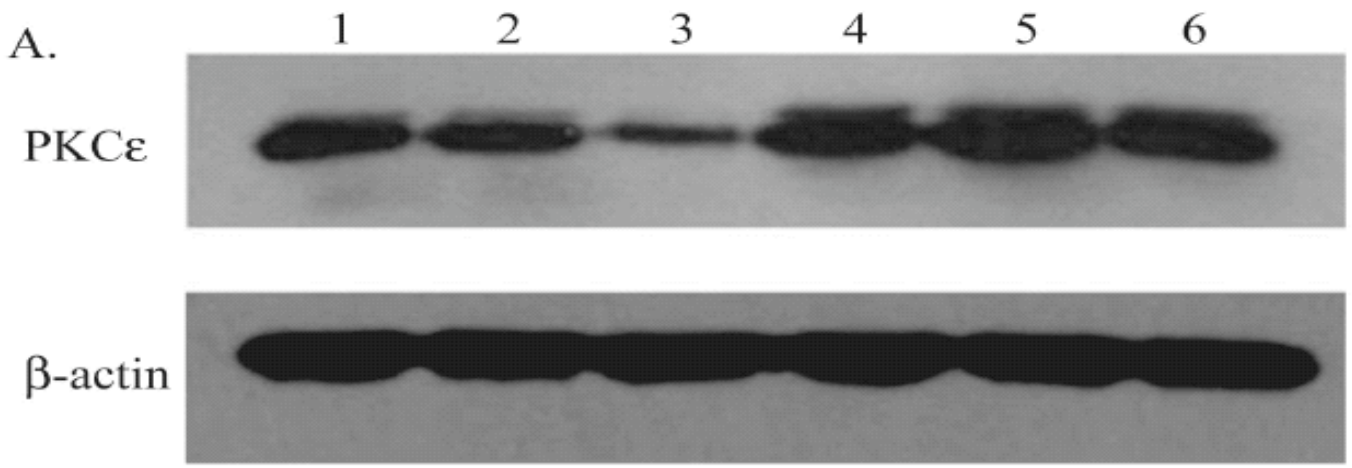

B.

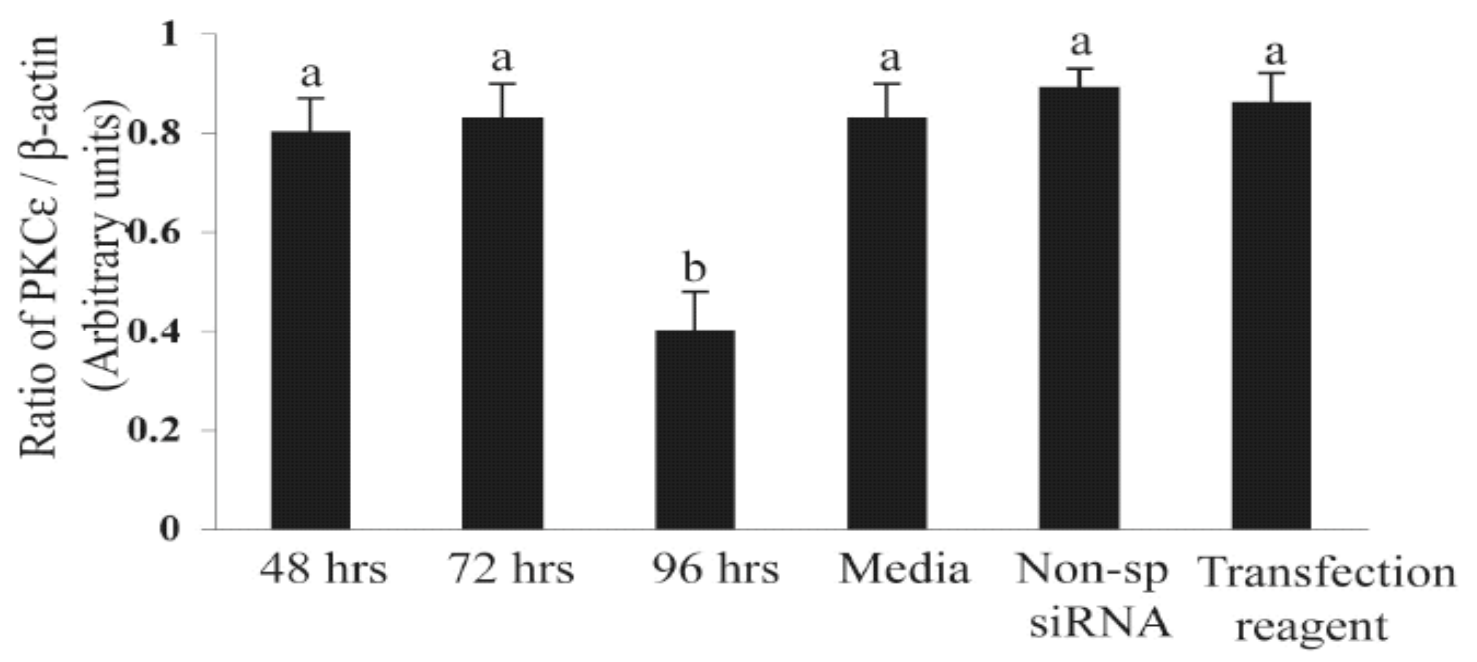

Figure 2. Reduction in PRKCE protein. (A) Representative Western blot showing the amount of PRKCE and actin expressed in protein samples prepared from luteal steroidogenic cells after 48, 72, and 96 h of transfection with PRKCE specific siRNA (lanes 1-3). Lanes labeled 4-6, contained protein samples from indicated control treatments (media, Non-sp siRNA, and transfection reagent, respectively). (B) Semi-quantitative analysis of the densitometry derived 
from four experiments similar to the one shown in panel A. the $y$-axis shows the ratio of the optical density ratio of PRKCE to that of its corresponding $\beta$-actin. The data are shown as mean $\pm \mathrm{SEM}$, and comparisons were made between different treatments. Values with different letters denote differences by one-way ANOVA followed by Tukey-Kramer honestly significant difference $(\mathrm{P}<0.05)$.

A.

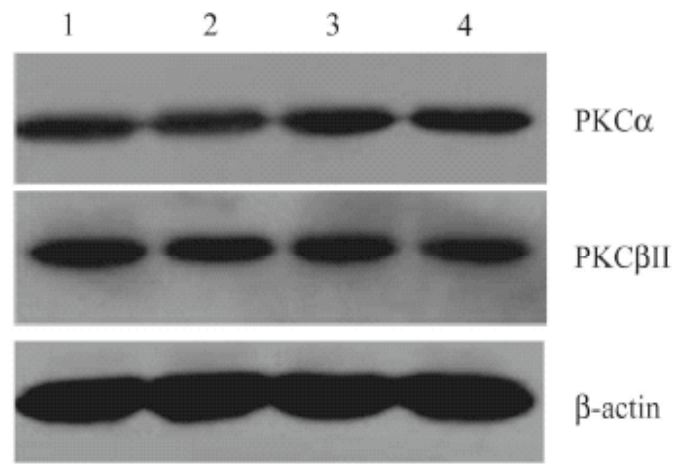

B.

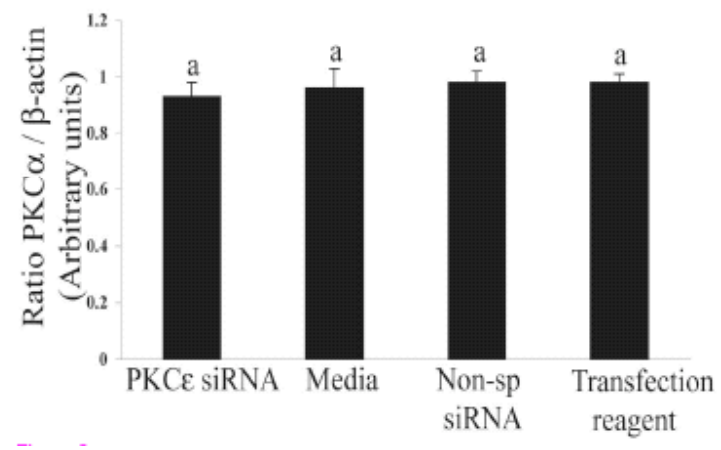

C.

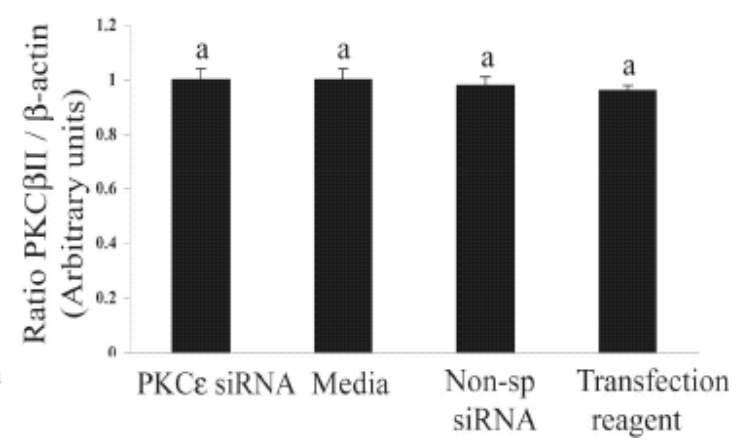

Figure 3. PKC $\alpha$ and PKC $\beta I I$ protein after $96 \mathrm{~h}$ transfection of luteal steroidogenic cells with PRKCE specific siRNA. (A) Representative Western blot showing the amount of PKC $\alpha$, PKC $\beta$ II KC $\varepsilon$ and actin detected in protein samples prepared from luteal steroidogenic cells after $96 \mathrm{~h}$ of transfection with PRKCE specific siRNA (lane 1). Lanes labeled 2 - 4, contained protein samples from indicated control treatments (media, Non-sp siRNA, and transfection reagent, respectively. B and C) Semi-quantitative analysis of the densitometry derived from four experiments similar to the one shown in panel A for PKC $\alpha(\mathrm{B})$ and PKC $\beta I I(C)$. The $\mathrm{y}-$ axis shows the ratio of the optical density ratio of PKC isozyme to that of its corresponding $\beta$ actin. The data are shown as mean \pm SEM, and comparisons were made between different 
treatments by one-way ANOVA followed by Tukey-Kramer honestly significant difference.

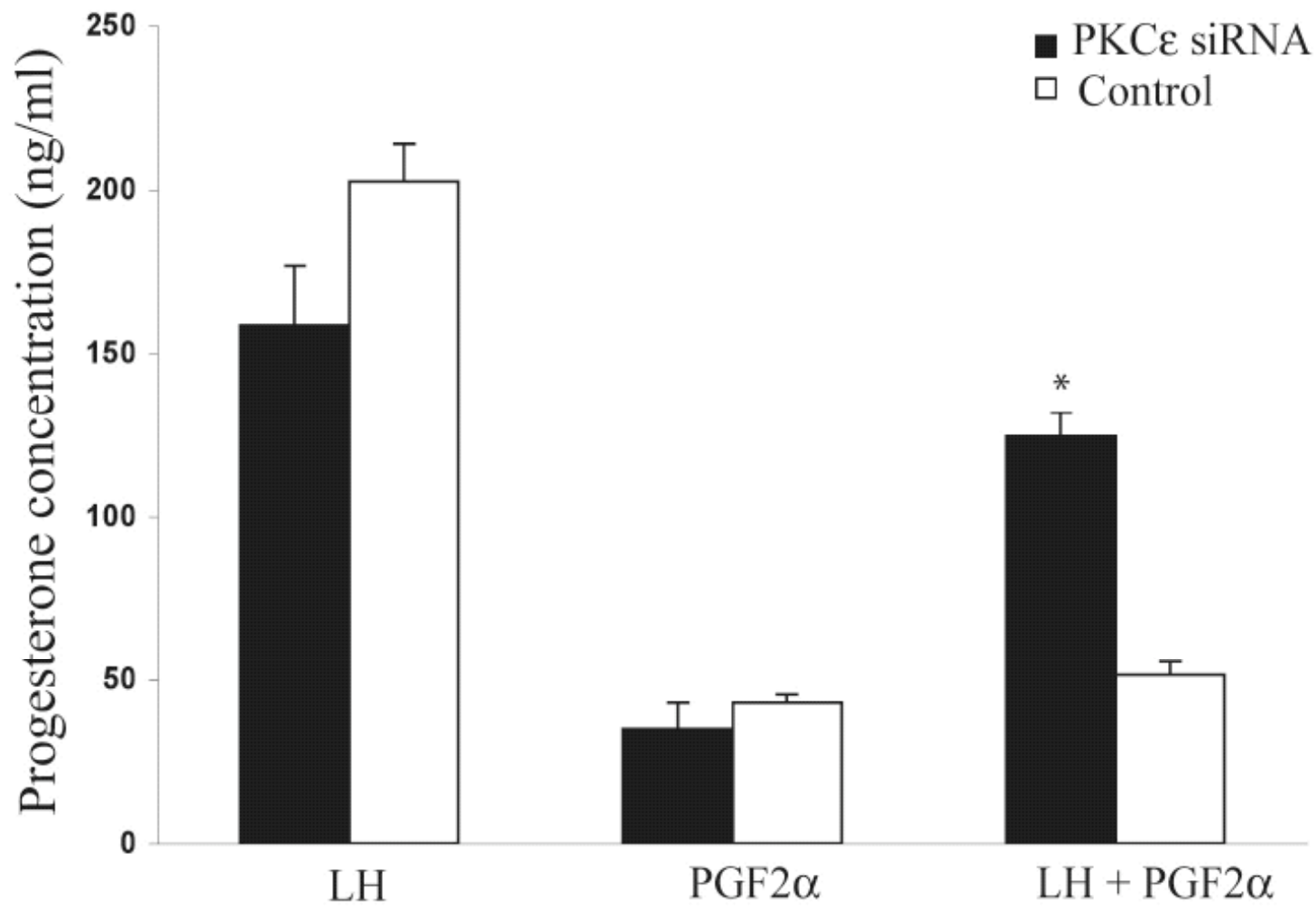

Figure 4. Effects of PRKCE down-regulation on the ability of $\mathrm{PGF}_{2 \alpha}$ to inhibit the LHstimulated progesterone synthesis/secretion in cultures of steroidogenic luteal cells transfected for $96 \mathrm{~h}$ with PRKCE specific siRNA (filled bars) or with transfection regents (control, open bars). Progesterone accumulation was determined in culture media after $4 \mathrm{~h}$ of incubation in the following treatments: $\mathrm{LH}(100 \mathrm{ng} / \mathrm{ml}), \mathrm{PGF}_{2 \alpha}(1 \mu \mathrm{g} / \mathrm{ml})$ and a combination of $\mathrm{PGF}_{2 \alpha}$ and LH. Data are presented as mean \pm SEM of four individual replicates $(n=4$ cows). For each treatment group, statistical comparisons were made between PRKCE down-regulated (PRKCE siRNA) and control (not PRKCE down-regulated); different letters above each SEM denote different values, $\mathrm{P}<0.05$. 
A.
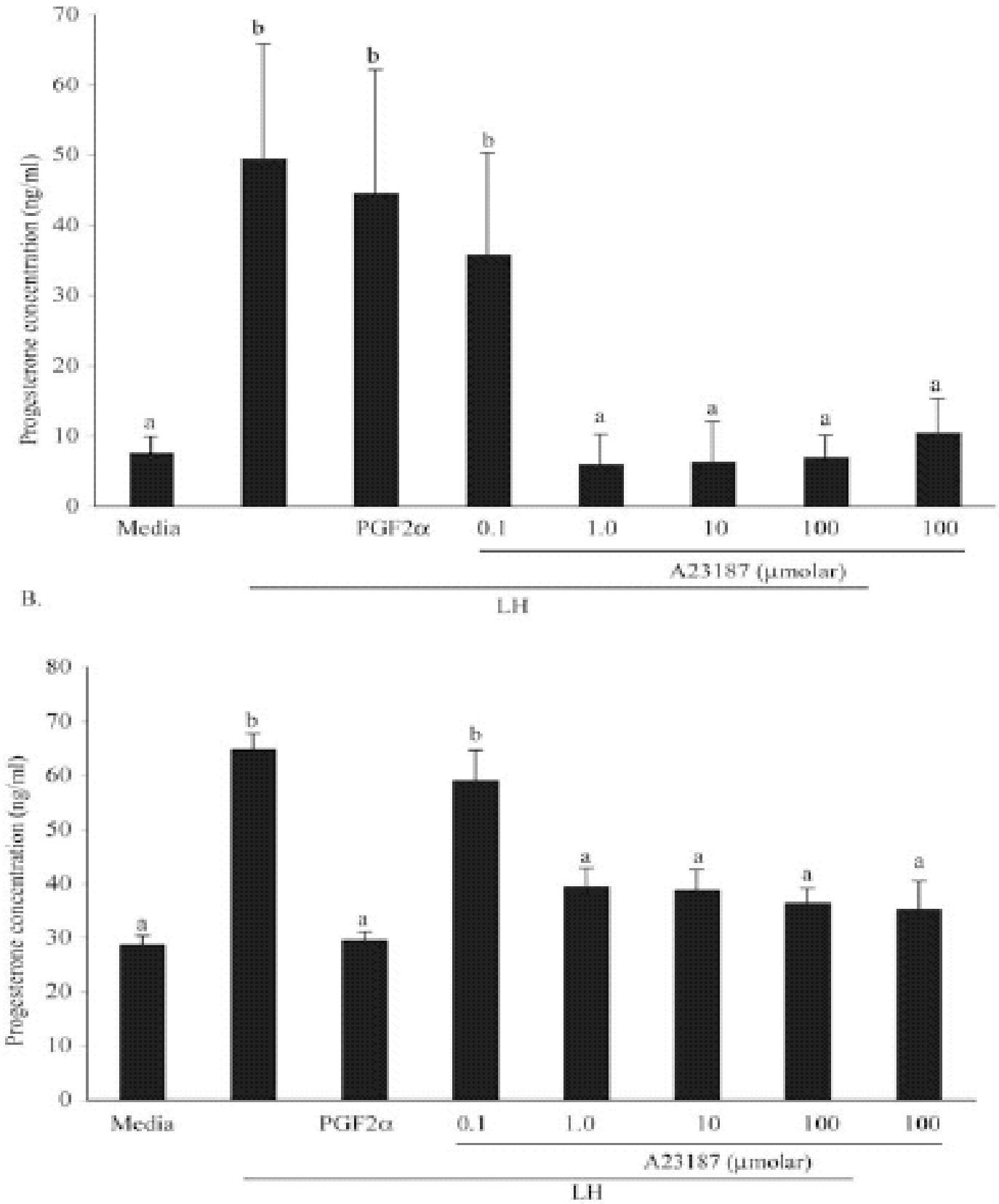
Figure 5. Effect of the $\mathrm{Ca}^{2+}$ ionophore, A23187, on basal and LH-stimulated progesterone synthesis/secretion ( $\mathrm{ng} / \mathrm{ml}$ ) in cultured steroidogenic cells collected from Day 4 (panel A) and Day 10 (panel B) bovine CL. Progesterone accumulated in culture media was determined after $4 \mathrm{~h}$ of incubation in the following treatments: media alone (Media), LH (100 ng/ml), LH and $\mathrm{PGF}_{2 \alpha}(1000 \mathrm{ng} / \mathrm{ml})$, or LH and A23187 (0.1, 1, 10, and $\left.100 \mu \mathrm{mol}\right)$. As explained in Materials and Methods, these treatments also contained $0.1 \%$ of the solvent used for $\mathrm{PGF}_{2 \alpha}$ and $\mathrm{A} 23187$, DMSO. Data are presented as the mean \pm SEM of four Day 4 and 10 Day 10 individual replicates ( $\mathrm{n}=4$ and 10 cows respectively). Statistical comparisons were made across treatments, and means with different letters, differ within each panel $(\mathrm{P}<0.05)$ 


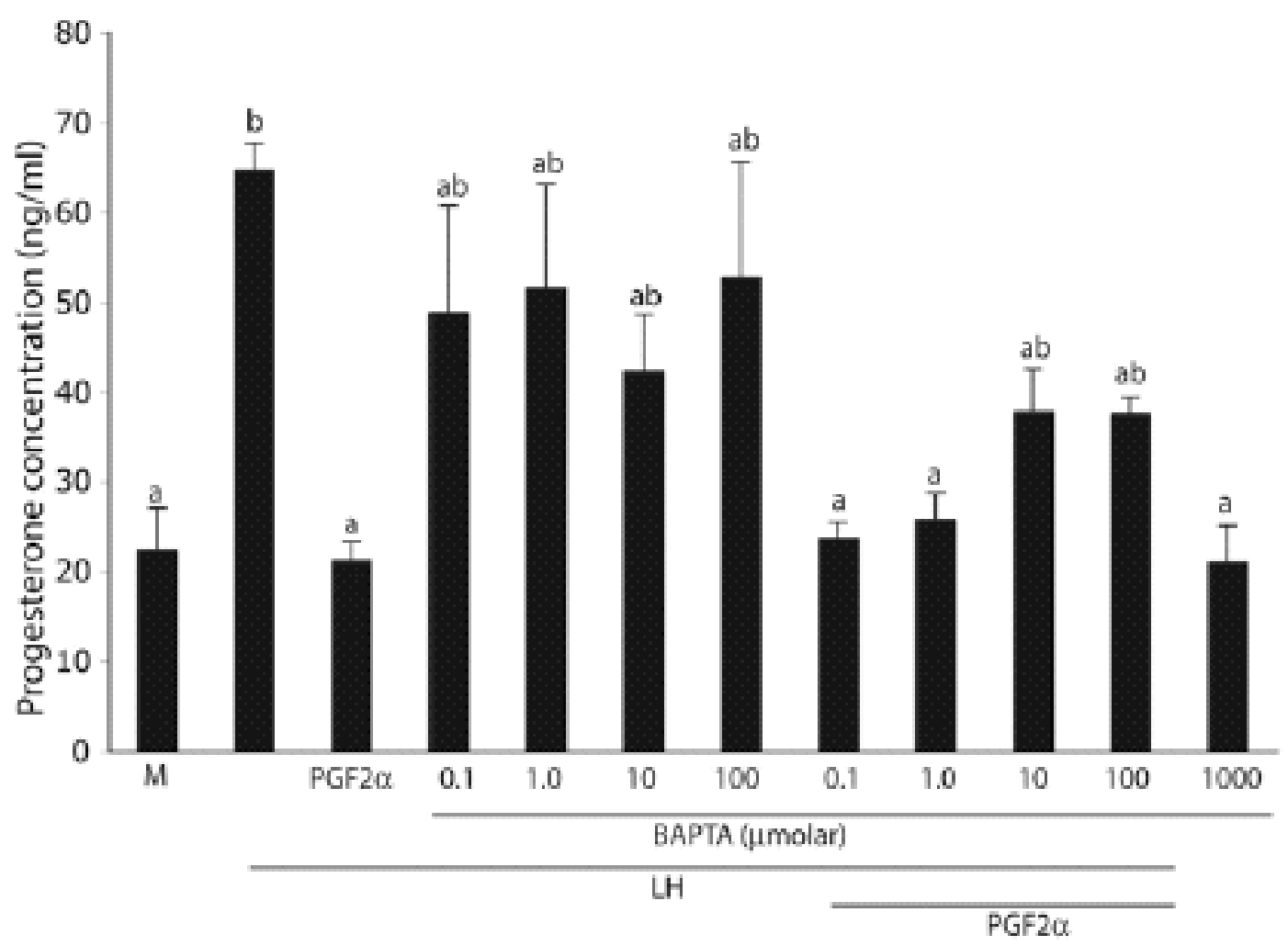

Figure 6. Effect of the cell-permeable calcium chelator, Bapta-AM, on basal and LHstimulated progesterone synthesis/secretion $(\mathrm{ng} / \mathrm{ml})$ in cultured steroidogenic cells collected Day 10 bovine CL. Progesterone accumulated in culture media was determined after $4 \mathrm{~h}$ of incubation in the following treatments: media alone (Media), LH (100 ng/ml), LH and PGF P $_{2}$ $(1000 \mathrm{ng} / \mathrm{ml})$, or LH and Bapta-AM $(0.1,1,10$, and $100 \mu \mathrm{mol})$. As explained in Materials and Methods, these treatments also contained $0.1 \%$ of the solvent used for $\mathrm{PGF}_{2 \alpha}$ and Bapta-AM, DMSO. Data are presented as the mean \pm SEM of four Day 10 individual replicates $(\mathrm{n}=4 \mathrm{CL}$ obtained from 4 cows). Statistical comparisons were made across treatments, and means with different letters denote different values, $\mathrm{P}<0.05$. 
A.

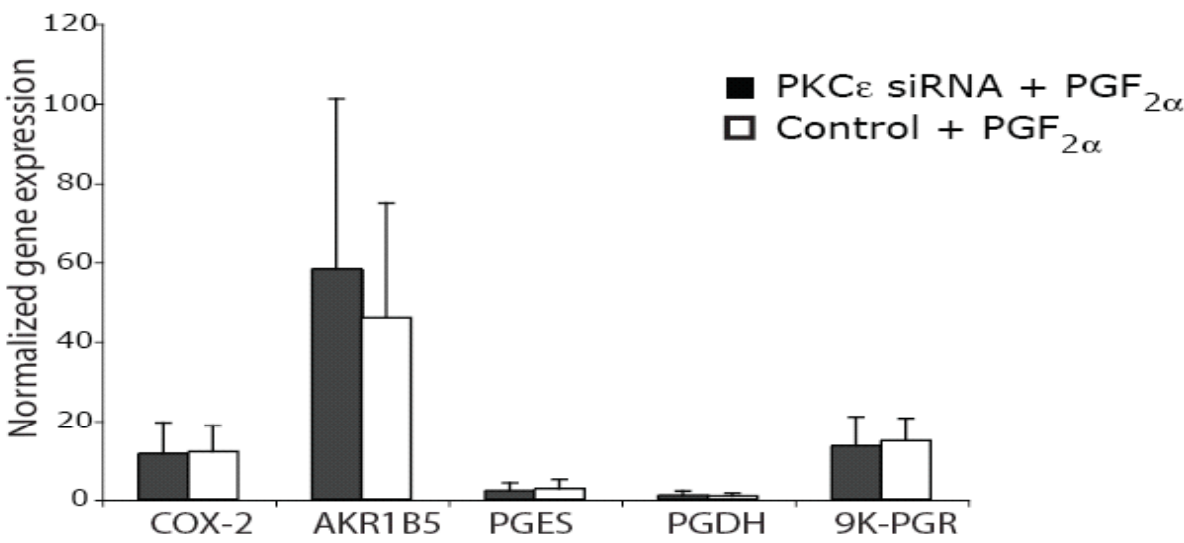

B.

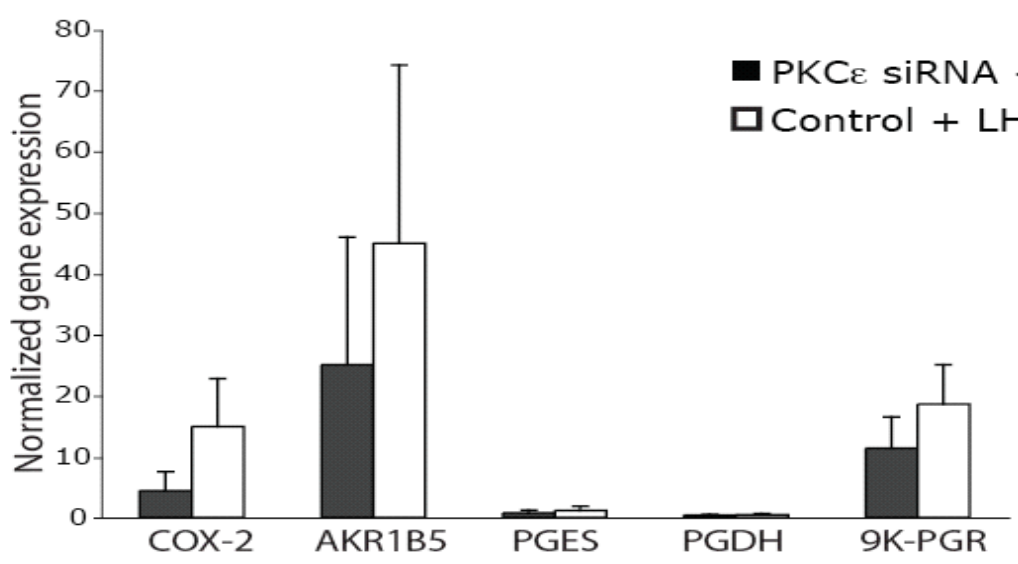

c.

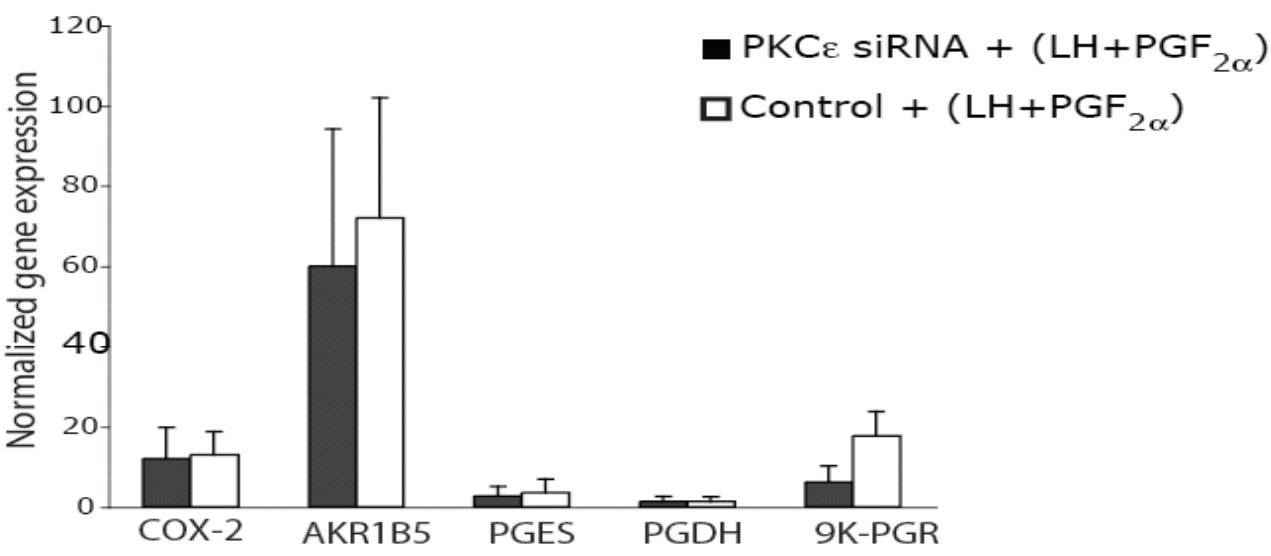


Figure 7. Real-time PCR analysis of the effect of down-regulation of PRKCE mRNA on the expression of $\mathrm{PGF}_{2 \alpha}$ metabolic genes. Comparisons of mRNA expression data were made between the control (without PRKCE down-regulation) and PRKCE down-regulated steroidogenic cells treated either with $\mathrm{PGF}_{2 \alpha}(\mathbf{A}), \mathrm{LH}(\mathbf{B})$, and combination of $\mathrm{PGF}_{2 \alpha}$ and LH (C). The genes analyzed were as follows: aldoketoredutase 1B5 (AKR1B5), prostaglandin-15 dehydrogenase (PGDH), prostaglandinE synthase (PGES), 9-keto-prostagalndin reductase (9KPGR), and cyclooxygenase-2 (COX-2). The expression data were presented as mean $\pm \mathrm{SE}$. The comparison of means between treatments by t-test did not show significant differences with any of the genes analyzed. 


\section{Chapter IV: Differential Gene Expression in the Bovine Corpus Luteum During Transition from Early to Mid-Phase and Its Potential Role in Acquisition of Luteolytic Sensitivity to Prostaglandin F2 Alpha}

\section{Introduction}

Luteal regression is required for normal ovarian cyclic activity. Prostaglandin $\mathrm{F}_{2 \alpha}\left(\mathrm{PGF}_{2 \alpha}\right)$ initiates luteal regression or luteolysis in cattle and most domestic species [McCracken JA et al, 1970; Niswender GD et al, 2000], and has been used for estrous synchronization in beef and dairy cattle [Inskeep EK, 1973; Lamb GC et al, 2006; Lauderdale JW et al, 1974; Silva E et al, 2007]. However, the bovine corpus luteum (CL) is resistant to luteolysis by exogenous PGF $_{2 \alpha}$ prior to day 5 of the estrous cycle [Choudhary E et al, 2005; Copelin JP et al, 1988; Goravanahally MP et al, 2007; Inskeep EK, 1973; Sayre BL et al, 2000; Watts TL and Fuquay JW, 1985; Wiltbank MC et al, 1995]. The cellular basis controlling luteal function during this physiological transition, although studied intensely, is incompletely understood. As in many biological systems, cellular responsiveness to a given agonist can be altered during development. Lack of $\mathrm{PGF}_{2 \alpha}$ receptors does not seem to explain luteal insensitivity to $\mathrm{PGF}_{2 \alpha}$ as the developing $\mathrm{CL}$ already expresses high affinity $\mathrm{PGF}_{2 \alpha}(\mathrm{FP})$ receptors [Sakamoto $\mathrm{K}$ et al, 1994; Wiltbank $\mathrm{MC}$ et al, 1995], and $\mathrm{PGF}_{2 \alpha}$ can elicit distinct physiological responses in the early CL [Sayre BL et al, 2000; Sen A et al, 2005; Tsai SJ and Wiltbank MC, 1998]. Therefore the nature of the elicited response or the ineffectiveness of $\mathrm{PGF}_{2 \alpha}$ to induced luteolysis in developing CL might be due to differences in post-receptor signaling events. Several studies have indicated that the lower efficacy of $\mathrm{PGF}_{2 \alpha}$ in inducing regression of early $\mathrm{CL}$ might be related to differences in signal transduction due to differential expressions of genes associated with the FP receptor at those two developmental stages. For instance, increased expression of protein kinase $\mathrm{C}$ inhibitor-1 (now known as histidine triad nucleotide binding protein, (HINT1) and tyrosine 3monooxygenase/tryptophan 5-monooxygense activation protein, zeta polypeptide (YWHAZ) was reported to be involved in the insensitivity of the early ovine CL [Juengel JL et al, 1998]. Higher expression of PRKCE in D10 bovine CL has been reported to be involved in acquisition of sensitivity of the CL to $\mathrm{PGF}_{2 \alpha}$-induced luteolysis [Sen A et al, 2005]. It has been suggested that the lack of luteolytic action by $\mathrm{PGF}_{2 \alpha}$ in the developing bovine CL might be due to alterations in components of the signal transduction associated with the receptor by locally 
produced hormones. For instance, resistance of early ovine CL has been attributed to increased expression of the $\mathrm{PGF}_{2 \alpha}$ catabolizing enzyme, hydroxyprostaglandin dehydrogenase 15-(NAD) (HPGD) [Silva PJ et al, 2000]. The inability of $\mathrm{PGF}_{2 \alpha}$ to induce expression of prostaglandinendoperoxide synthase 2 (PTGS2) and intraluteal $\mathrm{PGF}_{2 \alpha}$ synthesis in the early bovine CL was implicated in luteolytic insensitivity to $\mathrm{PGF}_{2 \alpha}$ [Tsai SJ and Wiltbank MC, 1998]. Therefore, the hypothesis tested was that differential gene expression during the developmental transition of corpora lutea from D-4 to D-10 might include genes encoding components of signal transduction pathways that might change the nature of the elicited response, or the luteal sensitivity to luteolytic actions of $\mathrm{PGF}_{2 \alpha}$. The two objectives of the present study were to 1) use a microarray-based approach to systematically analyze a large portion of the bovine CL transcriptome during the developmental transition from D-4 to -10 , when the luteolytic capability to $\mathrm{PGF}_{2 \alpha}$ is acquired; and 2) determine the responsiveness of selected genes found to be differentially expressed during this transition to an exogenous in vivo treatment with $\mathrm{PGF}_{2 \alpha}$ on the D-4 or -10 of the estrous cycle.

\section{Materials and Methods}

\section{Animal handling and surgical procedures}

Non-lactating beef cows were observed visually for estrus twice daily at approximately $12-\mathrm{h}$ intervals for a minimum of $30 \mathrm{~min}$ per observation. The day when standing estrus was observed was designated as Day 0. For experiment 1, ovaries on Day -4 $(n=3)$ or CL on Day $10(n=3)$ were collected surgically as described previously [Choudhary E et al, 2005] and transported to the laboratory in ice-cold saline for RNA isolation. Briefly, the surgical procedure was performed via supravaginal incision under epidural anesthesia (6-9 $\mathrm{ml} 2 \%$ lidocaine hydrochloride; Butler Company, Columbus, $\mathrm{OH}$ ) administered for cows weighing $450-700 \mathrm{~kg}$. For experiment 2, beef cows on Day 4 or 9 of estrous cycle were treated with 25 mg of PGF $_{2 \alpha}$ analog (Lutalyse; Pfizer Animal Health, New York, NY) and control groups received $5 \mathrm{ml}$ of normal saline ( $\mathrm{n}=3$ per group per day). After $24 \mathrm{~h}$, Day -5 or -10 ovaries or, CL were collected as described above. For experiment 4 , beef cows on days $10(n=4)$ were utilized for CL collection. For experiment 5 , corpora lutea from beef cows ( $\mathrm{n}=4$ per group) on days -4 and -10 were collected. The ovary or CL was collected into ice-cold saline (PBS) and 
transported to the laboratory within 15 to $30 \mathrm{~min}$ after collection. Developing corpora lutea were removed from the ovary in the laboratory because of the danger of crushing tissue if pressure is applied to the ovary during surgical collection. The Animal Care and Use Committee of West Virginia University approved all procedures for these experiments (ACUC protocol \# 06-0401).

\section{Isolation of total RNA}

Total RNA was isolated using Tri reagent (MRC, Cincinnati, OH) according to the manufacturer's instructions. Briefly, frozen CL tissue was mechanically pulverized while immersed in liquid nitrogen using an RNAase-free porcelain mortar. The pulverized tissue was homogenized in Tri reagent using a glass homogenizer. The RNA was solubilized in RNAsefree-water and its integrity was assessed using 1\% agarose gel electrophoresis, all samples were deemed of high quality. Final RNA concentration and purity were determined by spectrophotometry using a NanoDROP 3000 (Nano Drop technologies, Wilmington, DE).

\section{Luteal cell dispersion and purification}

For experiment 4, luteal tissue was trimmed to remove surrounding connective tissue, weighed and cut in to small fragments of approximately $1 \mathrm{~mm}^{3}$ size. During these procedures, tissue was immersed in cell dispersion media (CDM, M-199 containing 0.1\% BSA, 25 mM Hepes, $100 \mathrm{U} / \mathrm{ml}$ fungicide). Tissue fragments were dissociated as previously described [Choudhary $\mathrm{E}$ et al, 2005] and luteal endothelial cells were separated according to standard procedures [Choudhary E et al, 2005; Levy $\mathrm{N}$ et al, 2001; Mamluk R et al, 1998]. Briefly, magnetic tosylactivated beads (Dynal Biotech, Lake Success, NY) which, specifically attach endothelial cells were added to luteal cell suspension at bead to endothelial cell ratio of 1:3 and endothelial cells were separated. The remaining cell suspension represented an enriched steroidogenic cell population, which also contained other cell types of CL such as fibroblasts, pericytes, immune cells, and possibly few endothelial cells that were not separated by this procedure. Cell viability and density were determined using 4\% Trypan Blue exclusion procedure and a hemocytometer; luteal cell viability was usually greater than $95 \%$. 
Experiment 1: Microarray -based approach for systematically analyzing the bovine CL transcriptome at two developmental stages: Day-4 and -10, a transition when the luteolytic capability to $P G F_{2 \alpha}$ is acquired

Microarray, cDNA labeling, and Hybridization

The microarray assays were performed in Laboratory of Animal Biotechnology and Genomics, Division of Animal and Nutritional Sciences, WVU. Individual RNA samples were used to produce labeled cDNA that was hybridized to the bovine 70-mer long oligo nucleotide probes spotted in duplicates. This array contained 8,329 unique bovine genes developed by Center for Animal Functional Genomics (CAFG) at Michigan State University. Information on the list of genes and their annotations are available via GeneLink database http://cafg.msu.edu. Comparisons were made between RNA samples from $\mathrm{PGF}_{2 \alpha}$ insensitive and -sensitive CL for the changes in gene expression using a total of 6 beef cows ( 3 replicates $\mathrm{x} 2$ groups). The procedure for cDNA labeling and microarray hybridizations was followed as described previously [Salem $\mathrm{M}$ et al, 2006]. Briefly, $30 \mu \mathrm{g}$ total RNA was reverse transcribed using Supertscript II reversetrancriptase (Invitrogen, Hercules, CA) to generate cDNAcontaining minoallyl-dUTP. The cDNAs from two experimental groups were labeled randomly with Nhydroxysuccinate-derived Cy3 or Cy5 dyes (GEHealthcare, Piscataway, NJ) to limit the effect of differential dye incorporation. Unincorporated dyes were removed from the cDNA product using a PCR purification kit (Quiagen, Valencia, CA), followed by mixing the Cy3 and Cy5labeled cDNAs. The labeled cDNAs were concentrated to $20 \mu \mathrm{l}$ using Microcon YM-30 (Millipore, Billerica, MA) and mixed with $130 \mu$ of Slidehyb 3 solution (Ambion, Austin, Texas). The Tecan HS400 automated microarray hybridization station (Tecan US, Durham, NC) was used for array hybridization. The steps in the hybridization were as follows: 1) the slides were subjected to $60^{\circ} \mathrm{C}$ for 2 min and prehybridized at $55^{\circ} \mathrm{C}$ for $30 \mathrm{~m}$ using prehybridization solution (5 SSC, 1\% SDS, 1\% BSA) with medium agitation, 2) brief washing was carried out at $60^{\circ} \mathrm{C}$ for $1 \mathrm{~min}$ and $140 \mu \mathrm{l}$ of labeled cDNA mixture was loaded onto the hybridization chamber, 3) hybridization was performed at $60^{\circ} \mathrm{C}$ for $3 \mathrm{~h}$ followed by $55^{\circ} \mathrm{C}$ for $13 \mathrm{~h}, 4$ ) washing was carried out twice with in $2 \mathrm{X}$ SSC, $0.1 \%$ SDS and twice with in $0.1 \mathrm{X}$ $\mathrm{SSC}, 0.1 \% \mathrm{SDS}$ at room temperature, and 5) two more washes were given with $0.1 \mathrm{X}$ SSC followed by rinsing the slides with water and finally drying by centrifugation. 


\section{Microarray Data analysis}

After hybridization, the gene array was scanned for spots using ScanArray Lite microarray scanner (Perkin Elmer). The spots were aligned, integrated with original GAL files and signal intensities were quantified using ScanArray Express software (Perkin Elmer, Wellesley, MA). Micro array raw data were processed using GenePix Auto Processor (GPAP) software (http://darwin.biochem.okstate.edu/gpap3/) as described previously [Salem M et al, 2006]. Briefly, GPAP utilizes $\mathrm{R}$ statistical language, Bioconductor and a LIMMA package to preprocess the raw data by signal filtering, background correction and normalization. The data points with signal intensity values in both channels less than baseline value of 200 were filtered-out and the spots with log-transformed (base 2) ratio outside of 2 standard deviations from the mean were removed as outliers and average of technical replicates within and across replicates were calculated. Raw data were quality controlled manually by flagging and removing any spurious spots from analysis. The preprocessed expression data were normalized by the Loess-global intensity-dependent normalization. The GPAP output value consisted of $\mathrm{M}$ value [log2 (cy5/cy3)], t-statistic, $\mathrm{P}$ value (probability), and B-statistics for each spot. Twofold or more changes in the expressions of genes were indicated by $\mathrm{M}$ value $\geq 1.0$ (upregulated) or $\leq-1.0$ (down-regulated). The genes with two-fold or more changes in expression with $\mathrm{P}<0.05$ were considered significantly different and selected for further analysis. The microarray data were deposited (according to Microarray Gene Expression Data Society Standards) in NCBI gene expression omnibus (GEO). The curated microarray data can be retrieved with the series accession number GSE10662.

\section{Validation of Microarray Data by Real-time RT-PCR}

The pattern of gene expression observed in microarray analysis was confirmed by real-time RT-PCR. Total RNA from CL samples was used for cDNA synthesis using Superscript II reverse transcriptase (Invitrogen). The real-time PCR was performed according to the method described by Pfaffl in 2001 [Pfaffl MW, 2001]. This approach takes into consideration the actual efficiency of each primer. The cDNA generated from pooled RNA samples (D-4 and -10 CL) was diluted serially 10-fold and calibration curve for each gene was generated to determine the efficiency of each primer. The PCR reaction was standardized for optimum 
efficiency between 95 to $105 \%$ for 9 selected genes. The sequences of each gene primer were designed using primer3 software [Rozen S and Skaletsky H, 2000]. The names, abbreviations, primer sequences and accession numbers for the examined genes are listed in Table 1. The real-time PCR reaction was performed using $25 \mu 1$ total reaction containing 2x SYBR Green supermix (BIORAD) and $0.5 \mu \mathrm{M}$ primer concentration and $2 \mu 1$ of cDNA prepared from $20 \mu 1$ reverse transcriptase reaction using $1 \mu \mathrm{g}$ of total RNA. The conditions for the real-time PCR reactions were as follows: an initial reverse transcriptase inactivation and Taq polymerase activation step at $94{ }^{\circ} \mathrm{C}$ for $3 \mathrm{~min}$, followed by total 40 cycles of $94^{\circ} \mathrm{C}$ for 30 s to denature; 55$60{ }^{\circ} \mathrm{C}$ to anneal; and an extension at $72^{\circ} \mathrm{C}$ for $1 \mathrm{~min}$. The melt-curve was analyzed to make sure genes of interest produced single amplicons. The internal control glyceraldehydes-3phosphate dehydrogenase (GAPDH) was used to normalize the expression values due to differences in amount of RNA. Previous studies from our laboratory and by other investigators have validated the use of GAPDH as a normalizing standard while assessing gene expression at different luteal developmental stages [Buratini J, Jr. et al, 2007; Wright MF et al, 2001]. In the current studies, there were no differences in the values of GAPDH expression from samples collected on day 4 and day 10. The day-4 expression value was set as a calibrator sample (control) and the data were expressed as fold change in day-10 CL mRNA compared to D-4 CL mRNA normalized to GAPDH. The differences in the mean values of mRNA expression between two groups were analyzed by t-test using statistical analysis system JMP 3.0. Gene expression values with a $\mathrm{P}<0.05$ were considered significantly different.

Experiment 2: Responsiveness of selected differentially expressed genes to in vivo treatment with exogenous $P G F_{2 \alpha}$.

Real-time RT-PCR. Luteal tissues were collected and RNA samples were isolated for real-time RT-PCR as described above. The selected genes analyzed in this experiment were calcium/calmodulin-dependent protein kinase kinase 2, beta (CAMKK2), protein kinase N1 (PKN1), tyrosine 3monooxygenase/tryptophan 5-monooxygense activation protein, zeta polypeptide (YWHAZ), regulator of G-protein signaling 2, $24 \mathrm{kDa}$ (RGS2), guanine nucleotide binding protein (G protein), beta polypeptide 1 (GNB1), SPARC-like 1 (hevin) (SPARCL1). The selection of these genes was based on unpublished results from our laboratory and from literature review of genes whose expression was likely to be affected by PGF $_{2 \alpha}$ [Choudhary E et 
al, 2005; Juengel JL et al, 1998; Sen A et al, 2005]. The sequences and accession numbers of the primers are represented in Table 1.

Experiment 3: Semi-quantitative Western Blotting and Immunohistochemistry -based Approaches for Analyzing CAMKK2 Expression in the Bovine CL During Developmental Transition from Day-4 to -10, and Identifying the Luteal Cellular Source of CaMKK2.

Semi-quantitative Western Blotting. Proteins from frozen luteal tissue were isolated as previously described [Sen A et al, 2004]. Briefly, pulverized frozen tissue was homogenized in homogenization buffer (containing $20 \mathrm{nM}$ Tris-HCL, 0.25 M sucrose, $1.2 \mathrm{mM}$ EGTA, $0.1 \mathrm{mM}$ phenylmethylsulfonyl fluoride (Eastman Kodak Company, Rochester, NY), 20 (g/ml leupeptin, and $20 \mathrm{mM}$ 2-mercaptoethanol (Gibco BRL, Gaithersburg, MD). The luteal-homogenate was centrifuged at $100 \mathrm{Xg}$ for $10 \mathrm{~min}$ to separate coarse cellular particles. Protein concentration in the samples was determined by BioRad assay (Hercules, CA) with BSA (Gibco) as standard. Initially, 5, 10, 20, and 40 (g / lane of sample protein were used for semiquantitative western blot analysis as previously described \{Sen, 2004 \#148]. For assessment of development and treatment effects on amount of CAMKK2 expression, $40 \mu \mathrm{g} /$ lane of sample protein were used. The following primary antibodies were used in this experiment: mouse anti-actin monoclonal antibody (used at a dilution of 1:3000 [v / v]; Chemicon International, Inc., Temecula, CA); three CAMKK2 polyclonal antibodies were tested: SC 50341, SC 9629 (Santa Cruz Biotechnology, Santa Cruz, CA), and AP7117b (ABGENT, San Diego, CA). The antibodies were used at a dilution of 1:200, 1:200, and 1:50 [v/v] respectively. The following secondary antibodies were used in this experiment: anti-rabbit (1:5000 [v/v]; Amersham Pharmacia Biotech, Piscataway, NJ), anti-goat (1:5000), and antimouse (1:30,000 [v/v]; Gibco) and antigoat (1:4000 v/v; Gibco]) horseradish peroxide-conjugated antibodies.

Validation of the semi-quantitative western blot analysis and stripping conditions has been determined previously [Sen A et al, 2004]. The intensity of the signal corresponding to the protein of interest was standardized by the corresponding intensity of the actin control in that sample. Normalization of data allowed us to estimate, in a semi-quantitative manner, the amounts of protein in the samples of interest. 
Immunohistochemistry. Approximately one hour after surgical collection, portions of corpora lutea were fixed for $48 \mathrm{~h}$ by immersion in Bouin's solution $(75 \mathrm{ml}$ saturated picric acid, $25 \mathrm{ml}$ formaldehyde, $5 \mathrm{ml}$ glacial acetic acid). The tissue was processed by standard histology methodology for embedding tissue in paraffin (Paraplast plus; Tyco Healthcare Group LP, Manfield MA). Ten $\mu \mathrm{m}$ thick sections were prepared from Day-10 bovine CL $(\mathrm{n}=3$ different cows) using a HM 325 microtome (Fischer Scientific, Pittsburgh PA). Deparaffinized tissue sections were processed for immunohistochemistry according to the manufacturer instructions of a VECTASTIN Universal Quick kit (Vector Laboratories, Inc. Burlingame, CA). Briefly, after quenching endogenous peroxidase activity in $0.3 \% \mathrm{H} 2 \mathrm{O} 2$ in methanol for 30 minutes, sections were incubated in working solution of blocking serum to reduce non-specific binding. Sections were incubated overnight at $4^{\circ} \mathrm{C}$ with primary antibody, CAMKK2 goat polyclonal IgG (SC9629, Santa Cruz Biotechnology, Santa Cruz, CA) at a dilution of 1:100 (vol/vol). The antibodies, SC50341 (Santa Cruz Biotechnology) and AP71176 (ABGENTA) were also tested at a dilution of 1:100 and 1:25 ( $\mathrm{vol} / \mathrm{vol})$ respectively. Incubation with secondary antibody and strepavidin/peroxidase complex were carried out as indicated by the manufacturer's instructions (Universal Quick kit). Detection was made using the substrate, 3,3diaminobenzidine tetrahydrochloride chromogen solution (DAB, prepared according to the manufacturer's instructions; Biomedia Corp. Foster City, CA) at room temperature for 3 min. Slides were counterstained in Harris's Hematoxylin for $30 \mathrm{sec}$, and serially dehydrated at room temperature in ethanol and finally transferred into xylene for the application of cover slips using a mounting medium (Gel/Mount Biomedia Corp. Foster City, CA). The specificity control for the immunohistological detection was determined by 1) pre-incubation of the primary antibody with excess antigenic peptide $(1 \mu \mathrm{g}$ peptide/1 $\mu \mathrm{g}$ antibody prepared in blocking serum, SC9629 and AP71176), and 2) incubation with normal rabbit or goat serum in lieu of the primary antibody (for the rabbit and the goat primary antibodies). These slides were later observed under an Olympus PROVIS AX70 microscope (Olympus America Inc., Melville, NY) for the presence/absence of specific brown color accumulation indicating immunoreactivity and for microphotography. 
Experiment 4: Role of CAMKK2 in mediating the antisteroidogenic actions of increase in $\left[\mathrm{Ca}^{2+}\right]_{i}$ stimulated by $\mathrm{PGF}_{2 \alpha}$

The working hypothesis for this experiment was that the CAMKK2 mediate the progesterone inhibitory actions of increased $\left[\mathrm{Ca}^{2+}\right]_{\mathrm{i}}$ stimulated by $\mathrm{PGF}_{2 \alpha}$. Our prediction was that if the activity of CAMMK2 is inhibited, then ability of $\mathrm{PGF}_{2 \alpha}$ to inhibit the progesterone synthesis is abolished under in vitro conditions. We used commercially available STO-609 (Tocris Bioscience, Ellisville, MO) as CAMKK2 inhibitor. STO-609 (7H-Benz [de] benzimidazo[2,1a]isoquinoline-7-one-3-carboxylic Acid) is utilized as specific inhibitor of CAMKK. It has no significant effect on activities of CaM-KII (IC $50 \sim 10 \mu \mathrm{g} / \mathrm{ml})$, MLCK, CaM-KI, CaM-KIV, PKA, PKC, and p42 MAP kinase ( $\left.\mathrm{IC}_{50}>10 \mu \mathrm{g} / \mathrm{ml}\right)$. Indeed, STO-609 is 5-fold more potent in inhibiting CAMKK beta than CAMKK alpha. The working concentration of $10-20 \mu \mathrm{g} / \mathrm{ml}$ of STO-609 was able to completely inhibit the activity of CAMKK beta without significantly affecting the activity of other CaM kinases [Mount PF et al, 2008; Stahmann N et al, 2006; Tokumitsu H et al, 2002]. The enriched steroidogenic cells isolated from Day-10 of nonlactating beef cows were plated in $15 \mathrm{~mm} 24$-well culture plates at a cell density of $1 \times 10^{5}$ cells/well containing medium M199. Plated cells were treated with $20 \mu \mathrm{g} / \mathrm{ml}$ of STO-609 in presence or absence of $\mathrm{PGF}_{2_{\alpha}}(1000 \mathrm{ng} / \mathrm{ml})$ and incubated overnight at $37^{\circ} \mathrm{C}$ in presence of $5 \%$ $\mathrm{CO}_{2}$. Following day, media was collected and frozen for progesterone estimation by RIA. The RIA used for measurements of progesterone in the culture media has been described previously [Sheffel CE et al, 1982]. The standard curve for this RIA ranged from $10 \mathrm{pg} / \mathrm{ml}$ to $800 \mathrm{pg} / \mathrm{ml}$.

\section{Results}

Experiment 1: Microarray analysis of the bovine CL transcriptome during the developmental transition from Day-4 to -10.

Our microarray analysis identified 167 genes ( $2 \%$ of the analyzed transcriptome) that were differentially expressed as (with $\geq 2$ fold change in expression; $\mathrm{M}$ value $\leq-1$ or $\geq 1 ; \mathrm{P}<0.05$ ) the bovine CL transitioned from a $\mathrm{PGF}_{2 \alpha}$-resistant (D-4) to a $\mathrm{PGF}_{2 \alpha}$-sensitive (D-10) stage. Of these 167 genes, the majority was up-regulated in D-10 CL (77\%). Gene families that were dynamically up-regulated during this developmental transition most likely reflect a combination of genes involved in the process of active steroid secretion and in acquisition of 
sensitivity to $\mathrm{PGF}_{2 \alpha}$-induced luteolysis. The Gene ontology classification of the differentially expressed is shown in Table 2. List of genes with in different categories are listed in Tables 311.

One objective of this study was to identify potential genes involved in cell signaling that might participate in acquisition of luteolytic sensitivity to $\mathrm{PGF}_{2 \alpha}$. Twenty differentially expressed transcripts were found to be involved in various cell-signaling pathways. The identity, accession numbers, $\mathrm{P}$ values and foldchange data of these transcripts are presented in Table 3. Interestingly, nine of these twenty genes are linked to cell-signaling associated with G-protein coupled receptors. For example, a component of the heterotrimeric G-protein complex, guanine nucleotide-binding protein (G protein), beta polypeptide 1 (GNB1) was up-regulated in D-10 CL relative to D-4 CL, as were other genes such as SLIT-ROBO Rho GTPase-activating protein 1 (SRGAP1), Rho GTPase activating protein 8 isoform 1 (ARHGAP8), adenosine A1 receptor (ADORA1), protein kinase N1 isoform 1 (PKN1), and ADP-ribosylation factor 6 (ARF6). Genes in this same category but that were down-regulated in D-10 CL relative to D-4 included: a potent inhibitor of $\mathrm{G}$ protein signaling, regulator of G-protein signaling 2, $24 \mathrm{kDa}$ (RGS2); the adrenergic, alpha-1B, receptor (ADRA1B); and a gene encoding the G-protein coupled receptor-98 (GPR98). The transcripts of casein kinase 2, alpha prime polypeptide and NOTCH2 preprotein were up-regulated in D10 CL and these proteins are involved in notch signaling. The mRNAs of two genes mediating $\mathrm{Ca}^{2+}$ signaling, such as, calcium/calmodulindependent protein kinase kinase 2, beta (CAMKK2) was upregulated in D-10 CL. Additional cell-signaling genes which were down-regulated in D-10 relative to D4 included a calciumbinding protein P22 (CHP); transcripts encoding tyrosine 3monooxygenase/tryptophan 5monooxygense activation protein, zeta polypeptide (YWHAZ); and a gene called unc-51-like kinase 1 (ULK1).

\section{Validation of microarray by real-time RT-PCR}

Nine genes that were identified differentially expressed by microarray were selected for quantification of mRNA by real-time RT-PCR to validate the microarray results. The pattern of expression observed by real-time RT-PCR was similar to the patterns observed by the 
microarray analysis. The fold changes in expression of genes in D-10 relative to D-4 with each approach are presented side-by-side for comparison in figure 1. All nine genes showed statistically significant differential expression $(\mathrm{P}<0.05)$

Experiment 2: Responsiveness of selected differentially expressed genes to exogenous in vivo $P G F_{2 \alpha}$ treatment

There were developmentally related significant differences in expression of all 6 genes examined. Transcripts for CAMKK2, GNB1, SPARC-like 1 and PKN1 were all increased as the CL transitioned from D-4 to D-10; while transcripts for RGS2 and YWHAZ were decreased in this developmental comparison (figure. 2). Furthermore, expression of CAMKK2 and GNB1 were sensitive to exogenous $\mathrm{PGF}_{2 \alpha}$ in D-10 and D-4 CL samples respectively. Expression of CAMKK2 increased in D-10 CL from $1.16 \pm 0.04$ with saline to $2.0 \pm 0.25$ after treatment with $\mathrm{PGF}_{2 \alpha}(\mathrm{P}<0.05)$ without affecting its expression in D-4 CL. In contrast, the expression of GNB1 was increased $>10$ fold in $\mathrm{PGF}_{2 \alpha}$ treated D-4 CL compared to its saline D4 control (D-4 CL saline, $0.16 \pm 0.05$; D-4 CL with $\mathrm{PGF}_{2 \alpha}, 1.94 \pm 0.43$ ). The expression of GNB1 was not affected by treatment with $\mathrm{PGF}_{2 \alpha}$ in D-10 CL. There was no significant effect of treatment on the expressions of RGS2, SPARCL1, YWHAZ, and PKN1 within the examined developmental stages.

Experiment 3: Semi-quantitative Western Blotting and Immunohistochemistry -based Approaches for Analyzing CaMKK2 Protein Expression in the Bovine CL During Developmental Transition from Day-4 to -10, and Identifying the Luteal Cellular Source of CaMKK2 Protein.

Semi-quantitative Western Blotting. From the three CAMKK2-specific antibodies tested, only the Santa Cruz antibodies SC 50341 and SC 9629 detected a protein band of approximately 66 $\mathrm{kDa}$ (figure 3 and panel A figure 4). However, because the antigenic peptide for SC 50341 is not commercially available, the SC 9629 was selected for further Western blot analysis. The specificity of this $66 \mathrm{kDa}$ protein was demonstrated because its intensity was greatly reduced or abolished by incubating the antibody with its antigenic peptide. The antibody sometimes detected additional faint bands of high molecular weight, but these were not abolished when 
the antibody was pre-incubated with its antigenic peptide (figure 3). The $66 \mathrm{kDa}$ molecular weight band identified corresponds closely to the published size band for this kinase[Tokumitsu $\mathrm{H}$ et al, 1995]. This $66 \mathrm{kDa}$ protein band was detected at all protein concentrations $(5,10,20$, and $40 \mu \mathrm{g}$ ) tested in the samples from all D-10 CL (Panel A figure 4). In contrast, it required $40 \mu \mathrm{g}$ protein isolated from D-4 CL to obtain a comparable expression signal obtained with $5 \mu \mathrm{g}$ of protein isolated from D-10 CL (Panel A, figure 4). As in previous studies from our laboratory, a $43-\mathrm{kDa}$ protein was detected with the antibody for actin. The intensity of this $43-\mathrm{kDa}$ band was similar for each corresponding protein concentration used regardless of luteal development (Panel A, figure 4). The semi-quantitative Western blot analysis using $40 \mu \mathrm{g} /$ lane allowed us to estimate the amount of protein corresponding to CAMKK2 expressed in samples prepared from d-4 and -10 CL (Panel B, figure 4). The mean $\pm \mathrm{SEM}$ for the actin corrected ratio for CAMKK2 in the D-10 CL was 1.0 \pm 0.1 , while for the D-4 CL, it was only $0.57 \pm 0.04 \quad(\mathrm{P}<0.01$ ) (Panel B figure 3). In contrast, $\mathrm{PGF}_{2 \alpha}$ treatment had no effect on CAMKK2 expression in any of the luteal developmental stages examined, D-4 (0.61 \pm .08$)$ and D-10 $(0.93 \pm 0.1$ samples (Panel B, figure 4).

\section{Immunohistochemistry.}

All three CAMKK2-specific antibodies tested in the immunohistochemistry assay were effective in identifying luteal immunoreactive cells in a consistent manner. Cellular localization of CAMKK2 was routinely examined by immunohistochemistry in al least two areas from three corpora lutea ( $\mathrm{n}=3$, d-10 CL) using the SC 9699 antibody. Similar results were obtained with the other two antibodies tested. Representative photographs of cells expressing immunoreactivity are displayed in figure 5 . Repeating the immunohistochemistry procedure on serial sections from each CL on different areas produced similar results to those displayed in figure 5. Specific CAMKK2 immunoreactivity was clearly detected in large and small luteal steroidogenic cells (figure 5, panels B-D). This immunoreactivity was eliminated when the antibody was pre-incubated with the antigenic peptide prior to immunodetection (figure 5, panel A) and the other control described in materials and methods (data not shown). Endothelial cells were not immunoreactive (figure 5, panel D). 
Experiment 4: Role of CAMKK2 in mediating the antisteroidogenic actions of increase in $\left[\mathrm{Ca}^{2+}\right]_{i}$ stimulated by $P G F_{2 \alpha}$.

The values of progesterone were expressed as percent of control because of the variations in its concentrations among animals. Therefore the value of the mean basal progesterone concentration is represented as one. The results are presented in figure 6. Treatment with $\mathrm{PGF}_{2 \alpha}$ significantly $(\mathrm{P}<0.02)$ inhibited the basal accumulation of progesterone $(0.78 \pm 0.1)$. Basal amounts of progesterone accumulation in the media were not affected by STO-609 (0.99 $\pm 0.03)$. The inhibitory effect of $\mathrm{PGF}_{2 \alpha}$ on basal progesterone was prevented $(1.2 \pm 0.06)$ in presence of STO-609. These observations support our hypothesis that CAMKK2 mediate the antisteroidogenic actions of increased intracellular $\mathrm{Ca}^{2+}$ - stimulated by $\mathrm{PGF}_{2 \alpha}$.

\section{Discussion}

The present study identified 167 transcripts that are differentially expressed in the developmental transition when the CL acquires sensitivity to luteolytic actions of $\mathrm{PGF}_{2 \alpha}$. This represents a significant narrowing-down of the list of potential genes involved in modifying the intracellular signaling utilized by $\mathrm{PGF}_{2 \alpha}$ on its target cells, in such a way, that the actions of $\mathrm{PGF}_{2 \alpha}$ on the CL become luteolytic. The gene ontologies of the list of differentially expressed genes in corpora lutea from the early through mid-stage, further narrowed the list by allowing identification of 20 genes that were both differentially expressed and whose function was associated with multiple cell-signaling pathways (Table 2). The results from the second experiment allowed the list of genes whose expression might determine that the actions of $\mathrm{PGF}_{2 \alpha}$ in the CL become luteolytic to be narrowed further. Expression of both CAMKK2 and GNB1 were sensitive to exogenous PGF $_{2 \alpha}$. The combined increase in expression of CAMKK2 due to the developmental transition and the $\mathrm{PGF}_{2 \alpha}$ treatment might play a critical role in increased luteolytic sensitivity to $\mathrm{PGF}_{2 \alpha}$. This increase in CAMKK2 occurred at a developmental stage when $\mathrm{PGF}_{2 \alpha}$ has an increased ability to elicit a rise in $\left[\mathrm{Ca}^{2+}\right] \mathrm{i}$ compared to Day-4 CL [Choudhary E et al, 2005; Sen A et al, 2005]. CAMKK2 has been reported to mediate the action of increasing intracellular $\mathrm{Ca}^{2+}$ via phosphorylation of $\mathrm{Ca}^{2+} /$ calmodulindependent protein kinases (CAMKs) such as calcium/calmodulin-dependent protein kinases I and IV (CAMK1 and CAMK4). Once phosphorylated, the activity of these kinases is increased 
10-20 fold [Haribabu B et al, 1995; Selbert MA et al, 1995]. Furthermore, CAMKs have been shown to activate mitogen-activated protein kinases (MAPKs) such as MAPK1 and MAPK3, formerly known as extracellular signal regulated kinase $1 / 2$ or ERK1/2, in several ligandstimulated pathways [Illario M et al, 2003; Nguyen A et al, 2004; Rosengart MR et al, 2000]. The significance of this possibility is highlighted when considering that CAMK2 has been shown to mediate the actions of $\mathrm{PGF}_{2 \alpha}$ by activating MAPKs in cat iris sphincter smooth muscle [Ansari HR et al, 2001]. Also, MAPKs/ERKs signaling inhibited gonadotropinstimulated steroidogenesis in rat granulosal-derived cell lines [Seger R et al, 2001]. There is significance in the observation that MAPK1 and 3 mediated the $\mathrm{PGF}_{2 \alpha}$-stimulated expression of prostaglandin-endoperoxidase synthase 2 (PTGS2 or COX2) in neoplastic endometrial epithelial cells, which in turn stimulated the synthesis of $\mathrm{PGF}_{2 \alpha}$ in a positive feedback mechanism [Jabbour HN et al, 2005]. Such a positive feedback loop has been suggested to be operational within the CL with luteolytic capacity. MAPKs/ERKs have been involved in the $\mathrm{PGF}_{2 \alpha}$ mediated effects in the bovine and rodent CL. For instance, MAPK/ERKs mediate the $\mathrm{PGF}_{2 \alpha}$-induced apoptosis in the buffalo CL [Yadav VK et al, 2005]; and induction of FOS and JUN mRNA expression by $\mathrm{PGF}_{2 \alpha}$ is mediated by protein kinase C-dependent-MAPK/ERK pathway in bovine luteal cells [Chen D et al, 2001]. Furthermore, a calcium/caldmodulindependent activation of MAPK1 and 3 mediates JUND phosphorylation and induction of nur77 and $20 \alpha$-hsd genes by $\mathrm{PGF}_{2 \alpha}$ in luteinized rat granulosal cells [Stocco CO et al, 2002]. Transcriptional activation of CAMKK2 appears to be regulated by activation of G-protein coupled receptor 54 (GPCR54), acting through Gq/11 family of heterotrimeric G-proteins [Becker JA et al, 2005]. Further, transcription of CAMKK2 was regulated by an increase in intracellular $\mathrm{Ca}^{2+}$ [Okuno $\mathrm{S}$ et al, 1997]. Given that in the bovine CL, $\mathrm{PGF}_{2 \alpha}$ stimulates hydrolysis of phosphatidylinositol 4, 5-biphosphate and mobilizes intracellular $\mathrm{Ca}^{2+}$ [Davis JS et al, 1987b; Wiltbank MC et al, 1991] these mechanisms of transcriptional regulation might be relevant. In support of the importance of CAMKK2 in the acquisition of luteal sensitivity to the luteolytic actions of $\mathrm{PGF}_{2 \alpha}$ is the finding that YWHAZ was down-regulated in D-10 CL. This would be in agreement with the report that the protein encoded by YWHAZ inhibits the action of CAMKK2 [Davare MA et al, 2004], because down-regulation would increase the activity of CAMKK2. Therefore, taken together, the observations in these studies that a greater expression of CAMKK2 associated with the D-4 to D-10 CL transition, and the ability of 
$\mathrm{PGF}_{2 \alpha}$ to further stimulate its expression in the D-10 CL, and its role in mediating the antisteroidogenic actions of $\mathrm{PGF}_{2 \alpha}$ strongly supports the interpretation that CAMKK2 might be involved in acquisition of luteal sensitivity to the luteolytic actions of $\mathrm{PGF}_{2 \alpha}$. This interpretation is strongly supported by the finding that there was a parallel increase in the amount of CAMKK2 associated with the D-4 to D-10 CL transition (figure 3). More importantly, ability of $\mathrm{PGF}_{2 \alpha}$ to inhibit the progesterone synthesis was prevented by CAMKK2 inhibitor (figure 6). Although the in vivo effect of exogenous $\mathrm{PGF}_{2 \alpha}$ increased the mRNA encoding CAMKK2, there was no concomitant increase in the amount of CAMKK2 in D-10 CL. This might be simply due to the fact that it takes longer for the effect of $\mathrm{PGF}_{2 \alpha}$ to be observed at the protein than at the mRNA level. However it is also possible that despite the changes in mRNA, the protein is not stabilized by exogenous $\mathrm{PGF}_{2 \alpha}$. Important to the interpretation that CAMKK2 might be involved in acquisition of luteal sensitivity to the luteolytic actions of $\mathrm{PGF}_{2 \alpha}$ is the observation that both small and large steroidogenic cells are luteal sources of CAMKK2. These cells are then both target for $\mathrm{PGF}_{2 \alpha}$ actions, and also express mRNA and protein encoding calcium/calmodulin dependent kinase kinase 2, beta in a developmental manner that agrees with our suggestion that CAMKK2 might be involved in acquisition of luteal sensitivity to the luteolytic actions of $\mathrm{PGF}_{2 \alpha}$. Identifying the luteal steroidogenic cells as sources of mRNA and protein encoding $\mathrm{Ca}^{2+} /$ calmodulin dependent kinase kinase 2, beta is also important from the point of view of designing functional studies to up- and down-regulate the expression of this gene in order to test its function.

The expression of gene encoding the protein kinase $\mathrm{C}$ inhibitor, YWHAZ, was down-regulated in the D-10 CL and treatment with $\mathrm{PGF}_{2 \alpha}$ did not affect its expression either in D-4 or -10 CL [Robinson K et al, 1994; Toker A et al, 1990]. YWHAZ has been shown to inhibit the activity of PKCs by interacting with a cystein-rich C1 domain [Robinson K et al, 1994; Toker A et al, 1990]. Importantly, PKCs mediate the luteolytic actions of $\mathrm{PGF}_{2 \alpha}$ [Wiltbank MC et al, 1991]. Down-regulation of YWHAZ in the D-10 CL is in agreement with the findings by Juengel et al [Juengel JL et al, 1998] that mRNAs for YWHAZ was greater in D-5 sheep CL compared to D10 and $-15 \mathrm{CL}$ and that $\mathrm{PGF}_{2 \alpha}$ did not affect its expression. Based on these observations, they suggested that YWHAZ might be involved in the luteolytic resistance in the early ovine CL [Juengel JL et al, 1998]. Similarly, lowered expression of YWHAZ during latter stages of the bovine CL development might increase luteal sensitivity to $\mathrm{PGF}_{2 \alpha}$. At the same time, their data 
provides an independent validation of the data obtained in experiments 1 and 2 of the current study. Lower expression of GNB1 in the D-4 CL might explain, at least in part, the mechanism responsible for luteal insensitivity to $\mathrm{PGF}_{2 \alpha}$ in the early CL. The luteal FP receptors are coupled to heterotrimeric G proteins [Miwa M et al, 1990; Olofsson JI and Leung PC, 1996]. Activation of the linked $G$ protein leads to dissociation of $G \alpha$ and $G \beta \gamma$ subunits from the heterotrimeric complex [Davis JS et al, 1987b; Gilman AG, 1987; Simon MI et al, 1991; Wiltbank MC et al, 1991]. Both $\mathrm{G} \alpha$ and $\mathrm{G} \beta \gamma$ subunits activate downstream signal transduction mechanisms. It is conceivable that lower expression of GNB1 in the early CL could restrict, in part, full intracellular signaling by FP receptors. Indeed, reduced amounts of GNB1 in D-4 CL might explain the reduced ability of $\mathrm{PGF}_{2 \alpha}$ to stimulate a rise in [Ca $\left.{ }^{2+}\right] \mathrm{i}$ in D-4 CL [Sen A et al, 2005]. In rabbit $\mathrm{CL}, \mathrm{PLC}$ activators had luteolytic effects similar to that induced by $\mathrm{PGF}_{2 \alpha}$, not only on D-9 and D-13 CL, but also in D-4 CL, in which PGF $_{2 \alpha}$ was completely ineffective [Boiti C et al, 2001]. Boiti et al [Boiti C et al, 2001] suggested that the resistance of early CL might be due to impairment in G-proteins coupled to $\mathrm{PGF}_{2 \alpha}$ receptor. Interestingly, exogenous $\mathrm{PGF}_{2 \alpha}$ increased the expression of GNB1 in D-4 CL but not in D-10 CL. The magnitude of the increase in GNB1 expression in D-4 CL after exogenous PGF $_{2 \alpha}$ was similar to that seen in D-10 CL; perhaps indicating that expression of this gene was already maximally stimulated during the developmental transition from D-4 to D-10. It has been reported that repeated injections of $\mathrm{PGF}_{2 \alpha}$ could regress the bovine CL during its early stage [Sayre BL et al, 2000]; thus increased expression of GNB1 after $\mathrm{PGF}_{2 \alpha}$ injection might be one mechanism that makes the early $\mathrm{CL}$ acquire luteolytic sensitivity to $\mathrm{PGF}_{2 \alpha}$. An additional argument in favor of the significance of differential expression of GNB1 in the mechanism of luteolytic sensitivity to $\mathrm{PGF}_{2 \alpha}$ is the report that G $\beta 1 \gamma 1$ interacts with RACK1, a scaffold protein that interacts selectively with a specific PKC isozyme, PKC $\beta 11$ [Dell EJ et al, 2002; Stebbins EG and Mochly-Rosen D, 2001]. Each specific PKC isozymes has been shown to interact with a specific type of RACK protein. The protein kinase $\mathrm{C}$ specific isozymes, PRKCB and PRKCE, were differentially up-regulated in D$10 \mathrm{CL}$, and were activated following treatment with $\mathrm{PGF}_{2 \alpha}$ [Sen A et al, 2004]. Therefore, greater amounts of GNB1 in D-10 CL might help to localize the RACK1 to the membrane, followed by recruitment of activated PRKCB to the membrane and initiation of signal transduction. This mechanism might participate in acquisition of luteolytic sensitivity to $\mathrm{PGF}_{2 \alpha}$. The developmental down-regulation of RGS2 as the CL transitioned from D-4 to D-10 could 
participate in the mechanism of greater luteolytic sensitivity of the bovine CL. RGS proteins attenuate the signaling initiated by G proteins by two mechanisms, one by acting as GTPaseactivating proteins (GAPs) [Berman DM et al, 1996; Hepler JR et al, 1997], and also by inhibiting G-protein/effector interaction [Heximer SP et al, 1997]. Studies using in vivo and in vitro methods have demonstrated that RGS2 was a potent inhibitor for Gaq signaling [Heximer SP et al, 1999; Ingi T et al, 1998]. The Gq has been shown to activate phospholipace C, beta 1 (PLCB1) leading to downstream signaling such as increases in intracellular calcium and activation of protein kinase C [Berridge MJ and Irvine RF, 1984]. Interestingly, FP receptors are coupled to $\mathrm{Gq}$ family of $\mathrm{G}$ proteins and activate its downstream signaling pathway, such as increase in intracellular $\mathrm{Ca}^{2+}$ and activation of protein kinase $\mathrm{C}$ [Abramovitz $\mathrm{M}$ et al, 1994; Graves PE et al, 1995; Pierce KL et al, 1999; Watanabe T et al, 1994]. In this regard, the activity of RGS2 was inhibited by protein kinase $\mathrm{C}$ in a phosphorylation-dependent manner, thereby potentiating the G-protein stimulated signaling pathway [Cunningham ML et al, 2001]. Therefore decreased expression of RGS2 in D-10 CL might potentiate G-protein signaling, thereby increasing sensitivity of the $\mathrm{CL}$ to $\mathrm{PGF}_{2 \alpha}$-induced luteolysis. However, exogenous $\mathrm{PGF}_{2 \alpha}$ did not affect the expression of RGS2 either in D-4 or D-10 CL indicating a PGF $2 \alpha$ independent mechanism of transcriptional regulation for this gene during this developmental transition. The developmental down-regulation of adrenergic, alpha-1B, receptors during the luteal transition from D-4 to D-10 could be an additional mechanism contributing to the lower sensitivity to $\mathrm{PGF}_{2 \alpha}$. In vitro studies utilizing bovine luteal cells have indicated that noradrenaline (NA) stimulated progesterone secretion and reduced the ability of $\mathrm{PGF}_{2 \alpha}$ to increase the $\left[\mathrm{Ca}^{2+}\right] \mathrm{i}$ [Skarzynski DJ et al, 2000]. A reduction in the expression of adrenergic receptors would abolish luteo-protective effects of NA, and consequently, would increase the sensitivity of the $\mathrm{CL}$ to the luteolytic actions of $\mathrm{PGF}_{2 \alpha}$. In summary, these studies have effectively identified CAMKK2, the protein kinase C inhibitor, YWHAZ, GNB1, and RGS2 as important genes that might play important roles in the acquisition of luteal sensitivity to $\mathrm{PGF}_{2 \alpha^{-}}$ induced regression. Manipulating the expression of these genes might prove to be effective strategies for developing more effective estrous synchronization practices in mammals, thereby overcoming the limitation of insensitiveness of early CL to luteolytic actions of $\mathrm{PGF}_{2 \alpha}$. However many other genes, which were differentially expressed in this study might be of relevance in many aspects of luteal physiology, and needs further investigation. Finally, it 
should be stressed that the above discussion is based on reported actions of these genes in other systems, and therefore, is speculative in nature.

TABLE 1. List of primers and their sequences

\begin{tabular}{llll}
\hline \multicolumn{1}{c}{ Gene } & \multicolumn{1}{c}{ Forward primer } & \multicolumn{1}{c}{ Reverse primer } & \multicolumn{1}{c}{ Accession No } \\
\hline \hline$C A M K K 2$ & TGGAGACGAGTATTGCGACA & CGCCCAACGTAGTCAAACTT & XM587244 \\
$Y W H A Z$ & AACGAAGACCGAAACCTCCT & GGTAGGCCTTCACCTTCTCC & NM1744492 \\
$B X L B v 68$ & CGGAGGCTGTGCAGTATTATG & GCACACGATGTAGCGAATGA & XM872283 \\
$P T P R R$ & GAGAGGCGAGGGTCCAAC & AGCTGCGACCTTGTGAGAAT & NM001015662 \\
$C L 1$ & ACCTCCTGGGTGATGCAGAT & ATGAAGGCGACAGCTCCA & NM205779 \\
$R G S 2$ & CGAGGAGAAGCGAGAGAAGA & CCTCAGGAGAAGGCTTGATG & NM001075596 \\
$I N P P 1$ & ACCACGTTCAAGTGGGACTC & TTTCCCACGTGATACACCAG & NM174364 \\
$A U R K B$ & AGCGAACAGCCACGATCA & ACCAGCCGAAGTCAGCAAT & NM183084 \\
$G N B 1$ & GACAGGGCAGGGGTCTTG & GTCACTGTGGCGTCCACCT & NM175777 \\
$S P A R C L 1$ & GACCAAGTTTGTGGCACTGA & GAAGTCCGTACAAGCAGGAA & NM001034302 \\
$P K N 1$ & ACTTTGGGAAGGTGCTGCT & ATTGGTCACAGCTGCCAAG & XM585967 \\
$G A P D H$ & AATATCATCCCTGCTTCTACTGG & CATACTTGGCAGGTTTCTCCA & NM001034034
\end{tabular}

TABLE 2. Classification of differentially expressed genes according to their functions

\begin{tabular}{lccc}
\hline \multicolumn{1}{c}{ Gene category } & Upregulated & Downregulated & Percentage \\
\hline \hline Steroidogensis and metabolism & 14 & 3 & 10.2 \\
Transcription regulation and DNA & 25 & 6 & 18.5 \\
biosynthesis & 29 & 2 & 18.5 \\
Protein biosynthesis and modification & 5 & - & 3 \\
Antioxidant property & 12 & 4 & 9.5 \\
Extracellular matrix and cytoskeletal & 14 & 6 & 12 \\
proteins & 9 & 0 & 5.3 \\
Hormonal cell signaling & 14 & 14 & 17 \\
Protein degradation & 6 & 4 & 6 \\
Miscellaneous & & & 6 \\
Unknown functions & & & \\
\hline
\end{tabular}

Percentage $=$ percentage of total differentially expressed genes and includes both up and downregulated genes in the particular gene category 
TABLE 3: Genes classified under hormonal cell signaling

\begin{tabular}{|c|c|c|c|}
\hline Genes & Accession No. & $\mathbf{M}$ & $\mathbf{P}$ \\
\hline Casein kinase 2, alpha prime polypeptide (CSNK2A2) & CK769872 & 1.69 & 0.03 \\
\hline Inositol polyphosphate-1-phosphatase (INPP1) & CK773631 & 1.43 & 0.01 \\
\hline Protein inhibitor of activated STAT, 3 (PIAS3) & CK847890 & 1.37 & 0.04 \\
\hline $\begin{array}{l}\text { Guanine nucleotide-binding protein (G protein), beta } \\
\text { polypeptide } 1(G N B 1)\end{array}$ & CK775516 & 1.34 & 0.05 \\
\hline Regulator of Calcineurin $2(R C A N 2)$ & CK846982 & 1.32 & 0.01 \\
\hline Protein tyrosine phosphatase, receptor type, $\mathrm{R}(P T P R R)$ & CK773728 & 1.26 & 0.01 \\
\hline $\begin{array}{l}\text { Calcium/calmodulin-dependent protein kinase kinase } 2 \text {, } \\
\text { beta }(C A M K K 2)\end{array}$ & CK777876 & 1.22 & 0.01 \\
\hline Protein kinase $\mathrm{N} 1$ isoform $1(P K N 1)$ & CK777128 & 1.3 & 0.04 \\
\hline SLIT-ROBO Rho GTPase activating protein 1 (SRGAPl) & CK849538 & 1.12 & 0.04 \\
\hline Formin binding protein 4 (FNBP4) & CK775025 & 1.04 & 0.01 \\
\hline Adenosine $\mathrm{A} 1$ receptor $(A D O R A 1)$ & CK774279 & 1.12 & 0.01 \\
\hline ADP-ribosylation factor $6(A R F 6)$ & CK771198 & 1.09 & 0.04 \\
\hline Unc-51-like kinase 1 (ULK1) & CK778217 & 1.07 & 0.01 \\
\hline Rho GTPase activating protein 8 isoform 1 ( $A R H G A P 8$ ) & CK847626 & 1.26 & 0.03 \\
\hline NOTCH homolog 2 preproprotein (NOTCH2) & CK848127 & 1.05 & 0.02 \\
\hline Adrenergic, alpha-1B-, receptor $(A D R A 1 B)$ & CK771135 & -1.54 & 0.01 \\
\hline $\begin{array}{l}\text { Tyrosine 3-monooxygenase/tryptophan 5-monooxygenase } \\
\text { activation protein, zeta polypeptide (YWHAZ) }\end{array}$ & CK849522 & -1.06 & 0.01 \\
\hline Calcium binding protein $\mathrm{P} 22(\mathrm{CHP})$ & CK849565 & -1.00 & 0.01 \\
\hline Regulator of G-protein signaling 2, $24 \mathrm{kDa}(R G S 2)$ & CK948092 & -1.06 & 0.01 \\
\hline G-protein coupled receptor $98(G R P 98)$ & CK774105 & -1.03 & 0.01 \\
\hline
\end{tabular}

$1 \mathrm{M}=2$ fold change 
TABLE 4. Steroidogenesis and Metabolism

\begin{tabular}{|l|c|c|c|}
\hline \hline \multicolumn{1}{|c}{ Name of the gene } & Accession No. & \multicolumn{2}{c|}{ M P } \\
\hline Aldehyde dehydrogenase 1 & CK849144 & 1.69 & 0.03 \\
NADH-cytochrome b5 reductase & CK849313 & 1.48 & 0.01 \\
Ubiquinol-cytochrome c reductase complex 7.2kDa & CK777947 & 1.30 & 0.02 \\
protein isoform a & & \\
Proline dehydrogenase (oxidase) 1 & CK770371 & 1.35 & 0.01 \\
Ornithine decarboxylase-like protein & CK776792 & 1.24 & 0.03 \\
Pyruvate kinase, liver and RBC (PKLR) & CK778286 & 1.15 & 0.02 \\
ATP citrate lyase (ACLY) & CK956511 & 1.12 & 0.01 \\
Tricarboxylate transport protein (CTP) & CK773874 & 1.95 & 0.01 \\
Glycine dehydrogenase & CK770834 & -1.50 & 0.02 \\
Glutamine-fructose-6-phosphate transaminase & CK776508 & -1.15 & 0.02 \\
Dolichyl-phosphate beta-glucosyltransferase & CK775119 & -1.01 & 0.03 \\
Apolipoprotein A1 (APOA1) & CK943048 & 1.79 & 0.01 \\
Fatty acid binding protein (heart) & CK848552 & 2.30 & 0.01 \\
Alpha-2-macroglobulin receptor-associated protein & CK770545 & 1.71 & 0.01 \\
precursor & & & \\
Mevalonate (diphospho) decarboxylase & CK778011 & 1.42 & 0.01 \\
Homolog of yeast long chain polyunsaturated & CK943782 & 1.25 & 0.01 \\
fatty acid elongation & CK778352 & 1.24 & 0.01 \\
Lipid phosphate phosphatase-related protein type 2 & & & \\
\hline \hline
\end{tabular}


TABLE 5. RNA processing, transcription regulation and DNA synthesis

\begin{tabular}{|c|c|c|c|}
\hline Name of the gene & Accession No. & $\overline{\mathbf{M}}$ & $\mathbf{P}$ \\
\hline Activating transcription factor 4 & CK949341 & 2.02 & 0.02 \\
\hline Zinc finger protein 652 isoform 2 & CK770292 & 1.83 & 0.01 \\
\hline Zinc finger protein 287 ((Zinc finger protein SKAT-2) & CK771322 & 1.88 & 0.01 \\
\hline Homeodomain interacting protein kinase 4 & CK775259 & 1.46 & 0.01 \\
\hline LIM homeobox 9 & CK772768 & 1.45 & 0.01 \\
\hline CDC-like kinase 1 & CK848317 & 1.38 & 0.01 \\
\hline RNA-binding protein $\mathrm{S} 1$ & CK773442 & 1.63 & 0.01 \\
\hline Ring finger protein 5 isoform 1 & CK774044 & 1.24 & 0.05 \\
\hline Williams Beuren syndrome chromosome region 22 & CK774061 & 1.47 & 0.01 \\
\hline Ring finger protein 38 (RNF38) & CK778301 & 1.18 & 0.02 \\
\hline Paired box protein Pax- 8 & CK774334 & 1.18 & 0.01 \\
\hline Suppressor of Ty 6 homolog & CK954466 & 1.23 & 0.01 \\
\hline Zinc finger protein $197(\mathrm{ZnF} 20)$ & CK776693 & 1.13 & 0.01 \\
\hline PHD finger protein 10 & CK847333 & 1.17 & 0.01 \\
\hline $\mathrm{R} 3 \mathrm{H}$ domain containing 1 & CK775332 & 1.13 & 0.03 \\
\hline E2F family member 8 & CK774280 & 1.03 & 0.01 \\
\hline $\begin{array}{l}\text { DNA-directed RNA polymerase III } 47 \mathrm{kDa} \text { polypeptide } \\
((\mathrm{RPC} 4))\end{array}$ & CK772296 & 1.05 & 0.01 \\
\hline U5 snRNP specific & CK769585 & -1.29 & 0.01 \\
\hline Pirin & CK776403 & -1.16 & 0.01 \\
\hline Nuclear receptor subfamily 1 , group $\mathrm{H}$, member 2 & CK773128 & 1.02 & 0.02 \\
\hline Steroid receptor (TR2-11) & CK769911 & -1.27 & 0.01 \\
\hline G16 (HsRma1) (Ring finger protein 5) & CK775904 & 1.01 & 0.01 \\
\hline TAR DNA-binding protein-43 (TDP-43) & CK849045 & -1.29 & 0.02 \\
\hline $\begin{array}{l}\text { Early B-cell factor associated zinc finger transcription } \\
\text { factor }\end{array}$ & CK847452 & -1.05 & 0.02 \\
\hline Estrogen receptor-related protein & CK846360 & 1.03 & 0.03 \\
\hline RNA binding motif protein 19 & CK846624 & 1.02 & 0.03 \\
\hline GIY-YIG domain containing 2 & CK778699 & 1.50 & 0.05 \\
\hline Polymerase (DNA directed), alpha 2 (70kD subunit) & CK774876 & 1.39 & 0.01 \\
\hline DNA polymerase delta subunit 3 & CK773351 & 1.28 & 0.02 \\
\hline Tyrosyl-DNA phosphodiesterase 1 & CK775329 & -1.03 & 0.01 \\
\hline C-terminal binding protein 2 (CTBP2) & CK771864 & 2.10 & 0.04 \\
\hline
\end{tabular}


TABLE 6. Protein biosynthesis and modification

\begin{tabular}{|c|c|c|c|}
\hline Name of the gene & Accession No. & $\overline{\mathbf{M}}$ & $\overline{\mathbf{P}}$ \\
\hline Eukaryotic translation initiation factor $4 \mathrm{~A}$, isoform 2 & CK846258 & 1.31 & 0.01 \\
\hline $\begin{array}{l}\text { Activator of } 90 \mathrm{kDa} \text { heat shock protein ATPase homolog } 1 \\
\text { (AHA1) }\end{array}$ & CK776415 & 1.24 & 0.01 \\
\hline Disulfide isomerase & CK776692 & 1.17 & 0.02 \\
\hline Eukaryotic translation initiation factor 3 & CK849347 & 1.14 & 0.01 \\
\hline Elongation factor 1-gamma (EF-1-gamma) & CK773855 & 1.15 & 0.01 \\
\hline Elongation factor for selenoprotein translation & CK772036 & 1.42 & 0.03 \\
\hline 60 ribosomal protein $\mathrm{L} 17$ & CK771192 & 1.23 & 0.02 \\
\hline $40 \mathrm{~S}$ ribosomal protein $\mathrm{S} 27$ & CK771367 & 1.23 & 0.05 \\
\hline $40 \mathrm{~S}$ ribosomal protein $\mathrm{S} 10$ & CK772050 & 1.39 & 0.01 \\
\hline 40S ribosomal protein $\mathrm{S} 9$ & CK772107 & 1.66 & 0.01 \\
\hline $60 \mathrm{~S}$ ribosomal protein $\mathrm{L} 31$ & CK773025 & 1.98 & 0.01 \\
\hline $40 \mathrm{~S}$ ribosomal protein S15 & CK774452 & 1.23 & 0.02 \\
\hline 40 S ribosomal protein $S 25$ & CK775730 & 1.02 & 0.02 \\
\hline Ribosomal protein L27 & CK776228 & 1.28 & 0.01 \\
\hline $60 \mathrm{~S}$ acidic ribosomal protein $\mathrm{P} 2$ & CK776925 & 1.35 & 0.01 \\
\hline 40 S ribosomal protein $\mathrm{S} 29$ & CK846156 & 1.04 & 0.01 \\
\hline 40 S ribosomal protein $\mathrm{S} 24$ & CK847945 & 2.03 & 0.02 \\
\hline 60 S ribosomal protein $\mathrm{L} 26$ & CK848441 & 1.32 & 0.01 \\
\hline 60 S ribosomal protein $\mathrm{L} 12$ & CK848743 & 1.27 & 0.01 \\
\hline Ribosomal protein, large, P0 (RPLP0) & CK849066 & 1.14 & 0.01 \\
\hline $60 \mathrm{~S}$ ribosomal protein $\mathrm{L} 7 \mathrm{a}$ & CK849145 & 1.69 & 0.01 \\
\hline $60 \mathrm{~S}$ ribosomal protein L9 & CK849400 & 1.14 & 0.01 \\
\hline 40S ribosomal protein $\mathrm{S} 7$ & CK849595 & 1.17 & 0.02 \\
\hline $60 \mathrm{~S}$ ribosomal protein L13 & CK849627 & 1.92 & 0.01 \\
\hline 40S ribosomal protein S5 & CK849697 & 1.60 & 0.01 \\
\hline $40 \mathrm{~S}$ ribosomal protein $\mathrm{S} 11$ & CK945135 & 1.71 & 0.01 \\
\hline 60 S ribosomal protein L13 & CK946216 & 1.33 & 0.01 \\
\hline 40 S ribosomal protein $\mathrm{S} 29$ & CK949225 & 1.28 & 0.01 \\
\hline $40 \mathrm{~S}$ ribosomal protein $\mathrm{S} 15 \mathrm{a}$ & CK953239 & 1.14 & 0.01 \\
\hline Heat shock 70kDa protein 5 (grp78) & CK848695 & -1.4 & 0.02 \\
\hline $\begin{array}{l}\text { Translation initiation factor IF-2, mitochondrial precursor } \\
\text { (IF-2Mt) }\end{array}$ & CK769193 & -1.07 & 0.02 \\
\hline
\end{tabular}


TABLE 7. Antioxidant property

\begin{tabular}{|l|c|c|c|}
\hline \hline \multicolumn{1}{|c}{ Name of the gene } & Accession No. & \multicolumn{2}{l|}{ M } \\
\hline Selenoprotein P-like protein precursor & CK7777177 & 2.05 & 0.05 \\
Peroxiredoxin 5 & CK773035 & 1.86 & 0.02 \\
Glutathione S-transferase A2 & CK774267 & 1.67 & 0.01 \\
Glutathione S-transferase A1 & CK7778456 & 1.57 & 0.01 \\
Glutathione peroxidase 3 & CK770347 & 1.49 & 0.01 \\
\hline \hline
\end{tabular}

TABLE 8. Extracellular matrix and cytoskeletal proteins

\begin{tabular}{|l|c|c|c|}
\hline \hline \multicolumn{1}{|c}{ Name of the gene } & Accession No. & \multicolumn{2}{l|}{ M } \\
\hline SPARC-like 1 & CK849369 & 1.77 & 0.01 \\
Chondroitin sulfate glucuronyltransferase & CK775983 & 1.58 & 0.02 \\
Proteoglycan 1 precursor-like & CK769587 & 1.47 & 0.02 \\
Serine protease inhibitor, Kunitz type, 2 & CK849325 & 1.33 & 0.01 \\
Plakophilin 1- cell to cell adhesion molecule & CK774824 & 1.31 & 0.01 \\
Metalloproteinase inhibitor 4 precursor (TIMP-4) & CK849811 & 1.23 & 0.01 \\
Putative hyaluronan receptor for endocytosis & CK778012 & 1.16 & 0.02 \\
Collagen, type XXII, alpha 1 & CK847130 & 1.29 & 0.01 \\
Serine/threonine-protein kinase MARK1 & CK771345 & 1.05 & 0.01 \\
Keratin 7 & CK848899 & 1.23 & 0.03 \\
Dynactin-1 (150 kDa dynein-associated polypeptide) & CK774327 & 1.11 & 0.05 \\
Actin-related protein 6 (hArp6) & CK776995 & -1.09 & 0.02 \\
Keratin 8 & CK778284 & -1.29 & 0.03 \\
Type V preprocollagen alpha 2 chain & CK849288 & -1.14 & 0.02 \\
Plakophilin 2 & CK776740 & -1.65 & 0.02 \\
Myosin regulatory light polypeptide 9 & CK848506 & 1.26 & 0.02 \\
\hline \hline
\end{tabular}


TABLE 9. Miscellaneous

\begin{tabular}{|c|c|c|c|}
\hline Name of the gene & Accession No. & $\overline{\mathbf{M}}$ & \\
\hline Solute carrier family 39 (zinc transporter), member 4 & CK776598 & 1.20 & 0.03 \\
\hline Lutheran blood group & CK772614 & 1.38 & 0.02 \\
\hline SPATA2 & CK773652 & 1.68 & 0.01 \\
\hline Prostate stromal protein ps 20 & CK777307 & 1.23 & 0.01 \\
\hline SYAP1 & CK769966 & 1.12 & 0.01 \\
\hline $\begin{array}{l}\text { Potassium voltage-gated channel KQT-like protein } 2 \\
\text { isoform c }\end{array}$ & CK772601 & 1.10 & 0.01 \\
\hline Secretion regulating guanine nucleotide exchange factor & CK846026 & 1.04 & 0.01 \\
\hline Solute carrier family 35 , member $\mathrm{C} 2$ & CK777438 & 1.06 & 0.03 \\
\hline Survival motor neuron protein & CK774453 & 1.10 & 0.01 \\
\hline Dendritic cell protein GA17 & CK848907 & 1.03 & 0.05 \\
\hline Ferritin H subunit & CK848958 & 1.04 & 0.01 \\
\hline ERIC1 & CK940341 & 1.38 & 0.05 \\
\hline Transmembrane protein 176A (TMEM176) & CK770329 & -1.37 & 0.01 \\
\hline Macrophage C-type lectin Mincle & CK770579 & -1.19 & 0.02 \\
\hline Aurora kinase B (AURKB) & CK771597 & -1.10 & 0.02 \\
\hline Potassium voltage-gated channel subfamily $\mathrm{H}$ member 2 & CK773510 & -1.71 & 0.01 \\
\hline Fat cell-specific low molecular weight protein & CK774965 & -1.71 & 0.04 \\
\hline Sialin & CK845898 & -1.30 & 0.02 \\
\hline PKC-interacting cousin of thioredoxin (thioredoxin-like) & CK848430 & -1.05 & 0.01 \\
\hline Sprouty-like protein & CK849801 & -1.13 & 0.02 \\
\hline Chromosome 10 open reading frame 119 & CK848711 & -2.50 & 0.01 \\
\hline Synleurin & TC313344 & -1.04 & 0.01 \\
\hline $\mathrm{ABC}$ transporter ATP-binding protein & CK845991 & -1.19 & 0.02 \\
\hline Chloride channel 2 & TC351877 & -1.00 & 0.05 \\
\hline $\begin{array}{l}\text { Nuclear casein kinase and cyclin-dependent kinase } \\
\text { substrate } 1 \text { (Nucks1) }\end{array}$ & CK770111 & -1.04 & 0.04 \\
\hline Solute carrier family 35 , member F2 & CK770565 & -1.09 & 0.05 \\
\hline Phosphoglycerate mutase family member 5 (PGAM5) & CK847884 & 1.14 & 0.03 \\
\hline Tumor protein, translationally-controlled 1 (TPT1), P23 & CK774391 & 1.16 & 0.01 \\
\hline
\end{tabular}


TABLE 10. Protein degradation

\begin{tabular}{|l|c|c|c|}
\hline \hline \multicolumn{1}{|c}{ Name of the gene } & Accession No. & \multicolumn{2}{l|}{ M } \\
\hline Cathepsin K preproprotein (CTSK) & CK849357 & 1.29 & 0.01 \\
F-box protein 36 & CK944568 & 1.37 & 0.03 \\
Napsin A preproprotein & CK770924 & 1.24 & 0.05 \\
Pleckstrin homology-like domain family A member 1 & CK773551 & 1.24 & 0.03 \\
Apoptosis-associated speck-like protein containing a & CK954618 & 1.21 & 0.03 \\
CARD (ASC) & & 1.22 & 0.02 \\
AFG3-like protein 1 & CK776738 & 1.16 & 0.04 \\
Granzyme M precursor & CK774851 & 1.15 & 0.02 \\
UV excision repair protein RAD23 homolog A & CK776179 & 1.02 & 0.05 \\
Matrix metallopeptidase 23 (MMP-23) & CK846714 \\
\hline \hline
\end{tabular}

TABLE 11. Unknown functions

\begin{tabular}{|l|l|l|l|l|l|}
\hline \hline \multicolumn{2}{|c}{ Accession No. } & \multicolumn{1}{c}{ M } & \multicolumn{2}{c|}{ Accession No. } & M \\
\hline CK777911 & 1.70 & 0.01 & CK846545 & 1.08 & 0.01 \\
CK773556 & 1.63 & 0.05 & CK770138 & 1.16 & 0.04 \\
CK773395 & 1.61 & 0.02 & CK773493 & 1.02 & 0.03 \\
CK773691 & 1.30 & 0.02 & CK774123 & 1.49 & 0.01 \\
CK778328 & 1.34 & 0.03 & CK775464 & 1.01 & 0.03 \\
CK777602 & 1.33 & 0.01 & CK846118 & 1.00 & 0.01 \\
CK848506 & 1.26 & 0.02 & CK770657 & -1.02 & 0.05 \\
CK845982 & 1.26 & 0.04 & CK772076 & -1.28 & 0.01 \\
CK774613 & 1.15 & 0.03 & CK775423 & -1.33 & 0.01 \\
CK769920 & 1.10 & 0.02 & CK773288 & -1.01 & 0.01 \\
\hline \hline
\end{tabular}




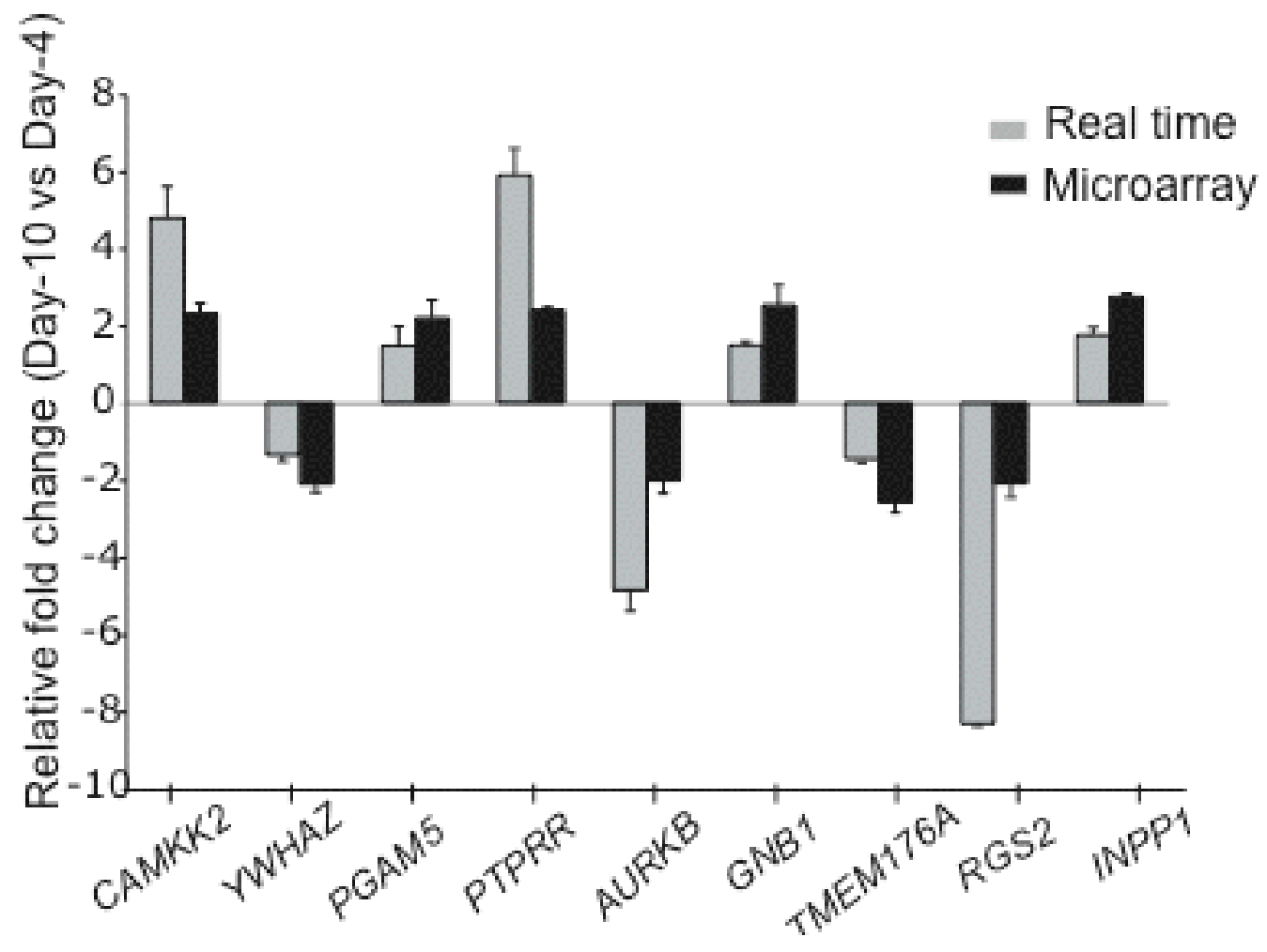

Figure 1. Real-time RT-PCR confirmation of 9 differentially expressed genes in Day-10 CL compared to Day-4 CL that were identified by microarray analysis, $\mathrm{P}<0.05$. CAMKK2: calcium/calmodulin dependent kinase kinase 2, beta; YWHA: tyrosine 3monooxygenase/tryptophan 5-monooxygenase activation protein, zeta polypeptide; PGAM5: phosphoglycerate mutase family member 5; PTPRR: protein tyrosine phosphatase, receptor type, R; AURKB: aurora kinase B; GNB1: guanine nucleotide binding protein (G protein), beta polypeptide 1; TMEM176A: transmembrane protein 176A; RGS2: regulator of G protein signaling 2, 24kDa; INPP1: inositol polyphosphate-1 phosphatase. The data is shown as mean \pm SEM, values with differing letters denoting statistically significant differences $(\mathrm{P}<0.05)$. 


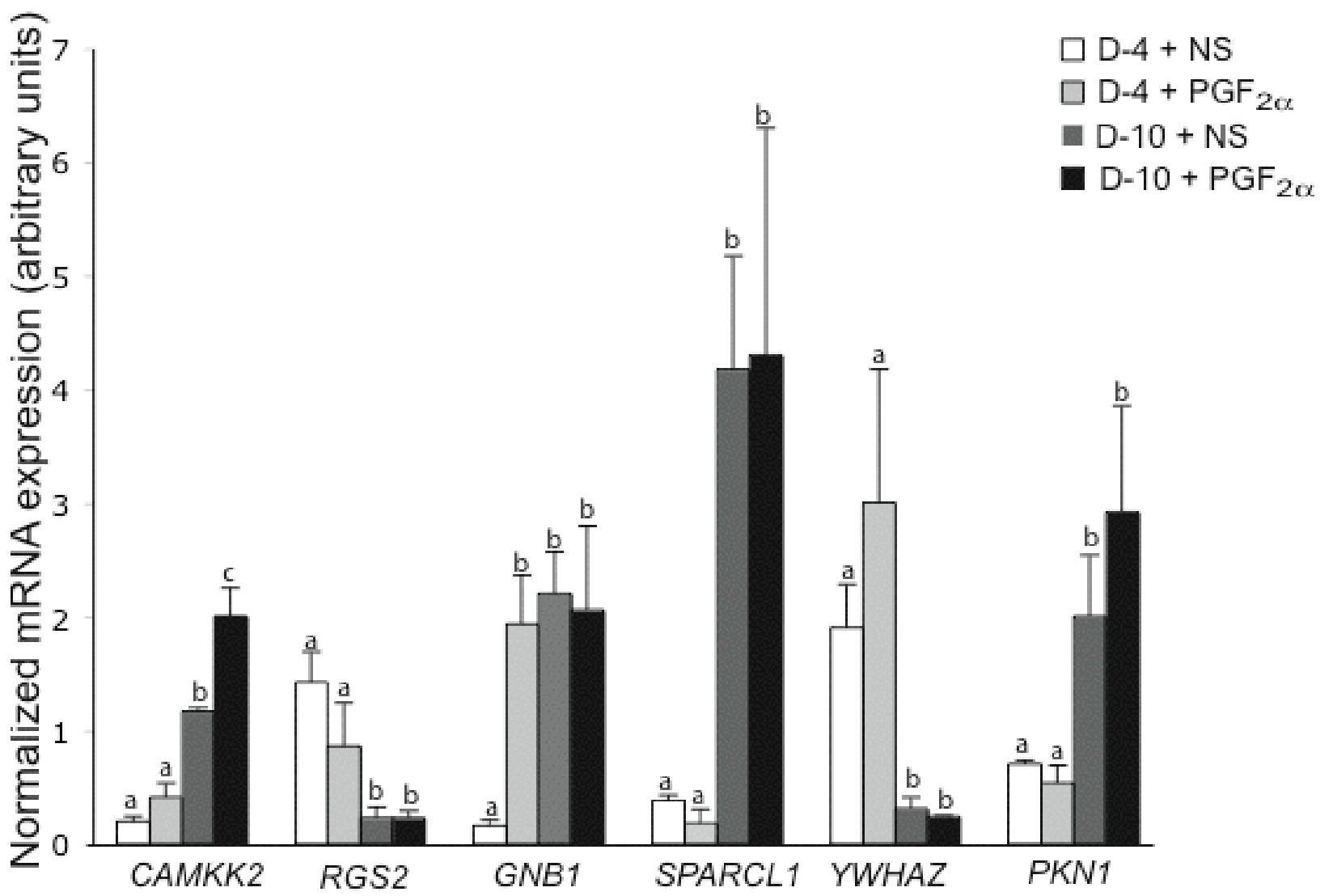

Figure 2. Real-time RT-PCR analysis of the effect of exogenous PGF2 $\alpha$ on expression of selected genes that are identified by microarray to be differentially expressed in Day-10 CL compared to Day-CL, $\mathrm{P}<0.05$. NS represents normal saline. CAMKK2: calcium/calmodulin dependent kinase kinase 2, beta; YWHAZ: tyrosine 3-monooxygenase/tryptophan 5monooxygenase activation protein, zeta polypeptide; RGS2: regulator of G protein signaling 2, 24kDa; GNB1: guanine nucleotide binding protein (G protein), beta polypeptide 1; SPARCL1: SPARC-like 1; PKN1: protein kinase N1. The data is shown as mean $\pm \mathrm{SEM}$, values with differing letters denoting statistically significant differences $(\mathrm{P}<0.05)$. 


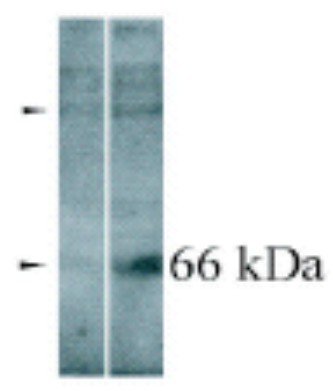

Figure 3. Specificity of the $66 \mathrm{kDa}$ protein band detected by the SC 9629 antibody. In this representative Western blot, $30 \mu \mathrm{g}$ sample proteins isolated from a day10 corpus luteum was run in each lane. The right lane is a representative Western blot demonstrating that the CaMKK2 antibody detected a protein band of approximately $66 \mathrm{kDa}$ (right panel). The left lane correspond with the experimental conditions where the primary antibody was preincubated with an excess amount of antigenic peptide prior to its use in the Western blot. 
A.

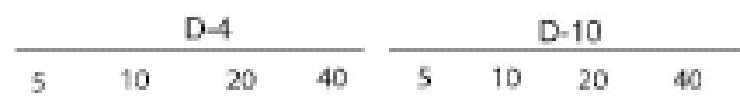

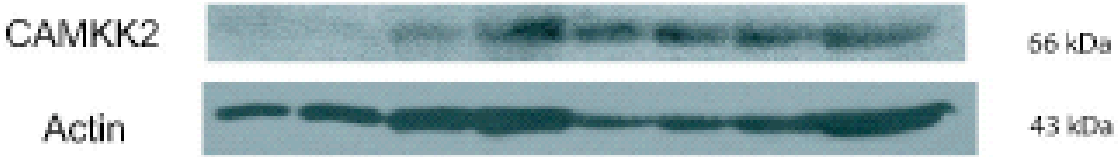

B.

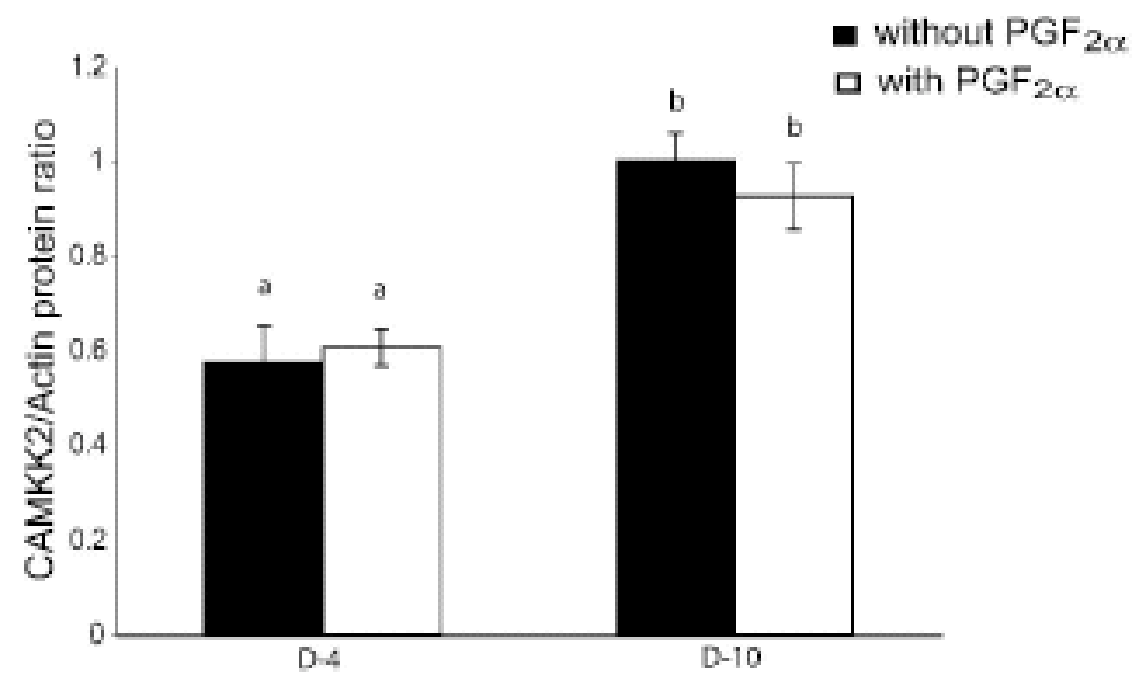

Figure 4. Representative Western blot analysis of the calcium/calmodulin dependent kinase kinase 2, beta (CAMKK2) expressed in the bovine CL and semi-quantitative analysis of the densitometry derived from Western blots using protein samples isolated from d-4 and d-10 bovine corpora lutea. Panel A compares the total sample protein needed to detect CaMKK2 in protein samples isolated from day 4 and 10 corpora lutea. For each developmental stage, 5, 10, 20, and $40 \mu \mathrm{g} /$ lane sample protein were used. This representative Western blot demonstrates the amount of CaMKK2 and actin expressed in each protein samples collected at d-4 (lanes 14) and d-10 (lanes 5-8) of the estrous cycle. The CaMKK2 antibody detected a protein band of approximately $66 \mathrm{kDa}$, whereas the actin antibody detected a protein band of about $43 \mathrm{kDa}$. In panel $\mathrm{B}$, the $\mathrm{y}$-axis shows the ratio of the optical density (o.d) for CaMKK2 corrected by the detected o. d. for its corresponding actin. The data is shown as mean \pm SEM, values with differing letters denoting statistically significant differences $(\mathrm{P}<0.001)$. 

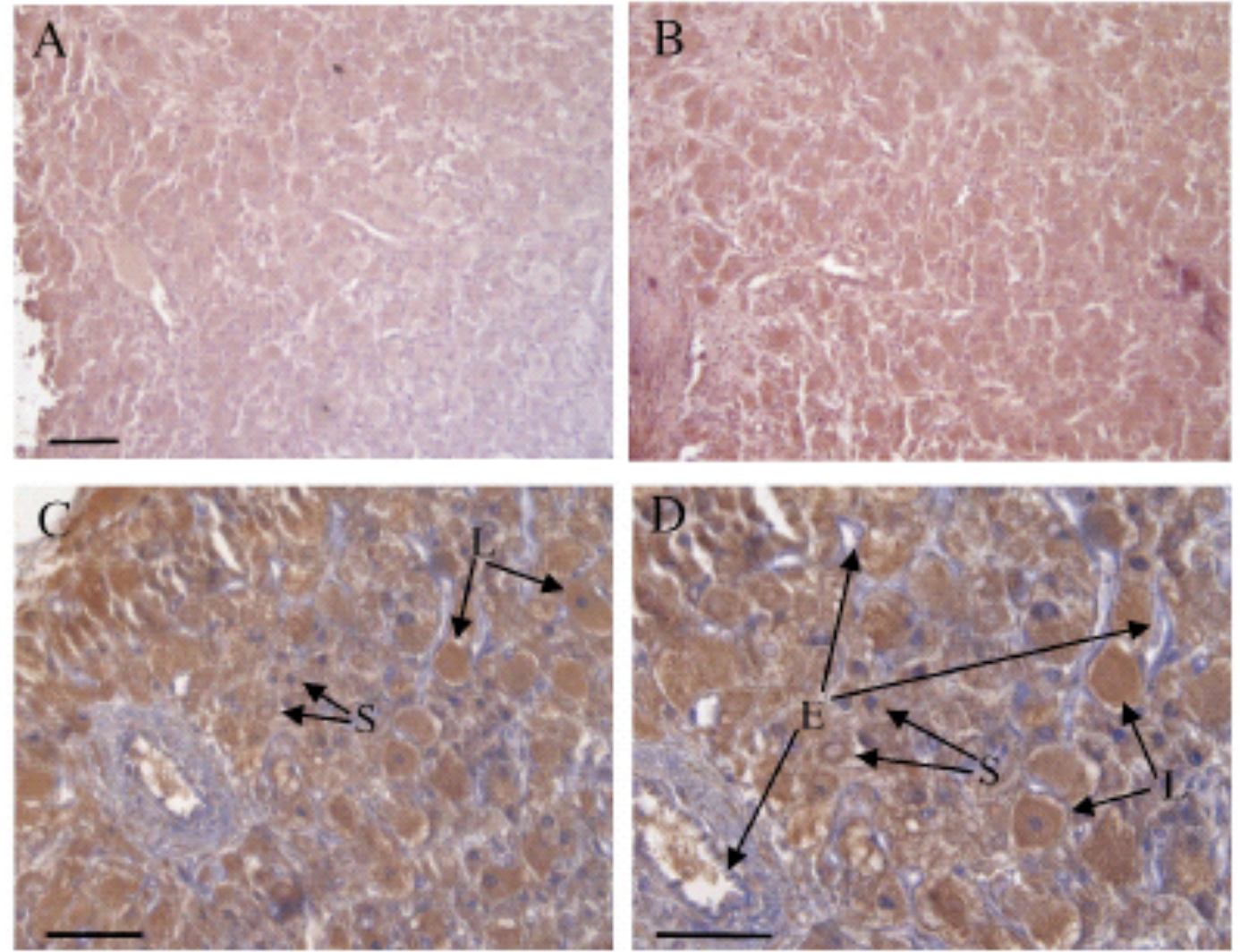

Figure 5. Specific detection of calcium/calmodulin dependent kinase kinase 2, beta (CAMKK2) in day 10 bovine CL (panels $\mathrm{A}$ and B) by immunohistochemistry. Panel A demonstrates the specificity of the assay by a dramatic reduction of immunoreactivity when the primary antibody was pre-incubated with the antigenic peptide. Panel $\mathrm{C}$ shows immunoreactivity in small (S) and large luteal cells (L). Panel D illustrate lack of immunoreactivity in endothelial cells (arrow labeled E) and immunoreactivity in the cytoplasm of a large (arrow labeled L) and small (arrow labeled (S) luteal cells. Some unidentified cells are observed in the lumen of the blood vessel. Images in panels A and B are shown at the same magnification and the bar on the lower right corner of panel A indicates $100 \mu \mathrm{m}$. In panels $\mathrm{C}$ and $\mathrm{D}$, the bars in the lower right corners indicate 100 and $50 \mu \mathrm{m}$ respectively. The nuclei were counterstained by brief exposure to Harris's Hematoxylin solution. 


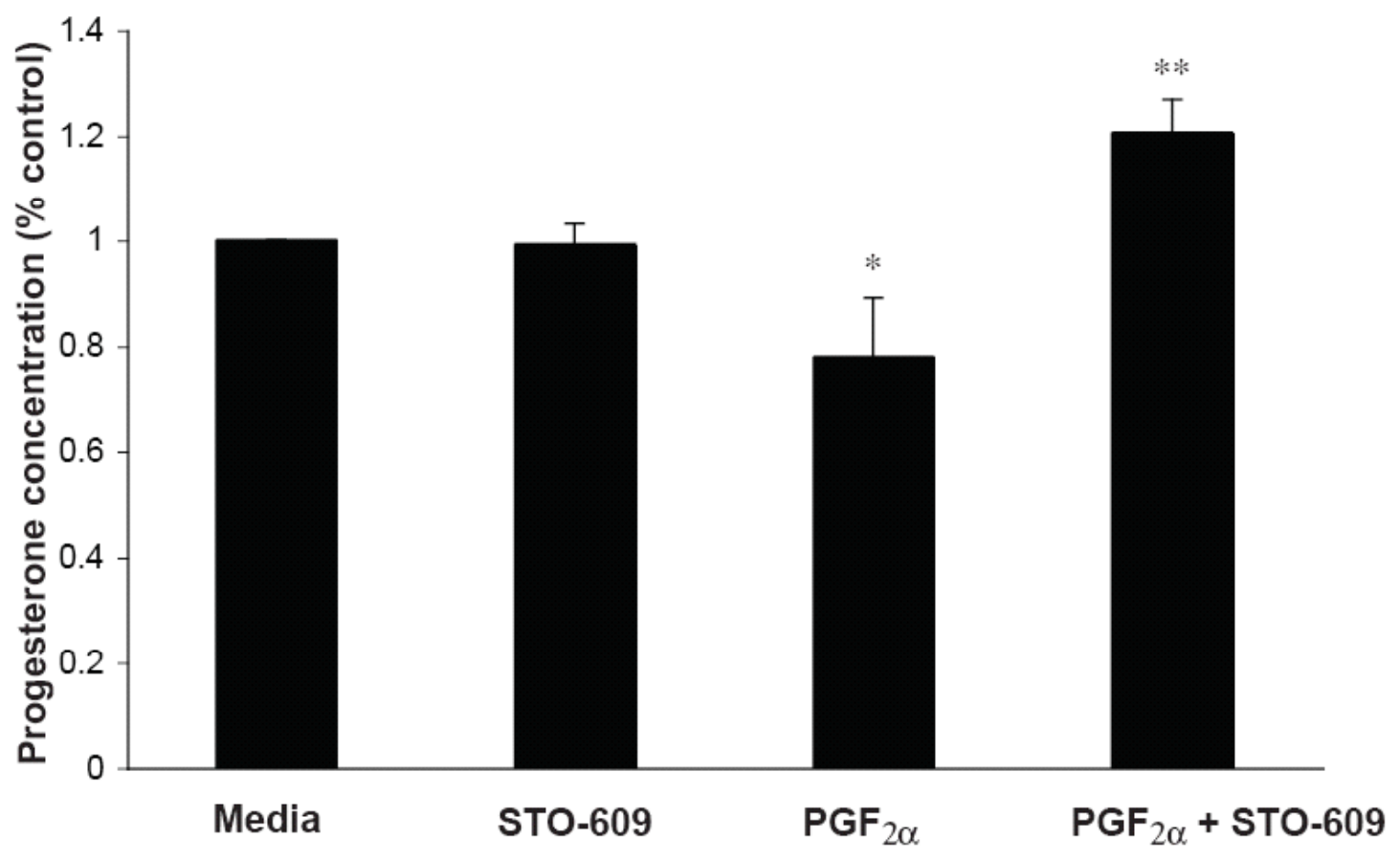

Figure 6. Role of CAMKK2 in mediating the antisteroidogenic actions of $\mathrm{PGF}_{2 \alpha}$. This figure represents the accumulation of progesterone in media secreted by steroidogenic cells derived from D-10 CL $(n=4)$ over a period of $12 \mathrm{~h}$. The treatments include media (control), CAMKK2 inhibitor, STO-609 in presence or absence of $\mathrm{PGF}_{2_{\alpha}}$. The progesterone values are expressed as percentage of control (mean $\pm \mathrm{SE}$ ), and the bars with symbol * and ** indicate significant differences $(\mathrm{P}<0.05)$ between treatment groups. 


\section{Chapter V: Discussion and future studies}

The current studies were carried out to investigate the mechanisms responsible for insensitivity of the early developmental stages of the bovine $\mathrm{CL}$ to luteolytic actions of $\mathrm{PGF}_{2 \alpha}$. Lack of $\mathrm{PGF}_{2 \alpha}$ receptors does not seem to explain this differential response because early CL already have high affinity receptors and $\mathrm{PGF}_{2 \alpha}$ can elicit distinct physiological response in early $\mathrm{CL}$ [Choudhary E et al, 2005; Levy $\mathrm{N}$ et al, 2000]. This led to general working hypothesis that differences in post-receptor signaling events activated by $\mathrm{PGF}_{2 \alpha}$ in the early versus the mature $\mathrm{CL}$ might be responsible for differential responsiveness to luteolytic actions of $\mathrm{PGF}_{2 \alpha}$.

Previous study by Sen et al [Sen A et al, 2004] investigated the expression of array of PRKC isozymes in the developing and mature CL. The results of this study showed that bovine CL expressed $\alpha, \beta I, \beta I I, \varepsilon$ and $\mu$ isozymes. Interestingly, the amount of PRKCE was greater in D-10 CL compared to the D-4 CL and only steroidogenic cells expressed PRKCE. These observations led authors to propose that differential expression of PRKCE could explain the mechanism of early luteal resistance to $\mathrm{PGF}_{2 \alpha}$. Therefore, ablation or over-expression of PRKCE in steroidogenic cells might provide useful technique to assess its physiological significance and mechanism in acquisition of luteolytic sensitivity. Therefore, siRNA approach was used to specifically downregulate PRKCE mRNA in steroidogenic cells. This approach has effectively downregulated the amount of PRKCE mRNA by $\sim 75 \%$ and protein by $\sim 50 \%$ and permitted examination of the specific function of PRKCE. Under the reduced cellular concentrations of PRKCE, the ability of $\mathrm{PGF}_{2 \alpha}$ to inhibit LH-stimulated progesterone accumulation was significantly inhibited. This observation strongly supported our hypothesis that low amounts/absence of PRKCE in the early CL might be responsible for inability of $\mathrm{PGF}_{2 \alpha}$ to inhibit progesterone synthesis. In general, PRKCs mediated antisteroidogenic actions of $\mathrm{PGF}_{2 \alpha}$ [Abayasekara DR et al, 1993; Wiltbank MC et al, 1990; Wiltbank MC et al, 1991], however the role of PRKC specific isozymes has drawn little attention to date. Therefore, our results are direct evidence that PRKCE mediate progesterone inhibitory actions of $\mathrm{PGF}_{2 \alpha}$. However, detailed mechanism of action and its cellular targets are not known. Inhibition of activity of PRKCE abolished the ability of $\mathrm{PGF}_{2 \alpha}$ to increase $\left[\mathrm{Ca}^{2+}\right]$ i, which suggested that PRKCE might regulate amounts of $\left[\mathrm{Ca}^{2+}\right]$ i [Sen $\mathrm{A}$ et al, 2005]. However, the exact mechanism by which 
PRKCE regulates $\left[\mathrm{Ca}^{2+}\right] \mathrm{i}$ needs to be investigated. In astrocytes activation of PRKCE increased the expression of mRNAs for voltage- dependent calcium channels (VGCCs). In addition, overexpression of PRKCE increased the density of $\mathrm{Ca}^{2+}$ currents [Burgos $\mathrm{M}$ et al, 2007]. Therefore, the role of PRKCE in expression of VGGCs or their direct activation by phosphorylation-dependent mechanism needs to be investigated. In addition, cellular colocalization studies of PRKCE with VGGCs might provide insight into its specific target sites of action.

It has been proposed that uterine $\mathrm{PGF}_{2 \alpha}$ amplifies its luteolytic effect by stimulating its own synthesis from CL [Tsai SJ and Wiltbank MC, 1997]. $\mathrm{PGF}_{2 \alpha}$ released from CL acts in an autocrine manner to complete the process of luteolysis. In early CL, the inability of $\mathrm{PGF}_{2 \alpha}$ to induce COX-2 expression, a key enzyme in biosynthesis of $\mathrm{PGF}_{2 \alpha}$, had been suggested to be cause for early luteal insensitivity [Tsai SJ and Wiltbank MC, 1998](discussed in chapter III). Moreover, the increase in $\left[\mathrm{Ca}^{2+}\right] \mathrm{i}$ activated PLA2 and subsequently released arachidonic acid [Rosenthal MD et al, 1995]. Therefore, expression of PRKCE and its activation by PGF $_{2 \alpha}$ in the late $\mathrm{CL}$ might increase $\left[\mathrm{Ca}^{2+}\right] \mathrm{i}$ sufficient to induce $\mathrm{COX}-2$ expression and probably other important genes involved in the metabolism of $\mathrm{PGF}_{2 \alpha}$. Supporting this idea, PRKCE induced the expression of COX-2 via Raf1-MEK1/2-p44/42 MAPK pathway in cardiac muscle [Xuan YT et al, 2005]. Therefore, the expression of key PG metabolic genes including COX-2 in PKCE-down regulated cells was innvestigated. Surprisingly, PRKCE-downregulation did not show significant effects on the expression of any of the genes tested (discussed in Chapter III). However, in the bovine luteal cells, activation of PRKC by $\mathrm{PGF}_{2 \alpha}$ stimulated Raf/MEK1/MAPKMAP pathway, which was suggested to activate the luteal genes containing AP-1 binding sites [Chen DB et al, 1998]. Therefore, possibility of involvement of other PRKC-specific isozymes in activating this metabolic pathway and subsequent induction of $\mathrm{PGF}_{2 \alpha}$-metabolic genes during luteolysis needs to be investigated.

The role of $\mathrm{Ca}^{2+}$ in inhibiting and supporting the synthesis of progesterone has been reported, which suggested its biphasic role in steroidogenesis (discussed in chapter III). Our observations strongly suggested that by simply raising the intraluteal $\mathrm{Ca}^{2+}$ concentration, one could inhibit 
progesterone synthesis irrespective of the developmental stage of CL. However, we did not quantified the amounts of $\left[\mathrm{Ca}^{2+}\right] \mathrm{i}$ that are required to inhibit progesterone synthesis. Therefore, titrating the quantity of progesterone-inhibitory concentrations of $\mathrm{Ca}^{2+}$ might be very important in designing suitable $\mathrm{Ca}^{2+}$ - based estrous synchronization protocols. In addition, understanding the $\left[\mathrm{Ca}^{2+}\right] \mathrm{i}$ homeostasis in $\mathrm{CL}$ is important in designing calcium based protocols. It is known that $\mathrm{PGF}_{2 \alpha}$ stimulates a the rise in $\left[\mathrm{Ca}^{2+}\right] \mathrm{i}$ via release from internal source (ER). However, the function of $\mathrm{Ca}^{2+}$ that is derived via VGGCs during $\mathrm{PGF}_{2 \alpha}$ stimulated anti-steroidogenesis needs further investigation. Recently it has been reported that human luteinized granulosal cells express L- and T-type VGCCs and T-type channel regulate LH-stimulated influx of $\mathrm{Ca}^{2+}$ and steroidogenesis [Agoston $\mathrm{A}$ et al, 2004]. In addition, $\mathrm{PGF}_{2 \alpha}$ stimulated influx of extracellular $\mathrm{Ca}^{2+}$ via receptor linked $\mathrm{Ca}^{2+}$ channels during uterine contraction [Perusquia $\mathrm{M}$ and KubliGarfias C, 1992]. Importantly, our preliminary results (data not shown) showed that mRNAs for L, N, and T-type VGGCs are expressed in bovine CL. Therefore utilization of specific $\mathrm{Ca}^{2+}$ channel blockers during inhibition of LH-stimulated progesterone by $\mathrm{PGF}_{2 \alpha}$ might provide insight into their specific roles during luteolysis. In addition, studying the expression patterns of VGCCs and IP3 receptors in early and mature CL might help to understand the mechanisms responsible for ability of $\mathrm{PGF}_{2 \alpha}$ to stimulate greater magnitudes of $\left[\mathrm{Ca}^{2+}\right] \mathrm{i}$.

It is apparent from our previous results that there were difference in the developmental expression/quantities of certain signal molecules (for example, $\mathrm{PKC \varepsilon} /\left[\mathrm{Ca}^{2+}\right] \mathrm{i}$ ) that might partly explain the difference in responsiveness of CL to $\mathrm{PGF}_{2 \alpha}$. Supporting this observation, investigators have reported that differential expression of PRKC inhibitors (YWHAZ, PKCI1), or $\mathrm{PGF}_{2 \alpha}$ metabolic enzymes (COX-2, PGDH) might be responsible for differential luteal sensitivity (discussed in chapter IV). Therefore, there might be global changes in the expression of genes associated with $\mathrm{PGF}_{2 \alpha}$ signaling during transition of CL from early to middevelopmental stage. This approach could explore and identify the novel signaling molecules that might play an important role during acquisition of luteal sensitivity. Accordingly, our microarray approach has identified 167 genes that are differentially expressed during transition from D4 to D-10 CL and the gene ontology allowed us to categorize the identified genes into various functional groups. Consistent with our hypothesis, we identified 20 various hormonal cell signaling genes that were developmentally differentially expressed (table 3 , chapter IV). 
The role of one of these 20 cell-signaling genes, CAMKK2 during acquisition of luteolytic sensitivity to $\mathrm{PGF}_{2 \alpha}$ was investigated. The expression of both mRNA and protein of CAMKK2 were up-regulated in the D-10 CL. Importantly, increased CAMKK2 expression occurred at a developmental stage at which $\mathrm{PGF}_{2 \alpha}$ can stimulate a greater magnitude of $\left[\mathrm{Ca}^{2+}\right]$ i. Therefore, greater availability of CAMKK2 in the mature CL might be important in mediating the actions of rise in $\left[\mathrm{Ca}^{2+}\right]$ i stimulated by $\mathrm{PGF}_{2 \alpha}$ and subsequent inhibition of progesterone synthesis. Supporting its role in antisteroidogenesis, both SLC and LLC expressed CAMKK2 and endothelial cells do not appear to express CAMKK2. Importantly, inhibitor of CAMKK2 prevented the ability $\mathrm{PGF}_{2 \alpha}$ to inhibit progesterone synthesis, providing direct evidence for involvement of CAMKK2 in antisteroidogenic action of $\mathrm{PGF}_{2 \alpha}$. However, the specific intracellular targets and mechanism of action of CAMMK2 needs to be examined. It has been shown that CAMKK2 is the upstream activator of AMPK and activation of AMPK with metformin inhibited progesterone synthesis in bovine granulosal cells [Hurley RL et al, 2005; Tosca L et al, 2007; Woods A et al, 2005]. AMPK inhibits the rate limiting enzymes in fatty acid and cholesterol biosynthesis such as acetylcoenzyme A carboxylase (ACC), fatty acid synthase, and 3-hydroxy-3-methylglutaryl-coenzyme A. Cholesterol is a precursor for the synthesis of progesterone in ovarian cells. Accordingly, activation of AMPK inhibited synthesis of progesterone through mitogen-activated protein kinases (MAPKs) such as extracellular signal regulated kinase 1/2 (ERK1/2) in rat granulosal cells [Tosca L et al, 2005]. Therefore, we propose that AMPK might be a likely target for CAMKK2 during its antisteroidognic action and needs future attention. However as a preliminary step, we examined the expression of AMPK subunit isoforms in two developmental stages of CL. The results indicated that $\alpha 1, \alpha 2, \beta 1, \beta 2$, and $\gamma 3$ AMPK subunits were upregulated in D-10 CL (data not shown). However, the significance of differential expression of AMPK subunits during acquisition of luteolytic sensitivity to $\mathrm{PGF}_{2 \alpha}$ needs to be investigated. In addition, the activation of AMPK is due to direct phosphorylation at threonine 172 ( $\mathrm{Thr}^{172}$ ) [Hurley RL et al, 2005]. Therefore, examination of activation of AMPK (phosphorylation studies) by $\mathrm{PGF}_{2 \alpha}$ might provide direct evidence for its participation during luteolysis.

Based on the results from our current studies, general model for luteolytic signaling pathway induced by $\mathrm{PGF}_{2 \alpha}$ can be proposed as shown in figure 1. Increased expression of PRKCE in Day-10 CL and its activation by $\mathrm{PGF}_{2 \alpha}$ results in stimulation of greater magnitude of rise in 
$\left[\mathrm{Ca}^{2+}\right] \mathrm{i}$. Greater availability of CAMKK2 in D-10 CL might be activated by the rise in $\left[\mathrm{Ca}^{2+}\right] \mathrm{i}$. Subsequently, CAMKK2 might activate its downstream targets such as MAPKs and AMPK to inhibit P4 synthesis. Decline in P4 is followed induction of apoptosis by intracellular $\mathrm{Ca}^{2+}$.

In summary, current observations strongly indicated that differential expression of PRKCE and CAMKK2 might be important factors during acquisition of luteolytic sensitivity to $\mathrm{PGF}_{2 \alpha}$. In addition, magnitude of $\left[\mathrm{Ca}^{2+}\right] \mathrm{i}$ stimulated by $\mathrm{PGF}_{2 \alpha}$ is critical in inhibiting synthesis of progesterone synthesis, which suggested that by altering $\left[\mathrm{Ca}^{2+}\right] \mathrm{i}$ in $\mathrm{CL}$, one could effectively inhibit progesterone synthesis irrespective of the developmental stage of CL. Studying the physiological roles of intracellular signaling molecules such as GNB1, RGS2, YWHAZ during acquisition of lueolytic sensitivity might help to answer the complexity of intracellular mechanism associated with early luteal resistance to luteolytic actions of $\mathrm{PGF}_{2 \alpha}$.

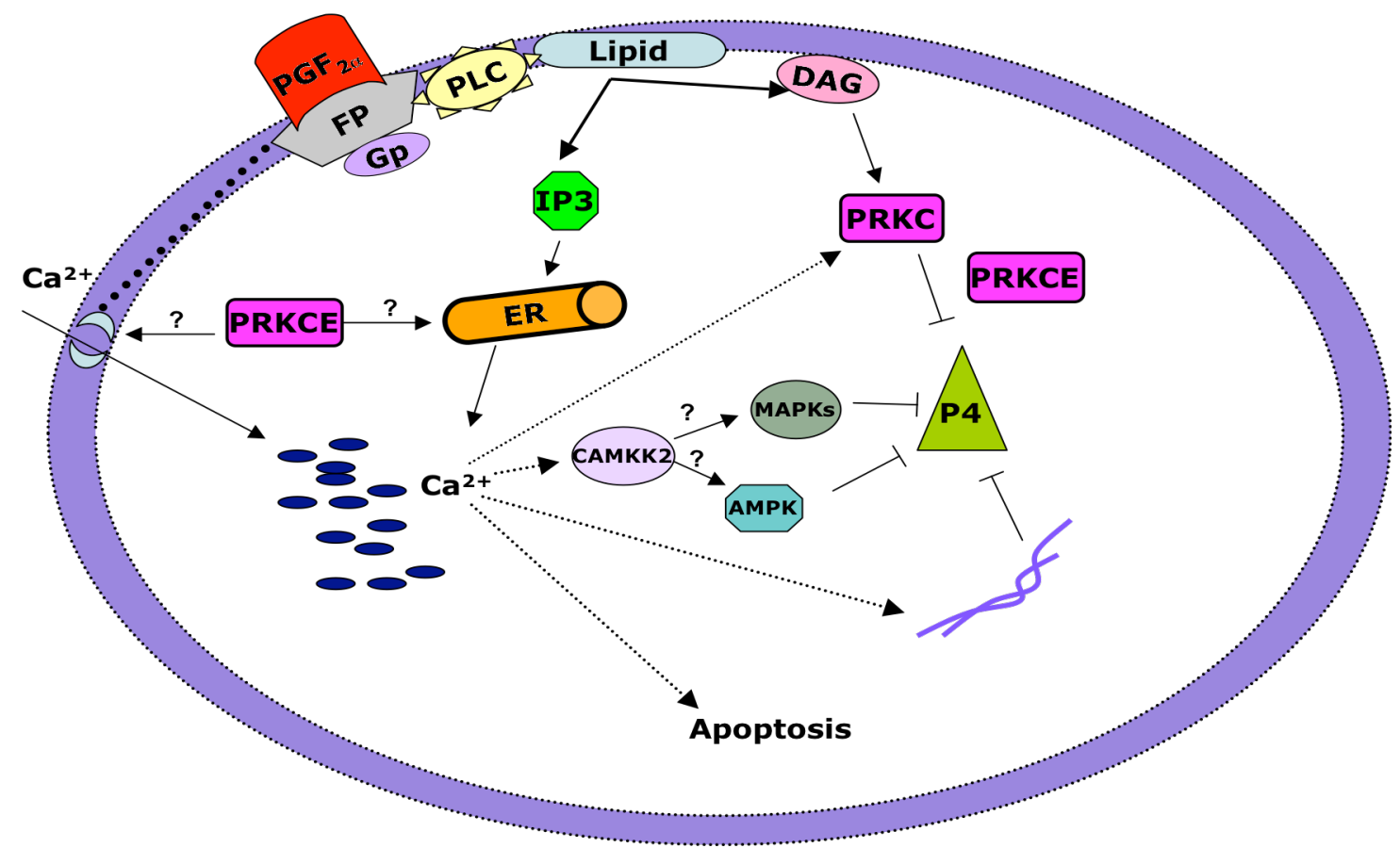

Figure 1. Proposed model for $\mathrm{PGF}_{2 \alpha}$-induced luteolytic signaling pathway. PLC: phospholipase $\mathrm{C} ; \mathrm{PGF}_{2 \alpha}: \mathrm{PGF}_{2 \alpha}$ receptor; ER: endoplasmic reticulum; PRKC: protein kinase C; PRKCE: protein kinase C epsilon; P4: progesterone; Gp: G-protein; DAG: diacylglycerol; IP3: inositoltriphosphate; CAMKK2: calcium-calmodulin-dependent kinase kinase 2, beta; AMPK: adenosine 5' monophosphate-activated protein kinase; MAPKs: mitogen-activated protein kinases. 


\section{Chapter V1: References}

1. Abayasekara DR, Michael AE, Webley GE, Flint AP. Mode of action of prostaglandin F2 alpha in human luteinized granulosa cells: role of protein kinase C. Mol Cell Endocrinol 1993; 97: 81-91.

2. Abramovitz M, Boie Y, Nguyen T, Rushmore TH, Bayne MA, Metters KM, Slipetz DM, Grygorczyk R. Cloning and expression of a cDNA for the human prostanoid FP receptor. J Biol Chem 1994; 269: 2632-2636.

3. Ackermann EJ, Dennis EA. Mammalian calcium-independent phospholipase A2. Biochim Biophys Acta 1995; 1259: 125-136.

4. Acosta TJ, Yoshizawa N, Ohtani M, Miyamoto A. Local changes in blood flow within the early and midcycle corpus luteum after prostaglandin $\mathrm{F}(2$ alpha) injection in the cow. Biol Reprod 2002; 66: 651-658.

5. Agoston A, Kunz L, Krieger A, Mayerhofer A. Two types of calcium channels in human ovarian endocrine cells: involvement in steroidogenesis. J Clin Endocrinol Metab 2004; 89: 4503-4512.

6. Agudo LS, Zahler WL, Smith MF. Effect of prostaglandin F2 alpha on the adenylate cyclase and phosphodiesterase activity of ovine corpora lutea. J Anim Sci 1984; 58: 955962.

7. Alila HW, Corradino RA, Hansel W. A comparison of the effects of cyclooxygenase prostanoids on progesterone production by small and large bovine luteal cells. Prostaglandins 1988a; 36: 259-270.

8. Alila HW, Davis JS, Dowd JP, Corradino RA, Hansel W. Differential effects of calcium on progesterone production in small and large bovine luteal cells. J Steroid Biochem 1990; 36: 687-693.

9. Alila HW, Dowd JP, Corradino RA, Harris WV, Hansel W. Control of progesterone production in small and large bovine luteal cells separated by flow cytometry. J Reprod Fertil 1988b; 82: 645-655.

10. Alila HW, Hansel W. Origin of different cell types in the bovine corpus luteum as characterized by specific monoclonal antibodies. Biol Reprod 1984; 31: 1015-1025.

11. Allen WM, Wintersteiner O. Crystalline Progestin. Science 1934; 80: 190-191.

12. Andersen JM, Dietschy JM. Relative importance of high and low density lipoproteins in the regulation of cholesterol synthesis in the adrenal gland, ovary, and testis of the rat. $\mathrm{J}$ Biol Chem 1978; 253: 9024-9032.

13. Anderson KA, Means RL, Huang QH, Kemp BE, Goldstein EG, Selbert MA, Edelman AM, Fremeau RT, Means AR. Components of a calmodulin-dependent protein kinase cascade. Molecular cloning, functional characterization and cellular localization of Ca2+/calmodulin-dependent protein kinase kinase beta. J Biol Chem 1998; 273: 3188031889.

14. Anderson LE, Wu YL, Tsai SJ, Wiltbank MC. Prostaglandin F(2alpha) receptor in the corpus luteum: recent information on the gene, messenger ribonucleic acid, and protein. Biol Reprod 2001; 64: 1041-1047.

15. Ansari HR, Husain S, Abdel-Latif AA. Activation of $\mathrm{p} 42 / \mathrm{p} 44$ mitogen-activated protein kinase and contraction by prostaglandin F2alpha, ionomycin, and thapsigargin in cat iris 
sphincter smooth muscle: inhibition by PD98059, KN-93, and isoproterenol. J Pharmacol Exp Ther 2001; 299: 178-186.

16. Arakane F, King SR, Du Y, Kallen CB, Walsh LP, Watari H, Stocco DM, Strauss JF, 3rd. Phosphorylation of steroidogenic acute regulatory protein (StAR) modulates its steroidogenic activity. J Biol Chem 1997; 272: 32656-32662.

17. Arosh JA, Banu SK, Chapdelaine P, Madore E, Sirois J, Fortier MA. Prostaglandin biosynthesis, transport, and signaling in corpus luteum: a basis for autoregulation of luteal function. Endocrinology 2004; 145: 2551-2560.

18. Asselin E, Fortier MA. Detection and regulation of the messenger for a putative bovine endometrial 9-keto-prostaglandin $\mathrm{E}(2)$ reductase: effect of oxytocin and interferon-tau. Biol Reprod 2000; 62: 125-131.

19. Asselin E, Lacroix D, Fortier MA. IFN-tau increases PGE2 production and COX-2 gene expression in the bovine endometrium in vitro. Mol Cell Endocrinol 1997; 132: 117-126.

20. Auletta FJ, Flint AP. Mechanisms controlling corpus luteum function in sheep, cows, nonhuman primates, and women especially in relation to the time of luteolysis. Endocr Rev 1988; 9: 88-105.

21. Balapure AK, Caicedo IC, Kawada K, Watt DS, Rexroad CE, Jr., Fitz TA. Multiple classes of prostaglandin F2 alpha binding sites in subpopulations of ovine luteal cells. Biol Reprod 1989; 41: 385-392.

22. Banu SK, Arosh JA, Chapdelaine P, Fortier MA. Molecular cloning and spatio-temporal expression of the prostaglandin transporter: a basis for the action of prostaglandins in the bovine reproductive system. Proc Natl Acad Sci U S A 2003; 100: 11747-11752.

23. Bao B, Garverick HA. Expression of steroidogenic enzyme and gonadotropin receptor genes in bovine follicles during ovarian follicular waves: a review. J Anim Sci 1998; 76: 1903-1921.

24. Bao Y, Pucci ML, Chan BS, Lu R, Ito S, Schuster VL. Prostaglandin transporter PGT is expressed in cell types that synthesize and release prostanoids. Am J Physiol Renal Physiol 2002; 282: F1103-1110.

25. Barrett PQ, Bollag WB, Isales CM, McCarthy RT, Rasmussen H. Role of calcium in angiotensin II-mediated aldosterone secretion. Endocr Rev 1989; 10: 496-518.

26. Bartke A. Influence of an IUD on the leucocytic content of the uterus and on the duration of pseudopregnancy in mice. J Reprod Fertil 1970; 23: 243-247.

27. Bazer FW, Thatcher WW. Theory of maternal recognition of pregnancy in swine based on estrogen controlled endocrine versus exocrine secretion of prostaglandin F2alpha by the uterine endometrium. Prostaglandins 1977; 14: 397-400.

28. Beard J. The span of Gestation and the Cause of Birth: a Study of the Critical Period and Its Effects in Manmmalia. Jena, Germany. Fischer 1897.

29. Becker JA, Mirjolet JF, Bernard J, Burgeon E, Simons MJ, Vassart G, Parmentier M, Libert F. Activation of GPR54 promotes cell cycle arrest and apoptosis of human tumor cells through a specific transcriptional program not shared by other Gq-coupled receptors. Biochem Biophys Res Commun 2005; 326: 677-686.

30. Belfiore CJ, Hawkins DE, Wiltbank MC, Niswender GD. Regulation of cytochrome P450scc synthesis and activity in the ovine corpus luteum. J Steroid Biochem Mol Biol 1994; 51: 283-290.

31. Bennegard B, Hahlin M, Hamberger L. Luteotropic effects of prostaglandins I2 and D2 on isolated human corpora luteum. Fertil Steril 1990; 54: 459-464. 
32. Bennegard-Eden $\mathrm{B}$, Hahlin $\mathrm{M}$, Kindahl $\mathrm{H}$. Interaction between oxytocin and prostaglandin F2 alpha in human corpus luteum? Hum Reprod 1995; 10: 2320-2324.

33. Benyo DF, Pate JL. Tumor necrosis factor-alpha alters bovine luteal cell synthetic capacity and viability. Endocrinology 1992; 130: 854-860.

34. Berman DM, Wilkie TM, Gilman AG. GAIP and RGS4 are GTPase-activating proteins for the Gi subfamily of G protein alpha subunits. Cell 1996; 86: 445-452.

35. Berridge MJ, Irvine RF. Inositol trisphosphate, a novel second messenger in cellular signal transduction. Nature 1984; 312: 315-321.

36. Betz R, Lagercrantz J, Kedra D, Dumanski JP, Nordenskjold A. Genomic structure, 5' flanking sequences, and precise localization in 1P31.1 of the human prostaglandin $\mathrm{F}$ receptor gene. Biochem Biophys Res Commun 1999; 254: 413-416.

37. Blaustein JD, Feder HH. Cytoplasmic progestin-receptors in guinea pig brain: characteristics and relationship to the induction of sexual behavior. Brain Res 1979; 169: 481-497.

38. Boiti C, Zampini D, Zerani M, Guelfi G, Gobbetti A. Prostaglandin receptors and role of $\mathrm{G}$ protein-activated pathways on corpora lutea of pseudopregnant rabbit in vitro. $\mathrm{J}$ Endocrinol 2001; 168: 141-151.

39. Bonnin P, Huynh L, L'Haridon R, Chene N, Martal J. Transport of uterine PGF2 alpha to the ovaries by systemic circulation and local lymphovenous-arterial diffusion during luteolysis in sheep. J Reprod Fertil 1999; 116: 199-210.

40. Bose H, Lingappa VR, Miller WL. Rapid regulation of steroidogenesis by mitochondrial protein import. Nature 2002; 417: 87-91.

41. Boshier DP, Holloway H. Effects of ovarian steroid hormones on histochemically demonstrable lipids in the rat uterine epithelium. J Endocrinol 1973; 56: 59-67.

42. Bowolaksono A, Nishimura R, Hojo T, Sakumoto R, Acosta TJ, Okuda K. Anti-apoptotic roles of prostaglandin E2 and F2alpha in bovine luteal steroidogenic cells. Biol Reprod 2008; 79: 310-317.

43. Bradbury J, Brown WE, Gray LA. Maintenance of corpus luteum and physiological actions of progesterone. Recent Prog Horm Res 1950; 5: 151.

44. Braun AP, Schulman H. The multifunctional calcium/calmodulin-dependent protein kinase: from form to function. Annu Rev Physiol 1995; 57: 417-445.

45. Brown MS, Goldstein JL. A receptor-mediated pathway for cholesterol homeostasis. Science 1986; 232: 34-47.

46. Budnik LT, Mukhopadhyay AK. Lysophosphatidic acid-induced nuclear localization of protein kinase $\mathrm{C}$ delta in bovine theca cells stimulated with luteinizing hormone. Biol Reprod 2002; 67: 935-944.

47. Buratini J, Jr., Pinto MG, Castilho AC, Amorim RL, Giometti IC, Portela VM, Nicola ES, Price CA. Expression and function of fibroblast growth factor 10 and its receptor, fibroblast growth factor receptor 2B, in bovine follicles. Biol Reprod 2007; 77: 743-750.

48. Burgos M, Pastor MD, Gonzalez JC, Martinez-Galan JR, Vaquero CF, Fradejas N, Benavides A, Hernandez-Guijo JM, Tranque P, Calvo S. PKCepsilon upregulates voltage-dependent calcium channels in cultured astrocytes. Glia 2007; 55: 1437-1448.

49. Burns PD, Hayes SH, Silvia WJ. Cellular mechanisms by which oxytocin mediates uterine prostaglandin F2 alpha synthesis in bovine endometrium: role of calcium. Domest Anim Endocrinol 1998; 15: 477-487.

50. Bussmann LE. Prostaglandin F-2 alpha receptors in corpora lutea of pregnant rats and 
relationship with induction of 20 alpha-hydroxysteroid dehydrogenase. J Reprod Fertil 1989; 85: 331-341.

51. Butenandt A, Westphal U, Hohlweg W. Uber das hormon des corpus luteum. Physiological chemistry 1934; 227: 84-98.

52. Caffrey JL, Fletcher PW, Diekman MA, O'Callaghan PL, Niswender GD. The activity of ovine luteal cholesterol esterase during several experimental conditions. Biol Reprod 1979; 21: 601-608.

53. Caldwell BV, Mazer RS, Wright PA. Luteolysis as affected by uterine transplantation in the Syrian hamster. Endocrinology 1967; 80: 477-482.

54. Carlson JC, Buhr MM, Riley JC. Alterations in the cellular membranes of regressing rat corpora lutea. Endocrinology 1984; 114: 521-526.

55. Carlsson B, Nilsson A, Isaksson OG, Billig H. Growth hormone-receptor messenger RNA in the rat ovary: regulation and localization. Mol Cell Endocrinol 1993; 95: 59-66.

56. Cary NC. Statistical Analysis System; Statistical software for the Apple Macintosh. JMP Statistics and Graphics Guide.

. In, Version 30 of JMP ed.

57. Casida LE. Research techniques in physiology of reproduction in the female. In: Chapman AB (ed.) Techniques and Procedures in Animal Production Research. New York: American Society of Animal Production; 1959: 106-121.

58. Cavazos LF, Anderson LL, Belt WD, Henricks DM, Kraeling RR, Melampy RM. Fine structure and progesterone levels in the corpus luteum of the pig during the estrous cycle. Biol Reprod 1969; 1: 83-106.

59. Channon JY, Leslie CC. A calcium-dependent mechanism for associating a soluble arachidonoyl-hydrolyzing phospholipase A2 with membrane in the macrophage cell line RAW 264.7. J Biol Chem 1990; 265: 5409-5413.

60. Chegini N, Lei ZM, Rao CV, Hansel W. Cellular distribution and cycle phase dependency of gonadotropin and eicosanoid binding sites in bovine corpora lutea. Biol Reprod 1991; 45: 506-513.

61. Chen D, Fong HW, Davis JS. Induction of c-fos and c-jun messenger ribonucleic acid expression by prostaglandin F2alpha is mediated by a protein kinase C-dependent extracellular signal-regulated kinase mitogen-activated protein kinase pathway in bovine luteal cells. Endocrinology 2001; 142: 887-895.

62. Chen DB, Westfall SD, Fong HW, Roberson MS, Davis JS. Prostaglandin F2alpha stimulates the Raf/MEK1/mitogen-activated protein kinase signaling cascade in bovine luteal cells. Endocrinology 1998; 139: 3876-3885.

63. Choudhary E, Sen A, Inskeep EK, Flores JA. Developmental sensitivity of the bovine corpus luteum to prostaglandin F2alpha (PGF2alpha) and endothelin-1 (ET-1): is ET-1 a mediator of the luteolytic actions of PGF2alpha or a tonic inhibitor of progesterone secretion? Biol Reprod 2005; 72: 633-642.

64. Clark JD, Lin LL, Kriz RW, Ramesha CS, Sultzman LA, Lin AY, Milona N, Knopf JL. A novel arachidonic acid-selective cytosolic PLA2 contains a $\mathrm{Ca}(2+)$-dependent translocation domain with homology to PKC and GAP. Cell 1991; 65: 1043-1051.

65. Clark JD, Schievella AR, Nalefski EA, Lin LL. Cytosolic phospholipase A2. J Lipid Mediat Cell Signal 1995; 12: 83-117.

66. Clarke CL. Cell-specific regulation of progesterone receptor in the female reproductive system. Mol Cell Endocrinol 1990; 70: C29-33. 
67. Concannon PW, Castracane M, Temple M, Montanez A. Endocrine control of ovarian function in dogs and other carnivores. Animal reproduction 2009; 6: 172-193.

68. Constantino CX, Keyes PL, Kostyo JL. Insulin-like growth factor-I stimulates steroidogenesis in rabbit luteal cells. Endocrinology 1991; 128: 1702-1708.

69. Cook B, Kaltenbach CC, Norton HW, Nalbandov AV. Synthesis of progesterone in vitro by porcine corpora lutea. Endocrinology 1967; 81:573-584.

70. Cooke GM, Robaire B. Phospholipases modulate the rat testicular androgen biosynthetic pathway in vitro. Biol Reprod 1988; 39: 329-339.

71. Cooke RG, Homeida AM. Delayed luteolysis and suppression of the pulsatile release of oxytocin after indomethacin treatment in the goat. Res Vet Sci 1984; 36: 48-51.

72. Copelin JP, Smith MF, Garverick HA, Youngquist RS, McVey WR, Jr., Inskeep EK. Responsiveness of bovine corpora lutea to prostaglandin F2 alpha: comparison of corpora lutea anticipated to have short or normal lifespans. J Anim Sci 1988; 66: 1236-1245.

73. Corner GW, Allen WM. Normal growth and implantation of embryos after very early ablation of the ovaries, under the influence of extracts of the corpus luteum. The American Journal of Physiology 1929; 88: 340-346.

74. Crivello JF, Jefcoate CR. Mechanisms of corticotropin action in rat adrenal cells. I. The effects of inhibitors of protein synthesis and of microfilament formation on corticosterone synthesis. Biochim Biophys Acta 1978; 542: 315-329.

75. Csukai M, Chen CH, De Matteis MA, Mochly-Rosen D. The coatomer protein beta'COP, a selective binding protein (RACK) for protein kinase Cepsilon. J Biol Chem 1997; 272: 29200-29206.

76. Csukai M, Mochly-Rosen D. Pharmacologic modulation of protein kinase C isozymes: the role of RACKs and subcellular localisation. Pharmacol Res 1999; 39: 253-259.

77. Culty ML, Boujrad N, Amri H, Vidic B, Bernassau JM, Reversat JL, Papadopoulos V. In vitro studies on the role of the peripheral-type benzodiazepine receptor in steroidogenesis. J Steroid Biochem Mol Biol 1999; 69: 123-130.

78. Cunningham ML, Waldo GL, Hollinger S, Hepler JR, Harden TK. Protein kinase C phosphorylates RGS2 and modulates its capacity for negative regulation of Galpha 11 signaling. J Biol Chem 2001; 276: 5438-5444.

79. Davare MA, Saneyoshi T, Guire ES, Nygaard SC, Soderling TR. Inhibition of calcium/calmodulin-dependent protein kinase kinase by protein 14-3-3. J Biol Chem 2004; 279: 52191-52199.

80. Davis JS, Alila HW, West LA, Corradino RA, Hansel W. Acute effects of prostaglandin F2 alpha on inositol phospholipid hydrolysis in the large and small cells of the bovine corpus luteum. Mol Cell Endocrinol 1988; 58: 43-50.

81. Davis JS, May JV, Keel BA. Mechanisms of hormone and growth factor action in the bovine corpus luteum. Theriogenology 1996; 45: 1351-1380.

82. Davis JS, Weakland LL, Farese RV, West LA. Luteinizing hormone increases inositol trisphosphate and cytosolic free Ca2+ in isolated bovine luteal cells. J Biol Chem 1987a; 262: 8515-8521.

83. Davis JS, Weakland LL, Weiland DA, Farese RV, West LA. Prostaglandin F2 alpha stimulates phosphatidylinositol 4,5-bisphosphate hydrolysis and mobilizes intracellular Ca2+ in bovine luteal cells. Proc Natl Acad Sci U S A 1987b; 84: 3728-3732.

84. De Graaf R. De Mullierum Organis Generationi Inservientibus. Leyden, 1672, translated by G. W. Corner. . Essays in Biology. Berkeley, CA: Univ. of California Press, 1943 
1643.

85. Dell EJ, Connor J, Chen S, Stebbins EG, Skiba NP, Mochly-Rosen D, Hamm HE. The betagamma subunit of heterotrimeric G proteins interacts with RACK1 and two other WD repeat proteins. J Biol Chem 2002; 277: 49888-49895.

86. Dennis EA. Diversity of group types, regulation, and function of phospholipase A2. J Biol Chem 1994; 269: 13057-13060.

87. Devoto L, Kohen P, Castro O, Vega M, Troncoso JL, Charreau E. Multihormonal regulation of progesterone synthesis in cultured human midluteal cells. J Clin Endocrinol Metab 1995; 80: 1566-1570.

88. Diaz FJ, Anderson LE, Wu YL, Rabot A, Tsai SJ, Wiltbank MC. Regulation of progesterone and prostaglandin F2alpha production in the CL. Mol Cell Endocrinol 2002; 191: 65-80.

89. Diekman MA, O'Callaghan PO, Nett TM, Niswender GD. Effect of prostaglandin F2alpha on the number of LH receptors in ovine corpora lutea. Biol Reprod 1978; 19: 1010-1013.

90. Doerr MD, Goravanahally MP, Rhinehart JD, Inskeep EK, Flores JA. Effects of endothelin receptor type-A and type-B antagonists on prostaglandin F2alpha-induced luteolysis of the sheep corpus luteum. Biol Reprod 2008; 78: 688-696.

91. Dorflinger LJ, Albert PJ, Williams AT, Behrman HR. Calcium is an inhibitor of luteinizing hormone-sensitive adenylate cyclase in the luteal cell. Endocrinology 1984; 114: 1208-1215.

92. Dorn GW, 2nd, Souroujon MC, Liron T, Chen CH, Gray MO, Zhou HZ, Csukai M, Wu G, Lorenz JN, Mochly-Rosen D. Sustained in vivo cardiac protection by a rationally designed peptide that causes epsilon protein kinase C translocation. Proc Natl Acad Sci U S A 1999; 96: 12798-12803.

93. Douglas RH, Ginther OJ. Concentration of prostaglandins F in uterine venous plasma of anesthetized mares during the estrous cycle and early pregnancy. Prostaglandins 1976; 11: 251-260.

94. Dubois RN, Abramson SB, Crofford L, Gupta RA, Simon LS, Van De Putte LB, Lipsky PE. Cyclooxygenase in biology and disease. Faseb J 1998; 12: 1063-1073.

95. Edelman AM, Mitchelhill KI, Selbert MA, Anderson KA, Hook SS, Stapleton D, Goldstein EG, Means AR, Kemp BE. Multiple $\mathrm{Ca}(2+)$-calmodulin-dependent protein kinase kinases from rat brain. Purification, regulation by $\mathrm{Ca}(2+)$-calmodulin, and partial amino acid sequence. J Biol Chem 1996; 271: 10806-10810.

96. Epstein LF, Orme-Johnson NR. Regulation of steroid hormone biosynthesis. Identification of precursors of a phosphoprotein targeted to the mitochondrion in stimulated rat adrenal cortex cells. J Biol Chem 1991; 266: 19739-19745.

97. Ezashi T, Sakamoto K, Miwa K, Okuda-Ashitaka E, Ito S, Hayaishi O. Genomic organization and characterization of the gene encoding bovine prostaglandin F2alpha receptor. Gene 1997; 190: 271-278.

98. Fairchild DL, Pate JL. Interferon-gamma induction of major histocompatibility complex antigens on cultured bovine luteal cells. Biol Reprod 1989; 40: 453-457.

99. Farin CE, Moeller CL, Sawyer HR, Gamboni F, Niswender GD. Morphometric analysis of cell types in the ovine corpus luteum throughout the estrous cycle. Biol Reprod 1986; 35: 1299-1308.

100. Fields MJ, Fields PA. Luteal neurophysin in the nonpregnant cow and ewe: 
immunocytochemical localization in membrane-bounded secretory granules of the large luteal cell. Endocrinology 1986; 118: 1723-1725.

101. Fields MJ, Fields PA. Morphological characteristics of the bovine corpus luteum during the estrous cycle and pregnancy. Theriogenology 1996; 45: 1295-1325.

102. Fields PA, Eldridge RK, Fuchs AR, Roberts RF, Fields MJ. Human placental and bovine corpora luteal oxytocin. Endocrinology 1983; 112: 1544-1546.

103. Fitz TA, Mayan MH, Sawyer HR, Niswender GD. Characterization of two steroidogenic cell types in the ovine corpus luteum. Biol Reprod 1982; 27: 703-711.

104. Fitz TA, Mock EJ, Mayan MH, Niswender GD. Interactions of prostaglandins with subpopulations of ovine luteal cells. II. Inhibitory effects of PGF2 alpha and protection by PGE2. Prostaglandins 1984; 28: 127-138.

105. Flint AP, Sheldrick EL. Ovarian secretion of oxytocin is stimulated by prostaglandin. Nature 1982; 297: 587-588.

106. Flint AP, Sheldrick EL, McCann TJ, Jones DS. Luteal oxytocin: characteristics and control of synchronous episodes of oxytocin and PGF2 alpha secretion at luteolysis in ruminants. Domest Anim Endocrinol 1990; 7: 111-124.

107. Flores JA, Aguirre C, Sharma OP, Veldhuis JD. Luteinizing hormone (LH) stimulates both intracellular calcium ion ([Ca2+]i) mobilization and transmembrane cation influx in single ovarian (granulosa) cells: recruitment as a cellular mechanism of $\mathrm{LH}-[\mathrm{Ca} 2+] \mathrm{i}$ dose response. Endocrinology 1998; 139: 3606-3612.

108. Fortier MA, Guilbault LA, Grasso F. Specific properties of epithelial and stromal cells from the endometrium of cows. J Reprod Fertil 1988; 83: 239-248.

109. Fraenkel L. Die Funktion des Corpus luteum. Archiv. Gynaekol 1903; 68: 438-443.

110. Fraser HM, Abbott M, Laird NC, McNeilly AS, Nestor JJ, Jr., Vickery BH. Effects of an LH-releasing hormone antagonist on the secretion of LH, FSH, prolactin and ovarian steroids at different stages of the luteal phase in the stumptailed macaque (Macaca arctoides). J Endocrinol 1986; 111: 83-90.

111. Fried J, Santhanakrishnan TS, Himizu J, Lin CH, Ford SH, Rubin B, Grigas EO. Prostaglandin antagonists: synthesis and smooth muscle activity. Nature 1969; 223: 208210.

112. Fujino H, Srinivasan D, Pierce KL, Regan JW. Differential regulation of prostaglandin F(2alpha) receptor isoforms by protein kinase C. Mol Pharmacol 2000; 57: 353-358.

113. Gadsby JE, Balapure AK, Britt JH, Fitz TA. Prostaglandin F2 alpha receptors on enzyme-dissociated pig luteal cells throughout the estrous cycle. Endocrinology 1990; 126: 787-795.

114. Garverick HA, Smith MF, Elmore RG, Morehouse GL, Agudo LS, Zahler WL. Changes and interrelationships among luteal LH receptors, adenylate cyclase activity and phosphodiesterase activity during the bovine estrous cycle. J Anim Sci 1985; 61: 216223.

115. Gavish M, Bachman I, Shoukrun R, Katz Y, Veenman L, Weisinger G, Weizman A. Enigma of the peripheral benzodiazepine receptor. Pharmacol Rev 1999; 51: 629-650.

116. Gilman AG. G proteins: transducers of receptor-generated signals. Annu Rev Biochem 1987; 56: 615-649.

117. Ginther OJ. Local versus systemic uteroovarian relationships in farm animals. Acta Vet Scand Suppl 1981; 77: 103-115.

118. Girsh E, Milvae RA, Wang W, Meidan R. Effect of endothelin-1 on bovine luteal cell 
function: role in prostaglandin F2alpha-induced antisteroidogenic action. Endocrinology 1996; 137: 1306-1312.

119. Goravanahally MP, Sen A, Inskeep EK, Flores JA. PKC epsilon and an increase in intracellular calcium concentration are necessary for PGF2 alpha to inhibit LH-stimulated progesterone secretion in cultured bovine steroidogenic luteal cells. Reprod Biol Endocrinol 2007; 5: 37.

120. Gospodarowicz D, Cheng J, Lui GM, Baird A, Esch F, Bohlen P. Corpus luteum angiogenic factor is related to fibroblast growth factor. Endocrinology 1985; 117: 23832391.

121. Graves PE, Pierce KL, Bailey TJ, Rueda BR, Gil DW, Woodward DF, Yool AJ, Hoyer $\mathrm{PB}$, Regan JW. Cloning of a receptor for prostaglandin F2 alpha from the ovine corpus luteum. Endocrinology 1995; 136: 3430-3436.

122. Grazul-Bilska AT, Redmer DA, Killilea SD, Kraft KC, Reynolds LP. Production of mitogenic factor(s) by ovine corpora lutea throughout the estrous cycle. Endocrinology 1992; 130: 3625-3632.

123. Grazzini E, Guillon G, Mouillac B, Zingg HH. Inhibition of oxytocin receptor function by direct binding of progesterone. Nature 1998; 392: 509-512.

124. Griffeth RJ, Nett TM, Burns PD, Escudero JM, Inskeep EK, Niswender GD. Is luteal production of PGF required for luteolysis? Biol Reprod 2002; 66.

125. Grosdemouge I, Bachelot A, Lucas A, Baran N, Kelly PA, Binart N. Effects of deletion of the prolactin receptor on ovarian gene expression. Reprod Biol Endocrinol 2003; 1: 12.

126. Grummer RR, Carroll DJ. A review of lipoprotein cholesterol metabolism: importance to ovarian function. J Anim Sci 1988; 66: 3160-3173.

127. Gupta S. Molecular signaling in death receptor and mitochondrial pathways of apoptosis (Review). Int J Oncol 2003; 22: 15-20.

128. Guthrie HD, Rexroad CE, Jr., Bolt DJ. In vitro synthesis of progesterone and prostaglandin $\mathrm{F}$ by luteal tissue and prostaglandin $\mathrm{F}$ by endometrial tissue from the pig. Prostaglandins 1978; 16: 433-440.

129. Hansel W, Concannon PW, Lukaszewska JH. Copora lutea of the large domestic animals. Biology of Reproduction 1973; 8: 222-245.

130. Hansel W, Shemesh M, Hixon J, Lukaszewska J. Extraction, isolation and identification of a luteolytic substance from bovine endometrium. Biol Reprod 1975; 13: 30-37.

131. Hanukoglu I. Steroidogenic enzymes: structure, function, and role in regulation of steroid hormone biosynthesis. J Steroid Biochem 1992; 43: 779-804.

132. Haribabu B, Hook SS, Selbert MA, Goldstein EG, Tomhave ED, Edelman AM, Snyderman R, Means AR. Human calcium-calmodulin dependent protein kinase I: cDNA cloning, domain structure and activation by phosphorylation at threonine-177 by calciumcalmodulin dependent protein kinase I kinase. Embo J 1995; 14: 3679-3686.

133. Harrison LM, Kenny N, Niswender GD. Progesterone production, LH receptors, and oxytocin secretion by ovine luteal cell types on days 6,10 and 15 of the oestrous cycle and day 25 of pregnancy. J Reprod Fertil 1987; 79: 539-548.

134. Hartmann H, Wettstein A. Ein krystallisiertes hormon aus corpus luteum. Helv. Chim.Acta 1934; 17: 878-882.

135. Hasumoto K, Sugimoto Y, Gotoh M, Segi E, Yamasaki A, Yamaguchi M, Honda H, Hirai H, Negishi M, Kakizuka A, Ichikawa A. Characterization of the mouse prostaglandin F receptor gene: a transgenic mouse study of a regulatory region that 
controls its expression in the stomach and kidney but not in the ovary. Genes Cells 1997; 2: $571-580$.

136. Hepler JR, Berman DM, Gilman AG, Kozasa T. RGS4 and GAIP are GTPase-activating proteins for $\mathrm{Gq}$ alpha and block activation of phospholipase $\mathrm{C}$ beta by gamma-thio-GTPGq alpha. Proc Natl Acad Sci U S A 1997; 94: 428-432.

137. Herschman HR. Prostaglandin synthase 2. Biochim Biophys Acta 1996; 1299: 125-140.

138. Heximer SP, Cristillo AD, Forsdyke DR. Comparison of mRNA expression of two regulators of G-protein signaling, RGS1/BL34/1R20 and RGS2/G0S8, in cultured human blood mononuclear cells. DNA Cell Biol 1997; 16: 589-598.

139. Heximer SP, Srinivasa SP, Bernstein LS, Bernard JL, Linder ME, Hepler JR, Blumer KJ. G protein selectivity is a determinant of RGS2 function. J Biol Chem 1999; 274: 3425334259.

140. Homanics GE, Silvia WJ. Effects of progesterone and estradiol-17 beta on uterine secretion of prostaglandin F2 alpha in response to oxytocin in ovariectomized ewes. Biol Reprod 1988; 38: 804-811.

141. Homeida AM, Cooke RG. Peripheral plasma concentrations of 13,14-dihydro-15-ketoprostaglandin F2 alpha and progesterone around luteolysis and during early pregnancy in the goat. Prostaglandins 1982; 24: 313-321.

142. Hooper SB, Watkins WB, Thorburn GD. Oxytocin, oxytocin-associated neurophysin, and prostaglandin F2 alpha concentrations in the utero-ovarian vein of pregnant and nonpregnant sheep. Endocrinology 1986; 119: 2590-2597.

143. Horton EW, Poyser NL. Uterine luteolytic hormone: a physiological role for prostaglandin F2alpha. Physiol Rev 1976; 56: 595-651.

144. Hoyer PB, Fitz TA, Niswender GD. Hormone-independent activation of adenylate cyclase in large steroidogenic ovine luteal cells does not result in increased progesterone secretion. Endocrinology 1984; 114: 604-608.

145. Hu YF, Sanders JD, Kurz SG, Ottobre JS, Day ML. In vitro prostaglandin production by bovine corpora lutea destined to be normal or short-lived. Biol Reprod 1990; 42: 801807.

146. Hurley RL, Anderson KA, Franzone JM, Kemp BE, Means AR, Witters LA. The $\mathrm{Ca} 2+/$ calmodulin-dependent protein kinase kinases are AMP-activated protein kinase kinases. J Biol Chem 2005; 280: 29060-29066.

147. Hwang J, Menon KM. Characterization of low density and high density lipoprotein receptors in the rat corpus luteum and regulation by gonadotropin. J Biol Chem 1983; 258: 8020-8027.

148. Illario M, Cavallo AL, Bayer KU, Di Matola T, Fenzi G, Rossi G, Vitale M. Calcium/calmodulin-dependent protein kinase II binds to Raf-1 and modulates integrinstimulated ERK activation. J Biol Chem 2003; 278: 45101-45108.

149. Ingi T, Krumins AM, Chidiac P, Brothers GM, Chung S, Snow BE, Barnes CA, Lanahan AA, Siderovski DP, Ross EM, Gilman AG, Worley PF. Dynamic regulation of RGS2 suggests a novel mechanism in G-protein signaling and neuronal plasticity. J Neurosci 1998; 18: 7178-7188.

150. Inskeep EK. Potential uses of prostaglandins in control of reproductive cycles of domestic animals. J Anim Sci 1973; 36: 1149-1157.

151. Ivell R, Hunt N, Abend N, Brackman B, Nollmeyer D, Lamsa JC, McCracken JA. Structure and ovarian expression of the oxytocin gene in sheep. Reprod Fertil Dev 1990; 
2: 703-711.

152. Jabbour HN, Sales KJ, Boddy SC, Anderson RA, Williams AR. A positive feedback loop that regulates cyclooxygenase-2 expression and prostaglandin F2alpha synthesis via the F-series-prostanoid receptor and extracellular signal-regulated kinase 1/2 signaling pathway. Endocrinology 2005; 146: 4657-4664.

153. Ji I, Slaughter RG, Ellis JA, Ji TH, Murdoch WJ. Analyses of ovine corpora lutea for tumor necrosis factor mRNA and bioactivity during prostaglandin-induced luteolysis. Mol Cell Endocrinol 1991; 81: 77-80.

154. Johnson JE, Giorgione J, Newton AC. The C1 and C2 domains of protein kinase C are independent membrane targeting modules, with specificity for phosphatidylserine conferred by the $\mathrm{C} 1$ domain. Biochemistry 2000; 39: 11360-11369.

155. Johnson MS, Ottobre AC, Ottobre JS. Prostaglandin production by corpora lutea of rhesus monkeys: characterization of incubation conditions and examination of putative regulators. Biol Reprod 1988; 39: 839-846.

156. Johnson WJ, Phillips MC, Rothblat GH. Lipoproteins and cellular cholesterol homeostasis. Subcell Biochem 1997; 28: 235-276.

157. Juengel JL, Garverick HA, Johnson AL, Youngquist RS, Smith MF. Apoptosis during luteal regression in cattle. Endocrinology 1993; 132: 249-254.

158. Juengel JL, Guy MK, Tandeski TR, McGuire WJ, Niswender GD. Steady-state concentrations of messenger ribonucleic acid encoding cytochrome P450 side-chain cleavage and 3 beta-hydroxysteroid dehydrogenase/delta 5,delta 4 isomerase in ovine corpora lutea during the estrous cycle. Biol Reprod 1994; 51: 380-384.

159. Juengel JL, Haworth JD, Rollyson MK, Silva PJ, Sawyer HR, Niswender GD. Effect of dose of prostaglandin F(2alpha) on steroidogenic components and oligonucleosomes in ovine luteal tissue. Biol Reprod 2000; 62: 1047-1051.

160. Juengel JL, Melner MH, Clapper JA, Turzillo AM, Moss GE, Nett TM, Niswender GD. Steady-state concentrations of mRNA encoding two inhibitors of protein kinase $\mathrm{C}$ in ovine luteal tissue. J Reprod Fertil 1998; 113: 299-305.

161. Juengel JL, Nett TM, Anthony RV, Niswender GD. Effects of luteotrophic and luteolytic hormones on expression of mRNA encoding insulin-like growth factor I and growth hormone receptor in the ovine corpus luteum. J Reprod Fertil 1997; 110: 291-298.

162. Juengel JL, Wiltbank MC, Meberg BM, Niswender GD. Regulation of steady-state concentrations of messenger ribonucleic acid encoding prostaglandin $\mathrm{F} 2$ alpha receptor in ovine corpus luteum. Biol Reprod 1996; 54: 1096-1102.

163. Kallen CB, Billheimer JT, Summers SA, Stayrook SE, Lewis M, Strauss JF, 3rd. Steroidogenic acute regulatory protein (StAR) is a sterol transfer protein. J Biol Chem 1998; 273: 26285-26288.

164. Kaltenbach CC, Graber JW, Niswender GD, Nalbandov AV. Luteotrophic properties of some pituitary hormones in nonpregnant or pregnant hypophysectomized ewes. Endocrinology 1968; 82: 818-824.

165. Kanai N, Lu R, Satriano JA, Bao Y, Wolkoff AW, Schuster VL. Identification and characterization of a prostaglandin transporter. Science 1995; 268: 866-869.

166. Khachigian LM, Lindner V, Williams AJ, Collins T. Egr-1-induced endothelial gene expression: a common theme in vascular injury. Science 1996; 271: 1427-1431.

167. Kindahl H, Edquist LE, Bane A, Granstrom E. Blood levels of progesterone and 15-keto13,14-dihydro-prostaglandin F2alpha during the normal oestrous cycle and early 
pregnancy in heifers. Acta Endocrinol (Copenh) 1976; 82: 134-149.

168. Kindahl H, Edqvist LE, Lindell JO. On the control of prostaglandin release during the bovine estrous cycle. Adv Prostaglandin Thromboxane Res 1980; 8: 1351-1355.

169. Kitanaka J, Hasimoto H, Sugimoto Y, Negishi M, Aino H, Gotoh M, Ichikawa A, Baba A. Cloning and expression of a cDNA for rat prostaglandin F2 alpha receptor. Prostaglandins 1994; 48: 31-41.

170. Knickerbocker JJ, Wiltbank MC, Niswender GD. Mechanisms of luteolysis in domestic livestock. Domest Anim Endocrinol 1988; 5: 91-107.

171. Korzekwa AJ, Okuda K, Woclawek-Potocka I, Murakami S, Skarzynski DJ. Nitric oxide induces apoptosis in bovine luteal cells. J Reprod Dev 2006; 52: 353-361.

172. Kudo I, Murakami M, Hara S, Inoue K. Mammalian non-pancreatic phospholipases A2. Biochim Biophys Acta 1993; 1170: 217-231.

173. Kunze H, Vogt W. Significance of phospholipase A for prostaglandin formation. Ann N Y Acad Sci 1971; 180: 123-125.

174. Kuranaga E, Kanuka H, Hirabayashi K, Suzuki M, Nishihara M, Takahashi M. Progesterone is a cell death suppressor that downregulates Fas expression in rat corpus luteum. FEBS Lett 2000; 466: 279-282.

175. Lacapere JJ, Delavoie F, Li H, Peranzi G, Maccario J, Papadopoulos V, Vidic B. Structural and functional study of reconstituted peripheral benzodiazepine receptor. Biochem Biophys Res Commun 2001; 284: 536-541.

176. Lacapere JJ, Papadopoulos V. Peripheral-type benzodiazepine receptor: structure and function of a cholesterol-binding protein in steroid and bile acid biosynthesis. Steroids 2003; 68: 569-585.

177. Lafrance M, Goff AK. Effects of progesterone and oestradiol-17 beta on oxytocininduced release of prostaglandin F-2 alpha in heifers. J Reprod Fertil 1988; 82: 429-436.

178. Lake S, Gullberg H, Wahlqvist J, Sjogren AM, Kinhult A, Lind P, Hellstrom-Lindahl E, Stjernschantz J. Cloning of the rat and human prostaglandin F2 alpha receptors and the expression of the rat prostaglandin F2 alpha receptor. FEBS Lett 1994; 355: 317-325.

179. Lamb GC, Larson JE, Geary TW, Stevenson JS, Johnson SK, Day ML, Ansotegui RP, Kesler DJ, DeJarnette JM, Landblom DG. Synchronization of estrus and artificial insemination in replacement beef heifers using gonadotropin-releasing hormone, prostaglandin F2alpha, and progesterone. J Anim Sci 2006; 84: 3000-3009.

180. Lands WE, Samuelsson B. Phospholipid precursors of prostaglandins. Biochim Biophys Acta 1968; 164: 426-429.

181. Landschulz KT, Pathak RK, Rigotti A, Krieger M, Hobbs HH. Regulation of scavenger receptor, class B, type I, a high density lipoprotein receptor, in liver and steroidogenic tissues of the rat. J Clin Invest 1996; 98: 984-995.

182. Lauderdale JW, Seguin BE, Stellflug JN, Chenault JR, Thatcher WW, Vincent CK, Loyancano AF. Fertility of cattle following PGF2 alpha injection. J Anim Sci 1974; 38: 964-967.

183. Leavitt WW, Okulicz WC, McCracken JA, Schramm W, Robidoux WF, Jr. Rapid recovery of nuclear estrogen receptor and oxytocin receptor in the ovine uterus following progesterone withdrawal. J Steroid Biochem 1985; 22: 687-691.

184. Lestavel S, Fruchart JC. Lipoprotein receptors. Cell Mol Biol (Noisy-le-grand) 1994; 40: 461-481.

185. Leung PC, Minegishi T, Ma F, Zhou FZ, Ho-Yuen B. Induction of polyphosphoinositide 
breakdown in rat corpus luteum by prostaglandin F2 alpha. Endocrinology 1986; 119: 1218.

186. Levy N, Gordin M, Mamluk R, Yanagisawa M, Smith MF, Hampton JH, Meidan R. Distinct cellular localization and regulation of endothelin-1 and endothelin-converting enzyme-1 expression in the bovine corpus luteum: implications for luteolysis. Endocrinology 2001; 142: 5254-5260.

187. Levy N, Kobayashi S, Roth Z, Wolfenson D, Miyamoto A, Meidan R. Administration of prostaglandin $\mathrm{f}(2$ alpha) during the early bovine luteal phase does not alter the expression of ET-1 and of its type A receptor: a possible cause for corpus luteum refractoriness. Biol Reprod 2000; 63: 377-382.

188. Li H, Papadopoulos V. Peripheral-type benzodiazepine receptor function in cholesterol transport. Identification of a putative cholesterol recognition/interaction amino acid sequence and consensus pattern. Endocrinology 1998; 139: 4991-4997.

189. Liebermann J, Schams D. Actions of somatotrophin on oxytocin and progesterone release from the microdialysed bovine corpus luteum in vitro. J Endocrinol 1994; 143: 243-250.

190. Lipner H. Mechanism of ovulation. . New York: Raven Press; 1988.

191. Loeb L. The effect of extirpation of the uterus on the life and function of the coprus luteum in guinea pigs. Proc Soc Exp Biol Med 1923; 20: 441-464.

192. Lu R, Kanai N, Bao Y, Schuster VL. Cloning, in vitro expression, and tissue distribution of a human prostaglandin transporter cDNA(hPGT). J Clin Invest 1996; 98: 1142-1149.

193. Lucy MC, Collier RJ, Kitchell ML, Dibner JJ, Hauser SD, Krivi GG. Immunohistochemical and nucleic acid analysis of somatotropin receptor populations in the bovine ovary. Biol Reprod 1993; 48: 1219-1227.

194. Madore E, Harvey N, Parent J, Chapdelaine P, Arosh JA, Fortier MA. An aldose reductase with 20 alpha-hydroxysteroid dehydrogenase activity is most likely the enzyme responsible for the production of prostaglandin $\mathrm{f} 2$ alpha in the bovine endometrium. $\mathrm{J}$ Biol Chem 2003; 278: 11205-11212.

195. Maizels ET, Shanmugam M, Lamm ML, Hunzicker-Dunn M. Hormonal regulation of PKC-delta protein and mRNA levels in the rabbit corpus luteum. Mol Cell Endocrinol 1996; 122: 213-221.

196. Malpighi M. De Structura Glandarum Conglobatarum. London: Apud Richardum Chiswell 1689.

197. Mamluk R, Chen D, Greber Y, Davis JS, Meidan R. Characterization of messenger ribonucleic acid expression for prostaglandin F2 alpha and luteinizing hormone receptors in various bovine luteal cell types. Biol Reprod 1998; 58: 849-856.

198. Manna PR, Pakarinen P, El-Hefnawy T, Huhtaniemi IT. Functional assessment of the calcium messenger system in cultured mouse Leydig tumor cells: regulation of human chorionic gonadotropin-induced expression of the steroidogenic acute regulatory protein. Endocrinology 1999; 140: 1739-1751.

199. Marsh JM. The role of cyclic AMP in gonadal steroidogenesis. Biol Reprod 1976; 14: 3053.

200. Marsh JM. The stimulatory effect of luteinizing hormone on adenyl cyclase in the bovine corpus luteum. J Biol Chem 1970; 245: 1596-1603.

201. McClellan MC, Dieckman MA, Abel JH, Jr., Niswender GD. Luteinizing hormone, progesterone and the morphological development of normal and superovulated corpora lutea in sheep. Cell Tissue Res 1975; 164: 291-307. 
202. McCracken J. Prostaglandin F-2 alpha and corpus luteum regression. Ann N Y Acad Sci 1971; 180: 456-472.

203. McCracken JA. Hormone receptor control of prostaglandin F2 alpha secretion by the ovine uterus. Adv Prostaglandin Thromboxane Res 1980; 8: 1329-1344.

204. McCracken JA, Baird DT, Goding JR. Factors affecting the secretion of steroids from the transplanted ovary in the sheep. Recent Prog Horm Res 1971; 27: 537-582 passim.

205. McCracken JA, Carlson JC, Glew ME, Goding JR, Baird DT, Green K, Samuelsson B. Prostaglandin F 2 identified as a luteolytic hormone in sheep. Nat New Biol 1972; 238: 129-134.

206. McCracken JA, Custer EE, Eldering JA, Robinson AG. The central oxytocin pulse generator: a pacemaker for the ovarian cycle. Acta Neurobiol Exp (Wars) 1996; 56: 819832.

207. McCracken JA, Custer EE, Lamsa JC. Luteolysis: a neuroendocrine-mediated event. Physiol Rev 1999; 79: 263-323.

208. McCracken JA, Glew ME, Scaramuzzi RJ. Corpus luteum regression induced by prostagland in F2-alpha. J Clin Endocrinol Metab 1970; 30: 544-546.

209. McCracken JA, Smith TT, Lamsa JC, Robinson A. The effect of estradiol.1713 and progesterone on the oxvtocin pulse generator in the ovexed sheep. . Biol Reprod 1991; 44 (suppl 1): 87 (Abstract 137).

210. McGuire WJ, Juengel JL, Niswender GD. Protein kinase C second messenger system mediates the antisteroidogenic effects of prostaglandin F2 alpha in the ovine corpus luteum in vivo. Biol Reprod 1994; 51: 800-806.

211. McLean MP, Billheimer JT, Warden KJ, Irby RB. Prostaglandin F2 alpha mediates ovarian sterol carrier protein-2 expression during luteolysis. Endocrinology 1995; 136: 4963-4972.

212. McNeilly AS, Crow WJ, Fraser HM. Suppression of pulsatile luteinizing hormone secretion by gonadotrophin-releasing hormone antagonist does not affect episodic progesterone secretion or corpus luteum function in ewes. J Reprod Fertil 1992; 96: 865874.

213. Means AR, Ribar TJ, Kane CD, Hook SS, Anderson KA. Regulation and properties of the rat $\mathrm{Ca} 2+/$ calmodulin-dependent protein kinase IV gene and its protein products. Recent Prog Horm Res 1997; 52: 389-406; discussion 406-387.

214. Meidan R, Milvae RA, Weiss S, Levy N, Friedman A. Intraovarian regulation of luteolysis. J Reprod Fertil Suppl 1999; 54: 217-228.

215. Midzak AS, Liu J, Zirkin BR, Chen H. Effect of myxothiazol on Leydig cell steroidogenesis: inhibition of luteinizing hormone-mediated testosterone synthesis but stimulation of basal steroidogenesis. Endocrinology 2007; 148: 2583-2590.

216. Milgrom E, Thi L, Atger M, Baulieu EE. Mechanisms regulating the concentration and the conformation of progesterone receptor(s) in the uterus. J Biol Chem 1973; 248: 63666374.

217. Miller WL. Molecular biology of steroid hormone synthesis. Endocr Rev 1988; 9: 295318.

218. Milvae RA, Alila HW, Hansel W. Methylation in bovine luteal cells as a regulator of luteinizing hormone action. Biol Reprod 1983; 29: 849-855.

219. Miwa M, Tokuda H, Tsushita K, Kotoyori J, Takahashi Y, Ozaki N, Kozawa O, Oiso Y. Involvement of pertussis toxin-sensitive GTP-binding protein in prostaglandin F2 alpha- 
induced phosphoinositide hydrolysis in osteoblast-like cells. Biochem Biophys Res Commun 1990; 171: 1229-1235.

220. Miyamoto A, Kobayashi S, Arata S, Ohtani M, Fukui Y, Schams D. Prostaglandin F2 alpha promotes the inhibitory action of endothelin-1 on the bovine luteal function in vitro. J Endocrinol 1997; 152: R7-11.

221. Mochly-Rosen D. Localization of protein kinases by anchoring proteins: a theme in signal transduction. Science 1995; 268: 247-251.

222. Moguilewsky M, Raynaud JP. The relevance of hypothalamic and hyphophyseal progestin receptor regulation in the induction and inhibition of sexual behavior in the female rat. Endocrinology 1979; 105: 516-522.

223. Moore PK. Prostanoids: Pharmacological, Physiological and Clinical Relevance. London: Cambridge University Press; 1985.

224. Mount PF, Lane N, Venkatesan S, Steinberg GR, Fraser SA, Kemp BE, Power DA. Bradykinin stimulates endothelial cell fatty acid oxidation by CaMKK-dependent activation of AMPK. Atherosclerosis 2008.

225. Murdoch WJ. Microtubular dynamics in granulosa cells of periovulatory follicles and granulosa-derived (large) lutein cells of sheep: relationships to the steroidogenic folliculo-luteal shift and functional luteolysis. Biol Reprod 1996; 54: 1135-1140.

226. Murdoch WJ, Steadman LE, Belden EL. Immunoregulation of luteolysis. Med Hypotheses 1988; 27: 197-199.

227. Muthalif MM, Benter IF, Uddin MR, Malik KU. Calcium/calmodulin-dependent protein kinase IIalpha mediates activation of mitogen-activated protein kinase and cytosolic phospholipase A2 in norepinephrine-induced arachidonic acid release in rabbit aortic smooth muscle cells. J Biol Chem 1996; 271: 30149-30157.

228. Nancarrow CD, Buckmaster J, Chamley W, Cox RI, Cumming IA, Cummins L, Drinan JP, Findlay JK, Goding JR, Restall BJ, Schneider W, Thorburn GD. Hormonal changes around oestrus in the cow. J Reprod Fertil 1973; 32: 320-321.

229. Nelson DL, COX MM. Biological membranes and transport. New York: Worth; 2000.

230. Neuvians TP, Schams D, Berisha B, Pfaffl MW. Involvement of pro-inflammatory cytokines, mediators of inflammation, and basic fibroblast growth factor in prostaglandin F2alpha-induced luteolysis in bovine corpus luteum. Biol Reprod 2004; 70: 473-480.

231. Newton AC. Protein kinase C: structural and spatial regulation by phosphorylation, cofactors, and macromolecular interactions. Chem Rev 2001; 101: 2353-2364.

232. Nguyen A, Chen P, Cai H. Role of CaMKII in hydrogen peroxide activation of ERK1/2, p38 MAPK, HSP27 and actin reorganization in endothelial cells. FEBS Lett 2004; 572: 307-313.

233. Nikonenko I, Bancila M, Bloc A, Muller D, Bijlenga P. Inhibition of T-type calcium channels protects neurons from delayed ischemia-induced damage. Mol Pharmacol 2005; 68: 84-89.

234. Nishizuka $\mathrm{Y}$. The molecular heterogeneity of protein kinase $\mathrm{C}$ and its implications for cellular regulation. Nature 1988; 334: 661-665.

235. Nissenson R, Fluoret G, Hechter O. Opposing effects of estradiol and progesterone on oxytocin receptors in rabbit uterus. Proc Natl Acad Sci U S A 1978; 75: 2044-2048.

236. Niswender GD. Influence of 2-Br-alpha-ergocryptine on serum levels of prolactin and the estrous cycle in sheep. Endocrinology 1974; 94: 612-615.

237. Niswender GD, Davis TL, Griffith RJ, Bogan RL, Monser K, Bott RC, Bruemmer JE, 
Nett TM. Judge, jury and executioner: the auto-regulation of luteal function. Soc Reprod Fertil Suppl 2007; 64: 191-206.

238. Niswender GD, Juengel JL, Silva PJ, Rollyson MK, McIntush EW. Mechanisms controlling the function and life span of the corpus luteum. Physiol Rev 2000; 80: 1-29.

239. Niswender GD, Nett TM. Corpus Luteum and its control in infraprimate species. New York: Raven; 1994.

240. Niswender GD, Nett TM. Mechanism of ovulation. . New York: Raven Press; 1988.

241. Nothnick WB, Pate JL. Interleukin-1 beta is a potent stimulator of prostaglandin synthesis in bovine luteal cells. Biol Reprod 1990; 43: 898-903.

242. O'Shaughnessy PJ, Pearce S, Mannan MA. Effect of high-density lipoprotein on bovine granulosa cells: progesterone production in newly isolated cells and during cell culture. J Endocrinol 1990; 124: 255-260.

243. O'Shea JD, Lee CS, Cumming IA. Normal duration of the oestrous cycle in ewes with congenital absence of one uterine horn. J Reprod Fertil 1974; 38: 201-204.

244. Ohara A, Mori T, Taii S, Ban C, Narimoto K. Functional differentiation in steroidogenesis of two types of luteal cells isolated from mature human corpora lutea of menstrual cycle. J Clin Endocrinol Metab 1987; 65: 1192-1200.

245. Ohashi M, Carr BR, Simpson ER. Lipoprotein-binding sites in human corpus luteum membrane fractions. Endocrinology 1982; 110: 1477-1482.

246. Ohtani M, Kobayashi S, Miyamoto A, Hayashi K, Fukui Y. Real-time relationships between intraluteal and plasma concentrations of endothelin, oxytocin, and progesterone during prostaglandin F2alpha-induced luteolysis in the cow. Biol Reprod 1998; 58: 103108.

247. Ohtani M, Takase S, Wijayagunawardane MP, Tetsuka M, Miyamoto A. Local interaction of prostaglandin F 2alpha with endothelin-1 and tumor necrosis factor-alpha on the release of progesterone and oxytocin in ovine corpora lutea in vivo: a possible implication for a luteolytic cascade. Reproduction 2004; 127: 117-124.

248. Okuda K, Korzekwa A, Shibaya M, Murakami S, Nishimura R, Tsubouchi M, Woclawek-Potocka I, Skarzynski DJ. Progesterone is a suppressor of apoptosis in bovine luteal cells. Biol Reprod 2004; 71: 2065-2071.

249. Okuno S, Fujisawa H. Requirement of brain extract for the activity of brain calmodulindependent protein kinase IV expressed in Escherichia coli. J Biochem 1993; 114: 167170.

250. Okuno S, Kitani T, Fujisawa H. Purification and characterization of Ca2+/calmodulindependent protein kinase kinase beta from rat cerebellum. J Biochem 1997; 121: 155160.

251. Olofsson J, Leung PC. Auto/paracrine role of prostaglandins in corpus luteum function. Mol Cell Endocrinol 1994; 100: 87-91.

252. Olofsson J, Norjavaara E, Selstam G. Synthesis of prostaglandin F2 alpha, E2 and prostacyclin in isolated corpora lutea of adult pseudopregnant rats throughout the luteal life-span. Prostaglandins Leukot Essent Fatty Acids 1992; 46: 151-161.

253. Olofsson JI, Leung PC. Prostaglandins and their receptors: implications for ovarian physiology. Biol Signals 1996; 5: 90-100.

254. Orr JW, Newton AC. Intrapeptide regulation of protein kinase C. J Biol Chem 1994a; 269: 8383-8387.

255. Orr JW, Newton AC. Requirement for negative charge on "activation loop" of protein 
kinase C. J Biol Chem 1994b; 269: 27715-27718.

256. Orwig KE, Bertrand JE, Ou BR, Forsberg NE, Stormshak F. Immunochemical characterization and cellular distribution of protein kinase $\mathrm{C}$ isozymes in the bovine corpus luteum. Comp Biochem Physiol Biochem Mol Biol 1994; 108: 53-57.

257. Ottander U, Leung CH, Olofsson JI. Functional evidence for divergent receptor activation mechanisms of luteotrophic and luteolytic events in the human corpus luteum. Mol Hum Reprod 1999; 5: 391-395.

258. Paavola LG. The corpus luteum of the guinea pig. IV. Fine structure of macrophages during pregnancy and postpartum luteolysis, and the phagocytosis of luteal cells. Am J Anat 1979; 154: 337-364.

259. Papadopoulos V. Peripheral-type benzodiazepine/diazepam binding inhibitor receptor: biological role in steroidogenic cell function. Endocr Rev 1993; 14: 222-240.

260. Pate JL. Regulation of prostaglandin synthesis by progesterone in the bovine corpus luteum. Prostaglandins 1988; 36: 303-315.

261. Patek CE, Watson J. Prostaglandin F and progesterone secretion by porcine endometrium and corpus luteum in vitro. Prostaglandins 1976; 12: 97-111.

262. Patwardhan VV, Lanthier A. Concentration of prostaglandins PGE and PGF, estrone, estradiol, and progesterone in human corpora lutea. Prostaglandins 1980; 20: 963-969.

263. Pederson ES. Histogenesis of lurein tissue of the albino rat. Am J Anat 1951; 88: 394427.

264. Pepperell JR, Preston SL, Behrman HR. The antigonadotropic action of prostaglandin F2 alpha is not mediated by elevated cytosolic calcium levels in rat luteal cells. Endocrinology 1989; 125: 144-151.

265. Pepperell JR, Wolcott K, Behrman HR. Effects of neutrophils in rat luteal cells. Endocrinology 1992; 130: 1001-1008.

266. Perusquia M, Kubli-Garfias C. External calcium dependence of the uterine contraction induced by prostaglandins E2 and F2 alpha and its antagonism with natural progestins. Prostaglandins 1992; 43: 445-455.

267. Peters CA, Maizels ET, Robertson MC, Shiu RP, Soloff MS, Hunzicker-Dunn M. Induction of relaxin messenger RNA expression in response to prolactin receptor activation requires protein kinase $\mathrm{C}$ delta signaling. Mol Endocrinol 2000; 14: 576-590.

268. Peters KE, Bergfeld EG, Cupp AS, Kojima FN, Mariscal V, Sanchez T, Wehrman ME, Grotjan HE, Hamernik DL, Kittok RJ, et al. Luteinizing hormone has a role in development of fully functional corpora lutea (CL) but is not required to maintain CL function in heifers. Biol Reprod 1994; 51: 1248-1254.

269. Pfaffl MW. A new mathematical model for relative quantification in real-time RT-PCR. Nucleic Acids Res 2001; 29: e45.

270. Pharriss BB, Wyngarden LJ. The effect of prostaglandin F 2alpha on the progestogen content of ovaries from pseudopregnant rats. Proc Soc Exp Biol Med 1969; 130: 92-94.

271. Picciotto MR, Czernik AJ, Nairn AC. Calcium/calmodulin-dependent protein kinase I. cDNA cloning and identification of autophosphorylation site. J Biol Chem 1993; 268 : 26512-26521.

272. Pierce KL, Bailey TJ, Hoyer PB, Gil DW, Woodward DF, Regan JW. Cloning of a carboxyl-terminal isoform of the prostanoid FP receptor. J Biol Chem 1997; 272: 883887.

273. Pierce KL, Fujino H, Srinivasan D, Regan JW. Activation of FP prostanoid receptor 
isoforms leads to Rho-mediated changes in cell morphology and in the cell cytoskeleton. J Biol Chem 1999; 274: 35944-35949.

274. Pittman RC, Khoo JC, Steinberg D. Cholesterol esterase in rat adipose tissue and its activation by cyclic adenosine $3^{\prime}: 5^{\prime}$-monophosphate-dependent protein kinase. J Biol Chem 1975; 250: 4505-4511.

275. Pitzel L, Jarry H, Wuttke W. Demonstration of oxytocin receptors in porcine corpora lutea: effects of the cycle stage and the distribution on small and large luteal cells. Biol Reprod 1993; 48: 640-646.

276. Powell WS, Hammarstrom S, Samuelsson B. Prostaglandin F2alpha receptor in ovine corpora lutea. Eur J Biochem 1974; 41: 103-107.

277. Prenant LA. La valeur morphologique du corps jaune. Son action physiologique et theripeutique possible. Rev. Gen. Sci. Pures Appl 1898; 9.

278. Priedkalns J, Weber AF. Ultrastructural studies of the bovine graafian follicle and corpus luteum. Z Zellforsch Mikrosk Anat 1968; 91: 554-573.

279. Priedkalns J, Weber AF, Zemjanis R. Qualitative and quantitative morphological studies of the cells of the membrame granulosa, theca interna and corpus luteum of the bovine ovary. Z Zellforsch Mikrosk Anat 1968; 85: 501-520.

280. Pucci ML, Bao Y, Chan B, Itoh S, Lu R, Copeland NG, Gilbert DJ, Jenkins NA, Schuster VL. Cloning of mouse prostaglandin transporter PGT cDNA: species-specific substrate affinities. Am J Physiol 1999; 277: R734-741.

281. Quest AF. Regulation of protein kinase C: a tale of lipids and proteins. Enzyme Protein 1996; 49: 231-261.

282. Rao CV, Griffin LP, Carman FR, Jr. Prostaglandin F2alpha binding sites in human corpora lutea. J Clin Endocrinol Metab 1977; 44: 1032-1037.

283. Raymond V, Leung PC, Labrie F. Stimulation by prostaglandin F2 alpha of phosphatidic acid-phosphatidylinositol turnover in rat luteal cells. Biochem Biophys Res Commun 1983; 116: 39-46.

284. Redmer DA, Reynolds LP. Angiogenesis in the ovary. Rev Reprod 1996; 1: 182-192.

285. Rexroad CE, Jr., Guthrie HD. Prostaglandin F2 alpha and progesterone release in vitro by ovine luteal tissue during induced luteolysis. Adv Exp Med Biol 1979; 112: 639-644.

286. Richards JS, Williams JJ. Luteal cell receptor content for prolactin (PRL) and luteinizing hormone (LH): regulation by LH and PRL. Endocrinology 1976; 99: 1571-1581.

287. Roberts JS, McCracken JA. Does prostaglandin F2alpha released from the uterus by oxytocin mediate the oxytocic action of oxytocin? Biol Reprod 1976; 15: 457-463.

288. Robinson K, Jones D, Patel Y, Martin H, Madrazo J, Martin S, Howell S, Elmore M, Finnen MJ, Aitken A. Mechanism of inhibition of protein kinase C by 14-3-3 isoforms. 14-3-3 isoforms do not have phospholipase A2 activity. Biochem J 1994; 299 ( Pt 3): 853-861.

289. Rodgers RJ, O'Shea JD, Bruce NW. Morphometric analysis of the cellular composition of the ovine corpus luteum. J Anat 1984; 138 ( Pt 4): 757-770.

290. Rodgers RJ, O'Shea JD, Findlay JK, Flint AP, Sheldrick EL. Large luteal cells the source of luteal oxytocin in the sheep. Endocrinology 1983; 113: 2302-2304.

291. Rodgers RJ, Vella CA, Young FM, Tian XC, Fortune JE. Concentrations of cytochrome P450 cholesterol side-chain cleavage enzyme and 3 beta-hydroxysteroid dehydrogenase during prostaglandin F2 alpha-induced luteal regression in cattle. Reprod Fertil Dev 1995; 7: 1213-1216. 
292. Rosengart MR, Arbabi S, Garcia I, Maier RV. Interactions of calcium/calmodulindependent protein kinases (CaMK) and extracellular-regulated kinase (ERK) in monocyte adherence and TNFalpha production. Shock 2000; 13: 183-189.

293. Rosenthal MD, Rzigalinski BA, Blackmore PF, Franson RC. Cellular regulation of arachidonate mobilization and metabolism. Prostaglandins Leukot Essent Fatty Acids 1995; 52: 93-98.

294. Rosiansky-Sultan M, Klipper E, Spanel-Borowski K, Meidan R. Inverse relationship between nitric oxide synthases and endothelin-1 synthesis in bovine corpus luteum: interactions at the level of luteal endothelial cell. Endocrinology 2006; 147: 5228-5235.

295. Rothchild I. The regulation of the mammalian corpus luteum. Recent Prog Horm Res 1981; 37: 183-298.

296. Rozen S, Skaletsky H. Primer3 on the WWW for general users and for biologist programmers. Methods Mol Biol 2000; 132: 365-386.

297. Rueda BR, Tilly KI, Botros IW, Jolly PD, Hansen TR, Hoyer PB, Tilly JL. Increased bax and interleukin-1beta-converting enzyme messenger ribonucleic acid levels coincide with apoptosis in the bovine corpus luteum during structural regression. Biol Reprod 1997; 56: 186-193.

298. Sakamoto K, Ezashi T, Miwa K, Okuda-Ashitaka E, Houtani T, Sugimoto T, Ito S, Hayaishi O. Molecular cloning and expression of a cDNA of the bovine prostaglandin F2 alpha receptor. J Biol Chem 1994; 269: 3881-3886.

299. Sakamoto K, Miwa K, Ezashi T, Okuda-Ashitaka E, Okuda K, Houtani T, Sugimoto T, Ito S, Hayaishi O. Expression of mRNA encoding the prostaglandin F2 alpha receptor in bovine corpora lutea throughout the oestrous cycle and pregnancy. J Reprod Fertil 1995; 103: 99-105.

300. Sakka E, Rae M, Aitken J, Bramley T. Protein kinase C- and Ca2+ ionophore-stimulated production of reactive oxygen species in mechanically dispersed isolated bovine luteal cells. Biol Reprod 1997; 57: 428-435.

301. Sakumoto R, Berisha B, Kawate N, Schams D, Okuda K. Tumor necrosis factor-alpha and its receptor in bovine corpus luteum throughout the estrous cycle. Biol Reprod 2000; 62: 192-199.

302. Salem M, Kenney PB, Rexroad CE, 3rd, Yao J. Microarray gene expression analysis in atrophying rainbow trout muscle: a unique nonmammalian muscle degradation model. Physiol Genomics 2006; 28: 33-45.

303. Sandhoff TW, McLean MP. Repression of the rat steroidogenic acute regulatory (StAR) protein gene by PGF2alpha is modulated by the negative transcription factor DAX-1. Endocrine 1999; 10: 83-91.

304. Sawyer HR, Niswender KD, Braden TD, Niswender GD. Nuclear changes in ovine luteal cells in response to PGF2 alpha. Domest Anim Endocrinol 1990; 7: 229-237.

305. Sayre BL, Taft R, Inskeep EK, Killefer J. Increased expression of insulin-like growth factor binding protein-1 during induced regression of bovine corpora lutea. Biol Reprod 2000; 63: 21-29.

306. Scallen TJ, Pastuszyn A, Noland BJ, Chanderbhan R, Kharroubi A, Vahouny GV. Sterol carrier and lipid transfer proteins. Chem Phys Lipids 1985; 38: 239-261.

307. Schams D. Ovarian peptides in the cow and sheep. J Reprod Fertil Suppl 1989; 37: 225231.

308. Schams D, Karg H. Hormonal responses following treatment with different prostaglandin 
analogues for estrous cycle regulation in cattle. Theriogenology 1982; 17: 499-513.

309. Schuster VL. Molecular mechanisms of prostaglandin transport. Annu Rev Physiol 1998; 60: 221-242.

310. Schuster VL. Prostaglandin transport. Prostaglandins Other Lipid Mediat 2002; 68-69: 633-647.

311. Seger R, Hanoch T, Rosenberg R, Dantes A, Merz WE, Strauss JF, 3rd, Amsterdam A. The ERK signaling cascade inhibits gonadotropin-stimulated steroidogenesis. J Biol Chem 2001; 276: 13957-13964.

312. Selbert MA, Anderson KA, Huang QH, Goldstein EG, Means AR, Edelman AM. Phosphorylation and activation of $\mathrm{Ca}(2+)$-calmodulin-dependent protein kinase IV by $\mathrm{Ca}(2+)$-calmodulin-dependent protein kinase Ia kinase. Phosphorylation of threonine 196 is essential for activation. J Biol Chem 1995; 270: 17616-17621.

313. Sen A, Browning J, Inskeep EK, Lewis P, Flores JA. Expression and activation of protein kinase $\mathrm{C}$ isozymes by prostaglandin $\mathrm{F}(2 \mathrm{alpha})$ in the early- and mid-luteal phase bovine corpus luteum. Biol Reprod 2004; 70: 379-384.

314. Sen A, Choudhary E, Inskeep EK, Flores JA. Effects of selective protein kinase c isozymes in prostaglandin2alpha-induced $\mathrm{Ca} 2+$ signaling and luteinizing hormoneinduced progesterone accumulation in the mid-phase bovine corpus luteum. Biol Reprod 2005; 72: 976-984.

315. Sen A, Wright M, Inskeep EK, Flores JA. Participation of specific PKC isozymes in the inhibitory effect of ET-1 on progesterone accumulation in cells isolated from early- and mid-phase corpora lutea. Domest Anim Endocrinol 2006; 31: 284-299.

316. Sharma SC, Fitzpatrick RJ. Effect of oestradiol-17beta and oxytocin treatment on prostaglandin F alpha release in the anoestrous ewe. Prostaglandins 1974; 6: 97-105.

317. Sharp JD, White DL, Chiou XG, Goodson T, Gamboa GC, McClure D, Burgett S, Hoskins J, Skatrud PL, Sportsman JR, et al. Molecular cloning and expression of human $\mathrm{Ca}(2+)$-sensitive cytosolic phospholipase A2. J Biol Chem 1991; 266: 14850-14853.

318. Shaw DW, Britt JH. Concentrations of tumor necrosis factor alpha and progesterone within the bovine corpus luteum sampled by continuous-flow microdialysis during luteolysis in vivo. Biol Reprod 1995; 53: 847-854.

319. Sheffel CE, Pratt BR, Ferrell WL, Inskeep EK. Induced corpora lutea in the postpartum beef cow. II. Effects of treatment with progestogen and gonadotropins. J Anim Sci 1982; 54: 830-836.

320. Shemesh M, Hansel W. Stimulation of prostaglandin synthesis in bovine ovarian tissues by arachidonic acid and luteinizing hormone. Biol Reprod 1975a; 13: 448-452.

321. Shemesh M, Hansel W. Levels of prostaglandin F (PGF) in bovine endometrium uterine venous, ovarian arterial and jugular plasma during the estrous cycle (38789). Proc Soc Exp Biol Med 1975b; 148: 123-126.

322. Shirasuna K, Asaoka H, Acosta TJ, Wijayagunawardane MP, Ohtani M, Hayashi KG, Matsui M, Miyamoto A. Real-time dynamics of prostaglandin F2alpha release from uterus and corpus luteum during spontaneous luteolysis in the cow. Reproduction 2004; 128: 189-195.

323. Shirasuna K, Watanabe S, Asahi T, Wijayagunawardane MP, Sasahara K, Jiang C, Matsui M, Sasaki M, Shimizu T, Davis JS, Miyamoto A. Prostaglandin F2alpha increases endothelial nitric oxide synthase in the periphery of the bovine corpus luteum: the possible regulation of blood flow at an early stage of luteolysis. Reproduction 2008; 135 : 
527-539.

324. Silva E, Sterry RA, Fricke PM. Assessment of a practical method for identifying anovular dairy cows synchronized for first postpartum timed artificial insemination. J Dairy Sci 2007; 90: 3255-3262.

325. Silva PJ, Juengel JL, Rollyson MK, Niswender GD. Prostaglandin metabolism in the ovine corpus luteum: catabolism of prostaglandin F(2alpha) (PGF(2alpha)) coincides with resistance of the corpus luteum to PGF(2alpha). Biol Reprod 2000; 63: 1229-1236.

326. Silvia WJ, Niswender GD. Maintenance of the corpus luteum of early pregnancy in the ewe. III. Differences between pregnant and nonpregnant ewes in luteal responsiveness to prostaglandin F2 alpha. J Anim Sci 1984; 59: 746-753.

327. Simon MI, Strathmann MP, Gautam N. Diversity of G proteins in signal transduction. Science 1991; 252: 802-808.

328. Simpson ER, Waterman MR. Regulation by ACTH of steroid hormone biosynthesis in the adrenal cortex. Can J Biochem Cell Biol 1983; 61: 692-707.

329. Skarzynski DJ, Jaroszewski JJ, Bah MM, Deptula KM, Barszczewska B, Gawronska B, Hansel W. Administration of a nitric oxide synthase inhibitor counteracts prostaglandin F2-induced luteolysis in cattle. Biol Reprod 2003; 68: 1674-1681.

330. Skarzynski DJ, Kobayashi S, Okuda K. Influence of nitric oxide and noradrenaline on prostaglandin $\mathrm{F}(2)$ (alpha)-induced oxytocin secretion and intracellular calcium mobilization in cultured bovine luteal cells. Biol Reprod 2000; 63: 1000-1005.

331. Skarzynski DJ, Okuda K. Different actions of noradrenaline and nitric oxide on the output of prostaglandins and progesterone in cultured bovine luteal cells. Prostaglandins Other Lipid Mediat 2000; 60: 35-47.

332. Slotta KH, Ruschig H, Fels E. Reindarstellung der hormone aus dem corpus luteum. Berich. Dtsch. Chem. Geselischaft 1934; 67.

333. Smith MF, McIntush EW, Smith GW. Mechanisms associated with corpus luteum development. J Anim Sci 1994; 72: 1857-1872.

334. Smith WL, DeWitt DL, Garavito RM. Cyclooxygenases: structural, cellular, and molecular biology. Annu Rev Biochem 2000; 69: 145-182.

335. Smith WL, Garavito RM, DeWitt DL. Prostaglandin endoperoxide H synthases (cyclooxygenases)-1 and -2. J Biol Chem 1996; 271: 33157-33160.

336. Soloff MS, Fernstrom MA, Periyasamy S, Soloff S, Baldwin S, Wieder M. Regulation of oxytocin receptor concentration in rat uterine explants by estrogen and progesterone. Can J Biochem Cell Biol 1983; 61: 625-630.

337. Spat A, Bradford PG, McKinney JS, Rubin RP, Putney JW, Jr. A saturable receptor for 32P-inositol-1,4,5-triphosphate in hepatocytes and neutrophils. Nature 1986; 319: 514516.

338. Spencer AG, Woods JW, Arakawa T, Singer, II, Smith WL. Subcellular localization of prostaglandin endoperoxide $\mathrm{H}$ synthases- 1 and -2 by immunoelectron microscopy. J Biol Chem 1998; 273: 9886-9893.

339. Spicer LJ, Ireland JJ, Roche JF. Changes in serum LH, progesterone, and specific binding of 125I-hCG to luteal cells during regression and development of bovine corpora lutea. Biol Reprod 1981; 25: 832-841.

340. Stabenfeldt GH, Hughes JP, Wheat JD, Evans JW, Kennedy PC, Cupps PT. The role of the uterus in ovarian control in the mare. J Reprod Fertil 1974; 37: 343-351.

341. Stahmann N, Woods A, Carling D, Heller R. Thrombin activates AMP-activated protein 
kinase in endothelial cells via a pathway involving $\mathrm{Ca} 2+/$ calmodulin-dependent protein kinase kinase beta. Mol Cell Biol 2006; 26: 5933-5945.

342. Stebbins EG, Mochly-Rosen D. Binding specificity for RACK1 resides in the V5 region of beta II protein kinase C. J Biol Chem 2001; 276: 29644-29650.

343. Stocco C, Telleria C, Gibori G. The molecular control of corpus luteum formation, function, and regression. Endocr Rev 2007; 28: 117-149.

344. Stocco CO, Lau LF, Gibori G. A calcium/calmodulin-dependent activation of ERK1/2 mediates JunD phosphorylation and induction of nur77 and 20alpha-hsd genes by prostaglandin F2alpha in ovarian cells. J Biol Chem 2002; 277: 3293-3302.

345. Stocco DM, Clark BJ. Regulation of the acute production of steroids in steroidogenic cells. Endocr Rev 1996; 17: 221-244.

346. Stone D, Hechter O. Studies on ACTH action in perfused bovine adrenals: site of action of ACTH on corticosteroidogenesis. Arch. Biochem. Biophys. 1954; 51: 457-469.

347. Sugimoto Y, Hasumoto K, Namba T, Irie A, Katsuyama M, Negishi M, Kakizuka A, Narumiya S, Ichikawa A. Cloning and expression of a cDNA for mouse prostaglandin $\mathrm{F}$ receptor. J Biol Chem 1994; 269: 1356-1360.

348. Suh DY, Hunt TK, Spencer EM. Insulin-like growth factor-I reverses the impairment of wound healing induced by corticosteroids in rats. Endocrinology 1992; 131: 2399-2403.

349. Sullivan $\mathrm{MH}$, Cooke BA. The role of $\mathrm{Ca} 2+$ in steroidogenesis in Leydig cells. Stimulation of intracellular free $\mathrm{Ca} 2+$ by lutropin (LH), luliberin (LHRH) agonist and cyclic AMP. Biochem J 1986; 236: 45-51.

350. Suzuki T, Fujii Y, Miyano M, Chen LY, Takahashi T, Watanabe K. cDNA cloning, expression, and mutagenesis study of liver-type prostaglandin F synthase. J Biol Chem 1999; 274: 241-248.

351. Tajima K, Babich S, Yoshida Y, Dantes A, Strauss JF, 3rd, Amsterdam A. The proteasome inhibitor MG132 promotes accumulation of the steroidogenic acute regulatory protein (StAR) and steroidogenesis. FEBS Lett 2001; 490: 59-64.

352. Taniguchi H, Yokomizo Y, Okuda K. Fas-Fas ligand system mediates luteal cell death in bovine corpus luteum. Biol Reprod 2002; 66: 754-759.

353. Tekpetey FR, Armstrong DT. Steroidogenic response of rat and pig luteal cells to estradiol-17 beta and catecholestrogens in vitro. Biol Reprod 1991; 45: 498-505.

354. Telleria CM, Deis RP. Effect of RU486 on ovarian progesterone production at prooestrus and during pregnancy: a possible dual regulation of the biosynthesis of progesterone. J Reprod Fertil 1994; 102: 379-384.

355. Telleria CM, Stocco CO, Stati AO, Deis RP. Progesterone receptor is not required for progesterone action in the rat corpus luteum of pregnancy. Steroids 1999; 64: 760-766.

356. Thorburn GD, Cox RI, Currie WB, Restall BJ, Schneider W. Prostaglandin F and progesterone concentrations in the utero-ovarian venous plasma of the ewe during the oestrous cycle and early pregnancy. J Reprod Fertil Suppl 1973; 18: 151-158.

357. Toker A, Ellis CA, Sellers LA, Aitken A. Protein kinase C inhibitor proteins. Purification from sheep brain and sequence similarity to lipocortins and 14-3-3 protein. Eur J Biochem 1990; 191: 421-429.

358. Tokumitsu H, Enslen H, Soderling TR. Characterization of a Ca2+/calmodulin-dependent protein kinase cascade. Molecular cloning and expression of calcium/calmodulindependent protein kinase kinase. J Biol Chem 1995; 270: 19320-19324.

359. Tokumitsu H, Inuzuka H, Ishikawa Y, Ikeda M, Saji I, Kobayashi R. STO-609, a specific 
inhibitor of the $\mathrm{Ca}(2+) /$ calmodulin-dependent protein kinase kinase. J Biol Chem 2002; 277: 15813-15818.

360. Tosca L, Chabrolle C, Uzbekova S, Dupont J. Effects of metformin on bovine granulosa cells steroidogenesis: possible involvement of adenosine 5' monophosphate-activated protein kinase (AMPK). Biol Reprod 2007; 76: 368-378.

361. Tosca L, Froment P, Solnais P, Ferre P, Foufelle F, Dupont J. Adenosine 5'monophosphate-activated protein kinase regulates progesterone secretion in rat granulosa cells. Endocrinology 2005; 146: 4500-4513.

362. Townson DH, Warren JS, Flory CM, Naftalin DM, Keyes PL. Expression of monocyte chemoattractant protein-1 in the corpus luteum of the rat. Biol Reprod 1996; 54: 513-520.

363. Tsai SJ, Juengel JL, Wiltbank MC. Hormonal regulation of monocyte chemoattractant protein-1 messenger ribonucleic acid expression in corpora lutea. Endocrinology 1997; 138: 4517-4520.

364. Tsai SJ, Wiltbank MC. Prostaglandin F2alpha regulates distinct physiological changes in early and mid-cycle bovine corpora lutea. Biol Reprod 1998; 58: 346-352.

365. Tsai SJ, Wiltbank MC. Prostaglandin F2alpha induces expression of prostaglandin G/H synthase-2 in the ovine corpus luteum: a potential positive feedback loop during luteolysis. Biol Reprod 1997; 57: 1016-1022.

366. Tsujishita Y, Hurley JH. Structure and lipid transport mechanism of a StAR-related domain. Nat Struct Biol 2000; 7: 408-414.

367. Tuckey RC, Headlam MJ, Bose HS, Miller WL. Transfer of cholesterol between phospholipid vesicles mediated by the steroidogenic acute regulatory protein (StAR). J Biol Chem 2002; 277: 47123-47128.

368. Vane JR, Botting RM. A better understanding of anti-inflammatory drugs based on isoforms of cyclooxygenase (COX-1 and COX-2). Adv Prostaglandin Thromboxane Leukot Res 1995; 23: 41-48.

369. Walters DL, Schallenberger E. Pulsatile secretion of gonadotrophins, ovarian steroids and ovarian oxytocin during the periovulatory phase of the oestrous cycle in the cow. J Reprod Fertil 1984; 71: 503-512.

370. Watanabe K. Prostaglandin F synthase. Prostaglandins Other Lipid Mediat 2002; 68-69: 401-407.

371. Watanabe K, Yoshida R, Shimizu T, Hayaishi O. Enzymatic formation of prostaglandin F2 alpha from prostaglandin $\mathrm{H} 2$ and D2. Purification and properties of prostaglandin $\mathrm{F}$ synthetase from bovine lung. J Biol Chem 1985; 260: 7035-7041.

372. Watanabe T, Nakao A, Emerling D, Hashimoto Y, Tsukamoto K, Horie Y, Kinoshita M, Kurokawa K. Prostaglandin F2 alpha enhances tyrosine phosphorylation and DNA synthesis through phospholipase $\mathrm{C}$-coupled receptor via $\mathrm{Ca}(2+)$-dependent intracellular pathway in NIH-3T3 cells. J Biol Chem 1994; 269: 17619-17625.

373. Wathes DC, Swann RW. Is oxytocin an ovarian hormone? Nature 1982; 297: 225-227.

374. Watts TL, Fuquay JW. Response and fertility of dairy heifers following injection with prostaglandin F(2alpha) during early, middle or late diestrus. Theriogenology 1985; 23: 655-661.

375. Webb BL, Lindsay MA, Seybold J, Brand NJ, Yacoub MH, Haddad EB, Barnes PJ, Adcock IM, Giembycz MA. Identification of the protein kinase C isoenzymes in human lung and airways smooth muscle at the protein and mRNA level. Biochem Pharmacol 1997; 54: 199-205. 
376. West LA, Horvat RD, Roess DA, Barisas BG, Juengel JL, Niswender GD. Steroidogenic acute regulatory protein and peripheral-type benzodiazepine receptor associate at the mitochondrial membrane. Endocrinology 2001; 142: 502-505.

377. Wiltbank J, Casida, LE. Alterations of ovarian activity by hystectomy. Journal of Animal Sciences 1956; 15: 134.

378. Wiltbank MC, Belfiore CJ, Niswender GD. Steroidogenic enzyme activity after acute activation of protein kinase (PK) A and PKC in ovine small and large luteal cells. Mol Cell Endocrinol 1993; 97: 1-7.

379. Wiltbank MC, Diskin MG, Flores JA, Niswender GD. Regulation of the corpus luteum by protein kinase C. II. Inhibition of lipoprotein-stimulated steroidogenesis by prostaglandin F2 alpha. Biol Reprod 1990; 42: 239-245.

380. Wiltbank MC, Diskin MG, Niswender GD. Differential actions of second messenger systems in the corpus luteum. J Reprod Fertil Suppl 1991; 43: 65-75.

381. Wiltbank MC, Shiao TF, Bergfelt DR, Ginther OJ. Prostaglandin F2 alpha receptors in the early bovine corpus luteum. Biol Reprod 1995; 52: 74-78.

382. Wolfenson D, Thatcher WW, Drost M, Caton D, Foster DB, LeBlanc MM. Characteristics of prostaglandin $\mathrm{F}$ measurements in the ovarian circulation during the oestrous cycle and early pregnancy in the cow. J Reprod Fertil 1985; 75: 491-499.

383. Woods A, Dickerson K, Heath R, Hong SP, Momcilovic M, Johnstone SR, Carlson M, Carling D. Ca2+/calmodulin-dependent protein kinase kinase-beta acts upstream of AMP-activated protein kinase in mammalian cells. Cell Metab 2005; 2: 21-33.

384. Wright MF, Sayre B, Keith Inskeep EK, Flores JA. Prostaglandin F(2alpha) regulation of the bovine corpus luteum endothelin system during the early and midluteal phase. Biol Reprod 2001; 65: 1710-1717.

385. Wuttke W, Spiess S, Knoke I, Pitzel L, Leonhardt S, Jarry H. Synergistic effects of prostaglandin F2alpha and tumor necrosis factor to induce luteolysis in the pig. Biol Reprod 1998; 58: 1310-1315.

386. Xiao CW, Liu JM, Sirois J, Goff AK. Regulation of cyclooxygenase-2 and prostaglandin F synthase gene expression by steroid hormones and interferon-tau in bovine endometrial cells. Endocrinology 1998; 139: 2293-2299.

387. Xuan YT, Guo Y, Zhu Y, Wang OL, Rokosh G, Messing RO, Bolli R. Role of the protein kinase C-epsilon-Raf-1-MEK-1/2-p44/42 MAPK signaling cascade in the activation of signal transducers and activators of transcription 1 and 3 and induction of cyclooxygenase-2 after ischemic preconditioning. Circulation 2005; 112: 1971-1978.

388. Yadav VK, Lakshmi G, Medhamurthy R. Prostaglandin F2alpha-mediated activation of apoptotic signaling cascades in the corpus luteum during apoptosis: involvement of caspase-activated DNase. J Biol Chem 2005; 280: 10357-10367.

389. Zazopoulos E, Lalli E, Stocco DM, Sassone-Corsi P. DNA binding and transcriptional repression by DAX-1 blocks steroidogenesis. Nature 1997; 390: 311-315.

390. Zhang G, Kazanietz MG, Blumberg PM, Hurley JH. Crystal structure of the cys2 activator-binding domain of protein kinase $\mathrm{C}$ delta in complex with phorbol ester. Cell 1995; 81: 917-924. 


\section{Resume}

\section{Madhusudan P Goravanahally}

Department of Biology

West Virginia University

Morgantown, West Virginia-26505

mgoravan@mix.wvu.edu

Tele No. 304-293-5201 ext 31466

Cell: $304-906-9300$

\section{EDUCATION}

West Virginia University, Morgantown, West Virginia, US

$\mathrm{PhD}$ in Biology, 2005 to present, Program: Cell and Molecular Biology program

August 2009

National Dairy Research Institute (NDRI), Haryana, India

Master of Veterinary Science (MVSc), 2004, Area of study: Animal Biochemistry

College of Veterinary Science, University of Agricultural Sciences (UAS), Karnataka, India Bachelor of Veterinary Science and Animal Husbandry (BVSc \& AH) equivalent to DVM, 2001

\section{TECHNICAL EXPERIENCES}

- Animal handling, medicine and some surgical procedures

- Immunohistochemistry

- Mammalian cell culture and transfection studies

- Microarray

- Small interfering RNA (SiRNA)

- Single Cell Calcium measurements using Epifluorescent Microscopy 
- Real-time PCR

- Radioimmunoassay (RIA)

- Western blotting

- Gene cloning and expression

- SDS- polyacrylamide gel electrophoresis and protein purification

\section{AWARDS and HONORS}

- Outstanding graduate student award (Doctoral student stipend enhancement fellowship) Department of Biology, West Virginia University, 2008.

- Eberly College of Arts and Science travel award, West Virginia University, 2008.

- Eberly College of Arts and Science travel Award, West Virginia University, 2006.

- Junior Research Institutional Fellowship for Masters Program, Indian Council of Agricultural Research (ICAR), Government of India, 2001-2004.

- Appreciation Certificate from University of Agricultural Sciences, Bangalore, India for excellent performance in All-India combined entrance examination conducted by ICAR, 2001.

\section{PUBLICATIONS}

Madhusudan GP, Dev R, Sharma MK, Singh D. Expression of mRNAs encoding tumor necrosis factor-alpha and its receptor-I in buffalo ovary. Indian J Exp Biol. 2007; 45(8): 669-75 (PMID: 17877142).

Goravanahally MP, Sen A, Inskeep EK, Flores JA. PKCepsilon and an increase in intracellular calcium concentration are necessary for PGF2alpha to inhibit LH-stimulated progesterone secretion in cultured bovine steroidogenic luteal cells. Reprod Biol Endocrinol. 2007; 5: 37 (PMID: 17760987).

Doerr MD, Goravanahally MP, Rhinehart JD, Inskeep EK, Flores JA. Effects of Endothelin Receptor Type-A and Type-B Antagonists on Prostaglandin F2alpha-Induced Luteolysis of the Sheep Corpus Luteum. Biol Reprod. 2008; 78: 688-696 (PMID: 18077801). 
Goravanahally MP, Salem M, Yao J, Inskeep EK, Flores JA. Differential gene expression in the bovine corpus 1uteum (CL) during transition from early to mid-phase and its potential role in acquisition of luteolytic sensitivity to prostaglandin F2 Alpha. Biol Reprod. 2009; 80 (5): 980-988.

\section{PLATFORM PRESENTATIONS}

Goravanahally MP, Sen A, Inskeep EK, Flores JA. Effects of intracellular calcium ion concentraion $\left(\left[\mathrm{Ca}^{2+}\right]_{\mathrm{i}}\right)$ on luteal progesterone (P4) accumulation: Implications for developing calcium based protocols to manipulate ovarian cycles. Society for the Study of Reproduction (SSR) $39^{\text {th }}$ Annual meeting 2006, Omaha, Nebraska.

Goravanahally MP, Salem M, Yao J, Inskeep EK, Flores JA. Identification of differential gene expression during transition of bovine corpus luteum from early to mid-phase and their potential role in acquisition of luteolytic sensitivity to prostaglandin F2 alpha. 2008 Joint ADSA-ASAS meeting 2008, Indianapolis, Indiana.

\section{POSTER PRESENTATIONS}

Flores JA, Doerr M, Goravanahally MP, Rhinhart J, Inskeep EK. Endothelin-independent and dependent luteolytic effects of prostaglandin F2 alpha in ewes. Society for the Study of Reproduction (SSR) $40^{\text {th }}$ Annual meeting 2008, San Antonio, Texas.

Flores JA, Sen A, Goravanahally MP \& Inskeep EK. Knockdown of protein kinase C $\varepsilon$ $(\mathrm{PKC} \varepsilon)$ in bovine luteal steroidogenic cells mitigates the effectiveness of prostaglandin $\mathrm{F} 2 \alpha$ (PGF2 $\alpha$ ) in reducing LH-stimulated accumulation of progesterone (P4). $7^{\text {th }}$ International Ruminant Reproduction Symposium. August 2006, Wellington, New Zealand

Flores JA, Perea FP, Mankey JE, Goravanahally MP, Inskeep EA. Effects of Chronic Administration of Endothelin Receptor Type A Antagonist (BQ-610) on Functional Lifespan of the Corpus Luteum in Sheep. July 2009, Society for the Study of Reproduction (SSR) $41^{\text {st }}$ Annual meeting, Pittsburgh, Pennsylvania.

Mankey JE, Perea FP Goravanahally MP, Flores JA, Inskeep EA. Effects of Atosiban on Progesterone Production During Early and Mid Cycle in the Ewe. July 2009, Society for the Study of Reproduction (SSR) $41^{\text {st }}$ Annual meeting, Pittsburgh, Pennsylvania 


\section{MEMBERSHIP}

American Society of Animal Science (ASAS)

Society for Study Reproduction (SSR)

\section{COMPUTER SKILLS}

MS office, Adobe Photoshop, Adobe illustrator, statistical software (JMP 3.0)

\section{TEACHING EXPERIENCE}

- Contract teacher, Department of Veterinary Biochemistry, College of Veterinary Science, Bangalore, India (2005)

General Biochemistry and Metabolism (Lecture and laboratory)

Clinical Biochemistry (Lecture and laboratory)

- Graduate Teaching Assistant, West Virginia University (2006-2009)

Vertebrate Histology (Biol 441)

Introductory physiology (Biol 117)

The Living Cell (Biol 219)

Introductory Biology (Biol 103)

Introductory Physiology (Biol 115)

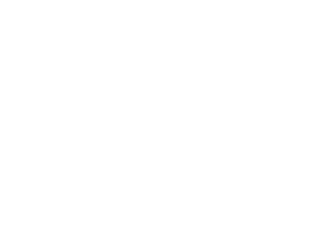

